\title{
Metabolic effects of weight cycling in obesity
}

Citation for published version (APA):

Kempen, K. P. G. (1996). Metabolic effects of weight cycling in obesity. [Doctoral Thesis, Maastricht University]. Maastricht University. https://doi.org/10.26481/dis.19960119kk

Document status and date:

Published: 01/01/1996

DOI:

10.26481/dis.19960119kk

Document Version:

Publisher's PDF, also known as Version of record

\section{Please check the document version of this publication:}

- A submitted manuscript is the version of the article upon submission and before peer-review. There can be important differences between the submitted version and the official published version of record.

People interested in the research are advised to contact the author for the final version of the publication, or visit the DOI to the publisher's website.

- The final author version and the galley proof are versions of the publication after peer review.

- The final published version features the final layout of the paper including the volume, issue and page numbers.

Link to publication

\footnotetext{
General rights rights.

- You may freely distribute the URL identifying the publication in the public portal. please follow below link for the End User Agreement:

www.umlib.nl/taverne-license

Take down policy

If you believe that this document breaches copyright please contact us at:

repository@maastrichtuniversity.nl

providing details and we will investigate your claim.
}

Copyright and moral rights for the publications made accessible in the public portal are retained by the authors and/or other copyright owners and it is a condition of accessing publications that users recognise and abide by the legal requirements associated with these

- Users may download and print one copy of any publication from the public portal for the purpose of private study or research.

- You may not further distribute the material or use it for any profit-making activity or commercial gain

If the publication is distributed under the terms of Article $25 \mathrm{fa}$ of the Dutch Copyright Act, indicated by the "Taverne" license above, 
METABOLIC EFFECTS OF WEIGHT CYCLING IN OBESITY 


\section{CIP-GEGEVENS KONINKLIJKE BIBLIOTHEEK, DEN HAAG}

Kempen, Kitty Petronella Gertruda

Metabolic effects of weight cycling in obesity /

Kitty Petronella Gertruda Kempen.

Maastricht: Universitaire Pers Maastricht - Ill.

Proefschrift Maastricht - Met lit. opg. -Met

samenvatting in het Nederlands.

ISBN 90-5278-209-1

Trefw.: gewichtsschommelingen / energiemetabolisme

Vormgeving: Kitty Kempen

Omslagillustratie: Fransz Witte 'De schoonheid van de volume'

Druk:

Datawyse Maastricht / Krips Repro Meppel 


\section{METABOLIC EFFECTS OF WEIGHT CYCLING IN OBESITY}

\section{PROEFSCHRIFT}

ter verkrijging van de graad van doctor

aan de Rijksuniversiteit Limburg te Maastricht, op gezag van de Rector Magnificus, Prof. mr. M.J. Cohen, volgens het besluit van het College van Dekanen, in het openbaar te verdedigen op vrijdag 19 januari 1996 om 16.00 uur

door

Kitty Petronella Gertruda Kempen

geboren te Venray op 21 september 1967 
Promotor:

Beoordelingscommissie: Prof. dr. G.J. van der Vusse (voorzitter)

Prof. dr. J.O. Hill (University of Colorado, Denver)

Prof. dr. A.C. Nieuwenhuijzen Kruseman

Dr. J. Seidell (RIVM, Bilthoven)

Prof. dr. R.J.A. Zwaal

Het onderzoek beschreven in dit proefschrift werd mogelijk gemaakt door subsidie van de Nederlandse Organisatie voor Wetenschappelijk onderzoek (NWO, project nummer MW 900-562-090), Den Haag.

Het verschijnen van dit proefschrift werd mede mogelijk gemaakt door financiële steun van de Nederlandse Hartstichting en de Stichting Dr. ir. J.H.J. van de Laar. 
Aan mijn ouders 



\section{CONTENTS}

Chapter 1 Introduction

Chapter 2 Effects of energy restriction on acute adrenoceptor and metabolic responses to exercise in obese subjects

Chapter 3 Skeletal muscle characteristics before and after energy restriction in obesity: fiber type, enzymatic $\beta$-oxidative capacity and fatty acid-binding protein content

Chapter 4 The effects of weight loss and apolipoprotein E polymorphism on serum lipids, apolipoproteins A-I and B, and lipoprotein(a)

Chapter 5 Predictors of fat loss during very-low calorie diet in obese females

Chapter 6 Weight cycling is associated with blunting of the sympathetically mediated thermogenesis in obesity

Chapter 7 Weight cycling does not adversely affect serum lipids and lipoproteins in obese women

Chapter 8 Energy balance during an 8-wk energy-restricted diet with and without exercise in obese women

Chapter 9 Can regular moderate exercise prevent adverse metabolic effects of weight cycling in obesity?

Chapter 10 General discussion

Summary

Samenvatting

Abbreviations

Dankwoord

Curriculum vitae

Publications 



\section{CHAPTER 1}

\section{Introduction}

\section{General}

The prevalence of overweight and obesity has been dramatically increased during the last decade. Recent estimates of the National Health and Nutrition Examination Surveys in the US population of 20 years and older indicated an increase of $8 \%$ and a rise in mean weight of $3.6 \mathrm{~kg}(44)$. A similar increase in the prevalence of obesity has been found in western Europe (53), whereas a progressive rise is indicated in children (51). There is convincing evidence that severe obesity and even mild-to-moderate overweight are associated with increased risk of coronary heart diseases, hypertension, dyslipidemia and non-insulin-dependent diabetes mellitus $(14,50,59,86)$. From a public health perspective, therefore, prevalence figures for overweight and obesity are alarming. Voluntary weight loss efforts have been shown to be not effective for treatment of obesity on the long-term $(19,26,87)$. Many obese people have a long history of dieting with often successful weight losses, but also disappointing relapses. Accurate information on prevalence and magnitude of weight fluctuations is currently unknown. Estimates indicate that nearly one out of three adults and $53 \%$ of overweight adults in the US are currently trying to lose weight (87).

A pattern of repeated weight loss and regain (weight cycling) may lead to metabolic adaptations that hamper subsequent efforts of weight loss and maintenance of reduced weight $(8,12)$. Moreover. several epidemiological studies indicate that variability in body weight may increase the risk of overall and cardiovascular mortality $(10,29,46$, 48). The weight cycling topic has yet received tremendous publicity and the scientific debate about potential metabolic and health effects of weight cycling has not ended ( 55 . $88,89,91$ ). For proper general recommendations, more scientific knowledge about metabolic effects of weight cycling is needed. The present thesis describes metabolic consequences of voluntary dietary-induced weight loss and weight cycling in obesity. In addition, a possible role of exercise in the regulation of body weight control and energy metabolism will be evaluated. 


\section{Metabolic effects of dietary-induced weight loss}

For the study of weight cycling-induced physiological adaptations, it is of interest to focus on energy metabolism. This implicates interest in the activity of the sympathetic nervous system which has been demonstrated to play a central role in the regulation of energy expenditure and substrate utilization $(6,7,84)$. Since an association between weight variability and cardiovascular mortality has been suggested $(55,88,89)$, weight cycling research may also concentrate on modulation of cardiovascular risk factors such as serum lipid and lipoprotein profiles.

Much of confusion about weight cycling effects can be traced to lack of a standardized definition of weight cycling (55). A possible definition of a weight cycle may involve weight loss followed by gain. Therefore, the first step in the project described in the present thesis was to organize a dietary weight loss trial consisting of an 8-week energy restriction period. Reduction of energy intake has been shown to create a negative energy balance. A variety of energy-sparing physiological adaptations is evoked such as reduced metabolic rate and altered substrate metabolism. This reduction in energy expenditure appears to be partially related to decrease of metabolic active tissue $(45,60$, 75). A reduced cellular metabolic rate has been suggested to contribute, mainly due to regulatory adaptations of several thermogenic hormones (75). Substrate mobilization and fuel use are modified by energy restriction in order to maintain glucose production by glycogenolysis and gluconeogenesis to meet the needs of obligate glucoseconsuming tissues. Release of fatty acids from adipose tissue is increased and skeletal muscle preferentially uses fatty acids for energy supply in this situation $(31,54,75)$.

Changes in sympathetic nervous system activity play an important role in the metabolic responses to energy restriction $(7,75)$. Adaptations of turnover rates and circulating levels of catecholamines, and changes in sensitivity and responsiveness at adrenoceptor or post-receptor level may be involved. Energy restriction has been shown to be associated with a lowering of basal circulating levels and turnover of norepinephrine (5, $56,74)$. Furthermore, adrenoceptors have been demonstrated to be dynamically regulated, but to what extent energy restriction modulates this regulation is still debated $(5,15,17,57,79)$. To obtain more information on dynamic regulation of adrenoceptors and its associated functional consequences for energy metabolism, a study is described in Chapter 2. In this study, modulation of adrenoceptors that are involved in lipolysis and thermogenesis by energy restriction in the obese was evaluated.

Overall body energy expenditure, both at rest and during exercise, is largely attributed to skeletal muscle tissue $(92,93)$. Owing to its large mass, skeletal muscle contributes for as much as $20-30 \%$ to total oxidative metabolism under resting conditions. Muscle cells possess a remarkable capacity to adapt to extreme metabolic demands and it is conceivable that muscular adaptations contribute to the energy-saving metabolic mechanisms during energy restriction. Muscular adaptations to energy restriction may involve changes of fiber type composition and activity of oxidative enzymes $(31,43$, 67). Currently, no information is available on possible energy restriction-induced adaptations of skeletal muscle cytoplasmic fatty acid-binding protein content.

Fatty acid-binding proteins have been convincingly found in cells of tissues that are actively involved in the uptake or utilization of fatty acids $(27,28)$ although their 
physiological significance for human energy metabolism remains to be established. For skeletal muscle, a significant quantitative relationship has been suggested between fatty acid-binding protein content and mitochondrial fatty acid oxidation capacity $(27,28$, 83). In Chapter 3, effects of an 8-week energy-restrictive regimen on skeletal muscle characteristics, including the cytosolic fatty acid-binding protein, are described.

Since weight cycling effects may involve modification of cardiovascular risk factors, part of the project described in the present thesis concentrates on serum lipid and lipoprotein profiles. Energy restriction-induced weight loss in obese subjects has been demonstrated to be a valuable approach in normalizing blood lipids and lipoproteins $(1,20)$. However, serum levels of lipoprotein(a), a strong and independent risk factor for cardiovascular disease $(66,72)$, appear to be mainly genetically determined (11). It has been suggested that lipoprotein(a) levels are rather resistant to pharmacological or dietary modifications. Studies to effects of weight loss on lipoprotein(a) are scarce and contradictory $(16,35$, 76). Apolipoprotein $\mathrm{E}$ polymorphism has now been suggested to be an important genetic factor involved in the metabolism of apo B-containing lipoproteins, such as lipoprotein(a) (42). Chapter 4 describes a study on effects of short-term substantially weight loss on serum lipoprotein(a) levels and other lipid variables. It was additionally examined whether energy restriction-induced changes in lipid and lipoprotein variables were modulated by apolipoprotein $\mathrm{E}$ polymorphism.

Ideally, a dietary weight loss treatment should result in the loss of excess body fat and preservation of amounts of lean body mass. It appears, however, that the amount of weight and fat mass lost as result of a dietary treatment program, considerably varies among individuals. Factors involved in the modulation of quantity and composition of weight loss remain to be established, but it has been suggested that total energy expenditure, fat oxidation and plasma norepinephrine may be involved $(2,40)$. To further elucidate predicting metabolic factors of weight loss in an obese population, a statistical analysis was performed in Chapter $\mathbf{5}$.

\section{Metabolic and health consequences of weight cycling}

One of the earliest studies in the weight cycling area was published by Brownell et al (12) in 1986. This study indicated that weight cycling results in increased metabolic efficiency in rodents, making subsequent weight loss more difficult and promoting regain. Since the study of Brownell et al (12), much attention has been focussed on possible adverse metabolic consequences of weight cycling. Numerous studies have examined effects of weight cycling on energy metabolism and body composition. Some of these studies support the hypothesis that weight cycling reduces the level of energy expenditure $(22,49,77)$ and increases total $(49)$ or central adiposity $(47,63,65)$. However, several recent reviews on animal and human research $(55,64,88)$ conclude that the majority of available data provides little evidence to support adverse effects of weight cycling on energy metabolism, body composition and fat distribution, although further research is recommended.

Much of inconsistencies in literature on weight cycling effects can be attributed to limitations of design of studies performed and lack of a standardized definition of weight 
cycling. Furthermore, several confounding factors may be involved such as paradigms for producing weight cycling, choice of control groups, and effects of gender and age $(9$, 55). Surprisingly, there are only few studies reported in the literature that investigated repeated intentional weight loss in the same individual and these studies show mixed results $(4,8,36,38,39)$. To improve the scientific knowledge on metabolic weight cycling effects in obesity, a prospective study on effects of two complete cycles of intentional weight loss followed by regain on energy metabolism and body composition in obese women is described in Chapter 6 .

Indications that weight fluctuations may be associated with increased cardiovascularand all-cause mortality came from several large epidemiological studies $(10,29,46,48)$ although not all studies could confirm this finding $(47,78)$. Studies on underlying mechanisms fail to demonstrate modulating effects of weight cycling on several cardiovascular risk factors so far $(37,48,52,55,62,73,88)$. To provide turther clarification on a possible modulating influence of weight cycling on cardiovascular risk factors, the serum lipid and lipoprotein profiles has been prospectively investigated in weight cycling obese women (Chapter 7).

\section{Physical exercise and weight cycling}

Physical exercise has been suggested to play an important role in the control of body weight. It has been shown to be related with more successful long-term maintenance of weight loss and body weight $(19,32,58,68,70,80,82)$. Furthermore, exercise appeared to be predictive for changes in body weight over time (25). A modulating influence of exercise on energy intake, energy expenditure, and substrate utilization has been suggested $(13,24,34,68,81,82)$. When exercise is added to energy restriction for weight loss treatment of obesity, conflicting results have been found. Although higher weight and fat loss, and preservation of fat-free mass due to addition of exercise have been reported $(3,30,33,61,69,71)$, others fail to find such effects $(18,21,23)$. Since the extent of adaptations to diet alone, or combined with exercise treatment, appears to be related to the magnitude of the energy deficit. lack of conclusive results may be partially explained by concomitant changes in other components determining energy balance. The doubly labeled water technique now provides an excellent method to measure total energy expenditure over 1-3 weeks under free-living conditions (85). This method has been used to evaluate adaptations of total energy expenditure and its various components to energy-restricted diet alone or combined with a moderate exercise program in obese women (Chapter 8).

Moderate regular exercise has been shown to have several beneficial effects on serum lipid profile, body composition, and energy metabolism. Modulation of exercisc-induced activity of the sympathetic nervous system has been demonstrated to be involved (41, $81,82,90$ ). It may be hypothesized that exercise prevents possible adverse metabolic effects of weight cycling in obesity. Influence of participation in a prolonged moderate regular exercise program on possible adverse metabolic effects of weight cycling in obesity has been studied as described in Chapter 9. 


\section{Outline of the thesis}

The studies described in the present thesis were part of an extensive longitudinal project intended to obtain information on effects of weight cycling on energy metabolism and body composition in obese women. The study design of the whole project is summarized in Figure 1.1.

diets

weeks

\section{Measurements}

skcletal muscle biopsy

lipids and lipoprotcins

maximal aerobic capacity

hody compnsition

slceping metabolic rate

exercise-induced thurmogenusis

isoprenaline-induced thermogenesis

average daily metabolic rate

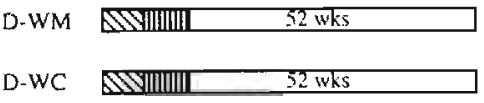

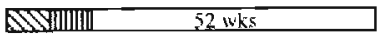

$0 \quad 8$

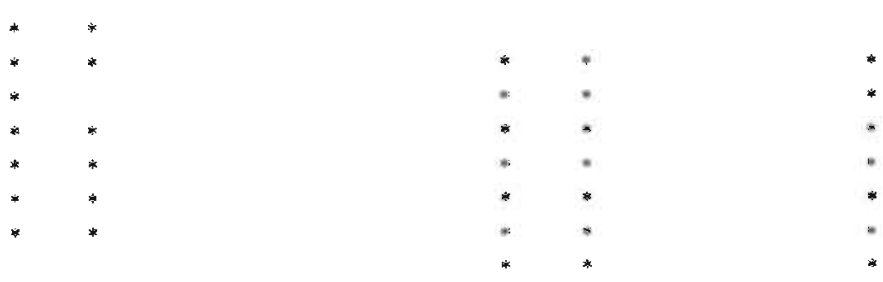

MIV dierary regimens with very-low calorie diet $(2.0 \mathrm{MJ} /$ day $)$

InIIIII dictary regimens with very-low calorie diet and free-choice normal food $(3.5 \mathrm{MJ} / \mathrm{day})$

non-diet controlled

Figure 1.1 Design of the study. D-WM, diet-weight maintainers defined as $<70 \%$ regain of previous weight loss after 1 year follow-up; D-WC, diet-weight cyclers defined as $\geq 70 \%$ regain of previous weight loss after 1 year follow-up; DEx-WC, diet/exercise-weight cyclers defined as $\geq 70 \%$ regain of previous weight loss after 1 year follow-up.

In summary, 63 healthy obese women were selected to participate in a controlled energy-restricted intervention period for 8 weeks. After a subsequent 1 -year noncontrolled follow-up period, 42 subjects repeatedly participated the same dietary intervention. Of those 42 subjects, 26 had regained $\geq 70 \%$ of the previous weight loss. Before the start of a second 8-week controlled energy-restricted intervention period, those 26 subjects were matched on the basis of body mass index and body fat percentage and randomly assigned to diet treatment with subsequent non-controlled 1 year follow-up alone (D-WC) or combined diet-exercise treatment and 1-year follow-up with participation in a moderate exercise program (DEx-WC).

Chapter 2 describes a pilot study intended to evaluate energy restriction-induced modulation of adrenoceptors involved in lipolysis and thermogenesis and its associated functional consequences for energy metabolism. Subsequently, effects of energy restriction on metabolic characteristics of skeletal muscle (Chapter 3 ) and serum lipid 
and lipoprotein profiles (Chapter 4) were evaluated. Chapter 5 describes an analysis on metabolic factors that predictively are involved in modulation of quantity and composition of weight loss to dietary treatment. Effects of weight cycling on energy metabolism, body composition, serum lipid and lipoprotein profiles are presented in Chapter 6 and Chapter 7. Possible favorable effects of physical exercise in the treatment of obesity when combined with energy restriction (Chapter 8) or on a longterm basis to prevent adverse metabolic effects of weight cycling (Chapter 9) were investigated. Finally, the results of this thesis are discussed and implications for future research are given in Chapter $\mathbf{1 0}$.

\section{References}

1. Andersen JW, Brinkman-Kaplan VL, Lee H, Wood CL. Relationship of weight loss to cardiovascular risk factors in morbidly obese individuals. J Am Coll Nutr 14: 256-261, 1994.

2. Astrup A, Beumann B, Gluud C, Bennett P, Tjur T, Christensen N. Prognostic markers for dietinduced weight loss in obese women. Int J Obes 19: 275-278, 1995.

3. Ballor DL, Poehlman ET. Exercise-training enhances fat-free mass preservation during dietinduced weight loss: a meta-analytical finding. Int J Obes 18: 35-40, 1994.

4. Beeson V, Ray C, Coxon A, Kreitzman S. The myth of the yo-yo: consistent rate of weight loss with successive dieting by VLCD. Int J Obes 13(suppl 2): 135-139, 1989.

5. Berlin I, Berlan M, Crespo-Laumonnier B, Landault C, Payan C, Puech AJ, Turpin G. Alterations in $\beta$-adrenergic sensitivity and platelet $\alpha_{2}$-adrenoceptors in obese women: effect of exercise and caloric restriction. Clin Sci 78: 81-87, 1990.

6. Blaak EE, van Baak MA, Kempen KPG, Saris WHM. Role of $\alpha$-and $\beta$-adrenoceptors in the sympathetically mediated thermogenesis. Am. J Physiol 264: E1 1-E17, 1993.

7. Blaak EE, van Baak MA. Kester ADM, Saris WHM. $\beta$-Adrenergically mediated thermogenesis and heart rate responses: effect of obesity and weight loss. Metabolism 44: 520-524, 1995.

8. Blackburn GL, Wilson GT, Kanders BS, Stein LJ, Lavin PT, Adler J, Brownell KD. Weight cycling: the experience of human dieters. Am J Clin Nutr 49: 1105-1109, 1989.

9. Blackburn GL, Borrazzo ECL. Weight cycling (editorial). JAMA 273: 998, 1995.

10. Blair SN, Shaten J, Brownell K, Collins G, Lissner L. Body weight change, all-cause mortality, and cause-specific mortality in the Multiple Risk Factor Intervention Trial. Ann Intern Med 119: 749.757, 1993.

11. Boerwinkle E, Leffert CC, Lin J, Lackner C, Chiesa G. Hobbs HH. Apolipoprotein(a) gene accounts for greater than $90 \%$ of the variation in plasma lipoprotein(a) concentration. $J$ Clin Invest 90: 52-60, 1992.

12. Brownell KD, Greenwood MRC, Stellar E. Shrager EE. The effects of repeated cycles of weight loss and regain in rats. Physiol Behav 38: 459-464, 1986.

13. Calles-Escandón J, Horton ES. The thermogenic role of exercise in the treatment of morbid obesity: a critical evaluation. Am J Clin Nutr 55: 533S-537S, 1992.

14. Chan JM, Rimm EB, Colditz GA, Stampfer MJ, Willett WC. Obesity, fat distribution, and weight gain as risk factors for clinical diabetes in men. Diabetes Care 17: 961-969, 1994.

15. Cignarelli M. de Pergola G, Garruti G, Corso M, Cospite MR, Paternostro A, Romanazzi V, Giorgino R. Changes in overall plasma norepinephrine turnover and lymphomonocyte betaadrenoceptor number during combined caloric and sodium restriction in normotensive obese subjects. Int J Obes 14: 429-437, 1990.

16. Corsetti JP. Sterry JA, Sparks JD, Sparks CE. Weintraub M. Effect of weight loss on serum lipoprotein(a) concentrations in an obese population. Clin Chem 37: 1191-1195, 1991.

17. Crampes F. Marceron M, Beauville M. Riviere D, Garrigues M, Berlan M, Lafontan M. Platelet alpha $_{2}$-adrenoceptors and adrenergic adipose tissue responsiveness after moderate hypocaloric diet in obese subjects. Int J Obes 13: 99-110, 1989. 
18. Dale van D, Saris WHM, Schoffelen PFM, ten Hoor F. Does exercise give an additional effect in weight reduction regimens? Int J Obes 11: 367-375, 1987.

19. Dale van D, Saris WHM, ten Hoor F. Weight maintenance and resting metabolic rate 18-40 months after a diet/exercise treatment. Int J Obes 14: 347-359, 1990.

20. Dattilo AM, Kris-Etherton PM. Effects of weight reduction on blood lipids and lipoproteins: a meta-analysis. Am J Clin Nutr 56: 320-328, 1992.

21. Dengel DR, Hagberg JM, Coon PJ, Drinkwater DT, Goldberg AP. Effects of weight loss by diet alone or combined with aerobic exercise on body composition in older obese men. Metabolism 43: $867-871,1994$.

22. Desaultes M, Dulos RA. Effects of repeated cycles of fasting-refeeding on brown adipose tissue composition in mice. Am J Physiol 255: E120-E128, 1988.

23. Donnelly JE, Pronk NP, Jacobsen DJ, Pronk SJ, Jakicic JM. Effects of a very-low-calorie diet and physical-training regimens on body composition and resting metabolic rate in obese females. Am J Clin Nutr 54: 56-61, 1991.

24. Flatt JP. Dietary fat, carbohydrate balance, and weight maintenance: effects of exercise. $A m J$ Clin Nutr 45: 296-306, 1987.

25. French SA, Jeffery RW, Forster JL, McGovern PG, Kelder SH, Baxter JE. Predictors of weight change over two years among a population of working adults: the Healthy Worker Project. Int $J$ Obes 18: 145-154, 1994.

26. Garner DM, Wooley SC. Confronting the failure of behavioral and dietary treatments for obesity. Clin Psychol Rev 11: 729-780, 1991.

27. Glatz JFC, van der Vusse GJ, Veerkamp JH. Fatty acid-binding proteins and their physiological significance. News Phys Sci 3: 41-43, 1988.

28. Glatz JFC, van der Vusse GJ. Cellular fatty acid-binding proteins: current concepts and future directions. Mol Cell Biochem 98: 237-251, 1990.

29. Hamm P, Shekelle RB, Stamler J. Large fluctuations in body weight during young adulthood and twenty-five year risk of coronary death in men. Am J Epidemiol 129: 312-318, 1989.

30. Hammer RL, Barrier CA, Roundy ES, Bradford JM, Fisher AG. (alorie-restricted low-fat diet and exercise in obese women. Am J Clin Nutr 49: 77-85. 1989.

31. Henriksson J. Energy metabolism in muscle: its possible role in the adaptation to energy deficiency. In Kinney JM, Tucker HN (eds). Energy metabolism: tissue determinants and cellular corollaries. Raven Press, New York pp 345-365, 1992.

32. Hensrud DD, Weinsier RL, Darnell BE. Hunter GR. A prospective study of weight maintenance in obese subjects reduced to normal body weight without weight-loss training. Am J Clin Nutr 60 : 688-694, 1994

33. Hill JO, Schlundt DG, Sbrocco T, Shärp T, Pope-Cordle J, Stetson B, Kaler M, Heim C. Evaluation of an alternating-calorie diet with and without exercise in the treatment of obesity. $\mathrm{Am} \mathrm{J} \mathrm{Clin}$ Nutr 50: 248-254, 1989.

34. Horton ES. Metabolic aspects of exercise and weight reduction. Med Sci Sports Exerc 18: 10-18, 1986.

35. Huisveld IA, Leenen R, van der Kooy K, Hospers JE. Seidell JC, Deurenberg P. Koppeschaar HP, Mosterd WL, Bouma BN. Body composition and weight reduction in relation to antigen and activity of plasminogen activator inhibitor (PAI-I) in overweight individuals. Fibrinolysis 4 (supp! 2): $84-85,1990$.

36. Jebb SA, Goldberg GR, Coward WA, Murgatroyd PR, Prentice AM. Effects of weight cycling caused by intermittent dieting on metabolic rate and body composition in obese women. Int $J$ Obes 15: 367-374, 1991.

37. Jeffery RW, Wing RR, French SA. Weight cycling and cardiovascular risk factors in obese men and women. Am J Clin Nutr 55: 641-644, 1992.

38. Kamrath RO, Diner RG, Plummer LJ, Sadur CN, Weinstein RL. Repeated use of the very-low calorie diet in a structured multidisciplinary weight-management program. Am J Clin Nutr 56: 288S-289S, 1992. 
39. Kaplan GD, Miller KC. Andersen JW. Comparative weight loss in obese patients restarting a supplemented very-low-calorie diet. Am J Clin Nutr 56: 290S-291S, 1992.

40. Keim NL. Barbieri TF, Van Loan M. Physiological and biochemical variables associated with body fat loss in overweight women. Int J Obes 15: 283-293, 1991.

41. Kjær M. Exercise effects on adrenergic regulation of energy metabolism. In Lamb DR, Gisolfi VD (eds). Perspectives in exercise science and sports medicine, vol 5: Energy metabolism in exercise and sport. Wm C Brown Communications Inc, Dubuque pp 345-376, 1992.

42. Knijff de P, Kaptein A, Boorsma D. Princen HM, Frants RR, Havekes LM. Apolipoprotein E polymorphism affects plasma levels of lipoprotein(a). Atherosclerosis 90: 169-174, 1991.

43. Krotkiewski M, Grimby G, Holm G, Szczepanik J. Increased muscle dynamic endurance associated with weight reduction on a very-low-calorie diet. Am J Clin Nutr 51: 32 1-330, 1990.

44. Kuczmarski RJ, Flegal KM, Campbell SM, Johnson CL. Increasing prevalence of overweight among US adults. The National Health and Nutrition Examination Surveys, 1960 to 1991. JAMA 272: $205-211,1994$.

45. Leibel RL, Rosenbaum M, Hirsch J. Changes in energy expenditure resulting from altered body weight. N Engl J Med 332: 62 I-628, 1995.

46. Lissner L, Bengtsson C, Lapidus L, Larson B, Bengtsson B, Brownell KD. Body weight variability and mortality in the Gothenburg Prospective Studies on men and women. In Bjorntorp P, Rossner S (eds). Obesity in Europe 88: Proceedings of the First European Congress on Obesity. Libbey, London pp 55-60, 1989.

47. Lissner L, Andres R, Muller DC, Shimokata H. Body weight variability in men: metabolic rate, health and longevity. Int J Obes 14: 373-383, 1990.

48. Lissner L, Odell PM, D'Agostino RB, Stokes J, Kreger BE, Belanger AJ, Brownell KD. Variability of body weight and health outcomes in the Framingham population. $N$ Engl J Med 324: 18391844, 1991.

49. Manore MM, Berry TE, Skinner JS, Caroll SS. Energy expenditure at rest and during exercise in nonobese female cyclical dieters and in nondieting control subjects. Am J Clin Nutr 54: 41-46, 1991.

50. Manson JE, Colditz GA, Stampfer MJ, Willett WC. Rosner B. Monson RR, Speizer FE. Hennekens $\mathrm{CH}$. A prospective study of obesity and risk of coronary heart disease in women. $N$ Engl J Med 322: $882-889,1990$.

51. Marelli G, Colombo E. Six years of epidemiological monitoring of childhood obesity. Int $J$ Obes 19(suppl 2): 52, 1995.

52. Melby CL. Sylliaasen S, Rhodes T. Diet-induced weight loss and metabolic changes in obese women with high versus low prior weight loss/regain. Nutr Res 11: 971-978, 1991.

53. Mikkelsen KL. Heitmann BL, Sorensen TIA. Secular changes in mean body mass index and in the prevalence of obesity. Three Danish population studies of 31,000 subjects. Int $J$ Obes 19(suppl 2): 52, 1995.

54. Minuk HL, Hanna AK, Marliss EB, Vranic M, Zinman B. Metabolic response to moderate exercise in obese man during prolonged fasting. Am $J$ Physiol 238: E322-E329, 1980.

55. National Task Force on the Prevention and Treatment of Obesity. Weight cycling. JAMA 272: 1196-1202, 1994.

56. O'Dea K, Esler M, Leonard P, Stockigt JR, Nestel P. Noradrenaline turnover during under- and over-eating in normal weight subjects. Metabolism 31: 896-899, 1983.

57. Östman J. Arner P, Kimura H. Wahrenberg H. Engfeldt P. Influence of fasting on lipolytic response to adrenergic agonists and on adrenergic receptors in subcutaneous adipocytes. Eur $J$ Clin Invest 14: 383-391, 1984.

58. Pavlou KN, Krey S, Steffee WP. Exercise as an adjunct to weight loss and maintenance in moderately obese subjects. Am J Clin Nutr 49: 1115-1123, 1989.

59. Pi-Sunyer FX. Health implications of obesity. Am J Clin Nutr 53: 1595S-1603S, 1991.

60. Prentice AM. Jebb S. Goldberg GR. Coward WA, Murgatroyd PR. Poppitt SD. Cole TJ. Effects of weight cycling on body composition. Am J Clin Nutr 56: 209S-216S. 1991. 
61. Racette SB, Schoeller DA, Kushner RF, Neil KM, Hering-Iaffaldano K. Effects of aerobic exercise and dietary carbohydrate on energy expenditure and body composition during weight reduction in obese women. Am J Clin Nutr 61: 486-494, 1995.

62. Rebuffé-Scrive M, Hendler R, Bracero N, Cummings N, McCarthy S, Rodin J. Biobehavioral effects of weight cycling. Int J Obes 18: 651-658, 1994.

63. Reed DR, Contreras RJ, Maggio C, Greenwood MRC, Rodin J. Weight cycling in female rats increases dietary fat selection and adiposity. Physiol Behav 42: 389-395, 1988.

64. Reed GW, Hill JO. Weight cycling: a review of the animal literature. Obes Res 1: 392-402, 1993.

65. Rodin J, Radke-Sharpe N, Rebuffé-Scrive M, Greenwood MRC. Weight cycling and fat distribution. Int J Obes 14: 303-310, 1990.

66. Rosengren A, Wilhelmsen L, Eriksson E, Risberg B, Wedel H. Lipoprotein(a) and coronary heart disease: a prospective case-control study in a general population sample of middle aged men. $\mathrm{Br}$ Med J 301: 1248-1251, 1990.

67. Russell McR D, Walker PM, Leiter LA, Sima AAF, Tanner WK, Mickle DAG, Whitwell J, Marliss $\mathrm{EB}$, Jeejeebhoy $\mathrm{KN}$. Metabolic and structural changes in skeletal muscle during hypocaloric dieting. Am J Clin Nutr 39: 503-513, 1984.

68. Saris WHM. Physiological aspects of exercise in weight cycling. Am J Clin Nutr 49: 1099-1104, 1989.

69. Saris WHM, van Dale D. Effects of exercise during VLCD diet on metabolic rate, body composition and aerobic power: pooled data of four studies. Int $J$ Obes 13(suppl 2): 169-170, 1989.

70. Saris WHM, Koenders MC, Pannemans DLE, van Baak MA. Outcome of a multicenter outpatient weight-management program including very-low-calorie diet and exercise. Am J Clin Nutr 56: 294S-296S, 1992.

71. Saris WHM. The role of exercise in the dietary treatment of obesity. Int J Obes 17(suppl 1) SI7-S21, 1993.

72. Scanu AM, Fless GM. Lipoprotein(a). Heterogeneity and biological relevance. J Clin Invest 85 : 1709-1715, 1990.

73. Schotte DE, Cohen E, Singh SP. Effects of weight cycling on metabolic control in male outpatients with Non-Insulin-Dependent Diabetes Mellitus. Health Psychol 9: 599-605, 1990.

74. Schwartz RS, Jaeger LF, Veith RC, Lakshminarayan S. The effect of diet or exercise on plasma norepinephrine kinetics in moderately obese young men. Int J Obes 14:1-11, 1990.

75. Shetty PS. Physiological mechanisms in the adaptive response of metabolic rates to energy restriction. Nutr Res Rev 3: 49-74, 1990.

76. Sönnichsen AC, Richter WO, Schwandt P. Reduction of lipoprotein(a) by weight loss. Int J Obes 14: 487-494, 1990.

77. Steen SN, Oppliger RA, Brownell KD. Metabolic effects of repeated weight loss and regain in adolescent wrestlers. JAMA 260: 47-50. 1988.

78. Stevens J, Lissner L. Body weight variability and mortality in the Charleston Heart Study. Int $J$ Obes 14: 385-386, 1990.

79. Sundaresan PR, Weintraub M, Hershey LA, Kroening BH, Hasday JD, Banerjee: SP. Platele! alphaadrenergic receptors in obesity: alteration with weight loss. Clin Pharmacol Ther 33: 776-785. 1983.

80. Svendsen OL, Hassager C. Christiansen C. Six months' follow-up on exercise added to short-term diet in overweight postmenopausal women - effects on body composition, resting metabolic rate, cardiovascular risk factors and bone. Int J Obes 18: 692-698, 1994.

81. Tremblay A, Coveney S, Després J-P, Nadeau A, Prud'homme D. Increased resting metabolic rate and lipid oxidation in exercise-trained individuals: evidence for a role of $\beta$-adrenergic stimulation. Can J Physiol Pharmacol 70: 1342-1347, 1992.

82. Tremblay A, Buemann B. Exercise-training, macronutrient balance and body weight control. Int J Obes 19: 79-86, 1995. 


\section{Chapter 1}

83. Vusse van der GJ, Reneman RS. Lipid metabolism in muscle. In Rowell LB, Shephard JT (eds). Handbook of physiology. Integration of motor, circulatory, respiratory and metabolic control during exercise. In press.

84. Welle S, Schwartz RG, Statt M. Reduced metabolic rate during $\beta$-adrenergic blockade in humans. Metabolism 40: 619-622, 1991.

85. Westerterp KR, Wouters L, van Marken Lichtenbelt WD. The Maastricht protocol for the determination of body composition and energy expenditure with labeled water. Obes Res 3(suppl 1): 49-57, 1995.

86. Willett WC, Manson JE, Stampfer MJ, Colditz GA, Rosner B, Speizer FE, Hennekens CH. Weight, weight change, and coronary heart disease in women. JAMA 273: 461-465, 1995.

87. Williamson DF, Serdula MK, Anda RF, Levy A. Byers T. Weight loss attempts in adults: goals, duration and rate of weight loss. Am J Public Health 82: 1251-1257, 1992.

88. Wing RR. Weight cycling in humans: a review of the literature. Ann Behav Med 14: 113-119, 1992.

89. Wing RR. Weight cycling: the public concern and the scientific data (editorial). Obes Res 1: 390$391,1993$.

90. Wood PD, Stefanick ML, Williams PT, Haskell WL. The effects on plasma lipoproteins of a prudent weight-reducing diet, with or without exercise, in overweight men and women. $N$ Eng $J$ Med 325: 461-466, 1991.

91. Zelitch Yanovski S. Weight cycling (editorial). JAMA 273: 999, 1995.

92. Zurlo F, Larson K, Bogardus C, Ravussin E. Skeletal muscle metabolism is a major determinant of resting energy expenditure. J Clin Invest 86: 1423-1427, 1990.

93. Zurlo F, Nemeth PM, Choksi RM, Sesodia S, Ravussin E. Whole-body energy metabolism and skeletal muscle biochemical characteristics. Metabolism 43: 481-486, 1994. 


\title{
CHAPTER 2
}

\section{Effects of energy restriction on acute adrenoceptor and metabolic responses to exercise in obese subjects}

Kempen KPG, Saris WHM, Senden JMG, Menheere PPCA', Blaak EE, van Baak MA

Department of Human Biology, University of Limburg and 'Department of Clinical Chemistry, University Hospital Maastricht, Maastricht, the Netherlands

Am J Physiol 267: E694-E701, 1994

\begin{abstract}
This study was intended to investigate the effects of energy restriction on the acute responses of platelet $\alpha_{2}$ - and lymphocyte $\beta_{2}$-adrenoceptors to exercise in obese female subjects. Seven obese females were restricted to a low-energy formula diet ( $2.0 \mathrm{MJ} /$ day) for 4 weeks. As result of the diet, there was a $7.8-\mathrm{kg}$ weight loss. No significant changes could be detected in sleeping and resting metabolic rate expressed per kilogram fat-free mass. Basal venous glucose, insulin, and norepinephrine levels decreased as a result of the diet, whereas free fatty acid values increased.

Before the diet, 60 min of exercise (45\% peak mechanical power) caused no alteration in the density of lymphocyte $\beta_{2}$-adrenoceptors. At the end of 4 weeks of dieting, the density was significantly increased in response to exercise, together with a higher thermogenic and lipolytic response and decreased venous insulin levels. Energy restriction resulted in an increased basal platelet $\alpha_{2}$-adrenoceptor density, whereas exercise did not modify density and affinity of platelet $\alpha_{2}$-adrenoceptors. The results indicate that adrenoceptor numbers can be modulated by energy restriction in obesity. Modulation of adrenoceptor density may play a role in increased exercise-induced lipolysis during energy restriction.
\end{abstract}




\section{Introduction}

The activity of the sympathetic nervous system (SNS) plays an important role in the regulation of energy expenditure (6). It has been suggested that in obese individuals an impaired activation of the SNS exists that may be responsible for a reduced diet-induced thermogenesis (3). A large part of the SNS-mediated energy expenditure takes place in skeletal muscle, predominantly consisting of $\beta_{2}$-adrenoceptors (18). The adrenoceptor populations of adipose tissue are mainly of the $\beta_{1^{-}}, \beta_{2^{-}}, \beta_{3^{-}}$, and $\alpha_{2}$-type (16), and their role becomes especially important during both exercise and energy restriction, when an increased need for fat as a fuel exists (1).

Conditions such as an altered food intake or physical activity are known to affect the activity of the SNS and may thereby influence metabolic rate and substrate metabolism. Acute physical exercise activates the SNS and increases energy expenditure and SNSmediated effects. The increased activation of SNS in response to exercise is accompanied by a rapid elevation of lymphocyte $\beta_{2}$-adrenoceptor density in normal-weight healthy subjects $(19,20)$. To our knowledge, changes in $\beta$-adrenoceptor density in response to exercise have not been investigated previously in obese subjects.

Weight loss or energy restriction causes a decreased basal sympathetic activity, as measured by lowered basal plasma norepinephrine levels or appearance rates $(5,24)$. The effect of energy restriction on adrenoceptor regulation in obese subjects has not been extensively studied, and the results of previous studies are conflicting. Beside unchanged lymphocyte $\beta_{2}$-adrenoceptor density and affinity (10), increased numbers of $\beta_{2}$-adrenoceptors have been shown on femoral adipocytes (22). Also, the density of platelet $\alpha_{2}$-adrenoceptors has been reported to increase $(11,28)$ or not to change $(5)$ in response to energy restriction, whereas $\alpha_{2}$-adrenoceptor density of adipocytes has been shown to decline (22).

The aims of the present study were to investigate whether a single bout of exercise results in a change of blood cell $\alpha_{2}$-and $\beta_{2}$-adrenoceptor numbers in obese subjects and whether energy restriction influences basal and exercise-induced changes in $\alpha_{2}$ - and $\beta_{2}$ adrenoceptor numbers. To investigate whether changes in adrenoceptor numbers arc ussociated with functional consequences for energy metabolism, metabolic parameters were also measured.

\section{Subjects and methods}

\section{Subjects}

Seven female subjects, aged 20-45 yr (mean \pm SE, $36 \pm 2 \mathrm{yr}$ ), participated in the study. They were selected on the basis of their body mass index (BMI; $28-38 \mathrm{~kg} / \mathrm{m}^{2}$ ) and had shown a stable weight over the previous 6 months. All subjects were medically screened to exclude metabolic abnormalities. The subjects were premenopausal and showed a normal regular menstrual cycle. One was taking contraceptives during the study period. They were normotensive and used no medication during the study. Descriptive data of the subjects are shown in Table 2.1. The subjects were informed about the nature of the 
investigation and gave their informed consent. The study protocol was reviewed and approved by the university's ethical committee.

Table 2.1 Changes in body composition, energy expenditure, and maximal aerobic power in response to 4-week diet.

\begin{tabular}{|c|c|c|c|}
\hline & week 0 & week 4 & $\begin{array}{c}\text { P value } \\
\text { week } 0 \text { vs } 4\end{array}$ \\
\hline Weight, kg & $91.1 \pm 2.6$ & $83.0 \pm 2.5$ & $<0.05$ \\
\hline Body mass index, $\mathrm{kg} / \mathrm{m}^{2}$ & $32.9 \pm 0.9$ & $30.1 \pm 0.9$ & $<0.05$ \\
\hline Body fat, $\%$ & $43.9 \pm 1.3$ & $41.5 \pm 1.7$ & $<0.05$ \\
\hline Fat mass, kg & $40.4 \pm 1.8$ & $34.6 \pm 1.7$ & $<0.05$ \\
\hline Fat free mass, $\mathrm{kg}$ & $51.1 \pm 1.7$ & $48.8 \pm 2.0$ & $<0.05$ \\
\hline SMR, kJ'kg FFM ${ }^{-1} \cdot h^{-1}$ & $5.54 \pm 0.24$ & $5.22 \pm 0.10$ & NS \\
\hline $\mathrm{RMR}, \mathrm{kJ} \cdot \mathrm{kg} \mathrm{FFM}{ }^{-1} \cdot \mathrm{h}^{-1}$ & $6.00 \pm 0.24$ & $5.58 \pm 0.22$ & NS \\
\hline $\mathrm{W}_{\max }, \mathrm{W}$ & $192 \pm 7$ & $186 \pm 11$ & NS \\
\hline $\mathrm{VO}_{2 \max }, \mathrm{ml} \cdot \mathrm{kg} \mathrm{BW}-1 \cdot \min ^{-1}$ & $27.9 \pm 1.2$ & $27.1 \pm 1.4$ & NS \\
\hline
\end{tabular}

Values are means \pm SE for 7 subjects. Diet is $2.0 \mathrm{MJ} /$ day. P value based on Wilcoxon's signed-rank test. SMR, sleeping metabolic rate; RMR, resting metabolic rate: FFM. fat-free mass; $\mathrm{W}_{\text {max }}$, peak mechanical power; $\mathrm{VO}_{2 \max }$, maximum oxygen uptake; $\mathrm{BW}$, body weight; NS, not significant.

\section{Procedure}

The study period lasted 4 weeks. Measurements of body composition, sleeping metabolic rate (SMR), resting metabolic rate (RMR), maximal aerobic capacity, exerciseinduced thermogenesis, and adrenoceptor numbers were performed before the start of the study and at the end of 4 weeks of energy restriction. Measurements were done in approximately the same phase of the menstrual cycle before and at the end of the diet.

\section{Diet}

Subjects were restricted to a low-energy formula diet (Modifast, Sandoz, Bern, Switzerland) containing $2.0 \mathrm{MJ} /$ day for 4 weeks. It provided $50 \mathrm{~g}$ carbohydrates, $52 \mathrm{~g}$ protein, $7 \mathrm{~g}$ fat, $1.1 \mathrm{~g}$ sodium per day, and a micronutrient content that meets the Dutch recommended daily allowance. During the energy-restriction period, the subjects came to the laboratory once a week to have their weight measured.

\section{Measurements}

Body composition: During the study, body weight was measured weekly on a digital balance accurate to $0.1 \mathrm{~kg}$. Before and at the end of the diet period, body fat was determined by hydrostatic weighing. Residual lung volume was measured with a spirometer (Volugraph 2000, Mijnhardt, Bunnik, the Netherlands) at the moment of underwater weighing. The percentage of body fat was calculated according to Siri (26). 


\section{Chapter 2}

Energy expenditure: SMR was determined using a computerized open-circuit, indirect caloric chamber $\left(14 \mathrm{~m}^{3}\right)$ equipped with a bed, toilet, television set, and chair. The volume of air drawn through the chamber was measured by a dry-gas meter (Schlumberger, Dordrecht, the Netherlands) and continuously analyzed by a paramagnetic $\mathrm{O}_{2}$-analyzer (Servomex, Crowborough, UK) and an infrared $\mathrm{CO}_{2}$-analyzer (Hartmann \& Braun, Frankfurt, Germany). Airflow rate and the $\mathrm{O}_{2}$ and $\mathrm{CO}_{2}$ concentrations of the ingoing and outgoing air were used to compute $\mathrm{O}_{2}$ consumption and $\mathrm{CO}_{2}$ production on-line through an automatic acquisition system interfaced with a Macintosh computer (Apple Computer, Cupertino, CA). The subjects remained in the respiration chamber for $12 \mathrm{~h}$ (1900-0700). SMR was calculated during the sleeping period between 0300 and 0600 and controlled for physical activity by a Doppler radar system. RMR was measured using an open-circuit ventilated hood system. RMR was determined during a 30 -min period between 0730 and 0830 while the subjects were resting supine. Subjects had fasted for $\geq 12 \mathrm{~h}$ and had slept in the institute. RMR was calculated according to Weir's formula (30).

Maximum aerobic capacity: Maximal aerobic capacity was determined at least 2 days, and at most 4 days. before the measurement of exercise-induced thermogenesis. Each subject's maximal $\mathrm{O}_{2}$ uptake $\left(\mathrm{VO}_{2 \max }\right)$ and peak mechanical power $\left(\mathrm{W}_{\max }\right)$ were measured by using an incremental exercise test on an electromagnetically braked cycle ergometer (Lode, Groningen, the Netherlands). $W_{\max }$ was defined as the maximum power a subject could maintain for $1 \mathrm{~min}$. After an initial period of $5 \mathrm{~min}$ of cycling at 40 $\mathrm{W}$ and $4 \mathrm{~min}$ at $80 \mathrm{~W}$, the workload was increased by $20 \mathrm{~W} / \mathrm{min}$ until the subjects were exhausted. During the test, ventilatory and gas-exchange responses were measured continuously, using a computerized open system (Sensormedics 2900, Anaheim, CA). Heart rate was recorded by a conventional electrocardiogram system. Criteria for maximal exercise were forced ventilation, leveling off of oxygen uptake, or a respiratory exchange ratio (RER) exceeding 1.1. The highest oxygen uptake achieved for at least 30 s was taken as $\mathrm{VO}_{2 \max }$.

Exercise-induced thermogenesis: Exercise-induced thermogenesis was measured after an overnight fast. Before the start of the experiment, between 0800 and 0830 , a canula was inserted in an antecubital vein of a forearm for blood sampling. Measurements were started $30 \mathrm{~min}$ after insertion of the catheter. The exercise protocol consisted of $60 \mathrm{~min}$ of exercise on a bicycle ergometer at a workload of $45 \%$ of the previously estimated $\mathrm{W}_{\max }$. The exercise was preceded by a 30 -min supine rest period (basal measurements) and followed by a 60 -min recovery period with the subject in supine rest. Respiratory exchange measurements were done continuously during the basal and recovery periods by means of computerized open-circuit indirect calorimetry, using a ventilated hood system. During exercise, respiratory exchange responses were measured periodically for a total of $30 \mathrm{~min}, 5 \mathrm{~min}$ each time, using a computerized open system (Sensormedics 2900). During the experiment, a electrocardiogram was monitored continuously.

Blood samples were collected in the basal state and at timed intervals during the exercise and recovery periods. Hematocrit, glucose, free fatty acids (FFA), and glycerol were determined before exercise $(t=-30$ and $0 \mathrm{~min})$, during exercise $(t=5,15,30$, and 60 min after starting exercise), and during the recovery period ( $t=75,90$ and $120 \mathrm{~min}$ ). Insulin, glucagon, and catecholamines were analyzed at $t=-30,0,30,60,90$ and 120 
min. Extra blood samples were taken at $t=0,60$ (during exercise), and $120 \mathrm{~min}$ for determination of density and affinity of $\alpha_{2}$-and $\beta_{2}$-adrenoceptors.

\section{Analytical procedure}

Plasma of heparinized blood was used for the determination of glucose by means of a hexokinase method (Cobas Bio; Roche Diagnostics, Hoffmann-La Roche, Basel, Switzerland). Hematocrit was determined by a microcapillary system. Serum was prepared for FFA analyses (Wako, NEFA C, Wako Chemicals, Neuss, Germany) and glycerol (Boehringer, Mannheim, Germany). Plasma insulin was measured, after polyethylene glycol precipitation to eliminate proinsulin and antibodies against insulin, using a double-antibody radioimmunoassay for human insulin (Kabi Pharmacia Diagnostics, Uppsala, Sweden). Glucagon levels were measured using a specific radioimmunoassay (Diagnostic Products, Los Angeles, CA). Concentrations of plasma epinephrine and norepinephrine, sampled with heparin and put into glutathione containing tubes on ice, were determined by means of high-performance liquid chromatography (27). The density of $\alpha_{2}$-adrenoceptors was assessed on platelets using $\left[{ }^{3} \mathrm{H}\right]$ yohimbine binding $(21)$, whereas the density of $\beta$-adrenoceptors was assessed on lymphocytes ( 8 ) by means of ${ }^{125}$ I] iodocyanopindolol (ICYP).

Platelets and lymphocytes: Platelets and lymphocytes were isolated from $20 \mathrm{ml}$ blood anticoagulated with $2 \mathrm{ml}$ EDTA $(1 \% \mathrm{wt} / \mathrm{vol})$. The blood sample was immediately centrifuged at $250 \mathrm{~g}$ for $12 \mathrm{~min}$ at room temperature. The platelet-rich plasma was removed and centrifuged at $1600 \mathrm{~g}$ for $10 \mathrm{~min}$. The supernatant was discarded, and the platelet pellet was resuspended in a buffer $(0.1 \% \mathrm{wt} / \mathrm{vol}$ EDTA, $150 \mathrm{mM} \mathrm{NaCl}, \mathrm{pH} 7.5)$. Protein determinations were made by the Coomassie brilliant blue method (25). The lymphocytes were harvested at room temperature from Lymphoprep gradients (Nyegaard, Oslo, Norway). Intact lymphocytes were resuspended in $10 \mathrm{ml}$ ice-cold twice-distilled water. Cell counts were performed by means of a hematocytometer.

Platelet and lymphocyte suspensions were homogenized for $15 \mathrm{~s}$ in an Ultra-Turrax. The homogenates were then centrifuged at $45000 \mathrm{~g}$ for $30 \mathrm{~min}$. The resulting pellets were diluted with $10 \mathrm{ml}$ ice-cold twice-distilled water and incubated for $45 \mathrm{~min}$ at $4{ }^{\circ} \mathrm{C}$ to complete lysis. The preparations were then centrifuged at $45000 \mathrm{~g}$ for $30 \mathrm{~min}$, and the final pellets were resuspended in $4 \mathrm{ml}$ ice-cold incubation buffer $(0.9 \% \mathrm{NaCl}, 10 \mathrm{mM}$ tris(hydroxymethyl)aminomethane $\cdot \mathrm{HCl}, \mathrm{pH} 7.5$ ). These suspensions were used for the binding assays.

Receptor-binding studies: Platelets were studied by means of saturation binding assays using $\left[{ }^{3} \mathrm{H}\right]$ yohimbine. Nonspecific binding was defined as the amount of $\left[{ }^{3} \mathrm{H}\right]$ yohimbine bound in the presence of $10 \mu \mathrm{M}$ phentolamine. Platelets were incubated with eight concentrations $(0.5-10.5 \mathrm{nM})$ of $\left[{ }^{3} \mathrm{H}\right]$ yohimbine (final volume $0.2 \mathrm{ml}$ ) for $30 \mathrm{~min}$ at 25 ${ }^{\circ} \mathrm{C}$. Incubation was stopped by the addition of $10 \mathrm{ml}$ of platelets assay buffer, and subsequent rapid filtration through Whatman GF/C filters (Whatman International, Maidstone, UK) placed on a Millipore manifold sampling unit. Filters were additionally rinsed with $10 \mathrm{ml}$ of assay buffer. Radioactivity on the filters was counted in a betascintillation counter. Lymphocyte $\beta$-adrenergic receptors were studied with ICYP, determining nonspecific binding with $1 \mu \mathrm{M}$ propranolol. Lymphocytes were incubated 
for $60 \mathrm{~min}$ at $37^{\circ} \mathrm{C}$, in assay buffer (final volume $0.2 \mathrm{ml}$ ) in duplicate, using eight concentrations of ICYP (3-180 pM) in the absence or presence of $1 \mu \mathrm{M}$ propranolol. The reaction was terminated by the addition of $10 \mathrm{ml}$ of incubation buffer, and lymphocyte contents were filtered over glass-fiber filters (Gelman type A/E). The tubes and filters were washed with an additional $10 \mathrm{ml}$ of buffer, and the filters were counted in a gamma counter at $80 \%$ efficiency. Number of binding sites $\left(\mathrm{B}_{\max }\right)$ and equilibrium dissociation constant $\left(K_{\mathrm{d}}\right)$ were defined according to Scatchard (23). Saturation was obtained in all experiments. Coefficients of variation (CV) for between-subjects variability for density and affinity of $\beta_{2}$-adrenoceptors were $27 \pm 3$ and $36 \pm 4 \%$, respectively; for $\alpha_{2}$-receptors these values were $27 \pm 3$ and $16 \pm 2 \%$. Repeated within-subjects CVs for density and affinity of $\beta_{2}$-adrenoceptors were $19 \pm 2$ and $30 \pm 3 \%$, respectively; for $\alpha_{2}$-receptors these values were $14 \pm 3$ and $9 \pm 1 \%$.

\section{Data analysis}

Data in the text, tables and figures are given as means \pm SE. The physiological responses to exercise were analyzed by a repeated measurements analysis of variance (ANOVA). Total plasma response curves were calculated as the total integrated changes over baseline values [areas under curve (AUC) from $t=0$ to $t=60 \mathrm{~min}\left(\mathrm{AUC}_{0-60}\right)$ ]. The CV is defined as SD divided by mean. expressed as a percentage. The Wilcoxon's signedrank test was used to analyze differences between before and at the end of a 4-week diet. Significance levels were set at $\mathrm{P}<0.05$.

\section{Chemicals}

ICYP $(2000 \mathrm{Ci} / \mathrm{mmol})$ and $\left[{ }^{3} \mathrm{H}\right]$ yohimbine $(89 \mathrm{Ci} / \mathrm{mmol})$ were purchased from Amersham International, UK. All other reagents were obtained from Sigma Chemical, St. Louis, MO.

\section{Results}

Body composition, energy expenditure and maximal aerobic capacity

The dietary restriction for 4 weeks resulted in significant decreases of body weight. fat, and fat-free mass (FFM), as shown in Table 2.1. SMR and RMR measurements, expressed on the basis of FFM tended to decline, although not significantly $(P=0.09)$. $\mathrm{VO}_{2 \max }$ and $\mathrm{W}_{\max }$ were not affected by the energy restriction.

\section{$\alpha$ - and $\beta$-Adrenergic receptors}

Four weeks of energy restriction did not result in a significant change of basal lymphocyte $\beta_{2}$-adrenoceptor density. Before diet, 60 -min exercise caused no change in the density of lymphocyte $\beta_{2}$-adrenoceptors (Table 2.2). At the end of the 4 th week of dieting, lymphocyte $\beta_{2}$-receptor $B_{\max }$ increased significantly in response to exercise. Both exercise and caloric restriction did not change the $K_{d}$ of lymphocyte $\beta_{2}$ - 
adrenoceptors. $\mathrm{B}_{\max }$ at rest for platelet $\alpha_{2}$-adrenoceptors was significantly higher during energy restriction than before diet (Table 2.2). Exercise did not significantly change $\mathrm{B}_{\max }$ or $K_{\mathrm{d}}$ of platelet $\alpha_{2}$-receptors, although during exercise, values of $\mathrm{B}_{\max }$ tended to be somewhat increased (ANOVA, $\mathrm{P}=0.07$ ). Caloric restriction did not influence the affinity of platelet $\alpha_{2}$-adrenoceptors.

Table 2.2 Responses of platelet $\alpha$-receptors and lymphocyte $\beta$-receptors to 60 -min exercise before and at the end of 4-week weight reduction.

\begin{tabular}{|c|c|c|c|c|}
\hline & \multicolumn{2}{|c|}{$\alpha$-Adrenoceptors } & \multicolumn{2}{|c|}{$\beta$-Adrenoceptors } \\
\hline & $\begin{array}{l}\mathrm{B}_{\max } \\
\text { fmol/mg protein }\end{array}$ & $\begin{array}{l}K_{\mathrm{d}} \\
\mathrm{nM}\end{array}$ & $\underset{\mathrm{fmol} / 10^{6} \text { cells }}{\mathrm{B}_{\mathrm{max}}}$ & $\begin{array}{l}K_{\mathrm{d}} \\
\mathrm{pM}\end{array}$ \\
\hline \multicolumn{5}{|l|}{ Before diet } \\
\hline At rest & $110.8 \pm 18.8$ & $4.3 \pm 0.4$ & $1.44 \pm 0.14$ & $24.9 \pm 1.9$ \\
\hline During exercise & $143.0 \pm 1.7 .0$ & $4.7 \pm 0.5$ & $1.42 \pm 0.23$ & $27.9 \pm 2.9$ \\
\hline After $60-\mathrm{min}$ recovery & $128.1 \pm 17.3$ & $4.2 \pm 0.2$ & $1.73 \pm 0.17$ & $34.1 \pm 4.2$ \\
\hline \multicolumn{5}{|l|}{ At the end of diet } \\
\hline At rest & $167.1 \pm 23.7^{*}$ & $4.7 \pm 0.2$ & $1.67 \pm 0.21$ & $29.0 \pm 2.6$ \\
\hline During exercise & $210.5 \pm 26.1$ & $5.0 \pm 0.3$ & $2.15 \pm 0.15 \dagger$ & $30.3 \pm 3.0$ \\
\hline After 60 -min recovery & $170.4 \pm 28.8$ & $5.0 \pm 0.3$ & $1.52 \pm 0.17$ & $32.6 \pm 3.0$ \\
\hline
\end{tabular}

Values are means $\pm \mathrm{SE}(n=7)$. Exercise is at $45 \% \mathrm{~W}_{\max } . \mathrm{B}_{\max }$, maximal binding sites; $K_{\mathrm{d}}$. dissociation constant. "Significantly different from week $0, \mathrm{P}<0.05$ Wilcoxon's signed-rank test. $\dagger$ Significantly different from resting and recovery value, $P<0.05$ analysis of variance for repeated measurement (ANOVA), post hoc Wilcoxon's signed-rank test.

\section{Exercise-induced thermogenesis and metabolism}

Respiratory gas exchanges and heart rate: Table 2.3 demonstrates the exerciseinduced changes in energy expenditure, respiratory quotient, and heart rate. Exercise resulted in significant increases in energy expenditure, RER and heart rate (ANOVA, P< 0.05 ). Energy expenditure at rest, expressed per kilogram FFM, was significantly decreased in response to dieting. The thermogenic response to exercise, expressed per kilogram FFM measured in week 0 was not significantly different from the values of week 4 (AUC $_{0-60} 1597 \pm 104$ vs $1667 \pm 88 \mathrm{~kJ} / 60 \mathrm{~min} \cdot \mathrm{kg}^{-1}, \mathrm{P}=0.31$ ). However, energy expenditure expressed as percentage of baseline values was significantly increased after energy restriction (Table 2.3), which might suggest an increased thermogenic response. Energy restriction resulted in a significant reduction of RER in rest, and during exercise and recovery periods, compared with the week 0 values. At the end of the diet, RER declined significantly below resting values during recovery, whereas it did not in week 0 . The total integrated responses to exercise of RER of week $O$ and 4 were not significantly different from each other $\left(\mathrm{AUC}_{0-60} 3.11 \pm 1.1\right.$ vs $2.59 \pm 0.6$ per $60 \mathrm{~min}, \mathrm{P}=$ $0.73)$. Resting heart rate was significantly diminished during energy restriction $(\mathrm{P}<$ 0.05 ); however, this was accompanied with a tendency to an increased total integrated response to exercise $\left(\mathrm{AUC}_{0.6 \mathrm{u}} 3901 \pm 417\right.$ vs $4886 \pm 250$ beats per $60 \mathrm{~min}$, week 0 vs 
$4, P=0.063)$. This increased response in heart rate reached significance if the values are expressed as percentage of basal values (Table 2.3).

Plasma glucose, FFA, glycerol, and hematocrit: Although plasma glucose significantly decreased with dieting from $5.50 \pm 0.12$ to $4.86 \pm 0.17 \mathrm{mmol} / \mathrm{l}(\mathrm{P}<0.05)$, exercise did not change plasma glucose level in either week 0 or week 4 (Figure 2.1). The total integrated response of glucose tended to be higher after the diet $\left(\mathrm{AUC}_{0-60}-0.5\right.$ \pm 12 vs $15.3 \pm 6 \mathrm{mmol} / 1 \cdot 60 \mathrm{~min}^{-1}$, week 0 vs $4, \mathrm{P}=0.091$ ). With dieting, resting plasma FFA values rose from $583 \pm 131$ to $1,134 \pm 186 \mu \mathrm{mol} / \mathrm{l}(\mathrm{P}<0.05)$, whereas no change occurred in resting plasma glycerol concentrations (Figure 2.1). During exercise and recovery, both FFA and glycerol values were significantly higher during the diet in comparison with values before diet. The total integrated response to exercise of glycerol was significantly higher during the diet compared with the values before $\left(\mathrm{AUC}_{0-60} 8025\right.$ \pm 2170 vs $24737 \pm 3772 \mu \mathrm{mol} / \mathrm{l} \cdot 60 \mathrm{~min}^{-1}$, week 0 vs $4, \mathrm{P}<0.05$ ). Only during the diet did exercise cause significant increments in plasma FFA and glycerol concentrations. With respect to FFA values, the total integrated response was only significantly increased at the end of the diet during recovery $\left(\mathrm{AUC}_{0-61} 28100 \pm 7,292\right.$ vs $60304 \pm$ $9,983 \mu \mathrm{mol} / 1 \cdot 60 \mathrm{~min}^{-1}$, week 0 vs $4, \mathrm{P}<0.05$ ). This increase was especially apparent 15 and $30 \mathrm{~min}$ after exercise $(t=75$ and $90 \mathrm{~min}$ ). Neither energy restriction nor exercise caused changes in hematocrit.

Plasma insulin, glucagon, and catecholamines: Fasting was associated with a significant decline in resting plasma insulin values from $16.5 \pm 5.2$ to $7.5 \pm 0.8 \mathrm{mU} / \mathrm{l}$ (Figure 2.2). After $30 \mathrm{~min}$ of exercise, plasma insulin was still significantly lower during the diet compared with before diet values $(\mathrm{P}<0.05)$. Exercise tended to reduce plasma insulin before the diet $(P=0.067)$, whereas no change occurred during exercise at the end of the diet. Total integrated response of plasma insulin during recovery was significantly higher for week 4 compared with values of week $0(-474 \pm 268$ vs $355 \pm$ $149 \mathrm{mU} \cdot \mathrm{I}^{-1} \cdot 60 \mathrm{~min}^{-1}$, week $O$ vs $4, \mathrm{P}<0.05$ ). Energy restriction did not change the exercise-induced increments $(\mathrm{P}<0.05)$ in plasma glucagon. Also, increases in plasma norepinephrine and epinephrine in response to exercise were not altered by dieting, although resting and recovery values of norepinephrine were significantly decreased during the diet. 
Table 2.3 Respiratory and heart rate responses during 60-min exercise before and at the end of 4-week weight reduction.

\begin{tabular}{|c|c|c|c|c|c|c|c|}
\hline & \multirow{2}{*}{ Week } & \multirow{2}{*}{ Rest } & \multicolumn{4}{|c|}{ Exercise, $\min$} & \multirow{2}{*}{ Recovery } \\
\hline & & & 5 & 15 & 30 & 60 & \\
\hline \multirow{2}{*}{$\mathrm{EF}, \mathrm{kJ} \cdot \mathrm{kg} \mathrm{FFM}{ }^{-1} \cdot \mathrm{h}^{-1}$} & 0 & $6.3 \pm 0 . .3$ & $30.6 \pm 1.5$ & $34.8 \pm 2.2$ & $35.4 \pm 2.2$ & $33.3 \pm 1.9$ & $6.2 \pm 0.3$ \\
\hline & 4 & $5.5 \pm 0.2 *$ & $30.0 \pm 1.2$ & $35.1 \pm 1.7$ & $35.4 \pm 1.6$ & $34.8 \pm 2.3$ & $5.8 \pm 0.2^{*}$ \\
\hline \multirow[t]{2}{*}{ EE, \% from haseline } & 0 & 100 & $488 \pm 25$ & $553 \pm 31$ & $562 \pm 30$ & $530 \pm 29$ & $99 \pm 3$ \\
\hline & 4 & 100 & $553 \pm 23^{*}$ & $646 \pm 29^{*}$ & $652 \pm 28 *$ & $637 \pm 32^{k}$ & $106 \pm 2$ \\
\hline \multirow[t]{2}{*}{ Respiratory exchange ratio } & 0 & $0.85 \pm 0.02$ & $0.95 \pm 0.04$ & $0.91 \pm 0.01$ & $0.89 \pm 0.02$ & $0.92 \pm 0.03$ & $0.84 \pm 0.01$ \\
\hline & 4 & $0.82 \pm 0.01^{*}$ & $0.90 \pm 0.03^{* k}$ & $0.85 \pm 0.02^{*}$ & $0.84 \pm 0.01 *$ & $0.88 \pm 0.02$ & $0.75 \pm 0.02^{*}$ \\
\hline \multirow[t]{2}{*}{ Heart rate, beats/min } & 0 & $72 \pm 3$ & $128 \pm 7$ & $138 \pm 10$ & $142 \pm 10$ & $145 \pm 9$ & $77 \pm 4$ \\
\hline & 4 & $64 \pm 3^{*}$ & $138 \pm 5$ & $149 \pm 5$ & $151 \pm 6$ & $153 \pm 6$ & $70 \pm 3$ \\
\hline \multirow[t]{2}{*}{ Heart rate, \% from haseline } & 0 & 100 & $177 \pm 5$ & $190 \pm 9$ & $196 \pm 9$ & $201 \pm 9$ & $107 \pm 8$ \\
\hline & 4 & 100 & $217 \pm 11 *$ & $234 \pm 11^{*}$ & $238 \pm 10^{*}$ & $240 \pm 9 *$ & $110 \pm 5$ \\
\hline
\end{tabular}

Values are means $\pm \mathrm{SE}$. Exercise is at $45 \% \mathrm{~W}_{\text {max }}$ EE, enerfy expenditure: FHM, fat-free mass. *Significantly different from week $0, P<0.05$ Wilcoxon's signed-rank test. 

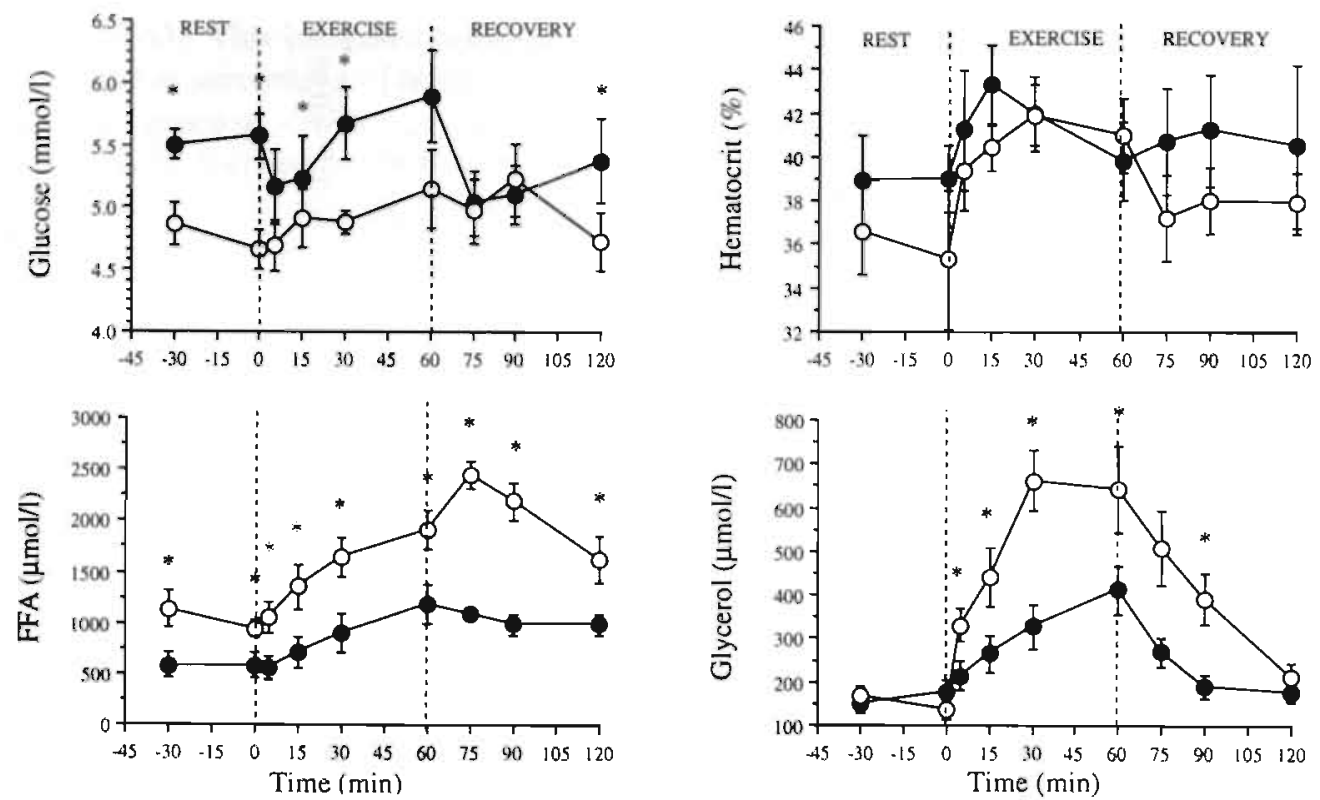

Figure 2.l Venous concentrations of glucose, free fatty acids (FFA), glycerol, and hematocrit during rest, exercise, and recovery periods in obese females before (closed circles) and at the end of 4-week diet (open circles). Values are means $\pm \operatorname{SE}(n=7)$. Repeated measurement ANOVA, post hoc Wilcoxon's signed rank test, $* \mathrm{P}<0.05$.
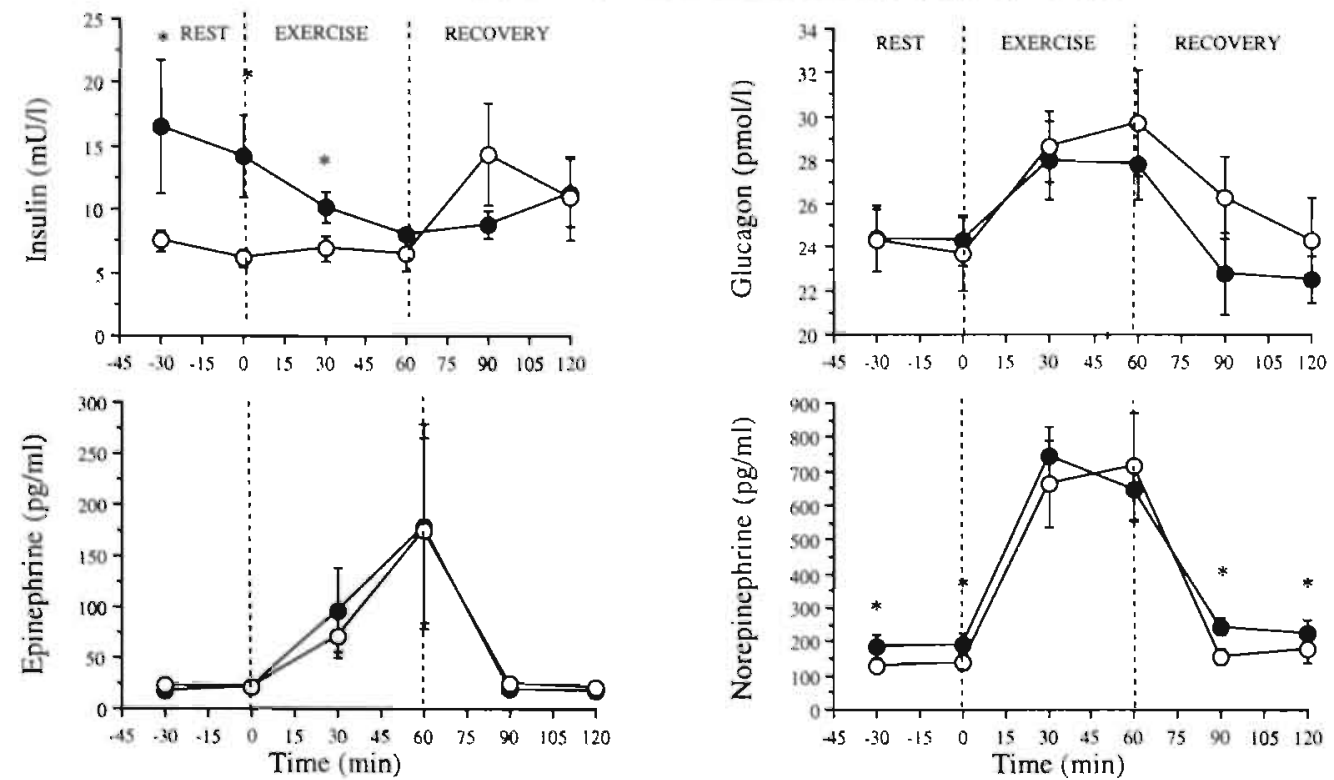

Figure 2.2 Venous concentrations of insulin, glucagon, norepinephrine, and epinephrine during rest, exercise, and recovery periods in obese females before (closed circles) and at the end of 4-week diet (open circles). Values are means \pm SE $(n=7)$. Repeated measurement ANOVA, post hoc Wilcoxon's signed rank test, ${ }^{*} \mathrm{P}<0.05$. 


\section{Discussion}

The objective of the present study was to investigate the effects of a single bout of exercise and energy restriction on lymphocyte $\beta_{2}$ - and platelet $\alpha_{2}$-adrenoceptor status in ohese subjects. It is known that the metabolic response to exercise is primarily related to the type, duration, and intensity of the exercise performed as well as the physical condition of the subject. In this study, the relative workload of exercise before and at the end of the diet was equal, because this type of dietary restriction did not affect $\mathrm{W}_{\max }$ nor $\mathrm{VO}_{2 \max }$, as confirmed by others (12). Therefore, the responses to exercise before and at the end of the diet can be adequately compared.

Skeletal muscle plays an important role in resting energy expenditure and thermogenesis (4). It has been shown that skeletal muscle mainly contains $\beta_{2}$-adrenoceptors (18), and their role in human energy metabolism has been demonstrated (6). The mobilization of lipids from adipose tissue plays a key role in the regulation of the energy balance at rest and during exercise and becomes even more important during periods of energy deficiency. Human adipose tissue has been shown to contain $\alpha_{2}, \beta_{1}-$, and $\beta_{2^{-}}$ adrenoceptors that seem to be involved in lipolysis (16). In addition, involvement of $\beta_{3}$ adrenoceptors in lipolysis is suggested (15), although the significance of $\beta_{3}$ adrenoceptors in human energy metabolism is still debated. With the use of a recently developed microdialysis technique, it was demonstrated that in vivo lipolysis is modulated by $\alpha$-adrenergic inhibitory effects at rest, whereas $\beta$-adrenergic stimulatory effects modulate lipolysis during exercise (2). Moreover, regional differences in lipid mobilization between abdominal and gluteal adipose tissues have been shown during exercise (2) and in vitro catecholamine stimulation (29) that might be related to differences in the balance of $\alpha_{2}$ - and $\beta$-adrenoceptors in these tissues.

For studying $\beta_{2}$-adrenergic receptor function in humans, circulating lymphocytes containing a homogeneous population of $\beta_{2}$-adrenoceptors, excitatory coupled to adenylate cyclase, are commonly used (8). It has been shown that changes in lymphocyte $\beta_{2}$-adrenoceptor density reflect changes of $\beta_{2}$-adrenoceptor density and responsiveness in solid, less accessible tissues such as heart, myometrium, lung, and skeletal muscle (18). We also found a significant relationship between density of skeletal muscle $\beta_{2}$-adrenoceptors and those of lymphocytes $(r=0.85, P<0.05)$ in this group of obese subjects. Liggett et al (18) showed that this reflection is only valid in a subtypespecific fashion. Therefore, for tissues containing mixed $\beta$-adrenoceptor subtypes, such as human heart or adipose tissue, the use of lymphocyte $\beta_{2}$-adrenoceptors as a tool for predicting $\beta$-adrenoceptor status may be limited.

Human platelets containing a homogeneous population of $\alpha_{2}$-adrenoceptors, inhibitorycoupled to adenylate cyclase, are a model commonly used to study changes of $\alpha_{2}$. adrenoceptors in humans (21). Changes in platelet $\alpha_{2}$-adrenoceptor density have been demonstrated to correlate with changes of $\alpha_{2}$-adrenoceptor density in myometrial membranes (9). However, despite similar in vitro properties of $\alpha_{2}$-adrenoceptors in platelets and various tissues, it is still not clear whether $\alpha_{2}$-adrenoceptor changes measured on platelets are related to changes occurring in other human tissues (11).

It has been shown that both acute and prolonged physical exercise causes an elevation of lymphocyte $\beta_{2}$-adrenoceptor density $(7,19,20)$, accompanied by increased 
responsiveness as measured by isoprenaline-induced adenosine 3',5'-cyclic monophosphate production, in normal healthy subjects. In our study with obese female subjects, this exercise-induced elevation occurred only at the end of 4 weeks of dieting. If the observed upregulation of lymphocyte $\beta_{2}$-adrenoceptor numbers in response to exercise at the end of the diet reflects changes in adrenoceptor status in metabolic tissues, then upregulation might be associated with functional consequences for aspects of thermogenesis and substrate metabolism that are $\beta_{2}$-receptor mediated. One of the consequences is likely to be the observed overall increase in lipolysis, as indicated by increased plasma FFA and glycerol values and responses, resulting in increased fat oxidation, as indicated by the lowered RER values. Furthermore, the tendency to increased exercise-induced thermogenic and heart rate responses at the end of energy restriction might also be associated with the observed upregulation of lymphocyte $\beta_{2}$ adrenoceptor numbers. The increased basal lipolysis and fat oxidation, despite a lack of change in basal $\beta_{2}$-adrenoceptor density does not preclude a basal upregulation in response to lower basal SNS activity due to energy restriction, because upregulation may occur distal to the receptor itself at post-receptor level (29).

The decreased resting plasma norepinephrine concentration during energy restriction observed in this study is in agreement with other studies $(5,10,24)$. It has been shown that this is a result of both reductions in appearance and clearance rates of norepinephrine. This might indicate that energy restriction is accompanied by decreased basal SNS activity. The energy restriction did not influence the responses of plasma norepinephrine and epinephrine to exercise. However, exercise resulted in an upregulation of lymphocyte $\beta_{2}$-adrenoceptor numbers at the end of the diet. Together with the observed increased thermogenic, heart rate, and lipolytic responses, it might indicate that energy restriction is accompanied with increased sensitivity to adrenergic stimulation. This seems to agree with several in vivo studies in humans showing an increased lipolytic response to catecholamine infusion during caloric restriction $(1,14)$. In vitro studies on adipocytes showed either no effects or inhibiting effects of catecholamines on lipolysis during dieting $(11,22)$. An explanation for this inconsistency is likely to be found in the absence of hormonal effects in the in vitro system $(13,16)$.

The mechanism of upregulation of lymphocyte $\beta_{2}$-adrenoceptors to acute exposure is still incompletely understood. Externalization of intracellularly sequestered receptor molecules seems to be a tempting possibility, although results are contradictory (20). Furthermore, rapid synthesis of new receptor protein has not been excluded (20). Failure to induce a $\beta_{2}$-adrenoceptor upregulation during exercise in obese subjects may reflect a decreased number of internalized receptors, possibly due to inhibition of receptor protein synthesis or a defect in the mobilization of internal receptors. On the other hand, it has been speculated that the exercise-induced increase in $\beta_{2}$-adrenergic receptors of mixed lymphocytes can at least partly be explained by a redistribution caused by exercise of circulating cell subsets that differ in their $\beta_{2}$-adrenoceptor numbers (19). Although such changes may contribute to exercise-induced increase in receptor density, it is unlikely that they would fully explain this increase, since $\beta$-blockade prevents the increase in receptor density but does not block the lymphocytosis (7).

It has also been shown that the upregulation takes place even in situations where there are no changes in the total blood lymphocyte count or the distribution of lymphocyte 
subpopulations (20). When the number of $\beta$-adrenoceptors in different $T$-lymphocyte subpopulations was measured during acute exercise, an equal upregulation of $\beta$ adrenoceptors was detected in cells originally containing small numbers of receptors and cells containing large numbers of receptors (20). Even if there are some effects of lymphocytosis on $\beta$-adrenoceptor density, there are no indications that the effects differ before and at the end of the diet.

In the present study, energy restriction resulted in a significant increase in platelet $\alpha_{2}$ adrenoceptor density, as reported in two other studies $(11,28)$ after 4 and 8 weeks of moderate diet, respectively. However, Berlin et al (5) did not find a significant rise in platelet $\alpha_{2}$-adrenoceptor density, probably because of the relative short duration (15 days) of the diet period. However, decreased $\alpha_{2}$-adrenoceptor density on adipocytes (22) has been shown during energy restriction. The observed increase in platelet $\alpha_{2}$ adrenoceptor density with energy restriction may represent an upregulation in response to decreased circulating norepinephrine values. Physiological significance of the increased platelet $\alpha_{2}$-adrenoceptor density remains speculative because adequate validation studies are lacking. Exercise did not modify the platelet $\alpha_{2}$-adrenergic receptor characteristics, either before or after the diet in this study, as confirmed by another study (5). The latter study reported, in contrast, that in lean women exercise resulted in an increase in platelet $\alpha_{2}$-density accompanied with a decrease in affinity, and it was suggested that obese women were unable to desensitize platelet $\alpha_{2}$ adrenoceptors in response to acute physical exercise.

However, the observed effects of energy restriction on SNS activity and adrenoceptor status might have been biased by the accompanying decreased sodium intake. Cignarelli et al (10) showed that sodium restriction prevailed over the effects of caloric restriction on sympathetic activity, thereby increasing the activity. However, in the study of Cignarelli et al (10), the sodium intake was extremely low ( $9 \mathrm{mmol} /$ day), and it is unlikely that such strong effects occurred in our study, with a daily sodium intake of $60 \mathrm{mmol}$. Moreover, we did not observe a downregulation of basal adrenoceptor numbers, as has been reported to occur as a result of strict sodium restriction (10). Furthermore, if there are some effects of the decreased dietary sodium intake, only an underestimation of the effects of energy restriction will be measured.

The data collected in this study do not allow us to distinguish between effects of the hypocaloric state and the effects of weight loss. However, they are likely to be the consequence of the combination of the two, because it has been reported that reducedobese subjects at stable body weight still showed a decreased basal catecholamine release but an increased lipolytic response to hypoglycemia and infused catecholamines, compared with obese and never-obese control subjects (17).

In conclusion, energy restriction in obese females resulted in an exercise-induced upregulation of lymphocyte $\beta_{2}$-adrenoceptors that did not occur before the diet. Therefore, exercise may play a role of importance in the regulation of thermogenesis, especially in the obese. The energy restriction resulted in an increase in basal platelet $\alpha_{2}$ adrenoceptor numbers. This indicates that adrenoceptor numbers can be modulated by energy restriction in obesity. Modulation of adrenoceptor density might play a role in increased exercise-induced lipolysis during energy restriction. 


\section{Chapter 2}

\section{References}

1. Arner P. Adrenergic receptor function in fat cells. Am J Clin Nutr 55: 228S-236S, 1992.

2. Amer $\mathrm{P}$, Kriegholm E, Engfeldt $\mathrm{P}$, Bolinder J. Adrenergic regulation of lipolysis in sito at rest and during exercise. J Clin lnvest 85: 893-898, 1990.

3. Astrup A, Andersen T, Christensen NJ, Bülow J, Madsen J, Breum L, Quaade F. Impaired glucoseinduced thermogenesis and arterial norepinephrine response persist after weight reduction in obese humans. Am J Clin Nutr 51: 331-337, 1990.

4. Astrup A, Bülow J, Madsen J, Christensen NJ. Contribution of BAT and skeletal muscle to thermogenesis induced by ephedrine in man. Am J Physiol 248: E507-E5 15, 1985.

5. Berlin I, Berlan M, Crespo-Laumonnier B, Landault C, Payan C, Puech AJ, Turpin G. Alterations in $\beta$-adrenergic sensitivity and platelet $\alpha_{2}$-adrenoceptors in obese women: effect of exercise and caloric restriction. Clin Sci 78: 81-87, 1990.

6. Blaak EE, van Baak MA, Kempen KPG, Saris WHM. Role of $\alpha$-and $\beta$-adrenoceptors in sympathetically mediated thermogenesis. Am J Physiol 264: E11-E17, 1993.

7. Brodde O-E, Daul AE, Wang XL, Michel MC, Galal O. Dynamic exercise-induced increase in lymphocyte beta-2-adrenoceptors: abnormality in essential hypertension and its correction by antihypertensives. Clin Pharmacol Ther 41: 371-379, 1987.

8. Brodde O-E, Engel G, Hoyer $D$, Bock $K D$, Weber $F$. The $\beta$-adrenergic receptor in human lymphocytes: subclassification by the use of a new radio-ligand, $( \pm)-{ }^{125}$ iodocyanopindolol. Life Sci 29: 2189-2198, 1981 .

9. Brodde O-E, Seher U, Nohlen M, Fischer WM, Michel MC. Correlation between human myometrial and platelet $\alpha_{2}$-adrenoceptor density. Eur J Pharmacol 150: 403-404, 1988.

10. Cignarelli M, de Pergola G, Garruti G, Corso M, Cospite MR, Paternostro A, Romanazzi V, Giorgino R. Changes in overall plasma norepinephrine turnover and lymphomonocyte betaadrenoceptor number during combined caloric and sodium restriction in normotensive obese subjects. Int J Obes 14: 429-437, 1990.

11. Crampes F, Marceron M, Beauville M, Riviere D, Garrigues M, Berlan M, Lafontan M. Platelet alpha $_{2}$-adrenoceptors and adrenergic adipose tissue responsiveness after moderate hypocaloric diet in obese subjects. Int J Obes 13: 99-110, 1989.

12. Dale van D, Saris WHM, Schoffelen PFM, ten Hoor F. Does exercise give an additional effect in weight reduction regimens? Int J Obes 11: 367-375. 1987.

13. Engfeldt P, Hellmér J, Wahrenberg $H$, Arner P. Effects of insulin on adrenoceptor binding and the rate of catecholamine-induced lipolysis in isolated human fat cells. J Biol Chem 263: 15553$15560,1988$.

14. Jensen MD, Haymond MW, Gerich JE, Cryer PE, Miles JM. Lipolysis during fasting. Decreased suppression by insulin and increased stimulation by epinephrine. $J$ Clin Invest 79: 207-213, 1987.

15. Krief S, Lönnquist F, Raimbault S, Baude B, van Spronsen A, Amer P, Strosberg AD, Ricquier D, Emorine LJ. Tissue distribution of $\beta_{3}$-adrenergic receptor mRNA in man. $J$ Clin Invest $91: 344-$ $349,1993$.

16. Lafontan M, Berlan M. Fat cell adrenergic receptors and the control of white and brown fat cell function. J Lipid Res 34: 1057-1091, 1993.

17. Leibel RL. Berry EM. Hirsch J. Metabolic and hemodynamic responses to endogenous and exogenous catecholamines in formerly obese subjects. Am J Physiol 260: R785-R791, 1991.

18. Liggett SB, Shah SD, Cryer PE. Human tissue adrenergic receptors are not predictive of responses to epinephrine in vivo. Am J Physiol 256: E600-E609. 1989.

19. Maisel AS. Harris T, Rearden CA. Michel MC. $\beta$-Adrenergic receptors in lymphocyte subsets after exercise. Alterations in normal individuals and patients with congestive heart failure. Circulation 82: 2003-2010, 1990. 
20. Mäki T, Kontula K, Härkönen M. The beta-adrenergic system in man: physiological and pathophysiological response. Regulation of receptor density and functioning. Scand J Clin Lab Invest 50(suppl 201): 25-43, 1990.

21. Motulsky HJ, Shattil SJ, Insel PA. Characterization of $\alpha_{2}$-adrenergic receptors on human platelets using $\left[{ }^{3} \mathrm{H}\right]$ yohimbine. Biochem Biophys Res Comm 97: 1562-1570, 1980.

22. Östman J, Arner P, Kimura H, Wahrenberg H, Engfeldt P. Influence of fasting on lipolytic response to adrenergic agonists and on adrenergic receptors in subcutaneous adipocytes. Eur $J$ Clin Invest 14: 383-391, 1984.

23. Scatchard G. The attractions of proteins for small molecules and ions. Ann NY Acad Sci 51: 660-672, 1949.

24. Schwartz RS, Jaeger LF, Veith RC, Lakshminarayan S. The effect of diet or exercise on plasma norepinephrine kinetics in moderately obese young men. Int J Obes 14: 1-11, 1990.

25. Sedmak JJ, Grossberg SE. A rapid, sensitive, and versatile assay for protein using Coomassie Brilliant Blue G250. Anal Biochem 79: 544-552, 1977.

26. Siri WE. The gross composition of the body. Adv Biol Med Physiol 4: 239-280, 1956.

27. Smedes F, Kraak JC, Poppe H. Simple and fast solvent extraction system for selective and quantitative isolation of adrenaline, noradrenaline and dopamine from plasma and urine. $J$ Chromatogr 231: 25-39, 1981.

28. Sundaresan PR, Weintraub M, Hershey LA, Kroening BH. Hasday JD, Banerjee SP. Platelet alphaadrenergic receptors in obesity: alteration with weight loss. Clin Pharmacol Ther 33: 776-785, 1983.

29. Wahrenberg $H$, Lönnqvist F, Arner P. Mechanisms underlying regional differences in lipolysis in human adipose tissue. $J$ Clin Invest 84: 458-467, 1989.

30. Weir JB de V. New methods for calculating metabolic rate with special reference to protein metabolism. J Physiol 109: 1-9, 1949. 



\title{
Skeletal muscle characteristics before and after energy restriction in obesity: fiber type, enzymatic $\beta$-oxidative capacity and fatty acid-binding protein content
}

\author{
Kempen KPG, Saris WHM, Kuipers $\mathrm{H}^{1,2}$, Glatz JFC 2 , van der Vusse GJ ${ }^{1,2}$
}

Departments of Human Biology, 'Physiology and ${ }^{2}$ Motion Sciences, University of Limburg, Maastricht, the Netherlands

Submitted for publication

\begin{abstract}
The effects of 8 weeks energy restriction on body composition, energy expenditure and skeletal muscle characteristics were investigated in 28 healthy obese females. Subjects were aged $37.9 \pm 1.5 \mathrm{yr}$ and had a body mass index of $32.0 \pm 0.8 \mathrm{~kg} / \mathrm{m}^{2}$. The energy restriction $(2.8 \mathrm{MJ} /$ day) resulted in a $10.8 \pm 0.5 \mathrm{~kg}$ weight loss consisting of $8.6 \pm 0.5 \mathrm{~kg}$ fat mass and $2.2 \pm 0.3 \mathrm{~kg}$ fat-free mass.

Basal respiratory exchange ratio, sleeping metabolic rate, and exercise-induced thermogenesis significantly declined in response to the diet. These changes were accompanied by a tendency to an increase $(P=0.077)$ in the skeletal muscle content of cytosolic fatty acid-binding protein (H-FABP), whereas no changes occurred in fiber type distribution or activity of enzymes reflecting $\beta$-oxidation and mitochondrial density (3-hydroxyacyl-CoA dehydrogenase and citrate synthase, respectively). The increase in $\mathrm{H}-\mathrm{FABP}$ was significant $(\mathrm{P}<0.05)$ when the data were clustered and analyzed according to amount of individual weight loss. The results suggest that physiological adaptations of fat metabolism to energy restriction in obesity involve increased intracellular fatty acid transport capacity of skeletal muscle.
\end{abstract}




\section{Chapter 3}

\section{Introduction}

Cytoplasmic fatty acid-binding proteins (FABPs) have been convincingly demonstrated in cells of tissues that are actively involved in the uptake or utilization of fatty acids (2, $9,10,30$ ). There is substantial evidence that FABPs are involved in transcytoplasmic transport and metabolism of the poorly soluble fatty acids (9). Dietary. hormonal, and pharmacological manipulations have been shown to change the FABP content of specific tissues in experimental animals $(2,5,11)$, but in humans hardly any data on effects of such interventions is available. Therefore, the physiological importance of FABPs for human energy metabolism remains to be established.

For healthy reasons, obese subjects are recommended to reduce weight and the most effective methods to attain this goal are energy-restrictive dietary interventions. Energy restriction causes a shift in substrate metabolism with an enhanced fatty acid utilization by skeletal muscle $(4,14,31)$. Adaptations in metabolic properties of skeletal muscle may occur in response to a period of energy restriction $(13,17,23)$, such as changes in fiber type composition and activity of oxidative enzymes. These muscular adaptations might contribute to energy retriction-induced alterations in substrate metabolism.

The FABP found in skeletal muscle has been shown to be identical with the heart-type FABP (H-FABP) (2l). Because a quantitative relation exists between skeletal muscle content of cytoplasmic FABP and mitochondrial fatty acid oxidation capacity $(9,10,31)$, it may be speculated that adaptations of muscle H-FABP are involved in changes of fuel metabolism to energy restriction. Furthermore, since fatty acid uptake and transport are the first events in cellular fatty acid oxidation H-FABP may be an early indicator of metabolic adaptations in skeletal muscle. Under the high oxidative fat condition of energy restriction, the challenge of physical exercise as a functional test is of interest to elucidate the importance of the different factors mentioned so far.

The aims of the present study were to investigate the effects of an 8-week energy restriction regimen on skeletal muscle H-FABP content, fiber type distribution and some marker enzymes of $\beta$-oxidative capacity. It was also examined whether these skeletal muscle characteristics were related to the contribution of lipids and carbohydrates to overall substrate oxidation, as represented by the respiratory exchange ratio (RER), during moderate exercise.

\section{Subjects and methods}

\section{Subjects}

The study population was a subsample from 63 obese females who were recruited for a weight loss program by advertisements in local newspapers. The subsample $(n=28)$ was created on the basis of their willingness to undergo muscle biopsies. The study population consisted of premenopausal women aged hetween 20 and 51 yr $(37.9 \pm 1.5$ yr). Selection criteria were a body mass index between 28 and $38 \mathrm{~kg} / \mathrm{m}^{2}$ and apparently healthy according to a medical examination. Before treatment all subjects gave their written informed consent. The study was approved by the university's ethical committee. 
The present subsample of 28 subjects neither did differ significantly in baseline characteristics from the other subjects in the study nor did they differ in changes in body composition and energy expenditure (EE) due to weight loss treatment (unpaired Student t-test, data not shown). Baseline characteristics of the present subsample of 28 subjects are listed in Table 3.1.

Table 3.1 Descriptive data of the subjects before and at the end of 8-week energy restriction.

\begin{tabular}{lll}
\hline Variables & Baseline & 8 -week weight loss \\
\hline Weight, $\mathrm{kg}$ & $88.5 \pm 2.5$ & $77.7 \pm 2.4 *$ \\
Body mass index, $\mathrm{kg} / \mathrm{m}^{2}$ & $32.0 \pm 0.8$ & $27.9 \pm 0.7 *$ \\
Percentage body fat, \% & $41.3 \pm 0.8$ & $35.8 \pm 1.0^{*}$ \\
Fat mass. kg & $36.9 \pm 1.6$ & $28.3 \pm 1.6 *$ \\
Fat-free mass, $\mathrm{kg}$ & $51.6 \pm 1.0$ & $49.4 \pm 1.0^{*}$ \\
Sleeping metabolic rate, $\mathrm{kJ} / \mathrm{min}$ & $4.82 \pm 0.18$ & $4.30 \pm 0.13^{*}$ \\
SMR/kg fat-free mass $\left(\mathrm{kJ} / \mathrm{h}^{\mathrm{k}} \mathrm{kg}^{-1}\right)$ & $5.59 \pm 0.10$ & $5.23 \pm 0.09^{*}$ \\
sleeping Respiratory exchange ratio & $0.81 \pm 0.01$ & $0.78 \pm 0.01^{*}$ \\
\hline
\end{tabular}

Values are means \pm SE for 28 subjects. Diet is $2.8 \mathrm{MJ} /$ day. SMR, sleeping metabolic rate; $* \mathrm{P}<$ 0.0001 paired t-test with respect to baseline values.

\section{Experimental design}

Measurements of maximal aerobic capacity, body composition, sleeping metabolic rate (SMR), and an exercise test were performed immediately before the start of an 8-week energy restrictive dietary intervention period. Measurements of body composition, sleeping, and exercise-induced EE were repcated at the end of the energy restriction period, but still during the diet. Needle muscle biopsies were taken percutaneously before and at the end of energy restriction for measurement of skeletal muscle H-FABP content and activity of 3-hydroxyacyl-CoA dehydrogenase (HAD) and citrate synthase (CS). Muscle fiber type composition was determined in 18 out of 28 biopsics.

\section{Diet}

The energy restrictive diet took place over an 8-week period that was divided into two parts. The first period consisted of a low-energy formula diet (Modifast, Bern. Sandoz, Switzerland) containing $2.0 \mathrm{MJ} /$ day for four weeks. It provided $50 \mathrm{~g}$ carbohydrates, 52 $\mathrm{g}$ protein, $7 \mathrm{~g}$ fat, and a micronutrient content which meets the Dutch recommended daily allowance. In the second part of the diet, from week 5 until 9, a mixed diet of 3.5 $\mathrm{MJ} /$ day was prescribed. This diet contained $1.4 \mathrm{MJ} /$ day of the formula diet and was supplemented to $3.5 \mathrm{MJ} /$ day by a free choice of foodstulfs. During the whole period subjects were instructed to keep a record of food intake. Subjects were asked to maintain their habitual activity pattern. During the energy restriction the subjects came to the laboratory once a week to have their weight measured and food records checked. 


\section{Measurements}

For determination of the maximal aerobic capacity each subject's maximal oxygen uptake $\left(\mathrm{VO}_{2 \max }\right)$ and maximal mechanical power output $\left(\mathrm{W}_{\max }\right)$ were measured, at least 3 and at most 7 days, prior to the other measurements at the beginning of the study. For this, a progressive continuous cycling test on an ergometer (Lode, Groningen, the Netherlands) was used, as previously described (14). During the test, ventilatory and gas exchange responses were measured continuously, using a computerized open-circuit system (Oxycon Beta, Mijnhardt, Bunnik, the Netherlands). Criteria for maximal exercise were forced ventilation, leveling off of oxygen uptake or a RER exceeding 1.1. The highest oxygen uptake achieved for at least $30 \mathrm{~s}$ was taken as $\mathrm{VO}_{2 \max }$.

SMR was measured during a 12-h overnight stay (1900-0700) in a respiration chamber as described before (14). Briefly, SMR and RER were calculated from $\mathrm{O}_{2}$ consumption and $\mathrm{CO}_{2}$ production (33) during the sleeping period between 0300 and 0600 controlled for extra physical activity by a Doppler radar system. After the overnight fast in the respiration chamber and body density measurement, an exercise test was performed. The exercise protocol consisted of $45 \mathrm{~min}$ of exercise on a bicycle ergometer at a workload of $45 \%$ of the previously determined $\mathrm{W}_{\max }$. Because this type of dietary restriction has been shown not to affect $\mathrm{W}_{\max }$ nor $\mathrm{VO}_{2 \max }(4,6)$, equal workloads were used before and at the end of the diet. The exercise was preceded by a 30-min resting period (baseline measurement) with the person in supine position. Respiratory exchange measurements were done continuously by means of a computerized open-circuit ventilated hood system during the baseline period. During exercise, the respiratory exchange responses were measured periodically for in total $20 \mathrm{~min}, 5 \mathrm{~min}$ each time, using a computerized open-circuit system (Oxycon Beta, Mijnhardt, Bunnik, the Netherlands). An electrocardiogram was monitored continuously during the experiment.

Before and at the end of the study, body weight was measured on a digital balance accurate to $0.1 \mathrm{~kg}$ (Sauter D-7470, Ebingen, Germany) and height to the nearest $0.1 \mathrm{~cm}$ using a wall-mounted stadiometer. Body mass index was calculated from weight and height $\left(\mathrm{kg} / \mathrm{m}^{2}\right)$. Body composition was measured with two different techniques: isotope dilution and underwater weighing with simultaneous lung volume measurement (Helium-dilution). Percentage of body fat was calculated from body density and total body water (TBW) using the method proposed by Siri (26). Deuterium dilution was used to measure TBW. Before going to bed during the stay in the respiration chamber, a ${ }^{2} \mathrm{H}_{2} \mathrm{O}$ dilution was drunk after emptying the bladder (baseline sample). The dosage calculation of ${ }^{2} \mathrm{H}_{2} \mathrm{O}$ was based on body weight in order to create a ${ }^{2} \mathrm{H}$ excess of $100 \mathrm{ppm}$. A second urine sample was collected in the morning of the next day from the second voiding between 0800 and 1000. Deuterium was measured in urine samples with an isotope ratio mass spectrometer (VG Aqua Sira). TBW was calculated as the measured deuterium dilution space divided by 1.04 (24). At the same morning, whole body density was determined by hydrostatic weighing with the subject in the fasted state. Underwater weight was measured to the nearest $0.1 \mathrm{~kg}$ (Sauter D-7470, Ebingen, Germany). Residual lung volume was measured with a spirometer (Volugraph 2000, Mijnhardt, Bunnik, the Netherlands) at the moment of underwater weighing. Measurements were done in triplicate and the average was used to calculate body density. 
Before the diet and at the end of the 8-week energy restriction, skeletal muscle biopsies were taken at rest after at least $6 \mathrm{~h}$ fast and low physical activity. After local anesthesia, a Bergström biopsy needle (diameter $5 \mathrm{~mm}$, Stöpler, Utrecht, the Netherlands) with simultaneous suction (8) was used to obtain $100-150 \mathrm{mg}$ of skeletal muscle from the muscular vastus lateralis. Blood and connective tissue were immediately removed from excised muscle samples and the tissue was divided into two pieces. One piece was frozen immediately in liquid nitrogen and stored at $-80^{\circ} \mathrm{C}$ until analyses of metabolic parameters. The other part of the biopsy was trimmed. mounted in an embedding medium (Tissue Tek, Miles Laboratory, Elkhart, US) and quickly frozen in isopentane, cooled by liquid nitrogen to its freezing point, and stored at $-80^{\circ} \mathrm{C}$ until histologically determination of fiber type composition was performed.

\section{Biochemical analyses}

Fiber type composition of the muscular vastus lateralis was analyzed according to Dubowitz (7). For this, transverse sections were cut at $10 \mu \mathrm{m}$ thickness by use of a cryostat maintained at $-22{ }^{\circ} \mathrm{C}$. On the basis of their staining reactions for myofibrillar ATPase after alkaline preincubation, muscle fibers were classified as either type I or type II. Type II fibers were further subclassified into IIA and IIB types by preincubation at $\mathrm{pH}$ 4.6 and 4.4. About 400-500 fibers were counted in each muscle sample. The other part of the muscle specimens was homogenized in ice-cold EDTA $(0.002 \mathrm{M}) / \mathrm{TRIS}(0.01 \mathrm{M})$ buffer at $\mathrm{pH}$ 7.4. The homogenates were subsequently sonicated for $4 \times 15 \mathrm{~s}$ and centrifuged at $10000 \mathrm{~g}$ for $2 \mathrm{~min}$ at $4{ }^{\circ} \mathrm{C}$ to remove cell debris. CS was analyzed at 37 ${ }^{\circ} \mathrm{C}$ according to the method of Shepherd and Garland (25) whereas HAD was assayed at $37^{\circ} \mathrm{C}$ according to Bergmeyer (3).

Tissue contents of H-FABP in skeletal muscle were measured by a newly developed ELISA that shows a lower detection limit of $0.2 \mu \mathrm{g} / \mathrm{l}(16)$. H-FABP content, and activity of CS and HAD are expressed per g wet weight (ww) skeletal muscle. This implicates the possibility of overestimation at the end of the diet due to glycogen depletion as result of the energy restriction. However, glycogen depletion due to the diet used in the present study is not likely $(4,22)$, and even if a decrease in muscle glycogen concentration is assumed from 1.5 to $1.0 \mathrm{~g} / 100 \mathrm{~g}$ ww (22), the consequences for the present data would be within the detection limits of the used analytical methods.

\section{Statistical analyses}

All data are given as means $\pm \mathrm{SE}$. Physiological responses to exercise were analyzed by repeated measurement analyses of variance (ANOVA), post hoc tested with paired Student t-tests corrected according to Bonferroni's inequalities. Total exercise-induced response curves of $\mathrm{EE}$ and heart-rate (HR) were calculated as the total integrated changes over baseline values $\left(\mathrm{AUC}_{0-45}\right)$. Two-sided paired t-test was used to analyze differences between before and after diet. $\mathrm{P}<0.05$ was considered as statistically significant. Correlations are Pearson product-moment correlations. 


\section{Results}

\section{Maximal aerobic capacity, body composition and energy expenditure}

The energy restriction resulted in a decrease of body weight of $10.8 \pm 0.5 \mathrm{~kg}$ (Table 3.1 ). Subjects lost $8.6 \pm 0.5 \mathrm{~kg}$ fat mass and $2.2 \pm 0.3 \mathrm{~kg}$ fat-free mass (FFM). SMR, $\mathrm{SMR} / \mathrm{kg}_{\mathrm{FFM}}$ and sleeping RER significantly declined in response to the diet. Pre-diet $\mathrm{W}_{\max }$ and $\mathrm{VO}_{2 \max }$ amounted to $172 \pm 2 \mathrm{~W}$ and $2.3 \pm 0.7 \mathrm{l} / \mathrm{min}$ respectively, whereas during maximal exercise HR was $178 \pm 2$ beats/min.

Table 3.2 shows values of EE, RER, and HR during the exercise test at $45 \%$ of the individual pre-diet $\mathrm{W}_{\max }$ (mean workload $77 \pm 2 \mathrm{Watt}$ ). Exercise resulted in significant increases of EE, RER, and HR (ANOVA, P < 0.0001). Energy restriction resulted in decreased values of EE during exercise. Also the total thermogenic response to exercise was significantly lower during diet in comparison to pre-diet value $\left(\mathrm{AUC}_{0-45} 1079 \pm 30\right.$ vs $947 \pm 37 \mathrm{~kJ} / 45 \mathrm{~min}$, before vs during diet, $\mathrm{P}<0.005$ ), whereas total integrated response of $\mathrm{HR}$ did not statistically change $\left(\mathrm{AUC}_{0-45} 3380 \pm 134\right.$ vs $3501 \pm 127$ beats $/ 45 \mathrm{~min}$, before vs during diet, NS). Baseline and recovery values of RER declined in response to the diet but during exercise those values were not statistically different.

\section{Fiber type composition}

Figure 3.1 shows the percentage distribution of muscle fibers of the vastus lateralis. Before the diet, the proportion of type I fibers was $43 \pm 3 \%$ whereas the percentages of type IIA and IIB were $27 \pm 2$ and $31 \pm 2 \%$, respectively. There was no significant change in muscle fiber type distribution with energy restriction. In addition, no significant correlations could be observed between the proportion of type I muscle fibers and the body fat percentage either at week $O(r=0.27, P=0.28)$ or week $8(r=$ $0.17, \mathrm{P}=0.50$ ). There were also no relationships between muscle fiber type and RER during exercise before the diet (Figure 3.2 A+B, mean RER during exercise, type I: $r=$ 0.03. $P=0.94$ and type I+IIA: $r=0.06, P=0.82$ ). However, at the end of the diet a significant relationship was found between muscle fiber type and mean RER during the exercise period. Percentage of oxidative fibers (type I or type I+IIA) was inversely correlated with mean RER value during exercise (Figure $3.2 \mathrm{C}+\mathrm{D}, \mathrm{r}=0.44, \mathrm{P}<0.05$ and $r=0.51, P<0.01$, respectively). The RER values of the separately measured time periods during exercise significantly correlated with muscle fiber type (data not shown). 
Table 3.2 Metabolic and heart rate responses to $45 \mathrm{~min}$ exercise $\left(45 \% \mathrm{~W}_{\max }\right)$ before and at the end of an 8 -week diet in obese women.

\begin{tabular}{|c|c|c|c|c|c|c|c|}
\hline & & \multirow{2}{*}{ Rest } & \multicolumn{4}{|c|}{ Exercise (min) } & \multirow{2}{*}{ Recovery } \\
\hline & & & $0-5$ & $15-20$ & $30-35$ & $40-45$ & \\
\hline Energy expenditure, $\mathrm{kJ} / \mathrm{min}$ & $\begin{array}{l}\text { week } 0 \\
\text { week } 8\end{array}$ & $\begin{array}{l}5.1 \pm 0.1 \\
4.8 \pm 0.1 \dagger\end{array}$ & $\begin{array}{l}25.8 \pm 0.7 \\
23.3 \pm 0.6+\end{array}$ & $\begin{array}{l}31.0 \pm 0.7 \\
28.1 \pm 0.7 *\end{array}$ & $\begin{array}{l}31.7 \pm 0.9 \\
28.7 \pm 0.8 \dagger\end{array}$ & $\begin{array}{l}32.2 \pm 0.8 \\
29.1 \pm 0.8+\end{array}$ & $\begin{array}{l}5.4 \pm 0.1 \\
5.1 \pm 0.1 \dagger\end{array}$ \\
\hline Respiratory exchange ratio & $\begin{array}{l}\text { week } 0 \\
\text { week } 8\end{array}$ & $\begin{array}{l}.85 \pm .01 \\
.79 \pm .01 \dagger\end{array}$ & $\begin{array}{l}.89 \pm .01 \\
.87 \pm .01\end{array}$ & $\begin{array}{l}.92 \pm .01 \\
.91 \pm .02\end{array}$ & $\begin{array}{l}.88 \pm .01 \\
.87 \pm .01\end{array}$ & $\begin{array}{l}.87 \pm .01 \\
.85 \pm .01\end{array}$ & $\begin{array}{l}.78 \pm .01 \\
.74 \pm .01+\end{array}$ \\
\hline Heart rate, beats/min & $\begin{array}{l}\text { week } 0 \\
\text { week } 8\end{array}$ & $\begin{array}{l}68 \pm 2 \\
68 \pm 2\end{array}$ & $\begin{array}{l}139 \pm 3 \\
138 \pm 3\end{array}$ & $\begin{array}{l}147 \pm 3 \\
147 \pm 3\end{array}$ & $\begin{array}{l}151 \pm 3 \\
153 \pm 3\end{array}$ & $\begin{array}{l}152 \pm 3 \\
155 \pm 3\end{array}$ & $\begin{array}{l}77 \pm 2 \\
74 \pm 2\end{array}$ \\
\hline
\end{tabular}

Values are means $\pm \mathrm{SE}(n=28)$. Diet is $2.8 \mathrm{MJ} /$ day. "Significantly different from week $0, \mathrm{P}<0.005$ paired $\mathrm{t}$-test, $\uparrow \mathrm{P}<0.001$. 


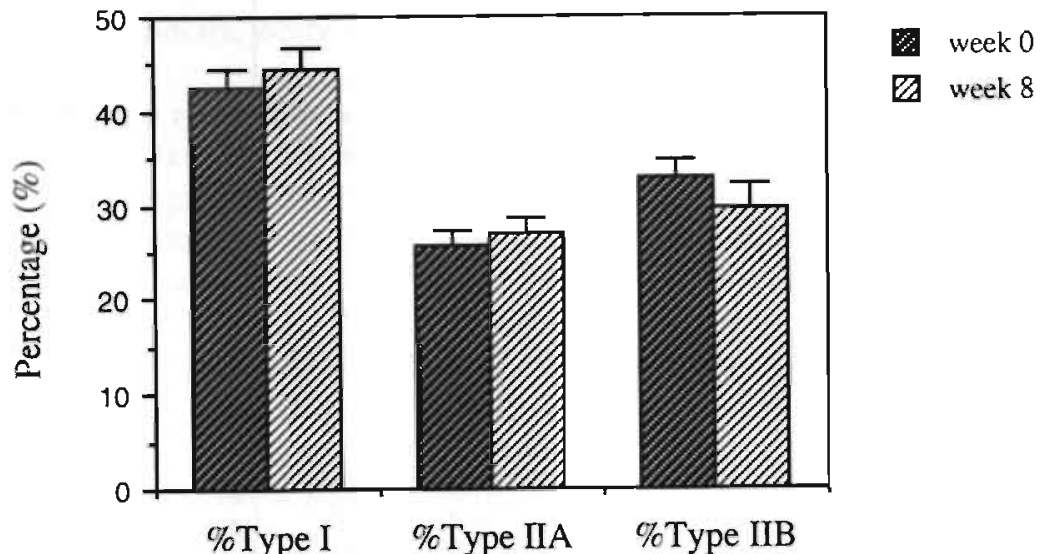

Figure 3.1 Percentage distribution of muscle fibers in vastus lateralis from obese women before and at the end of 8-week energy-restricted diet. Values are means \pm SE $(n=18)$.
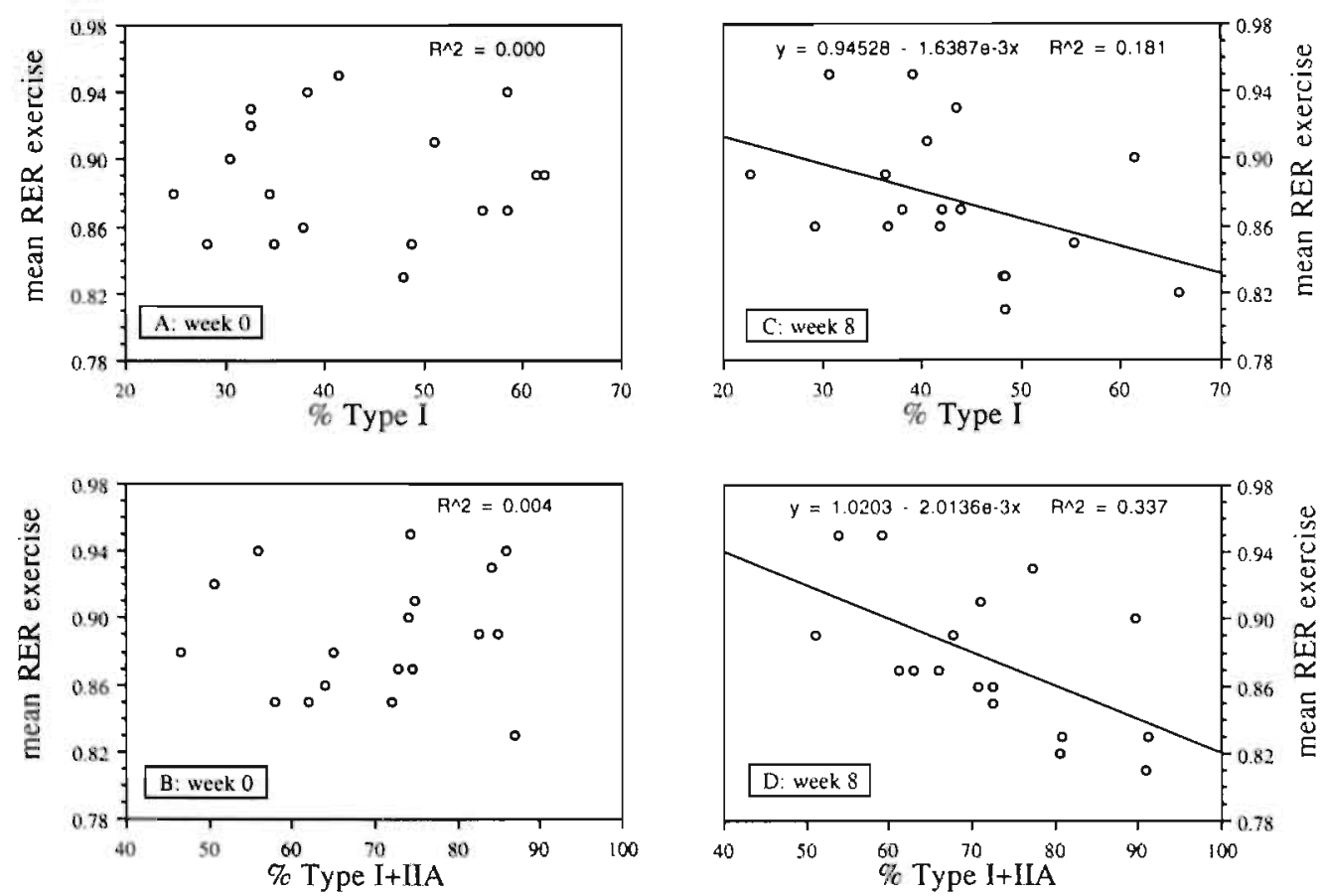

Figure 3.2 Relationships between muscle fiber type composition and mean respiratory exchange ratio (RER) during exercise in obese women before $(A+B)$ and at the end of an 8 week energy-restricted diet $(C+D, n=18)$. 
Table 3.3 Clustered analyses according to amount of weight loss of data on skeletal muscle H-FABP content, and activity of HAD and CS in obese women before and at the end of an 8-week energy restrictive diet.

\begin{tabular}{|c|c|c|c|}
\hline Clusters & week 0 & week 8 & $\begin{array}{l}\text { P value } \\
\text { wk } O \text { vs } 8\end{array}$ \\
\hline \multicolumn{4}{|l|}{ Total $(n=28)$} \\
\hline H-FABP, $\mu \mathrm{g} / \mathrm{g}$ ww & $173 \pm 12$ & $216 \pm 21$ & 0.077 \\
\hline HAD, U/g ww & $12.4 \pm 0.7$ & $12.9 \pm 1.0$ & 0.65 \\
\hline $\mathrm{CS}, \mathrm{U} / \mathrm{g}$ ww & $10.6 \pm 0.8$ & $11.3 \pm 0.8$ & 0.45 \\
\hline $\mathrm{HAD} / \mathrm{CS}$ ratio & $1.23 \pm 0.04$ & $1.17 \pm 0.05$ & 0.29 \\
\hline \multicolumn{4}{|l|}{ Weight loss $<10 \mathrm{~kg}(n=9)$} \\
\hline H-FABP, $\mu \mathrm{g} / \mathrm{g} w \mathrm{w}$ & $154 \pm 29$ & $175 \pm 28$ & 0.58 \\
\hline $\mathrm{HAD}, \mathrm{U} / \mathrm{g}$ ww & $10.8 \pm 1.8$ & $12.3 \pm 1.1$ & 0.42 \\
\hline $\mathrm{CS}, \mathrm{U} / \mathrm{g}$ ww & $9.8 \pm 1.8$ & $10.4 \pm 1.2$ & 0.66 \\
\hline $\mathrm{HAD} / \mathrm{CS}$ ratio & $1.19 \pm 0.07$ & $1.26 \pm 0.11$ & 0.52 \\
\hline \multicolumn{4}{|c|}{ Weight loss $\geq 10$ and $<12 \mathrm{~kg}(n=8)$} \\
\hline H-FABP, $\mu g / g w w$ & $193 \pm 20$ & $246 \pm 56$ & 0.46 \\
\hline $\mathrm{HAD}, \mathrm{U} / \mathrm{g}$ ww & $12.8 \pm 1.1$ & $15.6 \pm 2.9$ & 0.37 \\
\hline $\mathrm{CS}, \mathrm{U} / \mathrm{g}$ ww & $10.9 \pm 1.2$ & $13.6 \pm 2.4$ & 0.29 \\
\hline $\mathrm{HAD} / \mathrm{CS}$ ratio & $1.21 \pm 0.06$ & $1.14 \pm 0.07$ & 0.53 \\
\hline \multicolumn{4}{|l|}{ Weight loss $\geq 12 \mathrm{~kg}(n=11)$} \\
\hline H-FABP, $\mu \mathrm{g} / \mathrm{g} w w$ & $177 \pm 13$ & $228 \pm 18$ & $0.014^{*}$ \\
\hline $\mathrm{HAD}, \mathrm{U} / \mathrm{g} w \mathrm{w}$ & $13.4 \pm 0.9$ & $11.4 \pm 1.0$ & 0.15 \\
\hline $\mathrm{CS}, \mathrm{U} / \mathrm{g}$ ww & $10.9 \pm 1.2$ & $10.3 \pm 0.9$ & 0.63 \\
\hline HAD/CS ratio & $1.27 \pm 0.06$ & $1.13 \pm 0.05$ & 0.11 \\
\hline
\end{tabular}

Values are means \pm SE. Diet is $2.8 \mathrm{MJ}$ /day. H-FABP, heart-type fatty acid-binding protein; ww, wet weight; HAD, 3-hydroxyacyl-CoA dehydrogenase; CS, citrate synthase. *Statistically significant, Student paired t-test.

\section{Muscle H-FABP content and enzymatic activity}

$\mathrm{H}-\mathrm{FABP}$ content, activity of $\mathrm{HAD}$ and $\mathrm{CS}$, and $\mathrm{HAD} / \mathrm{CS}$ ratio of vastus lateralis muscle before and after the energy restriction are shown in Table 3.3. H-FABP values tended to increase after the diet $(n=28, \mathrm{P}=0.077)$, whereas activity of HAD and CS, and the ratio $\mathrm{HAD} / \mathrm{CS}$ did not change. When subjects with a weight loss amounting $<10 \%$ of initial body weight were excluded from the analysis the increase of H-FABP reached statistical significance $(n=21,169.6 \pm 14.6$ vs $228.0 \pm 26.4 \mu \mathrm{g} / \mathrm{g}$ ww, week 0 vs $8, \mathrm{P}$ $<0.05$ ). Also when H-FABP data were analyzed clusterwise according to the amount of weight lost (Table 3.3), it appeared that skeletal muscle H-FABP content significantly increased due to energy restriction, resulting in weight loss amounting $\geq 12 \mathrm{~kg}$.

Before as well as at the end of the diet, H-FABP content was significantly correlated to HAD and CS activity (week $0: r=0.69$ and $r=0.65$ respectively, $\mathrm{P}<0.0005$ and week $8: r=0.79$ and $r=0.78$ respectively, $P<0.0001$ ), whereas activity of $\mathrm{HAD}$ and CS were also related to each other (week $0: r=0.91$ and week $8: r=0.94, P<0.0001$, data not shown). H-FABP values also showed a significant relationship with the percentage of 
type I fibers $(n=18, \mathrm{r}=0.53, \mathrm{P}<0.05)$. However, no statistically significant relationships could be demonstrated between skeletal muscle H-FABP content and relative substrate utilization during rest or exercise, as estimated from the RER-value.

\section{Discussion}

Energy restrictive diets lead to a decrease of the whole body respiratory exchange ratio. suggesting that a greater proportion of the energy expended is supplied by oxidation of lipids. Since skeletal muscle represents the largest tissue of the body ( $>30 \%$ of body mass) and shows the ability to adapt (13), it has been suggested that adaptations of skeletal muscle contribute to this increased fat utilization $(13,20,31)$. However, so far no significant changes in fiber type composition or activity of enzymes involved in fat oxidation have been detected as a result of energy restriction $(13,23)$. In the present study, we demonstrate that skeletal muscle cytoplasmic fatty acid-binding protein ( $\mathrm{H}$ FABP) increased as a result of energy restriction in obesity, indicating that skeletal muscle indeed adapts to this new situation.

The physiological significance of the skeletal muscle cytoplasmic fatty acid carrier $\mathrm{H}$ FABP for human energy metabolism and adaptations to energy restriction remains to be established. As far as we are aware of, this is the first study demonstrating an increase of the H-FABP content of skeletal muscle in response to hypocaloric dieting in obese subjects. This increase became statistically significant when those subjects with a weight loss $<10 \%$ of initial body weight were excluded from the analysis or when the data were clustered and analyzed according to the amount of individual weight loss. This indicates that a certain degree of weight loss is required to be associated with enhanced skeletal muscle H-FABP levels. This finding suggests that an increased capacity to transport fatty acids in the muscular cytoplasmic space is related to substantial weight loss. Furthermore, a contribution of H-FABP to weight loss outcome may be further indicated by an observed significant inverse correlation between amount of weight loss and diet-induced change of basal RER value $(r=0.36, P<0.05)$.

Circumstantial evidence is available that the utilization of fatty acids by skeletal muscle is related to its H-FABP content $(10,27,31)$. Current knowledge indicates that H-FABP functions as a carrier of fatty acids between the plasma membrane and the outer mitochondrial membrane (29), although the precise mechanisms of action remain to be elucidated $(9,10)$. Dietary, hormonal and pharmacological interventions have been shown to alter the H-FABP content in experimental animals $(2,5,9,11)$. The results of the present study suggest an adaptation in H-FABP content of muscle to hypocaloric dieting in obese females that may play a role in the increased fat oxidation under basal conditions. The observed positive relationships between H-FABP content and proportion of oxidative fibers found in the present study in humans, has been found previously by Vork et al for rat muscles (28). Type IIB muscle fibers, which demonstrate minimal fatty acid utilization, have been shown to have the lowest amount of H-FABP $(2,5,21,31)$. The significant relations between skeletal muscle H-FABP content and activity of HAD and CS support the previously described existence of a quantitative relation between mitochondrial fatty acid oxidation capacity and H-FABP content $(9$, 
10). Therefore, the present study supports the notion that H-FABP is involved in intracellular fatty acid utilization in human skeletal muscle.

The mechanism by which FABP levels respond to changes in dietary intake is not yet elucidated. Recently, however, it has been demonstrated in vitro that exogenous longchain fatty acids induce gene-expression of adipocyte-type FABP at a transcriptional level in 3T3-adipocytes $(1,12)$. It may be speculated that such mechanism also applies to the in vivo skeletal muscle in the present study, as energy restriction has been shown to be associated with increased basal plasma fatty acid levels (14). The importance of the fatty acid concentrations in plasma, and possibly even more in muscle cells, as triggers for muscular H-FABP expression in vivo, however, remains to be determined.

The results of the present study also show that an 8-week lasting energy restricted diet, resulting in a weight loss of $10.8 \pm 0.5 \mathrm{~kg}$, did not effect skeletal muscle fiber type distribution and activity of measured oxidative enzymes (HAD and CS), as in accordance with findings of others $(13,17,18)$. This indicates no enzymatic adaptations of mitochondrial $\beta$-oxidation and subsequent oxidation of the products derived from $\beta$ oxidation with energy restriction. On the other hand, possible effects of hypocaloric dieting on skeletal muscle have been suggested to occur at the level of fiber type area instead of fiber type transformation $(13,18,23)$. Decreased cross-sectional area of type II fibers, due to decreases in glycogen content or activity of glycolytic enzymes as a result of energy restriction, together with unchanged capillarization may lead to a relative increase in capillary density in muscle tissue, consequently enhancing insulin sensitivity (19) and increasing oxidative capacity.

Theoretically, it is possible that effects of hypocaloric dieting in the present study might have been interfered when changes in physical activity occurred during the diet. It has been shown that physical training and reduction of energy intake have synergistic effects on skeletal muscle metabolic adaptations (18). However, as measured by heartrate monitoring and actometer recordings (6) or doubly labeled water (15) no compensatory decrease in physical activity has been shown in obese women receiving an energy restrictive diet treatment. Therefore, adaptations of skeletal muscle observed in the present study are likely to be largely described to effects of energy restriction, consisting of the combined influences of weight loss and hypocaloric state.

In the present study, a significant relationship between skeletal muscle fiber type distribution and substrate oxidation during exercise could be observed at the end of the diet. This finding appears to be in accordance with a study of wade et al (32), demonstrating that muscle fiber type proportion is related to oxidation of fatty acids during exercise. We have, however, no clear explanation for the fact that a relationship between substrate utilization during exercise and muscle fiber type could not be demonstrated before the start of the study. It might be speculated that less confounding arousal in measuring RER values at the end of the 8 -week treatment than before treatment may be involved, due to lower inter-individual variation in antecedent diet.

The results, however, suggest a role for muscle fïher type profile in overall substrate utilization during exercise, whereas H-FABP content is not likely to be a limiting factor. That transcytoplasmic fatty acid transport capacity is most likely not rate-limiting in overall intramuscular fatty acid utilization has been suggested previously by Vork et al (29). However, increased energy restriction-induced plasma free fatty acid levels (14) associated with increased H-FABP levels, as demonstrated in the presint study, will 
enhance the aqueous solubility of fatty acids in skeletal muscle (29) and may contribute to increased contribution of fatty acids to energy supply under resting conditions. Further research, however, should elucidate the physiological role of H-FABP in the regulation of skeletal muscle substrate utilization

In summary, the results of the present study demonstrate an adaptation of skeletal muscle cytosolic fatty acid-binding protein to energy restriction in obese women. Furthermore, H-FABP appears to be an early indicator of skeletal muscle adaptations to altered substrate utilization, since metabolic oxidative enzyme activity did not change. This suggests that skeletal muscle fatty acid utilization depends on adequate transcytoplasmic transport of fatty acids. Further research should elucidate the physiological importance of skeletal muscle H-FABP in human energy metabolism and obesity.

\section{References}

1. Amri EZ, Bertrand B, Ailhaud G, Grimaldi P. Regulation of adipose cell differentiation. I. Fatty acids are inducers of the aP2 gene expression. J Lipid Res 32: 1449-1456. 1991.

2. Bass NM. The cellular fatty acid binding proteins: aspects of structure, regulation, and function. Int Rev Cytol 111: 143-184, 1988.

3. Bergmeyer HU. In Methods of enzymatic analysis 1. Academic Press, New York pp 474-476, 1974.

4. Bogardus C, LaGrange BM, Horton ES. Sims EAH. Comparison of carbohydrate-containing and carbohydrate-restricted hypocaloric diets in the treatment of obesity. J Clin Invest 68: 399-404, 1981

5. Breda van E, Keizer HA, Vork MM, Surtel DAM, de Jong YF, van der Vusse GJ, Glatz JFC. Modulation of fatty acid-binding protein content of rat heart and skeletal muscle by endurance training and testosterone treatment. Pfiigers Arch 421: 274-279, 1992.

6. Dale van D, Schoffelen PFM, ten Hoor F, Saris WHM. Effects of addition of exercise to energy restriction on 24-hour energy expenditure, sleeping metabolic rate and daily physical activity. Eur J Clin Nutr 43: 441-451, 1989.

7. Dubowitz V. Muscle biopsy: a practical approach. The Lavenham Press, Lavenham, Suffolk pp 19-40, 1985.

8. Evans WJ, Phinney SD, Young VR. Suction applied to a muscle biopsy maximizes sample size. Med Sci Sports Exer 14: 101-102, 1982.

9. Glatz JFC, van der Vusse GJ, Veerkamp JH. Fatty acid-binding proteins and their physiological significance. News Phys Sci 3: 41-43, 1988.

10. Glatz JFC, van der Vusse GJ. Cellular fatty acid-binding proteins: current concepts and future directions. Mol Cell Biochem 98: 237-251, 1990.

11. Glatz JFC, van Breda E, Keizer HA, de Jong YF, Lakey JRT, Rajotte RV, Thompson A, van der Vusse GJ, Lopaschuk GD. Rat heart fatty acid-binding protein content is increased in experimental diabetes. Biochem Biophys Res Commun 199: 639-646, 1994.

12. Grimaldi PA, Knobel SM, Whitesell RR, Abumrad NA. Induction of aP2 gene expression by nonmetabolized long-chain fatty acids. Proc Natl Acad Sci USA 89: 10930-10934, 1992.

13. Henriksson J. Energy metabolism in muscle: its possible role in the adaptation to energy deficiency, In Kinney JM, Tucker HN (eds). Energy metabolism: tissue determinants and cellular corollaries. Raven Press, New York pp 345-365, 1992. 
14. Kempen KPG, Saris WHM, Senden JMG, Menheere PPCA, Blaak EE, van Baak MA. Effects of energy restriction on acute adrenoceptor and metabolic responses to exercise in obese subjects. Am J Physiol 267: E694-E701, 1994.

15. Kempen KPG, Saris WHM, Westerterp KR. Energy balance during an 8-wk energy-restricted diet with and without exercise in obese women. Am J Clin Nutr 62: 722-729, 1995.

16. Kleine AH, Glatz JFC, van Nieuwenhoven FA, van der Vusse GJ. Release of heart fatty acidbinding protein into plasma after acute myocardial infarction in man. Mol Cell Biochem 116 : 155-162, 1992.

17. Krotkiewski M, Grimby G, Holm G, Szczepanik J. Increased muscle dynamic endurance associated with weight reduction on a very-low-calorie diet. Am J Clin Nutr 51: 321-330, 1990.

18. Krotkiewski M. Role of muscle morphology in the development of insulin resistance and metabolic syndrome. Presse Med 23: 1393-1399, 1994.

19. Lillioja S, Young AA, Culter CL, Ivy JL, Abbott WGH, Zawadzki JK, Yki-Järvinen H, Christin L. Secomb TW, Bogardus C. Skeletal muscle capillary density and fiber type are possible determinants of in vivo insulin resistance in man. $J$ Clin Invest 80: 415-424, 1987.

20. Minuk HL, Hanna AK, Marliss EB, Vranic M, Zinman B. Metabolic response to moderate exercise in obese man during prolonged fasting. Am $J$ Physiol 238: E322-E329, 1980.

21. Peeters RA, in 't Groen MA, Veerkamp JH. The fatty acid-binding protein from human skeletal muscle. Arch Biochem Biophys 274: 556-563, 1989.

22. Phinney SD, Horton ES, Sims EAH, Hanson JS, Danforth Jr E, LaGrange BM. Capacity for moderate exercise in obese subjects after adaptation to a hypocaloric, ketogenic diet. $J$ Clin Invest 66: 1152-1161, 1980.

23. Russell McR D, Walker PM, Leiter LA, Sima AAF, Tanner WK, Mickle DAG, Whitwell J, Marliss $\mathrm{EB}$, Jeejeebhoy $\mathrm{KN}$. Metabolic and structural changes in skeletal muscle during hypocaloric dieting. Am J Clin Nutr 39: 503-513, 1984

24. Schoeller DA, Jones PJH. Measurement of total body water by isotopic dilution: a unified approach to calibrations. In Ellis KJ, Yasumura S, Morgan WD (eds). In vivo body composition studies. London, Institute of Physical Sciences in Medicine pp 131-136, 1987.

25. Shepherd D, Garland PB. Citrate synthase from the rat liver. Meth Enzymol 13: 11-16, 1969.

26. Siri WE. Body composition from fluid spaces and density: analysis of methods. In Brozek J, Henschel A (eds). Techniques for measuring body composition. National Academy of Sciences, Washington DC pp 223-244, 1961.

27. Spener F, Börchers T, Mukherjea M. On the role of fatty acid binding proteins in fatty acid transport and metabolism. FEBS letters 244: 1-5, 1989.

28. Vork MM, Glatz JFC, Surtel DAM, Knubben HJM, van der Vusse GJ. A sandwich enzyme linked immuno-sorbent assay for the determination of rat heart fatty acid-binding protein using the streptavidin-biotin system. Application to tissue and effluent samples from normoxic rat heart perfusion. Biochim Biophys Acta 1075: 199-205, 1991.

29. Vork MM, Glatz JFC, van der Vusse GJ. On the mechanism of long chain fatty acid transport in cardiomyocytes as facilitated by cytoplasmic fatty acid-binding protein. J Theor Biol 160: 207 $222,1993$.

30. Vusse van der GJ, Glatz JFC, Stam HCG, Reneman RS. Fatty acid homeostasis in the normoxic and ischemic heart. Physiol Rev 72(4): 881-940, 1992.

31. Vusse van der GJ, Reneman RS. Lipid metabolism in muscle, In Rowell LB, Shephard JT (eds). Handbook of Physiology. Integration of motor, circulatory, respiratory and metabolic control during exercise. In press.

32. Wade AJ, Marbut MM, Round JM. Muscle fibre type and aetiology of obesity. Lancet 33: 805$808,1990$.

33. Weir JB de V. New methods for calculating metabolic rate with special reference to protein metabolism. J Physiol 109: 1-9, 1949. 


\title{
The effects of weight loss and apolipoprotein $\mathrm{E}$ polymorphism on serum lipids, apolipoproteins A-I and $B$, and lipoprotein(a)
}

\author{
Muls $E^{1}$, Kempen KPG, Vansant $G^{1}$, Cobbaert $C^{2}$, Saris WHM
}

Departments of ${ }^{1}$ Endocrinology, Metabolism and Nutrition and ${ }^{2}$ Clinical Chemistry. University Hospital Gasthuisberg, Leuven, Belgium and Department of Human Biology,

University of Limburg, Maastricht, the Netherlands

Int J Obes 17: 711-716, 1993

\begin{abstract}
Serum levels of lipoprotein(a) $[\mathrm{Lp}(\mathrm{a})]$, an independent risk factor for coronary heart disease, are strongly influenced by genetic factors. To evaluate the effect of weight loss on serum $\mathrm{Lp}(\mathrm{a}), 54$ normolipidemic obese women were examined before and after a twomonth weight reduction program. A mean weight loss of $10.1 \mathrm{~kg}$ was associated with decreases of serum triglycerides, total cholesterol (TC), LDL-C, HDL-C, apo B, and apo A-I $(P=0.0001$ for all variables), but not $L p(a)$. However, initial $L p(a)$ values were related to $L p(a)$ responses during dietary intervention $(P=0.0001)$. In subjects with pretreatment $\mathrm{Lp}(\mathrm{a})$ values above $30 \mathrm{mg} / \mathrm{dl}$, a mean $26.3 \%$ decrease was observed with weight loss, while no change was found in subjects with low $L p(a)$ values at bascline (P $=0.007$ for group comparison).

Apo E polymorphism contributes to the variation in lipid levels in the general population and in the obese. The relative contributions of the apo $E$ locus to the total variance of TC, LDL-C and Lp(a) at baseline in these obese women were estimated to be $3.3,1.7$ and $3.2 \%$. respectively, which is less than previously reported in healthy adults. Pretreatment TC was increased in subjects with the apo E $3 / 4$ phenotype compared to those with the common apo $\mathrm{E} 3 / 3$ phenotype $(\mathrm{P}=0.03)$. Apo $\mathrm{E}$ polymorphism did not affect $\mathrm{Lp}$ (a) levels at baseline nor the changes in lipoprotein variables, including $L p(a)$, during weight loss. In conclusion, short-term substantial weight loss in normolipidemic obese women resulted in a lowering of $L p(a)$ only in individuals with pre-treatment $L p(a)$ levels above $30 \mathrm{mg} / \mathrm{dl}$. This effect was independent of apo E polymorphism.
\end{abstract}




\section{Introduction}

Lipoprotein(a) [Lp(a)], a genetic variant of LDL, is a strong and independent risk factor for cardiovascular disease in Caucasian populations $(24,34)$. Consistent with its mainly genetically determined serum levels, $L p(a)$ appears to be largely unrelated to endocrinemetabolic or anthropometric variables (41). Most attempts to reduce serum Lp(a) levels by pharmacological intervention have been unsuccessful. Among the currently used hypolipidemic drugs, only nicotinic acid has a pronounced $L p(a)$-lowering effect $(5,17)$. Early reports $(1,27)$ have suggested that $L p(a)$ levels are also resistant to dietary changes. Recently, however, various types of dietary manipulation have been demonstrated to influence $L p($ a) levels: trans fatty acid-enriched diets increase serum $\mathrm{Lp}(\mathrm{a})$ in normolipidemic subjects (26) and in mildly hypercholesterolemic men (30), while palm oil lowers $\mathrm{Lp}(\mathrm{a})$ in normocholesterolemic volunteers (17). Fish oil supplements decrease $\mathrm{Lp}(\mathrm{a})$ levels in some $(3,16,35)$ but not all subjects $(22.25)$. Reports on the effect of weight loss on $L p(a)$ are scarce and contradictory. Significant $L p(a)$ reductions were previously noticed after weight loss in females but not in males (18), and in both men and women (40), while no changes were observed in other studies $(6,16,21)$.

Apolipoprotein (apo) E polymorphism is now considered to be an important genetic factor that influences the metabolism of apo B-containing lipoproteins. It substantially alters the relation of obesity and abdominal fat accumulation to plasma lipoproteins in women (3l). A significant interaction exists between apo E polymorphism and weight gain as they combine to affect plasma triglyceride (TG) and beta-lipoprotein, but not total cholesterol (TC) (13). In addition, apo $E$ polymorphism has been reported to influence $L p(a)$ levels (20). In the present study, we have investigated the effect of short-term substantially weight loss on serum $L p(a)$ in obese normolipidemic women. In addition, we have examined the influence of apo $E$ polymorphism on baseline and weight reduction-induced changes in lipoprotein variables that include $L p(a)$.

\section{Subjects and methods}

\section{Subjects}

Fifty-four Dutch women, aged 19 to $53 \mathrm{yr}$ (mean $\pm \mathrm{SD}, 36.4 \pm 8.7 \mathrm{yr}$ ), with a body mass index (BMI) of 25.4 to $41.9 \mathrm{~kg} / \mathrm{m}^{2}$ were studied before and after an 8-week weight loss program. The subjects daily ingested a $2.0 \mathrm{MJ}$ formula diet (Modifast, Bern Nutrition, Basel, Switzerland) containing $52 \mathrm{~g}$ protein. $7 \mathrm{~g}$ fat, and $50 \mathrm{~g}$ carbohydrates for 4 weeks, followed by a $3.5 \mathrm{MJ}$ mixed diet for an additional 4-week period. Except for being obese, all subjects were judged to be in good health according to a medical history and physical examination. The participants gave informed consent to the study protocol, which was reviewed and approved by the Ethical Committee of the University of Limburg. 
Body fat distribution was assessed before and after weight loss by measuring the waist girth to the nearest $0.5 \mathrm{~cm}$ at the minimum circumference and the hip circumference to the nearest $0.5 \mathrm{~cm}$ at the widest point of the hip area. All measurements were taken twice and the mean values were used to determine the waist-hip ratio (WHR). Body composition was evaluated by densitometry (38) and deuterium isotope dilution (36).

Before and after the weight reduction program, blood for lipoprotein analyses was drawn from each subject after an overnight 12-h fast. Serum levels of TG and TC were assayed enzymatically using GPO-PAP (glycerol phosphate oxidase-phenol 4-amino phenazone) and CHOD-PAP (cholesterol oxidase-phenol 4-amino phenazone) kits from Boehringer Mannheim, Germany. HDL-C was determined after precipitation with phosphotungstate-Mg2+, and LDL-C after polyvinyl sulphate/magnesium chloride precipitation. Apo A-I and B were assayed by immunonephelometry with kits from Boehringer Mannheim, Germany. Lp(a) was assessed with the 'TintElize' Lp(a) enzyme immunoassay (Biopoo AB, Umea, Sweden). Apo E phenotyping was performed by isoelectric focusing and immunoblotting techniques (15).

\section{Statistics}

Results are shown as means $\pm S D$. The body composition data on fat-free mass and fat mass are given as the means of measurements made by densitometry and deuterium isotope dilution. Statistical evaluations were performed with SPSS statistical software (SPSS/PC+, V2.0). The skewed distribution of Lp(a) data was normalized by logarithmic conversion. For comparison of data, the two-sided Student's t-test for paired or nonpaired data was used. To study relationships, Pearson correlation coefficients were calculated. A stepwise multiple regression analysis was used to quantify the effect of study variables on serum lipoproteins. Except for the regression analysis in Figure 4.1, changes $(\Delta)$ were calculated as the value before minus the value after weight reduction. Apo $\mathrm{E}$ allele frequencies were estimated using the gene-counting method. The relative contribution of genetic variance associated with the apo E locus to the total phenotypic variance of $\mathrm{TC}, \mathrm{LDL}-\mathrm{C}$, apo $\mathrm{B}$, and $\mathrm{Lp}(\mathrm{a})$ was estimated according to the method of Sing and Davignon (37).

\section{Results}

Anthropometric and metabolic parameters in 54 obese women before and after the eight-week weight reduction program are listed in Table 4.1. Energy restriction significantly reduced body weight, BMI, and WHR. Loss of fat-free mass accounted for $20.8 \%$ of the weight reduction. Serum TG, TC, LDL-C, apo B, HDL-C, and apo A-I were all significantly decreased. Overall, no significant change in serum $L p(a)$ concentrations were observed. Median $L p(a)$ values before and after dietary intervention were 4.80 and $4.45 \mathrm{mg} / \mathrm{dl}$, respectively. However, $\mathrm{Lp}(\mathrm{a})$ responses were dependent on pre-treatment values, as a highly significant negative correlation was observed between initial $L p(a)$ 
and the difference after dietary intervention (Figure 4.1: $\mathrm{r}=-0.44, \mathrm{P}=0.0001$ ). In nine subjects with initial $L p(a)$ values $\geq 30 \mathrm{mg} / \mathrm{dl}$, a $26.3 \%$ reduction $(-10.9 \pm 8.9 \mathrm{mg} / \mathrm{dl})$ in Lp(a) was observed with weight loss, while no change $(-0.3 \pm 3.5 \mathrm{mg} / \mathrm{dl})$ was found in 45 subjects with baseline levels $<30 \mathrm{mg} / \mathrm{dl}$ ( $\mathrm{P}=0.007$ for group comparison by MannWhitney test for log-transformed data). Lp(a) responses during weight loss in subjects with elevated $\mathrm{Lp}(\mathrm{a})$ at baseline were not related to changes in TG, LDL-C. or apo B.

Table 4.1 Anthropometric and metabolic variables of obese women before and after the 8 -week weight reduction program.

\begin{tabular}{lccc}
\hline & Before & After & P value \\
\hline Height, cm & $166 \pm 5$ & & \\
Weight, $\mathrm{kg}$ & $87.5 \pm 12.0$ & $77.4 \pm 10.7$ & 0.0001 \\
Body mass index, $\mathrm{kg} / \mathrm{m}^{2}$ & $31.8 \pm 4.0$ & $28.0 \pm 3.5$ & 0.0001 \\
Waist circumference, cm & $93 \pm 10$ & $83 \pm 9$ & 0.0001 \\
Hip circumference, cm & $113 \pm 9$ & $103 \pm 9$ & 0.0001 \\
Waist-hip ratio & $0.83 \pm 0.05$ & $0.81 \pm 0.04$ & 0.001 \\
Fat mass, kg & $36.9 \pm 8.8$ & $29.0 \pm 7.5$ & 0.0001 \\
Fat free mass, $\mathrm{kg}$ & $50.9 \pm 5.1$ & $48.8 \pm 4.9$ & 0.0001 \\
Triglycerides, mg/dl & $118 \pm 51$ & $92 \pm 36$ & 0.0001 \\
Total cholesterol, mg/dl & $203 \pm 34$ & $174 \pm 32$ & 0.0001 \\
LDL cholesterol, mg/dl & $142 \pm 38$ & $116 \pm 33$ & 0.0001 \\
Apolipoprotein B, mg/dl & $79 \pm 19$ & $66 \pm 16$ & 0.0001 \\
HDL cholesterol, mg/dl & $45 \pm 10$ & $42 \pm 8$ & 0.0001 \\
Apolipoprotein A-I, mg/dl & $119 \pm 19$ & $104 \pm 16$ & 0.0001 \\
Lipoprotein(a), mg/dl & $11.6 \pm 14.9$ & $10.0 \pm 12.3$ & 0.07 \\
ln Lipoprotein(a), mg/dl & $3.96 \pm 1.35$ & $3.92 \pm 1.22$ & 0.50 \\
\hline
\end{tabular}

Values are means $\pm \mathrm{SD}(n=54)$; P values are from paired t-tests.

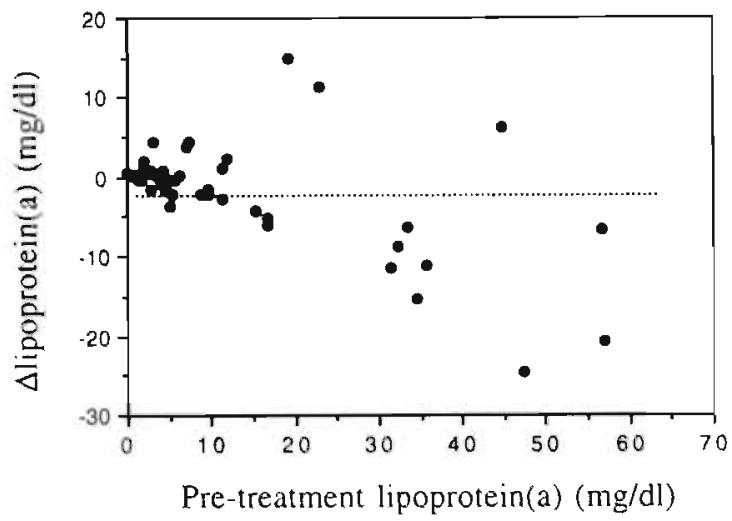

Figure 4.1 The lipoprotein(a) response to weight loss $[\Delta \mathrm{Lp}(\mathrm{a})]$ is dependent on pre-treatment $\mathrm{Lp}$ (a) values ( $\mathrm{r}=0.44, \mathrm{P}=0.0001$ by linear regression analysis). $\Delta \mathrm{Lp}(\mathrm{a})$ represents values after minus values before weight loss. 
The apo E phenotype distribution and allele frequencies among the 54 obese women are presented in Table 4.2. The gene frequencies in the Dutch women enrolled in this weight reduction program were similar to those in two previously reported random population samples from the Netherlands $(20,39)$. The relative contributions of apo $\mathrm{E}$ polymorphism to the total variance of TC. LDL-C, apo B and $\mathrm{Lp}(\mathrm{a})$ at baseline were calculated to be $3.3,1.7,1.7$, and $3.2 \%$, respectively.

Pre-treatment anthropometric parameters were not statistically different between subjects with the apo E $3 / 3(n=34)$ and apo $\mathrm{E} 3 / 4(n=14)$ phenotypes. Among the lipoprotein variables, TC at baseline was significantly higher in the apo E $3 / 4$ subset compared to those homozygous for apo E $3(221 \pm 30 \mathrm{vs} 199 \pm 31 \mathrm{mg} / \mathrm{dl}, \mathrm{P}=0.03)$. Similar trends for LDL-C, apo B, and apo A-I did not reach statistical significance. The apo $E^{* 4}$ locus did not affect $L p(a)$ values. Within the apo $E 3 / 3$ group, WHR at baseline, but not BMI, correlated positively with TG $(r=0.33, P=0.03)$ and negatively with HDL-C $(r=-0.29, P=0.05)$. In addition, fat mass correlated negatively with LDL-C and apo $\mathrm{B}$ (for both, $\mathrm{r}=-0.37, \mathrm{P}=0.02$ ) and apo $\mathrm{B}$ showed a positive relationship with fatfree mass $(r=0.40, P=0.01)$ in apo $E 3 / 3$ subjects. These associations between pretreatment anthropometric variables and lipoproteins at baseline were not observed within the apo E $3 / 4$ group. Changes in anthropometric and metabolic parameters in response to the low calorie diet and weight loss were identical in the apo E $3 / 3$ and apo E $3 / 4$ subgroups.

Table 4.2. Apolipoprotein E phenotype and allele frequencies.

\begin{tabular}{lcr}
\hline Phenotype & Number observed & Relative frequency $(\%)$ \\
\hline E2/E2 & 1 & 1.85 \\
E2/E3 & 4 & 7.41 \\
E2/E4 & 1 & 1.85 \\
E3/E3 & 34 & 62.96 \\
E3/E4 & 14 & 25.93 \\
E4/E4 & 0 & 0 \\
Total & 54 & 100 \\
Gene frequencies & & \\
E*2 & 0.065 & \\
E*3 & 0.796 & \\
E*4 & 0.139 & \\
\hline
\end{tabular}




\section{Chapter 4}

A multivariate procedure was used to quantify the relative contribution of apo $\mathrm{E}$ polymorphism and anthropometric parameters to the variance in serum lipoproteins. The impact of apo E polymorphism was evaluated using three patient groups: E 2/2 and 2/3 and $\mathrm{E}$ 3/4. The analysis of baseline data is summarized in Table 4.3. Two variables, age and fat-free mass, entered the model as significant predictors of TG level. The only variable predictive of HDL-C was WHR, while the significant effect of age on Lp(a) disappeared when natural logarithms of $L p(a)$ data were used. Only fat mass as a predictor of TG, and fat-free mass for both TG and HDL-C reached the 0.05 level of significance in a similar analysis, relating changes in lipoprotein parameters during weight reduction to changes in the independent variables (Table 4.4).

Table 4.3. Multiple stepwise regression analysis with lipoprotein parameters as dependent variables and apo E phenotype (E $2 / 2$ and $2 / 3, E 3 / 3$ or E $3 / 4$ ), age, BMI, WHR, fat mass and fatfree mass as independent continuous variables in 54 obese women before weight loss.

\begin{tabular}{lclcl}
\hline $\begin{array}{l}\text { Dependent } \\
\text { variable }\end{array}$ & Step & $\begin{array}{c}\text { Independent } \\
\text { variable }\end{array}$ & $\begin{array}{c}\text { Multiple } \\
\mathrm{r}^{2}\end{array}$ & $\mathrm{P}$ \\
\hline Triglycerides & 1 & Age & 0.11 & 0.02 \\
& 2 & Fat-free mass & 0.21 & 0.004 \\
HDL cholesterol & 1 & WHR & 0.08 & 0.04 \\
Lipoprotein(a) & 1 & Age & 0.10 & 0.03 \\
$\begin{array}{l}\text { Total cholesterol } \\
\text { LDL cholesterol }\end{array}$ & & & & No variables \\
$\begin{array}{l}\text { Apolipoprotein B } \\
\text { Apolipoprotein A-1 }\end{array}$ & & & & 0.05 limit \\
In Lipoprotein(a) & & & & reach the \\
& & &
\end{tabular}

Table 4.4 Multiple stepwise regression analysis with changes in lipoprotein parameters during weight loss as dependent variables and apo $E$ phenotype and changes in body mass index, waist-hip ratio, fat mass, and fat-free mass as independent variables in 54 obese women.

\begin{tabular}{|c|c|c|c|c|}
\hline $\begin{array}{l}\text { Dependent } \\
\text { variable }\end{array}$ & Step & $\begin{array}{l}\text { Independent } \\
\text { variable }\end{array}$ & $\begin{array}{c}\text { Multiple } \\
r^{2}\end{array}$ & $\mathrm{P}$ \\
\hline$\Delta$ Triglycerides & $\begin{array}{l}1 \\
2\end{array}$ & $\begin{array}{l}\Delta \text { fat mass } \\
\Delta \text { fat-free mass }\end{array}$ & $\begin{array}{l}0.13 \\
0.30\end{array}$ & $\begin{array}{l}0.02 \\
0.0003\end{array}$ \\
\hline $\begin{array}{l}\Delta \text { HDL cholesterol } \\
\Delta \text { Total cholesterol } \\
\Delta \text { LDL cholesterol }\end{array}$ & 1 & $\Delta$ fat-free mass & 0.09 & 0.03 \\
\hline $\begin{array}{l}\Delta \text { Apolipoprotein B } \\
\Delta \text { Apolipoprotein A-I }\end{array}$ & & & & No variables \\
\hline $\begin{array}{l}\Delta \text { Lipoprotein(a) } \\
\Delta \text { In Lipoprotein(a) }\end{array}$ & & & & 0.05 limit \\
\hline
\end{tabular}

Changes $(\Delta)$ were calculated as the value before weight loss minus the value after weight reduction. 


\section{Discussion}

Serum Lp(a) concentrations in this group of normolipidemic obese women were unrelated to anthropometric variables. This observation extends previous reports on non-obese healthy adults (41) and diabetics (29).

The decreases in TC, LDL-C, and TG induced by a $10-\mathrm{kg}$ weight loss in this study were substantially greater than those predicted from a recent meta-analysis of 70 studies designed to examine the effects on blood lipids of weight reduction by dieting (8). This was not unexpected since blood lipid reductions have been shown to be more pronounced during active weight loss on a very low caloric diet than on a normal food intake (32). However, changes in lifestyle as well as intra-individual, between-sample variations in lipid levels, reflecting both biological and methodological variability $(4,28)$ may also have contributed to the changes in lipid variables observed in this study.

Despite the considerable decreases in TC, LDL-C and TG, no overall significant change in serum $\mathrm{Lp}(\mathrm{a})$ levels was observed. These data confirm previous reports showing no change of $L p(a)$ concentrations after weight loss in obese subjects $(6,21)$, but are in disagreement with another study documenting mean Lp(a) decreases of $19 \%$ in men and of $30 \%$ in premenopausal women after moderate weight loss (40). The reasons for these discrepancies are not clear, especially since the average decrease in BMI was greater in the studies reporting no overall Lp(a)-lowering effect of weight reduction.

Our data, together with those from Sönnichsen et al (40) and Corsetti et al (6), suggest, however, that weight loss may have an Lp(a)-lowering effect in the subgroup of obese subjects with elevated initial $\mathrm{Lp}$ (a) values (above 25 to $30 \mathrm{mg} / \mathrm{dl}$ ). This observation appears to be of clinical relevance since $L p(a)$ concentrations above this level are associated with an 1.5 to 2 -fold increased risk for coronary heart disease (2). Interestingly, Lp(a) responses to other types of dietary or pharmacological manipulation also seem to be dependent on baseline $L p(a)$ values, since both increases of $L p(a)$ on diets high in trans-mono-unsaturated fatty acids (26) and decreases by palm oil (17), fish oil (35), and neomycin-niacin treatment (14) are related to intrinsic Lp(a) levels. Apo E polymorphism contributes to the variation in lipid levels seen in the population. Three common alleles ( $E^{*} 2, E^{*} 3$, and $E^{*} 4$ ) code for the three major isoforms (E2, E3, and E4), giving rise to six apo $\mathrm{E}$ phenotypes in plasma. Absorption efficacy of dietary cholesterol is increased and serum TC and LDL-C are higher in subjects with the E*4 allele, while cholesterol absorption and both TC and LDL-C levels are lower in people with $\mathrm{E}^{*} 2$ when compared to those with $\mathrm{E}^{*} 3(9,19)$. In addition, TG levels are elevated and HDL-C concentrations are decreased in apo E 2/2, 2/3,2/4 and $3 / 4$ subsets compared to the more common apo E $3 / 3$ group (7). The relationships between the apo E phenotype and plasma lipid levels previously documented in the population at large have now also been shown to exist in the obese, since the $E^{*} 4$ allele increases both the risk of hypercholesterolemia (10) and hypertriglyceridemia (11) among obese individuals. Within our group of obese women, TC at baseline was higher in the subjects carrying the $E 3 / 4$ phenotype than in those with E $3 / 3$, but, probably due to the small sample size, no significant differences were observed in LDL-C, apo B, TG, HDL-C, and apo A-I. Also, the relative contribution of apo E polymorphism to the total variance of TC, LDL$\mathrm{C}$, and $\mathrm{Lp}(\mathrm{a})$ was less pronounced than previously observed in non-obese subjects ( 20 , 
37). No association was observed between pre-treatment $L p(a)$ and apo $E$ polymorphism in these obese Dutch women, although a previous report from the Netherlands has described an apo E genotype effect on Lp(a) similar to that on LDL (20). Apo E polymorphism substantially alters the association between body fatness, body fat distribution, and plasma lipoprotein levels in obese women (31). In women homozygous for apo E3, Pouliot et al (31) have observed positive associations of body fat mass, WHR, and computerized tomography-derived total and intra-abdominal fat areas with VLDL lipids, LDL-C and LDL-apo B, and negative correlations of these body fatness variables with HDL-C. In our apo E $3 / 3$ subjects, WHR was positively related to TG and negatively to HDL-C, but no association was observed with LDL-C or apo B. In contrast to the observations of Pouliot et al (31), we found an inverse relationship between fat mass and both LDL-C and apo B, while apo B was positively related to fatfree mass. These conflicting results emphasize the need for further studies that explore the interplay between genes relevant to lipoprotein metabolism and body fatness or its components.

The response to dietary fat and cholesterol may vary between individuals with different apo $\mathrm{E}$ phenotypes $(23,27,42)$. However, two recent studies failed to detect this association $(12,33)$. In both investigations, only relatively small numbers of subjects were studied. We have therefore explored whether apo E polymorphism might modulate the response to weight reduction. The data were analyzed firstly by comparing changes in anthropometric and lipoprotein variables in subjects with apo $E 3 / 3$ or $E 3 / 4$ phenotypes, and secondly by multivariate stepwise analyses that included apo $\mathrm{E}$ polymorphism together with anthropometric parameters as independent variables. Neither approach was able to demonstrate a modulating effect of apo E polymorphism on changes induced by weight loss. This could partly be related to the relative homogeneity of baseline lipid values in our normolipidemic subjects. In two earlier reports $(27,42)$ which observed an association of the $E^{*} 4$ allele with a greater sensitivity to diet, pre-treatment cholesterol levels were significantly higher in carriers of the E*4 allele than in subjects without E*4. In a third study (23) showing that both baseline total cholesterol and apo E4 phenotype independently predicted the degree of cholesterol reduction following dietary intervention in dyslipidemic men, baseline levels of TC and LDL-C were similar in subjects with and without the $E^{*} 4$ allele.

In conclusion, short-term, substantially weight loss in normolipidemic obese women was associated with decreases of VLDL. LDL, and HDL. A lowering of serum Lp(a) was observed only in individuals with pre-treatment $L p(a)$ levels above $30 \mathrm{mg} / \mathrm{dl}$. Although pre-treatment TC was increased in subjects with the apo E 3/4 phenotype compared to those with the common apo E $3 / 3$ phenotype, apo E polymorphism did not affect $L p(a)$ at baseline, nor did it affect the changes in lipoprotein variables, including $L p(a)$, during weight loss.

\section{References}

1. Albers JJ, Cabana VG, Warnick GR, Hazzard W. Lp(a) lipoprotein: relationship to sinking prebeta lipoprotein, hyperlipoproteinemia, and apolipoprotein B. Metabolism 24: 1047-1054, 1975 
2. Armstrong VW, Cremer P, Eberle E, Mankc A, Schulze F, Wieland H, Kreuzer H, Seidel D. The association between serum $L p(a)$ and angiographically assessed coronary atherosclerosis. Atherosclerosis 62: 249-257, 1986.

3. Beil FU, Terres W, Orgass M, Greten H. Dietary fish oil lowers lipoprotein(a) in primary hypertriglyceridemia. Atherosclerosis 90: 95-97, 1991.

4. Brown SA, Boerwinkle E, Kashanian FK, Swanson N, Patsch W. Variation in concentrations of lipids, lipoprotein lipids, and apolipoproteins A-I and B in plasma from healthy women. Clin Chem 36: 207-210, 1990.

5. Carlson LA, Hamsten A, Asplund A. Pronounced lowering of serum levels of lipoprotein Lp(a) in hyperlipidaemic subjects treated with nicotinic acid. J Intern Med 226: 271-276, 1989.

6. Corsetti JP, Sterry JA, Sparks JD, Sparks CE, Weintraub M. Effect of weight loss on serum lipoprotein(a) concentrations in an obese population. Clin Chem 37: 1191-1195, 1991.

7. Dallongeville J, Lussier-Cacan S, Davignon J. Modulation of plasma triglyceride levels by apo $E$ phenotype: a meta-analysis. J Lipid Res 33: 447-454, 1992.

8. Dattilo AM, Kris-Etherton PM. Effects of weight reduction on blood lipids and lipoproteins: a meta-analysis. Am J Clin Nutr 56: 320-328, 1992.

9. Davignon J, Gregg RE, Sing CF. Apolipoprotein E polymorphism and atherosclerosis. Artherioscler Thromb 8: 1-21, 1988.

10. Eto $\mathrm{M}$, Watanabe $\mathrm{K}$. Ishii $\mathrm{K}$. Apolipoprotein $\mathrm{E}$ polymorphism and hyperlipoproteinemia in obesity. Int J Obes 13: 433-440, 1989.

I l. Fumeron F, Rigaud D, Bertiere MC, Bardon S, Dely D, Apfelbaum M. Associations of apolipoprotein E4 allele with hypertriglyceridemia in obesity. Clin Genet 34: 258-264, 1988.

12. Glatz JFC, Demacker PN, Turner PR, Katan MB. Response of serum cholesterol to dietary cholesterol in relation to apolipoprotein E phenotype. Nutr Merab Cardiovasc Dis 1: 13-17, 1991.

13. Guegen R, Visvikis S, Steinmetz J, Siest G, Boerwinkle E. An analysis of genotype effects and their interactions by using the apolipoprotein E polymorphism and longitudinal data. $\mathrm{Am} J \mathrm{Hum}$ Genet 45: 793-802, 1989.

14. Gurakar A, Hoeg JM. Kostner G, Papadopoulos NM, Brewer HB. Levels of lipoprotein Lp(a) decline with neomycin and niacin treatment. Atherosclerosis 57: 293-301, 1985.

15. Havekes LM, de Knijff P, Beisiegel U, Havinga J, Smit M, Klasen E. A rapid micromethod for apolipoprotein E phenotyping directly in serum. J Lipid Res 28: 455-463, 1987.

16. Herrmann W, Biermann J, Lindhofer H-G, Kostner G. Beeinflussung des atherogenen Risicofaktors $\mathrm{Lp}(\mathrm{a})$ durch supplementäre Fischölaufnahme bei Patienten mit moderatem physischem Training, Med Klin 84: 429-433, 1989.

17. Hornstra G. Partial replacement of habitual dietary fat by palm oil lowers serum lipoprotein(a) in normocholesterolaemic volunteers. In Halpern MJ (ed). Molecular Basis of Atherosclerosis. John Libbey, London pp 465-472, 1992.

18. Huisveld IA, Leenen R, van der Kooy K, Hospers JE, Seidell JC, Deurenberg P, Koppeschaar HP, Mosterd WL, Bouma BN. Body composition and weight reduction in relation to antigen and activity of plasminogen activator inhibitor (PAI-I) in overweight individuals. Fibrinolysis 4 (suppl 2): 84-85, 1990.

19. Kesäniemi YA, Ehnholm C, Miettinen TA. Intestinal cholesterol absorption efficiency in man is related to apoprotein E phenotype. J Clin Invest 80: 578-581, 1987.

20. Knijff de P, Kaptein A, Boorsma D, Princen HM. Frants RR, Havekes LM. Apolipoprotein E polymorphism affects plasma levels of lipoprotein(a). Atherosclerosis 90: 169-174, 1991.

21. Kostner G, Klein G, Krempler F. Can serum Lp(a) concentrations be lowered by drugs and/or diet? In Carlson LA, Olsson AG (eds). Treatment of Hyperlipoproteinemia. Raven Press, New York pp 151-156, 1984.

22. Malle E, Sattler W, Prener E, Leis H, Hermetter H, Gries A, Kostner G. Effect of dietary fish oil supplementation on platelet aggregability and platelet membrane fluidity in normolipidemic subjects with and without high plasma Lp(a) concentrations. Atherosclerosis 88: 193-201, 1991. 
23. Mänttäri M, Koshinen P, Ehnholm C, Huttunene JK, Manninen V. Apolipoprotein E polymorphism influences the serum cholesterol response to dietary intervention. Metabolism 40: 217-221, 1991.

24. Mbewu AD, Durrington PN. Lipoprotein(a): structure, properties and possible involvement in thrombogenesis and atherogenesis. Atherosclerosis 85: 1-14, 1990.

25. Mehrabian M, Peter JB, Barnard RJ, Lusis AJ. Dietary regulation of fibrinolytic factors. Atherosclerosis 84: 25-32, 1990.

26. Mensink RP, Zock PL, Katan MB, Hornstra G. Effect of dietary cis and trans fatty acids on serum lipoprotein(a) levels in humans. J Lipid Res 33: 1493-1501, 1992.

27. Miettinen TA, Kesäniemi YA. Cholesterol absorption: regulation of cholesterul synthesis and elimination and within-population variations of serum cholesterol levels. Am J Clin Nutr 49 : 629-635, 1989.

28. Mogadam M, Ahmed SW, Mensch AH, Goldwin ID. Within-person fluctuations of serum cholesterol and lipoproteins. Arch Intern Med 150: 1645-1648, 1990.

29. Muls E, Cobbaert C, Bex M. Diabetes mellitus and lipoprotein(a). In Halpern MJ (ed). Molecular Basis of Atherosclerosis. John Libbey, London pp 431-435, 1992.

30. Nestel P, Noakes M, Belling B, McArthur R, Clifton P, Janus E, Abbey M. Plasma lipoprotein lipid and $\mathrm{Lp}$ (a) changes with substitution of elaidic for oleic acid in the diet. I Lipid Res 33: 10291036, 1992.

31. Pouliot M-C. Després J-P, Moorjani S, Lupien PJ, Tremblay A, Bouchard C. Apolipoprotein E polymorphism alters the association between body fatness and plasma lipoproteins in women. $J$ Lipid Res 31: 1023-1029, 1990.

32. Saris WHM, Koenders MC, Pannemans DLE, van Baak MA. Outcome of a multicenter outpatient weight-management program including very-low-calorie diet and exercise. Am J Clin Nutr 56: 294S-296S, 1992.

33. Savolainen MJ, Rantala M, Kervinen K, Järvi L, Suvanto K, Rantala T. Kesäniemi YA. Magnitude of dietary effect on plasma cholesterol concentration: role of sex and apolipoprotein $E$ phenotype. Alherosclerosis 86: 145-152, 1991.

34. Scanu AM. Fless GM. Lipoprotein(a). Heterogeneity and biological relevance. J Clin Invest 85 : 1709-1715. 1990.

35 Schmidt EB, Klausen IC, Kristensen SD, Lervang H-H, Faergeman O, Dyerberg J. The effect of n-3 polyunsaturated fatty acids on Lp(a). Clin Chim Acra 198: 271-278, 1991.

36. Schoeller DA, Jones PJ. Measurement of total body water by isotope dilution: a unified approach to calibrations. In Ellis $\mathrm{KJ}$, Yasumara S, Morgan WD (eds). In vivo body composition studies. Institute of Physical Sciences in Medicine, London pp 131-136, 1987.

37. Sing CF, Davignon J. Role of the apolipoprotein $E$ polymorphism in determining normal plasma lipid and lipoprotein variation. Am J Hum Genet 37: 268-285, 1985.

38. Siri WE. The gross composition of the body. Adv Biol Med Physiol 4: 239-280, 1956.

39. Smit M, de Knijff P, Rosseneu M, Bury J, Klasen E, Frants R, Havekes L. Apolipoprotein E polymorphism in the Netherlands and its effect on plasma lipid and apolipoprotein levels. Hum Genet 80: 287-292, 1988.

40. Sönnichsen AC, Richter WO, Schwandt P. Reduction of lipoprotein(a) by weight loss. Int J Obes 14: 487-494, 1990.

41. Sundell IB, Nilsson TK, Hallmans G, Hellsten G, Dahlén GH. Interrelationships between plasma levels of plasminogen activator inhibitor, tissue plasminogen activator, lipoprotein(a), and established cardiovascular risk facturs in a North Swedish population. Atherosclerosis 80: 9-16, 1989.

42. Tikkanen MJ, Huttunen JK, Ehnholm C, Pietinen P. Apolipoprotein E4 homozygosity predisposes to serum cholesterol elevation during high fat diet. Artherioscler Thromb 10: 285288. 1990. 


\title{
CHAPTER 5
}

\section{Predictors of fat loss during very-low calorie diet in obese females}

\author{
Kempen KPG, Saris WHM, Blaak EE, Stegen JCHC, Kester ADM ${ }^{1}$
}

Department of Human Biology and 'Department of Methodology and Statistics, University of Limburg, Maastricht, the Netherlands

Submitted for publication

\begin{abstract}
The magnitude of reductions of weight and fat mass considerably varies among individuals on the same weight loss regime. The present study evaluates whether metabolic variables reflecting aerobic fitness, energy expenditure, sympathetic nervous system activity, lipolysis, insulin sensitivity, and substrate oxidation predict the amount of body fat loss in response to an 8-week dietary weight reduction intervention. Before the energy restriction period $(2.8 \mathrm{MJ} /$ day $)$, measurements were performed on maximal aerobic capacity, body composition, sleeping metabolic rate and exercise-induced energy expenditure.

The weight loss due to energy restriction amounted $10.1 \pm 0.4 \mathrm{~kg}$, consisting of $7.9 \pm$ $0.4 \mathrm{~kg}$ body fat and $2.2 \pm 0.2 \mathrm{~kg}$ fat-free mass. The results analyzed by partial regression analyses demonstrated that basal catecholamines were positively and exercise-induced response of plasma glucose inversely related to the decrease in body fat percentage as result of energy restriction $(\mathrm{P}<0.05)$. In addition, decrease in body fatness tended to be inversely related to the relative contribution of fatty acids to energy expenditure during exercise $(P=0.09)$. These results suggest that basal sympathetic nervous system activity and insulin resistance are predicting factors for loss of body fat in response to dietary treatment.
\end{abstract}




\section{Introduction}

Obesity is a common metabolic and nutritional disorder in affluent societies. Recent lines of evidence suggest that the development and maintenance of obesity might be associated with abnormalities of fuel metabolism. Lipolysis and fat oxidation might be decreased in obese subjects or subjects with a predisposition to obesity $(2,5,7,20,27)$ and activity of the sympathetic nervous system may be involved (2). Furthermore, obesity, especially with visceral localization of adipose tissue, is often associated with an insulin resistant state which interferes with metabolism (5).

The frequent occurrence of obesity is associated with a high prevalence of preoccupation with dieting and weight loss. Dieting alters the physiology of energy and substrate metabolism and resuls in a shift from carbohydrate to fat metabolism (12). Stored body energy is utilized to meet energy deficits created by declined energy intake. Ideally, weight loss treatments should result in loss of excess body fat and preservation of appropriate amounts of lean body mass. However, the amount of weight and fat mass lost, considerably varies among individuals on the same weight loss regime. This interindividual variation in success to weight loss treatment has been suggested to be related to adherence, initial body weight, body fatness, and total energy expenditure $(13,16$, 23 ). Recently, it has been suggested that substrate metabolism may also be involved in the regulation of weight and fat loss outcome as result of dietary treatment $(1,11)$.

We hypothesized that the capacity to mobilize and utilize fatty acids for energy requirements might influence the rate and amount of body fat loss due to energy restriction. In addition, catecholamines and insulin might be involved, since they play an important role in the regulation of substrate metabolism. Therefore the aim of the present study was to investigate whether metabolic variables reflecting aerobic fitness, energy expenditure, sympathetic nervous system activity. Jipolysis, insulin sensitivity, and/or fat oxidation would predict the amount of body fat loss in response to a weight reduction intervention. Since correlations between measured metabolic variables and body fat loss might be hard to detect due to inter-individual variation, possible changes and correlations would be more likely to be apparent during a metabolic challenge. Therefore several metabolic variables were measured before, during and after a moderate exercise bout.

\section{Subjects and methods}

Subjects participating in the present study were 63 obese women, recruited by advertisements in local newspapers. They were selected on the basis of their body mass index (BMI; between 28 and $38 \mathrm{~kg} / \mathrm{m}^{2}$ ) and aged between 19 and $53 \mathrm{yr}$ (mean $\pm \mathrm{SE}$ $36.2 \pm 1.2 \mathrm{yr}$ ). The women were premenopausal and apparently healthy as evaluated by a medical history and a physical examination. None of the subjects received any medication known to affect the variables measured and none of them reported to have been on an energy-restricted diet in the 6 months prior to the study. All subjects gave their written informed consent to participate in the study that was approved by the Medical Ethical Committee of the University. Six subjects did not complete the weight 
loss intervention ( 1 due to illness, 1 for personal reasons, and 4 because of lack of motivation). Baseline characteristics of the remaining study population $(n=57)$ are listed in Table 5.1. The subjects participated in an energy restriction program for 8 weeks. Before the start of the diet, measurements of maximal aerobic capacity, body composition, sleeping metabolic rate (SMR), and exercise-induced energy expenditure were performed. Measurements were repeated at the end of the diet intervention.

Table 5.I Characteristics of the subjects before and at the end of an 8-week weight loss treatment.

\begin{tabular}{lll}
\hline Characteristics & Baseline & 8-week weight loss \\
\hline Body weight, $\mathrm{kg}$ & & $77.0 \pm 1.4 \dagger$ \\
Body mass index, $\mathrm{kg} / \mathrm{m}^{2}$ & $87.1 \pm 1.6$ & $28.0 \pm 0.5 \dagger$ \\
Percentage body fat, \% & $31.7 \pm 0.5$ & $37.1 \pm 0.7 \dagger$ \\
$\quad$ fat mass, $\mathrm{kg}$ & $41.9 \pm 0.6$ & $28.9 \pm 1.0 \dagger$ \\
$\quad 36.8 \pm 1.1$ & $48.1 \pm 0.6 \dagger$ \\
Waist-free mass, kg ratio & $50.3 \pm 0.7$ & $0.81 \pm 0.01^{*}$ \\
Sleeping metabolic rate, $\mathrm{kJ} / \mathrm{min}$ & $0.83 \pm 0.01$ & $4.21 \pm 0.07 \dagger$ \\
basal respiratory exchange ratio & $4.70 \pm 0.09$ & $0.78 \pm 0.01 \dagger$ \\
\end{tabular}

Values are means \pm SE $(n=57), * \mathrm{P}<0.0005, \dagger \mathrm{P}<0.0001$ Student paired t-test with respect to baseline values.

Diet

The energy restriction program took place over an 8-week period which was divided into two parts. The first period consisted of a low-energy formula diet (Modifast, Sandoz, Bern, Switzerland) containing $2.0 \mathrm{MJ} /$ day for four weeks. It provided $50 \mathrm{~g}$ carbohydrates, $52 \mathrm{~g}$ protein, $7 \mathrm{~g}$ fat, and a micronutrient content which meets the Dutch recommended daily allowance. In the second part of the energy restriction period, from week 5 until week 9, subjects were prescribed a mixed diet of $3.5 \mathrm{MJ} /$ day, containing 1.4 MJ of the formula diet supplemented to $3.5 \mathrm{MJ}$ by a free choice of foodstuffs. During the whole period, subjects were instructed to keep a record of food intake. Subjects were asked to keep their habitual activity pattern. During the energy restriction period the subjects came to the laboratory once a week to have their weight measured and food records checked.

\section{Measurements}

At least 3 , and at most 7 days prior to the other measurements at the beginning of the study, each subject's maximal oxygen uptake $\left(\mathrm{VO}_{2 \mathrm{mux}}\right)$ and peak mechanical power $\left(\mathrm{W}_{\text {nux }}\right)$ were determined by using a progressive-continuous cycling test on an ergometer (Lode, Groningen, the Netherlands) as described before (12). $\mathrm{W}_{\max }$ was defined as the highest load a subject could maintain for $1 \mathrm{~min}$. Values of $\mathrm{W}_{\max }$ were used to assess the individual intensity of an exercise test. During the test, ventilatory and gas exchange 
responses were measured continuously, using a computerized open-circuit system (Oxycon Beta, Mijnhardt, Bunnik, the Netherlands). Heart rate (HR) was recorded by a electrocardiogram. Criteria for maximal exercise were forced ventilation, leveling off of oxygen uptake, or a respiratory exchange ratio (RER) exceeding 1.1. The highest oxygen uptake achieved for at least $30 \mathrm{~s}$ was taken as $\mathrm{VO}_{2 \max }$.

SMR was measured during a overnight stay (1900-0700), using a computerized opencircuit indirect calorimeter as described before (12). Briefly, basal RER and energy expenditure were calculated from $\mathrm{O}_{2}$ consumption and $\mathrm{CO}_{2}$ production (24), during the sleeping period between 0300 and 0600 , whereas physical activity was checked by a Doppler radar system. After the overnight fast in the respiration chamber and body density measurement, an exercise test was performed. Before the start of the test, between 0800 and 0830 , a canula was inserted in an anticubital vein of a forearm for blood sampling. Measurements were started half an hour after insertion of the catheter. The exercise protocol consisted of $45 \mathrm{~min}$ of exercise on a bicycle ergometer at a workload of $45 \%$ of the previously estimated $\mathrm{W}_{\max }$. The exercise was preceded by a 30min lasting resting period (baseline measurement) and followed by a 60 -min recovery period, with the person in supine position. Respiratory exchange measurements were done continuously during baseline and recovery periods, by means of a computerized open-circuit ventilated hood system. During exercise, respiratory exchange responses were measured periodically for in total $20 \mathrm{~min}, 5 \mathrm{~min}$ each time, using a computerized open system (Oxycon Beta, Mijnhardt, Bunnik, the Netherlands). Both systems were calibrated with standard gas prior to each measurement. Measured RER values were used to calculate carbohydrates and fat oxidation rates, assuming that the RER reflected the non-protein respiratory quotient (14). An electrocardiogram was monitored continuously during the experiment. Venous blood samples were collected during baseline period $(t=-30$ and $0 \mathrm{~min})$, and at timed intervals during exercise $(t=5,15,30$ and $45 \mathrm{~min})$ and recovery period $(t=60,75$ and $105 \mathrm{~min})$. Blood samples of all subjects were used for determinations of hematocrit, glucose, free fatty acids (FFA), and glycerol. Catecholamines were measured in blood samples of 49 subjects. Insulin was measured in samples of all subjects at $t=0$, and in samples at $t=15,30,45,75$ and $105 \mathrm{~min}$ of 40 subjects. There were no significant differences in characteristics of these subjects and the remaining group.

Before and at the end of the study, body weight (BW) was measured on a digital balance accurate to $0.1 \mathrm{~kg}$ (Sauter D-7470, Ebingen, Germany) after the overnight fast in the respiration chamber. Height was measured to the nearest $0.1 \mathrm{~cm}$ using a wallmounted stadiometer. BMI was calculated from BW and height $\left(\mathrm{kg} / \mathrm{m}^{2}\right)$. Waist circumference was measured as the smallest circumference between the rib cage and the iliac crest, with the subject in standing position and breathing quietly. The hip circumference was measured at the level of the widest circumference between the waist and the thighs. Waist-hip ratio (WHR) was calculated as waist circumference divided by hip circumference. Body composition was measured with two different techniques: isotope dilution and underwater weighing with simultaneously lung volume measurement (Helium-dilution). The percentage of body fat (\%FM) was calculated from body density and total body water (TBW) according to the 3-compartment model of Siri (21). Deuterium dilution technique was used to measure TBW. Before going to bed at 
night during the stay in the respiration chamber, a ${ }^{2} \mathrm{H}_{2} \mathrm{O}$ dilution was drunk after emptying the bladder (baseline urine sample). The dosage calculation was based on $\mathrm{BW}$ in order to create a ${ }^{2} \mathrm{H}$ excess of $100 \mathrm{ppm}$. A second urine sample was collected on the next day in the morning, from the second voiding between 0700 and 1000 . Deuterium was measured in urine samples with an isotope ratio mass spectrometer (VG Aqua Sira). TBW was calculated as the measured deuterium dilution space divided by 1.04 (18). At the same morning after the overnight stay in the respiration chamber, whole body density was determined by hydrostatic weighing with the subject in the fasted state. Underwater weight was measured to the nearest $0.1 \mathrm{~kg}$ (Sauter D-7470, Ebingen, Germany). Residual lung volume was measured with a spirometer (Volugraph 2000, Mijnhardt, Bunnik, the Netherlands) at the moment of underwater weighing. The measurements were done in triplicate and the average was used to calculate body density.

\section{Biochemical analyses}

Plasma of heparinized blood was used for determination of glucose by means of a hexokinase method (Cobas Bio, Roche Diagnostics, Hoffmann-La Roche, Basle, Switzerland). Hematocrit was determined by a microcapillary system. Serum was prepared for FFA analyses (Wako, NEFA C, Wako Chemicals, Neuss, Germany) and glycerol (Boehringer, Mannheim, Germany). Plasma insulin was measured using a double antibody radioimmunoassay for human insulin (Kabi Pharmacia Diagnostics AB, Uppsala, Sweden). Concentrations of plasma epinephrine and norepinephrine, sampled with heparine and put into glutathione containing tubes on ice, were determined by means of high performance liquid chromatography (10).

\section{Statistical analyses}

Data in the text and tables are given as means \pm SE. Physiological responses to exercise were analyzed by a repeated measurement analysis of variance (ANOVA), post hoc tested with paired Student t-tests (corrected for Bonferroni's inequalities). Total exercise-induced response curves were calculated as the total integrated changes over baseline values (areas under curve from $t=0$ to $45 \mathrm{~min}, \mathrm{AUC}_{0.45}$ ). Paired Student t-tests were used to analyze differences between before and at the end of the diet, whereas unpaired Student t-tests were used to analyze differences between subjects. Single correlations were calculated as Pearson product-moment correlation coefficients. The relationships between body fat loss as dependent variable, and $\mathrm{VO}_{2 \max }$, exercise-induced energy expenditure, basal- and exercise-induced responses of catecholamines, exerciseinduced responses of glucose and glycerol, and relative fat oxidation during exercise as independent variables, were evaluated by means of multiple regression analysis. Partial regression coefficients were calculated in order to correct for colinearity between independent variables. Body fat loss was expressed as decrease in \% FM given by the equation $\Delta \mathrm{FM}(\%)=\left(\right.$ fat mass $\left.\mathrm{wk}_{\mathrm{k} 0} / \mathrm{BW}_{\mathrm{wk} 0}\right) \times 100 \%$ - (fat mass $\left.\mathrm{wk} 8 / \mathrm{BW}_{\mathrm{wk} \delta}\right) \times 100 \%$. To adjust for initial values, $\% \mathrm{FM}$ was also included as independent variable in the multiple regression analysis. Since the initial magnitude of a variable may automatically 


\section{Chapter 5}

be related to the magnitude of change in this variable as a result of intervention, an artificial correlation may be obtained (3). Therefore, the initial magnitude of body fatness was defined as the average of \% FM values before and after diet, as described elsewhere (4). $\mathrm{P}<0.05$ was accepted as statistically significant.

\section{Results}

The weight loss due to the energy restriction amounted $10.1 \pm 0.4 \mathrm{~kg}$, consisting of 7.9 $\pm 0.4 \mathrm{~kg}$ body fat and $2.2 \pm 0.2 \mathrm{~kg}$ fat-free mass. WHR, SMR and basal RER significantly declined in response to the diet (Table 5.1). Partial correlation coefficients between decrease in \%FM and independent metabolic variables are given in Table 5.2. The decline in \%FM was significantly and positively related to basal catecholamines and inversely related to exercise-induced response of plasma glucose. Furthermore, the decrease in $\% \mathrm{FM}$ tended to be inversely related to the percentual contribution of fat oxidation to exercise-induced energy expenditure $(P<0.10)$. Together these factors could explain $36 \%$ of the inter-individual variation in the decrease of $\% \mathrm{FM}$.

Decrease in \%FM as a result of the dietary treatment divided in upper and lower $50 \%$ percentiles were $6.5 \pm 0.3$ and $3.0 \pm 0.3 \%$ respectively (Student unpaired t-test, $\mathrm{P}<$ $0.0001)$. The pre-treatment characteristics stratified into highest $(n=28)$ and lowest $(n$ = 28) $50 \%$-percentiles based on decline of \%FM as result of the diet are shown in Table 5.3. The two groups significantly differed in basal plasma norepinephrine, exerciseinduced absolute oxidation of carbohydrates and insulin response, whereas they tended to differ in basal plasma epinephrine values and the relative contribution of fat oxidation to exercise-induced energy expenditure.

Table 5.2 Partial correlation coefficients between decrease in body fat percentage (\%FM) and several baseline variables, each variable adjusted for the others.

\%FM decrease

\begin{tabular}{|c|c|}
\hline Body fat percentage (before minus after), $\%$ & 0.26 \\
\hline Maximal oxygen uptake, $1 /$ min & 0.08 \\
\hline AUC $_{0-45}$ energy expenditure, $\mathrm{kJ} / \mathrm{ml} \cdot 45 \mathrm{~min}^{-1}$ & 0.10 \\
\hline Basal norepinephrine. $\mathrm{pg} / \mathrm{ml}$ & $0.32 *$ \\
\hline AUC $_{0.45}$ norepinephrine, $\mathrm{pg} / \mathrm{ml} \cdot 45 \mathrm{~min}^{-1}$ & 0.07 \\
\hline Basal epinephrine, $\mathrm{pg} / \mathrm{ml}$ & $0.33 *$ \\
\hline $\mathrm{AUC}_{0-45}$ epinephrine, $\mathrm{pg} / \mathrm{ml}^{-45} \mathrm{~min}^{-1}$ & 0.11 \\
\hline $\mathrm{AUC}_{0-45}$ glycerol, $\mu \mathrm{mol} / 1 \cdot 45 \mathrm{~min}^{-1}$ & 0.13 \\
\hline AUC $_{0-45}$ glucose, $\mathrm{mmol} / 1 \cdot 45 \mathrm{~min}^{-1}$ & -0.33 \\
\hline Exercise-induced fat oxidation. $\%$ & -0.26 \\
\hline
\end{tabular}

${ }^{*} \mathrm{P}<0.05 ; \mathrm{AUC}_{0-45}$, total exercise-induced response. 
Table 5.3 Characteristics of subjects who successful (upper $50 \%$ percentile, $n=28$ ) and less successful (lower $50 \%$ percentile, $n=28$ ) attained a decrease in body fat percentage in response to an 8 -week very-low calorie diet.

$50 \%$ percentiles

Pre-treatment variable

Age, yr

Weight, $\mathrm{kg}$

Height, $m$

Body mass index, $\mathrm{kg} / \mathrm{m}^{2}$

Waist-hip ratio

Maximal oxygen uptake, $1 / \min$

Sleeping metabolic rate, $\mathrm{kJ} / \mathrm{min}$

Sleeping respiratory exchange ratio

Basal concentrations of norepinephrine, $\mathrm{pg} / \mathrm{ml}$

epinephrine, $\mathrm{pg} / \mathrm{ml}$

insulin, $\mathrm{mU} / \mathrm{l}$

glycerol, $\mu \mathrm{mol} / \mathrm{l}$

free-fatty acids, $\mu \mathrm{mol} /$

glucose, mmol/l

Exercise-induced responses of

energy expenditure, $\mathrm{kJ} / 45 \mathrm{~min}$

$\mathrm{CHO}$ oxidation, $\mathrm{g} / 45 \mathrm{~min}$

fat oxidation, $g / 45 \mathrm{~min}$

fat oxidation, \% of $\mathrm{EE}$

norepinephrine, $\mathrm{pg} / \mathrm{ml}^{-4} 4 \mathrm{~min}^{-1}$

epinephrine, $\mathrm{pg} / \mathrm{ml} \cdot 45 \mathrm{~min}^{-1}$

insulin, $\mathrm{mU} / \mathrm{l} \cdot 45 \mathrm{~min}^{-1}$

glycerol, $\mu \mathrm{mol} / 1 \cdot 45 \mathrm{~min}^{-1}$

free-fatty acids, $\mu \mathrm{mol} / 1 \cdot 45 \mathrm{~min}^{-1}$

glucose, $\mathrm{mmol} / \mathrm{l} \cdot 45 \mathrm{~min}^{-1}$

\begin{tabular}{ccr}
\hline Upper & Lower & P value* \\
\hline $36.7 \pm 1.5$ & $34.7 \pm 1.7$ & 0.21 \\
$86.1 \pm 2.0$ & $88.1 \pm 2.5$ & 0.52 \\
$1.65 \pm 0.01$ & $1.66 \pm 0.01$ & 0.58 \\
$31.7 \pm 0.7$ & $31.9 \pm 0.8$ & 0.90 \\
$0.83 \pm 0.01$ & $0.82 \pm 0.01$ & 0.27 \\
$2.3 \pm 0.6$ & $2.2 \pm 0.7$ & 0.16 \\
$4.61 \pm 0.10$ & $4.80 \pm 0.15$ & 0.31 \\
$0.81 \pm 0.01$ & $0.81 \pm 0.01$ & 0.81 \\
& & \\
$236 \pm 14$ & $199 \pm 13$ & $<0.05$ \\
$63 \pm 11$ & $41 \pm 6$ & 0.09 \\
$16.5 \pm 1.7$ & $15.9 \pm 1.4$ & 0.77 \\
$38 \pm 4$ & $42 \pm 6$ & 0.59 \\
$461 \pm 34$ & $472 \pm 32$ & 0.81 \\
$5.21 \pm 0.12$ & $5.33 \pm 0.11$ & 0.47 \\
$1095 \pm 28$ & $1035 \pm 27$ & \\
$50.8 \pm 2.2$ & $43.7 \pm 1.7$ & 0.13 \\
$7.5 \pm 0.9$ & $8.5 \pm 0.5$ & 0.05 \\
$27 \pm 3$ & $33 \pm 2$ & 0.33 \\
$36516 \pm 2861$ & $34277 \pm 3207$ & 0.09 \\
$2384 \pm 447$ & $2112 \pm 391$ & 0.60 \\
$-218 \pm 55$ & $-44 \pm 51$ & 0.65 \\
$4972 \pm 506$ & $4423 \pm 535$ & $<0.05$ \\
$4153 \pm 1620$ & $3900 \pm 1501$ & 0.46 \\
$-18.3 \pm 4.7$ & $-7.6 \pm 5.2$ & 0.83 \\
& & 0.13 \\
& &
\end{tabular}

Values are means $\pm \mathrm{SE}$. *Unpaired Student t-test. CHO. carbohydrates.

\section{Discussion}

Variation among individuals with respect to weight reduction and fat loss in response to dietary treatment is very common. Ideally, weight reduction treatments should result in a decrease of excess body fat and conservation of lean body mass. In the present study, metabolic factors that may play a role in the regulation of loss of fat mass were evaluated in obese women. It was hypothesized, that factors regulating mobilization and utilization of fatty acids might be of importance in determining the amount of fat mass lost in response to subsequent energy restriction. To adjust for disturbing influence of initial fat mass, the decrease in fat mass was expressed as decline in body fat percentage. which was used as dependent variable in multiple stepwise and partial regression analyses, whereas initial \%FM was included as independent variable. 
It appeared that basal catecholamines were positively and exercise-induced response of glucose were negatively related to the decrease in body fat percentage, as assessed by partial regression analysis. This implicates that these factors significantly and independently contributed to the variation in fat loss. In addition, the relative contribution of fat oxidation to exercise-induced energy expenditure tended to be related to the decrease in body fat percentage. These metabolic variables explained in total $36 \%$ of the variability in the decline of body fat percentage due to the energy restrictive dietary treatment.

The role that basal catecholamines may play in predicting subsequent fat loss as result of energy restriction, might be related to the contribution of the sympathetic nervous system to energy expenditure (25). Higher basal levels of catecholamines may indicate increased basal sympathetic activity (9) implicating increased levels of energy expenditure (26). Activity of the sympathetic nervous system have been previously shown to be inversely correlated with body fatness (15) and may contribute to the development of obesity (26).

Also substrate utilization appeared to be involved in the amount of fat loss to dietary treatment, as indicated by the data on absolute contribution of carbohydrates to energy expenditure during exercise. However, individuals oxidizing more carbohydrates during exercise were more successful in losing fat on a very-low calorie diet, than those oxidizing lower amounts of carbohydrates. In addition, an inverse relationship was observed between the total exercise-induced response of plasma glucose and the decrease in body fat percentage as a result of the dietary treatment. Because the exercise-induced responses of glucose and insulin were strongly correlated $(r=0.73, P<$ 0.001 ), the data indicate that hyperinsulinemia and insulin sensitivity are involved in the regulation of mobilization of body fat stores. This might be related to the finding that insulin resistance has been shown to be associated with diminished thermogenic responses such as after carbohydrate administration due to decreased glucose uptake (8, 17). Lower oxidation of carbohydrates may reduce activity of the glycogen cycle resulting in lower energy costs (6). Furthermore, activity of the glycogen cycle has been suggested to regulate relative carbohydrate intake (22) that may be of importance in regulation of body energy stores since a higher contribution of dietary fat is associated with weight gain.

The results of the present study appear to be in contrast with others indicating that the proportion of energy expenditure covered by fat is positively associated with reductions in weight and fat mass in response to dietary treatment $(1,11)$. In a study of Astrup et al (1), 24-h fat oxidation was positively related to the amount of weight loss. Since we did not measure 24-h fat oxidation, no further conclusions can be drawn on the importance of total daily fat oxidation in the regulation of body fat stores on the basis of the present data. The finding that a low ratio of fat to carbohydrate oxidation, as reflected by the 24-h RER value is associated with subsequent weight gain, however, further indicates its importance in the regulation of body energy stores (27).

The results of a study of Keim et al (11) indicating fat oxidation to be related with loss of body fat have to be cautiously interpreted since multiple regression analysis was performed with 20 variables in 10 subjects, who where divided in dietary $(n=5)$ or combined dietary and exercise treatment $(n=5)$. Furthermore, fat loss was expressed in 
$\mathrm{kg}$ (11), that may lead to apparent correlations because initial fat mass is strongly and pusitively correlated with serum lipid levels (19) and subsequent body fat loss. In our view, it is better to express fat loss as decline in body fatness and include the initial level in partial regression analyses to avoid disturbing influence of initial body fat mass.

In summary, the results of the present study indicate that significant factors in the regulation of dietary-induced fat loss involve basal sympathetic nervous system activity, insulin resistance, and hyperglycemia. It is therefore favorable to combine dietary and exercise interventions for successful treatment of obesity, since both sympathetic nervous system activity and insulin resistance are positively influenced by physical activity.

\section{References}

1. Astrup A, Beumann B, Gluud C, Bennet P, Tjur T, Christensen NJ. Prognostic markers for dietinduced weight loss in obese women. Int J Obes 19: 275-278, 1995.

2. Blaak EE, van Baak MA, Kester ADM, Saris WHM. $\beta$-Adrenergic stimulation of entrgy expenditure and forearm skeletal muscle metabolism in lean and obese men. Am J Physiol 267: E306-E315, 1994.

3. Blaak EE, van Baak MA, Kester ADM, Saris WHM. $\beta$-Adrenergically mediated thermogenic and heart rate responses: effect of obesity and weight loss. Metabolism 44: 520-524, 1995.

4. Bland JM, Altman DG. Statistical methods for assessing agreement between two methods of clinical measurement. Lancet 1: 307-310, 1986.

5. Colberg SR, Simoneau J, Thaete FL, Kelley DE. Skeletal muscle utilization of free fatty acids in women with visceral obesity. J Clin Invest 95: 1846-1853, 1995.

6. Felber JP. Golay A. Regulation of nutrient metabolism and energy expenditure. Metabolism 44(suppl 2): 4-9, 1995.

7. Flatt JP. Dietary, fat, carbohydrate balance, and weight maintenance: effects of exercise. Am J Clin Nutr 45: 296-306, 1987.

8. Golay A. Schutz Y, Meyer HU. Thiébaud D. Curchod B, Maeder E, Felber J-P. Jequier E. Glucose-induced thermogenesis in nondiabetic and diabetic obese subjects. Diabetes 31: 1023 . 1028, 1982.

9. Goldstein DS, McCarty R, Polinsky RJ, Kopin IJ. Relationship between plasma norepinephrine and sympathetic neural activity. Hypertension 5: 552-559, 1983.

10. Hjemdahl P. Plasma catecholamine: analytical challenges and physiological limitations. Baillière's Clin Endocrinol Metab 7: 307-353, 1993.

11. Keim NL, Barbieri TF, Van Loan M. Physiological and biochemical variables associated with body fat loss in overweight women. Int J Obes 15: 283-293, 1991.

12. Kempen KPG, Saris WHM, Senden JMG, Menheere PPCA, Blaak EE, van Baak MA. Effects of energy restriction on acute adrenoceptor and metabolic responses to exercise in obese subjects. Am J Physiol 267: E694-E701, 1994.

13. Kreitzman SN, Coxon AY, Johnson PG, Ryde SJS. Dependence of weight loss during very-low calorie diets on total energy expenditure rather than on resting metabolic rate, which is associated with fat-free mass. Am J Clin Nutr 56: 258S-261S, 1992.

14. Péronnet F, Massicotte D. Table of nonprotein respiratory quotient: an update. Can J Spr Sci 16: 23-29, 1991

15. Peterson HR, Rothschild M, Weinberg CR, Fell RD, McLaish KR, Pfeifer MA. Body fat and the activity of the autonomic nervous system. $N$ Engl J Med 318: 1077-1083. 1988.

16. Prentice AM, Goldberg GR, Jebb SA, Black AE, Murgatroyd PR. Physiological responses 10 slimming. Proc Nutr Soc 50: 441-458, 1991. 


\section{Chapter 5}

17. Ravussin E, Acheson KJ, Vernet O, Danforth E, Jéquier E. Evidence that insulin resistance is responsible for the decreased thermic effect of glucose in human obesity. $J$ Clin Invest 76 : 1268-1273, 1985.

18. Schoeller DA, Jones PJH. Measurement of total body water by isotopic dilution: a unified approach to calibrations. In Ellis KJ, Yasumura S, Morgan WD (eds). In vivo body composition studies. Institute of Physical Sciences in Medicine, London pp 131-136, 1987.

19. Schutz Y. The adjustments of energy expenditure and oxidation to energy intake: the role of carbohydrate and fat balance. Int J Obes 17: S23-S27, 1993.

20. Seidell JC. Fasting respiratory exchange ratio and resting metabolic rate as predictors of weight gain: the Baltimore Longitudinal study on aging. Int J Obes 16: 667-674, 1992.

21. Siri WE. Body composition from fluid spaces and density: analysis of methods. In Brozek J, Henschel A (eds). Techniques for measuring body composition. National Academy of Sciences, Washington DC pp 223-244, 1961.

22. Tremblay A, Buemann B. Exercise-training, macronutrient balance and body weight control. Int $J$ Obes 119: 79-86, 1995.

23. Webster JD, Garrow JS. Weight loss in 108 obese women on a diet supplying $800 \mathrm{kcal} / \mathrm{d}$ for $21 \mathrm{~d}$. Am J Clin Nutr 50: 41-45, 1989.

24..Weir JB. New methods for calculating metabolic rate with special reference to protein metabolism. J Physiol 109: 1-9, 1949.

25. Welle S, Schwartz RG, Statt M. Reduced metabolic rate during $\beta$-adrenergic blockade in humans. Metabolism 40: 619-622, 1991.

26. Young JB, MacDonald IA. Sympathoadrenal activity in human obesity: heterogeneity of findings since 1980. Int J Obes 16: 959-967, 1992.

27. Zurlo F, Lillioja S, Esposito-del Puente A, Nyomba BL, Raz I, Saad MF. Swimburn BA, Knowler WC, Bogardus C, Ravussin E. Low ratio of fat to carbohydrate oxidation as predictor of weight gain: study of 24-h RQ. Am J Physiol 259: E650-657, 1990. 


\title{
CHAPTER 6
}

\section{Weight cycling is associated with blunting of the sympathetically mediated thermogenesis in obesity}

\author{
Kempen KPG, Blaak EE, van Baak MA, Saris WHM
}

Department of Human Biology, University of Limburg, Maastricht, the Netherlands

Submitted for publication

\begin{abstract}
Treatments for obesity fail on the long-term and this might be related to compensatory metabolic processes as a result of weight cycling. We prospectively investigated whether weight cycling is associated with adverse effects on body composition and energy metabolism, under resting and stimulated conditions, in obese women.

All measurements were repeatedly performed in 22 obese women before, during and after two cycles of weight loss and regain over 2 years. The weight changes were -10.7 $\pm 0.4,+6.0 \pm 1.2,-6.3 \pm 0.6$ and $+6.2 \pm 0.9 \mathrm{~kg}$ consecutively. Weight cycling was not associated with significant changes in sleeping metabolic rate, but with decreases in exercise-induced $(-15.0 \%, \mathrm{P}<0.001)$ and isoprenaline-induced $(-24 \%, \mathrm{P}<0.05)$ thermogenic responses. The decreased exercise-induced thermogenic response was associated with declines in responses of norepinephrine $(P<0.005)$, heart rate $(P<0.05)$ and glycerol $(\mathrm{P}<0.001)$. The decreased isoprenaline-induced thermogenesis was accompanied by blunted norepinephrine and heart rate responses $(P<0.05)$. The quantity of weight cycling was significantly related to the magnitude of changes in sympathetically mediated thermogenic responses during the study.

The results of the present study demonstrate that a pattern of repeated weight loss and regain over two years in obese women is associated with decreased thermogenic, heart rate and lipolytic responses during increased activity of the sympathetic nervous system. These adverse effects of weight cycling on energy metabolism stress the importance of maintenance of a reduced body weight after successful weight loss on the long-term.
\end{abstract}




\section{Introduction}

The high prevalence of overweight and obesity in affluent societies (11) is associated with a high preoccupation with dieting. Nevertheless, there are indications that the prevalence of overweight is still increasing in industrialized countries (11). This implicates serious adverse health consequences and makes prevention and treatment of obesity recommendable. However, because of high recidivism rates after weight loss. a pattern of weight cycling frequently occurs. Accurate information on prevalence and magnitude of weight fluctuations is currently unavailable. Estimates indicate that $40 \%$ of American women and $25 \%$ of men are dieting at any time (31).

In 1986, Brownell et al (3) suggested that weight cycling may lead to increased metabolic efficiency in rodents, making subsequent weight loss more difficult and promoting regain. Since then, much attention has been focussed on possible physiological hazards of weight cycling. Numerous studies have examined effects of weight cycling on metabolism and body composition, some supporting the hypothesis that weight cycling reduces energy expenditure $(15,26)$ and increases total $(23)$ or central adiposity $(14,21,23)$. However, several recent reviews on animal and human research $(17,22,32)$ show that the majority of available data does not support adverse effects of weight cycling on energy metabolism, body composition and fat distribution. Much of inconsistencies about effects of weight cycling can be traced to several confounding factors and limitations of study designs, including paradigms for producing weight cycling, choice of control groups, and effects of gender and age (17). Furthermore, in the majority of studies in humans, effects of self-reported weight cycling histories were investigated retrospectively. Further prospective research in humans should elucidate a possible causal link between weight cycling and negative effects on metabolism and health. The present study was intended to prospectively investigate whether weight cycling is associated with detrimental effects on body composition and energy metabolism under resting and stimulated conditions, with special interest for the sympathetic nervous system that has been demonstrated to play an important role in the regulation of energy metabolism $(1,12)$.

\section{Methods}

\section{Subjects}

The study population was a subsample $(n=22$, age $37.4 \pm 1.9 \mathrm{yr}$, mean \pm SE) of 57 obese women who where recruited by advertisements in local newspapers and participated in an 8-week dietary intervention trial to achieve weight loss. One year later, 42 of the 57 subjects were willing to participate a second energy restriction period. Of those 42 subjects, 26 had regained $\geq 70 \%$ of the weight loss one year after the first dietary intervention. Those 26 subjects were matched on the basis of their body mass index (BMI) and fat percentage, and randomly assigned to a second dietary treatment and an 1-year follow-up alone $(n=13)$ or second diet and follow-up in combination with an 1-year exercise program $(n=13)$. Effects of additional exercise intervention 
during the second year of the study will be described elsewhere. Altogether, 29 subjects started the second dietary treatment and 1-yr follow-up without exercise intervention. Seven subjects dropped out during the second year of the study ( 3 because of pregnancy, 1 due to moving, 2 because of illness, and 1 for personal reasons).

The obese women recruited for the weight loss program were selected when they were premenopausal (between 19 and $53 \mathrm{yr}$ ) and had a BMI between 28 and $40 \mathrm{~kg} / \mathrm{m}^{2}$. All subjects had an apparently good health according to a medical examination. Our aim was to select women without a self-reported history of repeated dieting and who had never lost more than $3 \mathrm{~kg}$. However, the latter selection criterion turned out to be unrealistic, and therefore women reporting the fewest previous weight cycles were selected. The subjects $(n=22)$ reported dieting an average of $2.3 \pm 0.3$ times (range 1 to 4 times) and lost, in total, an average of $21.2 \pm 3.2 \mathrm{~kg}$ (range 4 to $40 \mathrm{~kg}$ ) before joining our study. None of them took any medication known to affect the variables measured, and none of them reported to have been on an energy-restricted diet in the 6 months prior to the study. Before treatment, all subjects gave written informed consent to participate in the study, which was approved by the Ethics Committee of the University of Limburg. Table 6.1 includes the baseline characteristics of the present subsample of 22 subjects which did not differ significantly from the remaining group of subjects and the subjects who dropped out.

\section{General procedures}

The study lasted 120 weeks and consisted of a controlled dietary weight loss intervention ( 8 weeks, diet 1 ), a non-controlled follow-up (on average 52 , ranging from 49 to 56 weeks, follow-up 1), a second dietary weight loss intervention ( 8 weeks, diet 2) and a second non-controlled follow-up period (on average 52, ranging from 49 to 56 weeks, follow-up 2). Measurements of body composition, fat distribution, sleeping metabolic rate (SMR), exercise-induced and isoprenaline-induced thermogenesis were done before the start of the study (week 0 ), at the end of diet 1 (week 8 ), at the end of follow-up 1 (week 60; before diet 2), at the end of diet 2 (week 68), and at the end of follow-up 2 (week 120). Maximal aerobic capacity was measured at week $0,60,68$ and 120 .

\section{Diet}

During both 8 -week dietary treatment interventions, subjects were prescribed to the same very low-calorie diet. The first 4 weeks of the diet consisted of a low-energy formula diet (Modifast, Sandoz, Bern, Switzerland) containing $2.0 \mathrm{MJ} /$ day. It provided $50 \mathrm{~g}$ carbohydrates, $52 \mathrm{~g}$ protein, $7 \mathrm{~g}$ fat per day, and a micronutrient content which meets the Dutch recommended daily allowance. During the second 4 weeks of the energy restriction period, a mixed diet of $3.5 \mathrm{MJ} /$ day was prescribed. This diet contained $1.4 \mathrm{MJ} /$ day of the formula diet and was, based on provided reference guides with information on energy content of food, supplemented to $3.5 \mathrm{MJ} /$ day by a free choice of foodstuffs. During the two diet periods, subjects were instructed to keep a record of food intake and they weekly came to the laboratory to have their body weight 
measured and food records checked. No directives regarding diet or physical activity were given for both follow-up periods.

\section{Measurements}

Maximal aerobic capacity: For determination of each subject's maximal oxygen uptake $\left(\mathrm{VO}_{2 \max }\right)$ and maximal aerobic power output $\left(\mathrm{W}_{\mathrm{mix}}\right)$, a progressive continuous cycling test on an ergometer (Lode, Groningen, the Netherlands) was performed (9), at least 3 and at most 7 days prior to the other measurements. During the test, ventilatory and gas exchange responses were measured continuously, using a computerized opencircuit system (Oxycon Beta, Mijnhardt, Bunnik, the Netherlands). Criteria for maximal exercise were forced ventilation, leveling off of oxygen uptake or a respiratory exchange ratio (RER) exceeding 1.1. The highest oxygen uptake achieved for at least $30 \mathrm{~s}$ was taken as $\mathrm{VO}_{2 \max }$.

Energy expenditure: SMR was measured during an overnight stay (1900-0700) in a respiration chamber as described before (9). Briefly, SMR and RER were calculated from $\mathrm{O}_{2}$ consumption and $\mathrm{CO}_{2}$ production (30) during the sleeping period between 0300 and 0600 , whereas non-sleeping physical activity was checked by a Doppler radar system. After the overnight fast in the respiration chamber, exercise-induced thermogenesis was determined using a submaximal exercise test. Between 0800 and 0830 , a cannula was inserted in an antecubital vein for blood sampling. Measurements were started at least $30 \mathrm{~min}$ after insertion of the catheter. The exercise protocol consisted of 45-min exercise on a cycle ergometer at a workload of $45 \%$ of the pre-determined $\mathrm{W}_{\text {mixx }}$. The exercise was preceded by a 30 -min resting period (baseline measurement) and followed by a recovery period $(60 \mathrm{~min})$ with the person in supine position. Respiratory exchange measurements were done continuously during baseline and recovery periods, by means of a computerized open-circuit ventilated hood system [Human Biology, University of Limburg, Maastricht, the Netherlands; paramagnetic $\mathrm{O}_{2}$-analyzer (Servomex, Crowborough, UK), infrared $\mathrm{CO}_{2}$-analyzer (Hartmann \& Braun, Frankfurt, Germany) and dry-gas meter (Schlumberger, Dordrecht, the Netherlands)]. During exercise, ventilation and gas exchange were measured periodically for in total $20 \mathrm{~min}(0-5,15-20,30-35$ and 40-45 min) using a computerized open system (Oxycon Beta, Mijnhardt, Bunnik, the Netherlands). Energy expenditure (EE) was calculated according to Weir (30). An electrocardiogram was monitored continuously during the experiment. Venous blood samples were collected during baseline $(t=-30$ and $0 \mathrm{~min})$, exercise $(t=5,15,30$ and $45 \mathrm{~min}$ after starting exercise), and recovery periods ( $t=60,75$ and $105 \mathrm{~min}$ after starting exercise) for determinations of hematocrit, and concentrations of glucose, frec fatty acids, glycerol, norepinephrine, and epinephrine.

Two days after the exercise test, isoprenaline-induced thermogenesis was determined after a 12 -h fast (overnight). During the experiment, the room temperature was kept between $23-25{ }^{\circ} \mathrm{C}$. Between 0800 and 0830 , a catheter was inserted in an antecubital vein and after at least $30 \mathrm{~min}$ the experiment was started. After a 30-min baseline measurement period, a continuous infusion of isoprenaline was started in stepwise increasing doses of $6,12,23$ and $46 \mathrm{ng} / \mathrm{kg}_{\text {fat-free mass }}$ min, each dose for $30 \mathrm{~min}$. The dose in the text is related to isoprenaline sulphate, $69 \%$ of which corresponds to isoprenaline 
free base. During the experiment, heart rate (HR) was recorded continuously. When HR had risen 30 beats/min or more, the infusion was stopped. During the whole experiment, EE and RER were determined continuously by an open-circuit ventilated hood system (Human Biology, University of Limburg, Maastricht, the Netherlands). Values of EE were calculated according to Weir (30). At the end of the baseline and each infusion period, venous blood samples were taken for determinations of norepinephrine, epinephrine, glucose, free fatty acids, and glycerol.

The computerized open-circuit systems used for assessments of EE and RER were carefully calibrated before and at timed intervals during each test. Measured RER values during exercise-induced and isoprenaline-induced EE were used to calculate carbohydrate and fat oxidation rates, assuming that the RER value reflected the nonprotein respiratory quotient (18). The precision of the gas analyzers and the calibration procedures was periodically checked during the whole study period by methanol (Merck 64271, Darmstadt, Germany) combustion tests. The duration of these combustion tests was on average $2 \mathrm{~h}$, ranging from 1 to $4 \mathrm{~h}$. The respiratory quotient of in total 40 methanol combustion tests was found to be $0.676 \pm 0.001$ (range 0.650 to 0.690 ) with a coefficient of variation of $1.2 \%$. Oxygen was on average overestimated by $1.1 \pm 0.3 \%$ (range -4.6 to $4.1 \%$ ) and carbondioxide by $1.3 \pm 0.3 \%$ (range -2.7 to $4.6 \%$ ).

Body composition and fat distribution: Body weight was measured on a digital balance accurate to $0.1 \mathrm{~kg}$ (Sauter D-7470, Ebingen, Germany). Height was measured to the nearest $0.1 \mathrm{~cm}$ using a wall-mounted stadiometer (Seca, model 220, Hamburg, Germany). BMI was calculated from weight and height $\left(\mathrm{kg} / \mathrm{m}^{2}\right)$. Fat distribution was evaluated by measuring the waist-hip ratio (WHR) and sagittal diameter. Waist circumference was measured as the smallest circumference between the rib cage and the iliac crest, with the subject in standing position and breathing quietly. The hip circumference was measured at the level of the widest circumference between the waist and the thighs. WHR was calculated as waist circumference divided by hip circumference. For measurement of the sagittal diameter, the distance between abdomen and back was measured by means of a stadiometer with a subject in supine position.

Body composition was measured by means of isotope dilution and densitometry. Percentage of body fat was calculated from body density and total body water (TBW) according to Siri (25). Deuterium dilution was used to measure TBW. Before going to bed during the stay in the respiration chamber a ${ }^{2} \mathrm{H}_{2} \mathrm{O}$ dilution was drunk after emptying the bladder (baseline urine sample). The dosage calculation was based on body weight in order to create a ${ }^{2} \mathrm{H}$ excess of $100 \mathrm{ppm}$. A second urine sample was collected in the morning of the next day from the second voiding (0800-1000). Deuterium was measured in urine samples with an isotope ratio mass spectrometer (VG-Isogas Aqua Sira, Middlewhich, Cheshire, UK). TBW was calculated as the measured deuterium dilution space divided by 1.04 (24). At the same morning, whole body density was determined by densitometry with the subject still in the fasted state. Underwater weight was measured to the nearest $0.1 \mathrm{~kg}$ (Sauter D-7470, Ebingen, Germany). Residual lung volume was measured by helium-dilution with a spirometer (Volugraph 2000, Mijnhardt, Bunnik, the Netherlands) at the moment of underwater weighing. Measurements were done in triplicate and the average was used to calculate body density. 


\section{Biochemical analysis}

Glucose was measured in plasma of heparinized blood by a hexokinase method (Cobas Bio, Roche Diagnostics, Hoffmann-La Roche, Basel, Switzerland). A microcapillary system was used for determination of hematocrit. Plasma anticoagulated with EDTA was prepared for enzymatic free fatty acids analysis (Cobas Fara, Wako, NEFA-C, Wako Chemicals, Neuss, Germany) and glycerol (Cobas Bio, Boehringer, Mannheim, Germany). Concentrations of plasma norepinephrine and epinephrine sampled with heparin and put into glutathione containing tubes on ice, were determined by means of highperformance liquid chromatography (6).

\section{Statistical analysis}

Data in the text, tables and figures are given as means \pm SE. For each dose of isoprenaline infused, EE and HR responses reached a steady state after $10 \mathrm{~min}$. Therefore, mean values of the last 20 min were taken as being representative for that dose. The RER reached a steady state after $20 \mathrm{~min}$ infusion as described before (1) and therefore, the mean of the last $10 \mathrm{~min}$ of infusion was taken as representative. $\beta$ Adrenergic sensitivity was defined as the dose of isoprenaline necessary to increase resting $\mathrm{EE}$ by $15 \%$ (dose $\triangle \mathrm{EE}=15 \%$ ). The sensitivity for $\mathrm{HR}$ responses was defined as the dose of isoprenaline necessary to increase resting $\mathrm{HR}$ by 25 beats/min $\left(\mathrm{CD}_{25}\right)$. Total exercise-induced (area under curve, $\mathrm{AUC}_{\mathrm{EX}}$ ) and isoprenaline-induced $\left(\mathrm{AUC}_{\mathrm{ISO}}\right)$ response curves were calculated as the total integrated changes over baseline values. Statistical analysis was performed with repeated measurement analysis of variance (ANOVA), post hoc tested with Student paired t-tests corrected according to Bonferroni's inequalities. For determining effects of weight cycling values of week 0 , 60 , and 120 were included in the statistical analysis since data of week 8 and 68 reflect the combined effects of weight reduction and hypocaloric state. Analysis of covariance, with fat-free mass as the covariate, was used to adjust for differences in body composition when comparing EE values.

A weight cycling index $\left(W C_{\text {index }}\right)$ was constructed, independently on body weight, to quantify the magnitude of weight cycling during the study. The $\mathrm{WC}_{\text {index }}$ was defined as [(regain $1 /$ weight loss 1$)+($ regain $2 /$ weight loss 2)]. The relationships between on the one hand changes in measured exercise-induced adrenergic and thermogenic responses and isoprenaline-induced thermogenesis as dependent variables and on the other hand $\mathrm{WC}_{\text {index }}$ and changes in body composition as independent variables, were evaluated by means of partial regression analysis. $\mathrm{P}<0.05$ was regarded as statistically significant. 


\section{Results}

Body composition, fat distribution, and sleeping metabolic rate

Figure 6.1 shows individual and mean values of body weight during the study. It revealed that the subjects underwent two weight cycles during the study. Substantial weight was lost during both energy-restricted diets, although weight loss 2 was significantly smaller than weight loss 1 (Table $6.1,6.3 \pm 0.6 \mathrm{~kg}$ vs $10.7 \pm 0.4$, respectively, $\mathrm{P}<0.001)$ also when expressed as percentage of body weight $(\mathrm{P}<0.001)$. Regain 1 and 2 were $6.0 \pm 1.2$ and $6.2 \pm 0.9 \mathrm{~kg}$ respectively (Table 6.1. NS). Consequently, mean value of body weight was significantly lower at week 120 compared to week $O(81.1 \pm 2.4$ vs $85.9 \pm 1.8 \mathrm{~kg}$ respectively, $\mathrm{P}=0.001)$. The calculated $W_{\text {index }}$ ranged from -0.52 to 2.67 with a mean of $1.60 \pm 0.18$.

Table 6.1 shows the results of body composition, fat distribution, and SMR. Body fat percentage, fat mass, fat-free mass, sagittal diameter, SMR, and sleeping RER decreased in response to the two diets. At the end of both follow-up periods, fat-free mass, SMR, SMR per $\mathrm{kg}$ fat-free mass, and sleeping RER were no longer statistically significant different from values at week 0 . Analysis of covariance revealed that the regression lines of SMR and fat-free mass (20) were not significantly different at week 0 and 120 .

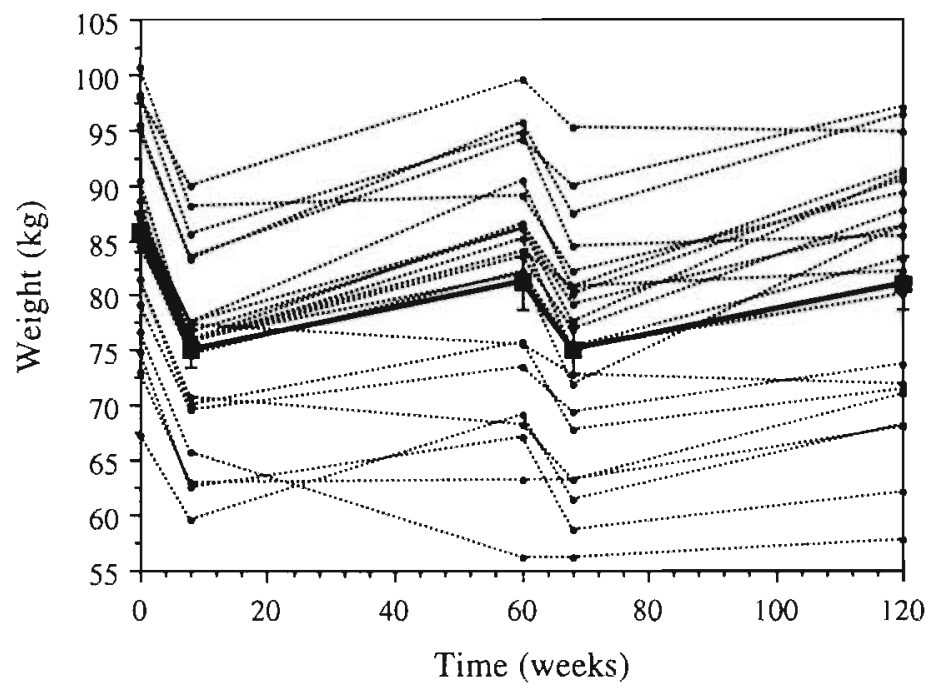

Figure 6.1 Individual and mean ( \pm SE) values of body weight of 22 obese women during the study. 
Table 6.I Results of body composition, fat distribution and sleeping metabolic rate of 22 obese females during two weight cycles.

\begin{tabular}{|c|c|c|c|c|c|c|}
\hline Variable & week 0 & week 8 & week 60 & week 68 & week 120 & $\begin{array}{l}\text { ANOVA** } \\
0,60,120\end{array}$ \\
\hline Body weight, kg & $85.9 \pm 1.8$ & $75.2 \pm 1.7^{*}$ & $81.2 \pm 2.4$ & $75.0 \pm 2.2^{*}$ & $81.1 \pm 2.4$ & $P<0.001$ \\
\hline Body fat, $\%$ & $42.0 \pm 0.9$ & $36.6 \pm 1.0 t$ & $39.2 \pm 1.3$ & $36.1 \pm 1.3^{*}$ & $39.2 \pm 1.2$ & $P<0.005$ \\
\hline fat mass, $\mathrm{kg}$ & $36.3 \pm 1.3$ & $27.8 \pm 1.3^{*}$ & $32.4 \pm 1.9^{*}$ & $27.5 \pm 1.7^{*}$ & $32.3 \pm 1.8$ & $\mathrm{P}<0.005$ \\
\hline fat-free mass, $\mathrm{kg}$ & $49.7 \pm 0.9$ & $47.7 \pm 0.8^{*}$ & $48.9 \pm 1.0$ & $47.5 \pm 0.9 *$ & $48.8 \pm 0.9$ & $P=0.12$ \\
\hline Waist-hip ratio & $0.83 \pm 0.01$ & $0.81 \pm 0.01$ & $0.83 \pm 0.01$ & $0.82 \pm 0.01$ & $0.83 \pm 0.01$ & $P=0.86$ \\
\hline Sagittal diameter, $\mathrm{cm}$ & $22.1 \pm 0.5$ & $18.8 \pm 0.5^{*}$ & $21.0 \pm 0.7$ & $18.2 \pm 0.5^{*}$ & $20.7 \pm 0.7$ & $P<0.005$ \\
\hline $\mathrm{SMR}, \mathrm{kJ} / \mathrm{min}$ & $4.63 \pm 0.09$ & $4.18 \pm 0.08^{*}$ & $4.66 \pm 0.09$ & $4.19 \pm 0.07^{*}$ & $4.55 \pm 0.10$ & $\mathrm{P}=0.48$ \\
\hline $\mathrm{SMR} / \mathrm{kg}_{\mathrm{IFM}} \cdot \mathrm{kJ} / \mathrm{h} \cdot \mathrm{kg}^{-1}$ & $5.63+0.09$ & $5.26 \pm 0.06 \ddagger$ & $5.70 \pm 0.13$ & $5.24 \pm 0.08 \S$ & $5.51 \pm 0.15$ & $P=0.40$ \\
\hline Sleeping RFR & $0.81 \pm 0.01$ & $0.78 \pm 0.019$ & $0.81 \pm 0.01$ & $0.78 \pm 0.01^{\ldots}$ & $0.82 \pm 0.01$ & $P=0.31$ \\
\hline
\end{tabular}

Values are means \pm SE. Statistical significance was determined by an analysis of variance for repeated measurements (ANOVA), post-hoc tested by Student paired t-tests (corrected for Bonferonni's inequalities). Values of week $0,8,60,68$ and $I 20$ are included in the analysis to demonstrate diet effects. $* \mathrm{P}<0.05$ for the comparison with week 0,60 and $120, \dagger \mathrm{P}<0.05$ for the comparison with week 0 , $\ddagger \mathrm{P}<0.05$ for the comparison with week 0 and $60, \$ \mathrm{P}<0.01$ for the comparison with week $60, \mathbb{P}<0.05$ for the comparison with week 60 and 120 .

**To analyze weight cycling effects, only values of week 0,60 and 120 are included in the analysis of variance. SMR. sleeping metabolic rate;

FFM, fat-free mass; RER, respiratory exchange ratio. 
Respiratory gas exchange and heart rate: Weight cycling was associated with decreases in $\mathrm{VO}_{2 \max }$ (week 0,60 and $120,2.21 \pm 0.59,2.06 \pm 0.72$ and $1.94 \pm 0.64$ $1 / \mathrm{min}$, respectively, ANOVA, $\mathrm{P}<0.001$; week 0 vs $60, \mathrm{P}<0.05$; week 0 vs $120, \mathrm{P}<$ 0.005 and week 60 vs $120, P<0.01$ ), also when expressed per kilogram fat-free mass (ANOVA, $\mathrm{P}<0.0001$ ). In addition, $\mathrm{HR}$ at maximal exercise declined significantly during the study (week 0,60 and $120,175 \pm 3,170 \pm 3$ and $165 \pm 3$ beats $/ \mathrm{min}$, respectively, ANOVA, $\mathrm{P}<0.001$; week 0 vs $120, \mathrm{P}<0.005$ and week 60 vs $120, \mathrm{P}<0.05$ ), whereas $W_{\max }$ and the RER value at maximal performance did not significantly change during the study (week 0,60 and $120,163 \pm 7,161 \pm 6$ and $157 \pm 6$ Watt, ANOVA, P $=0.38$ and $1.13 \pm 0.02,1.11 \pm 0.03$ and $1.11 \pm 0.02$, ANOVA, $P=0.50$, respectively).

At week 0,60 and 120 , baseline values of $\mathrm{EE}$ and $\mathrm{HR}$ before the moderate exercise test $\left(45 \% \mathrm{~W}_{\max }\right)$ did not differ significantly (Table 6.2). Exercise induced significant increases in EE, HR, and RER (ANOVA, $\mathrm{P}<0.001$ ). Total exercise-induced thermogenesis $\left(\mathrm{AUC}_{\mathrm{EX}}\right)$ and response of HR significantly decreased during the study (Figure 6.2). Analysis of covariance revealed that a significant smaller $y$-intercept of the regression line of exercise-induced thermogenesis and fat-free mass (20) was observed at the end of the study compared to week $0(\mathrm{P}<0.01)$. In addition, it appeared that the contribution of fat oxidation to total exercise-induced EE tended to decline during the study (Figure 6.2).

Table 6.2 Baseline values before an exercise test ( $45 \mathrm{~min} .45 \% \mathrm{~W}_{\max }$ ) of several mitabolic parameters of 22 obese women during two cycles of weight loss and regain.

\begin{tabular}{lcccc}
\hline Variable & week 0 & week 60 & week $/ 20$ & ANOVA \\
\hline EE/kgFFM, $\mathrm{kJ} / \mathrm{h} \cdot \mathrm{kg}^{-1}$ & $6.02 \pm 0.11$ & $5.93 \pm 0.11$ & $5.89 \pm 0.14$ & $\mathrm{P}=0.33$ \\
Respiratory exchange ratio & $0.84 \pm 0.01$ & $0.84 \pm 0.01$ & $0.83 \pm 0.01$ & $\mathrm{P}=0.38$ \\
Heart rate, beats/min & $69 \pm 2$ & $69 \pm 2$ & $67 \pm 2$ & $\mathrm{P}=0.27$ \\
Norepinephrine, $\mathrm{pg} / \mathrm{ml}$ & $226 \pm 17$ & $206 \pm 22$ & $180 \pm 21$ & $\mathrm{P}=0.26$ \\
Epinephrine, $\mathrm{pg} / \mathrm{ml}$ & $74 \pm 15$ & $79 \pm 17$ & $69 \pm 13$ & $\mathrm{P}=0.82$ \\
Hematocrit, \% & $39 \pm 1$ & $39 \pm 1$ & $39 \pm 1$ & $\mathrm{P}=0.45$ \\
Free fatty acids, $\mu \mathrm{mol} / \mathrm{l}$ & $458 \pm 28$ & $404 \pm 23$ & $449 \pm 24$ & $\mathrm{P}=0.28$ \\
Glycerol, $\mu \mathrm{mol} / \mathrm{I}$ & $57.7 \pm 7.4$ & $44.1 \pm 6.9$ & $36.8 \pm 6.5$ & $\mathrm{P}=0.29$ \\
Glucose, mmol/l & $4.84 \pm 0.06$ & $5.06 \pm 0.10$ & $4.89 \pm 0.08$ & $\mathrm{P}=0.45$
\end{tabular}

Values are means \pm SE. Statistical significance was determined by an analysis of variance for repeated measurements. EE, energy expenditure; FFM, fat-free mass. 

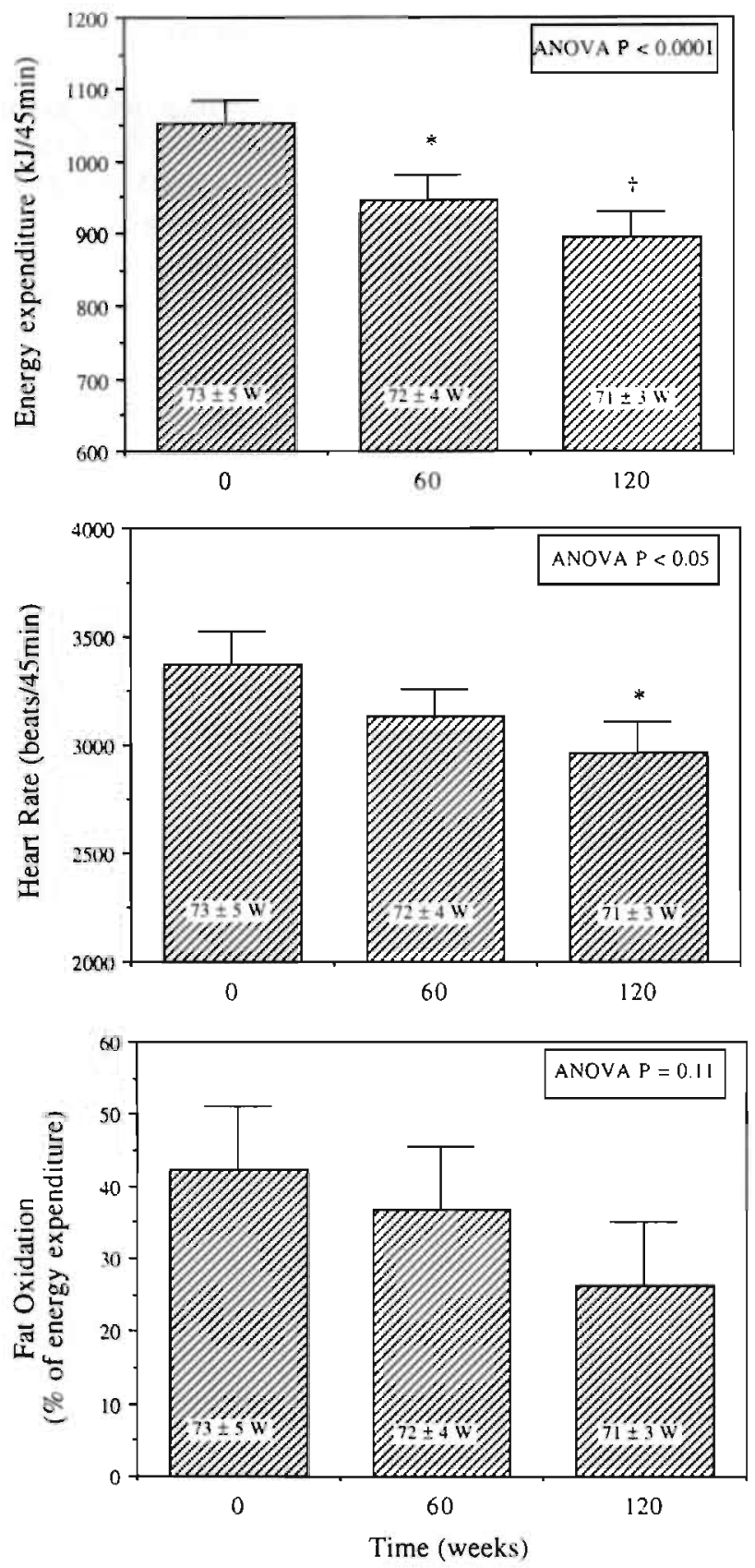

Figure 6.2 Exercise-induced responses ( $45 \mathrm{~min}, 45 \% \mathrm{~W}_{\max }$ ) of energy expenditure, heart rate and fat oxidation during the study. Values are means $\pm \mathrm{SE}(n=22)$. Statistical significance was determined by in analysis of variance for repeated measurements (ANOVA), posthoc tested with Student paired t-tests (corrected for Bonferonni's inequalitics). $* P<$ 0.05 and $\dagger \mathrm{P}<0.005$ for the comparison with week 0 . 
Plasma norepinephrine, epinephrine, free fatty acids, glycerol, glucose, hematocrit: No significant differences were observed in baseline levels of measured venous variables at week 0,60 , and 120 (Table 6.2). Exercise resulted in significant increases of norepinephrine, epinephrine, and hematocrit (ANOVA, $\mathrm{P}<0.005$ ). Exercise-induced increases in hematocrit values measured at week 0,60 , and 120 did not differ significantly from each other. Total exercise-induced responses of norepinephrine significantly declined during the study, whereas the decrease of epinephrine did not reach significance (Figure 6.3).Venous concentrations of free fatty acids and glycerol were significantly increased as a result of exercise, whereas levels of glucose declined (ANOVA, $\mathrm{P}<0.005$ ). Total exercise-induced responses of glycerol significantly decreased during the study, whereas the change in total response of free fatty acids did not reach significance (Figure 6.3). Total exercise-induced response of glucose did not change significantly.
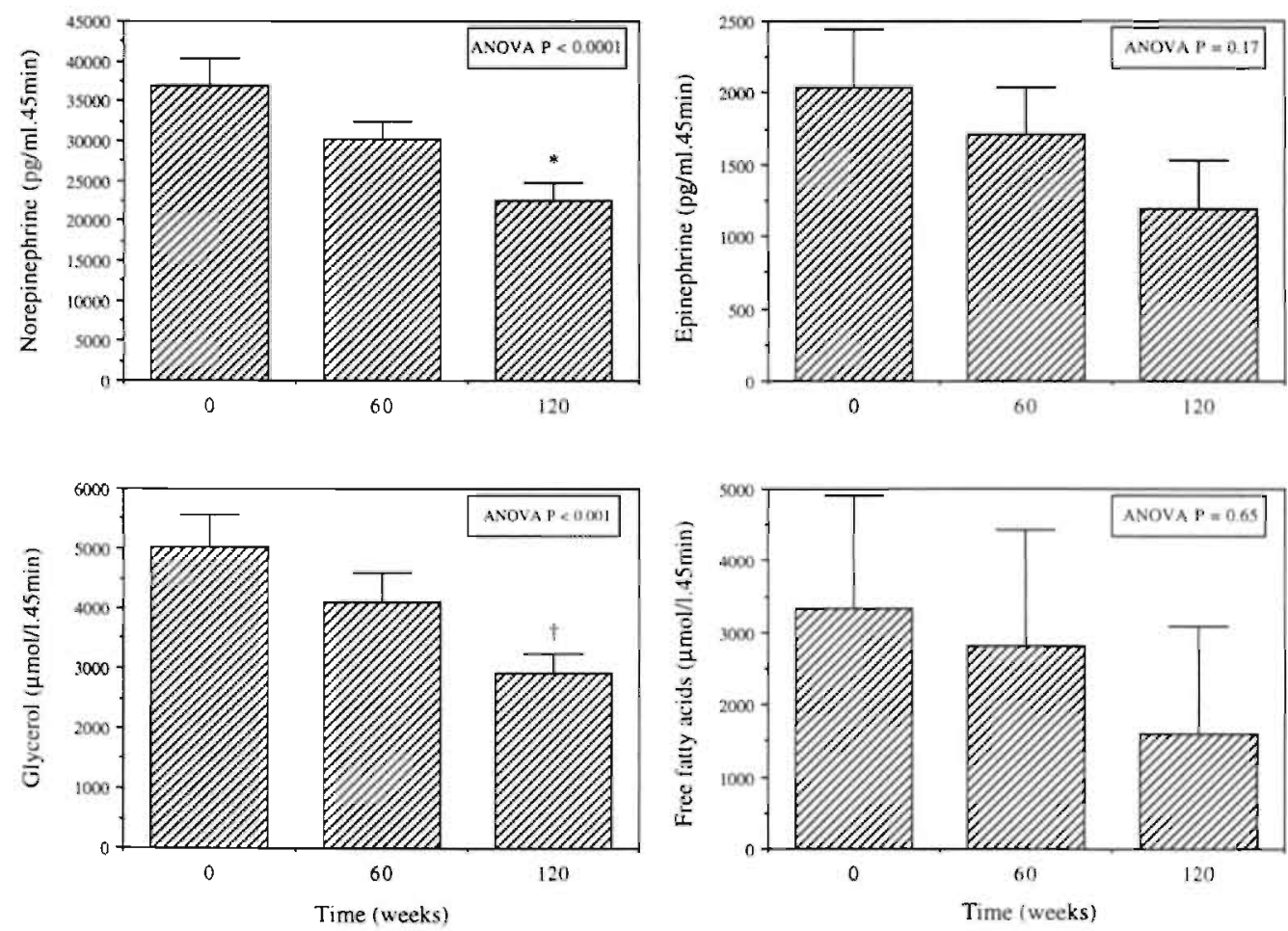

Figure 6.3 Exercise-induced responses (45 $\mathrm{min}, 45 \% \mathrm{~W}_{\mathrm{max}}$ ) of venous norepinephrine, epinephrine. glycerol, and free fatty acid concentrations during the study. Values are means $\pm \mathrm{SE}(n=22)$. Statistical significance was determined by an analysis of variance for repeated measurements (ANOVA), post-hoc tested with Student paired t-tests (corrected for Bonferonni's inequalities). "P $\mathrm{P}<0.005$ for the comparison with week 0 and 60 , and $\uparrow P<0.005$ for the comparison with week 0 . 


\section{Chapter 6}

\section{Isoprenaline-induced thermogenesis}

Data on the highest infusion rate of isoprenaline $\left(46 \mathrm{ng} / \mathrm{kg}_{\text {fat-free mass }}\right)$ are not presented because these infusions were not started in most subjects due to our criteria for stopping the infusion (see methods). Therefore, all total isoprenaline-induced responses were integrated over 90-min, including the infusion of 6,12 and $23 \mathrm{ng} / \mathrm{kg}_{\text {fat-free mass }}$. During the isoprenaline infusions, all subjects had dose-related increases in EE, HR, plasma norepinephrine, free fatty acids and glycerol (ANOVA, $\mathrm{P}<0.001$ ). The total over 90-min integrated increases in resting $\mathrm{EE}$ and $\mathrm{HR}$ as result of isoprenaline infusion significantly decreased during the study (Figure 6.4), whereas values of $\triangle \mathrm{EE}=15 \%$ and $\mathrm{CD}_{25}$ significantly increased (week 0,60 , and 120 , for $\triangle \mathrm{EE}=15 \%$ : $15.5 \pm 2.1,20.8 \pm 2.2$ and $21.3 \pm 2.5 \mathrm{ng} / \mathrm{kg}_{\text {fat-free mass }} \cdot \min$, respectively, ANOVA, $\mathrm{P}<0.05$, and for $\mathrm{CD}_{25}: 25.6 \pm$ $2.9,30.9 \pm 2.3$ and $34.5 \pm 4.7 \mathrm{ng} / \mathrm{kg}_{\text {fat-free mass }} \cdot \mathrm{min}$, respectively, ANOVA, $\mathrm{P}<0.05$ ). Analysis of covariance demonstrated that the $y$-intercept of the regression line of isoprenaline-induced thermogenesis and fat-free mass (20) significantly decreased during the study (week 0 vs $120, \mathrm{P}<0.05$ ).

No significant differences were observed in the responses of RER, free fatty acids, glycerol, and glucose to isoprenaline infusion measured at week 0,60 , and 120 . However, total integrated isoprenaline-induced response of norepinephrine significantly declined during the study, whereas that of epinephrine tended to decrease (Figure 6.4). Data on relative substrate utilization rates demonstrated no significant changes in isoprenaline-induced amounts of carbohydrates and fat oxidized during the study.

\section{Partial regression analysis}

Table 6.3 demonstrates partial correlations between $W_{\text {index }}$, (adjusted for changes in fat mass and fat-free mass) and changes in exercise-induced thermogenic and norepinephrine responses, isoprenaline-induced thermogenesis, and $\beta$-adrenergic sensitivity ( $\Delta$ week $0-120$ ). This adjusted $\mathrm{WC}_{\text {index }}$ showed significant positive correlations with the changes in exercise-induced norepinephrine response and isoprenaline-induced thermogenic response and a negative correlation with $\beta$-adrenergic sensitivity. The $W C_{\text {index }}$ (adjusted for $\Delta$ fat mass and $\Delta$ fat-free mass) tended to be positively related to the change in exercise-induced thermogenesis.

Table 6.3 Partial correlation coefficients between weight cycling index adjusted for changes in fat mass and fat-free mass $\left(W C_{i n d e x}\right.$ ) and changes in metabolic variables ( $\triangle$ week $0-120$ ).

$$
\triangle \mathrm{EE}\left(\mathrm{AUC}_{\mathrm{EX}}\right) \quad \triangle \mathrm{NE}\left(\mathrm{AUC}_{\mathrm{EX}}\right) \quad \triangle \mathrm{EE}\left(\mathrm{AUC}_{\mathrm{ISO}}\right) \quad \triangle \mathrm{EE}=15 \%
$$

\begin{tabular}{lllll}
\hline$W_{\text {index }}$ & $0.39^{*}$ & $0.68 \dagger$ & $0.70 \dagger$ & $-0.83 \dagger$
\end{tabular}

" $\mathrm{P}<0.1 . \dagger \mathrm{P}<0.01 . \triangle \mathrm{EE}\left(\mathrm{AUC} \mathrm{C}_{\mathrm{EX}}\right)$, total exercise-induced response of energy expenditure: $\triangle N E\left(A U C_{E X}\right)$. total exercise-induced response of norepinephrine: $\triangle E E\left(A U C_{I S O}\right)$, total isoprenalineinduced response of energy expenditure: $\triangle \mathrm{EE}=15 \%$, dose of isoprenaline necessary 10 increase resting energy expenditure by $15 \%$ ( $\beta$-adrenergic sensitivity). 

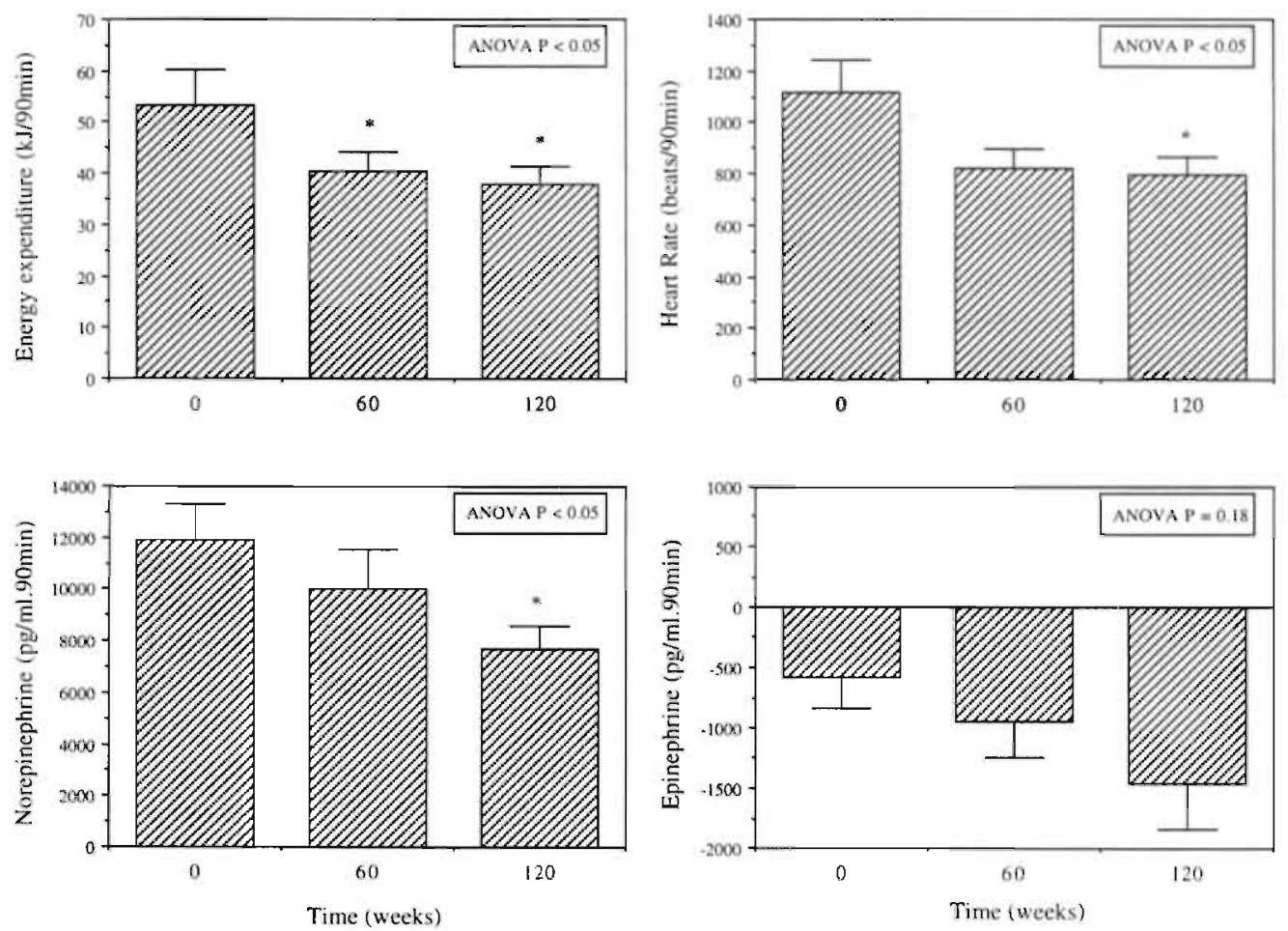

Figure 6.4 Total (over $90 \mathrm{~min}$ integrated) isoprenaline-induced responses of energy expenditure, heart rate, and catecholamines during the study. Values are means $\pm \operatorname{SE}(n=22)$. Statistical significance was determined by an analysis of variance for repeated measurements (ANOVA), post-hoc tested with Student paired t-tests (corrected for Bonferonni's inequalities). ${ }^{*} \mathrm{P}<0.05$ for the comparison with week 0 .

\section{Discussion}

Recent research indicates that development of a reduced level of energy expenditure may be one of the factors contributing to possible adverse effects of weight cycling (15, 26). To our knowledge, this is the first study that prospectively investigated metabolic effects of weight cycling, with rather large magnitudes of weight loss and regain, in obese women over a time period of two years to mimic the real life situation.

The results demonstrate that this pattern of weight cycling is associated with decreased exercise-induced and isoprenaline-induced thermogenic responses of $-15 \%$ and $-24 \%$ respectively. The data indicate an overall blunted adrenergic response to stimulation with weight cycling, as became apparent from decreased catecholamine responses ($35 \%$ ) and reduced sympathetically mediated thermogenic, lipolytic, and heart rate responses. Significant partial correlation coefficients were found between $\mathrm{WC}_{\text {index }}$ (adjusted for $\Delta$ fat mass and $\Delta$ fat-free mass) and changes in metabolic responses (Table 6.3). This indicates that the quantity of weight cycling is related to the magnitude of changes in sympathetically mediated thermogenic responses during the study. 
Several intervening factors may have biased the results of the present study. These factors include possible changes in dietary and/or physical activity pattern during the study. It has been suggested that weight cycling increases preference for and intake of fat (21). However, no differences in resting RER values were observed at week 0,60 , and 120 indicating no major differences in oxidation of fatty acids reflecting fat intake (28). In addition, the fatty acid composition of plasma lipids was determined in a representative sample of nine subjects, showing no differences at week 0,60 , and 120 (linoleic acid, as percentage: $33.7 \pm 1.5,33.9 \pm 1.3$ and $32.5 \pm 1.6 \%$ of total fatty acids, ANOVA, $\mathrm{P}=0.57$, and as concentration in plasma: $217 \pm 12,223 \pm 15$ and $225 \pm 14$ $\mu \mathrm{g} / \mathrm{ml}$, ANOVA, $\mathrm{P}=0.54$, for week 0,60 , and 120 respectively, unpublished results). This suggests that there were no major differences in amount and composition of fat intake, as the fatty acid composition of plasma lipids reflects the dietary intake of fatty acids (7). Furthermore, a lower level of physical activity could be a confounding factor in the present study. However, no decrease in activity level was found between week 60 and 120 in a representative sample of nine subjects (non-resting energy expenditure as measured by doubly labeled water method $5.18 \pm 0.39$ and $5.08 \pm 0.29$ $\mathrm{MJ} /$ day for week 60 and 120 respectively, $\mathrm{P}=0.12$, unpublished results).

Therefore, the present study demonstrates strong metabolic consequences of weight cycling in obese females. The results indicate that weight cycling is associated with diminished endogenous sympathetic nervous system activity and decreased $\beta$ adrenergic sensitivity to catecholamines. This may have serious consequences for weight and body composition on the longer term, since it has been shown that human obesity is associated with decreased activity of the autonomic nervous system (19). Although not indicated by the results of the present 2-year study, it remains unanswered whether body weight regulation adversely adapts to weight cycling on a longer term.

Other prospective studies in humans could not demonstrate adverse metabolic effects of weight cycling $(8,10,16)$. In addition, several recent reviews conclude that the majority of available data do not support detrimental effects of weight cycling on energy metabolism $(17,22,32)$. However, none of these studies determined energy metabolism under stimulated conditions. Also in the present study no detrimental effects of weight cycling on energy expenditure could be detected under resting conditions. The present data show that weight cycling is associated with blunting of metabolic responses during increased activity of the sympathetic nervous system. One previous retrospective study of Manore et al (15) determined energy expenditure during exercise in cyclical dieting nonobese women and weight stable controls. In this study, increased metabolic efficiency was suggested in weight cycling women compared to controls. However, these conclusions were based on standardization of exercise metabolic rates per unit of total body weight, whereas a difference disappeared when expressed per unit fat-free mass or as absolute value.

That weight loss and regain may have an impact on energy metabolism was recently shown in a study of Leibel et al (13). In this study, it was demonstrated that weight loss resulted in decreased total, nonresting and resting energy expenditure levels when adjusted for metabolic mass after weight stabilization. The study of Leibel et al (13) did neither examine the permanence of these changes in energy expenditure nor whether energy expenditure normalized when body weight was regained after weight loss. The 
results of our study demonstrated for the first time a persistently decreased sympathetically mediated thermogenesis after weight cycling in obese females, that appeared to be independent of changes in body composition.

The blunted sympathetically mediated thermogenic response demonstrated in the present study may contribute to an explanation why weight loss was significantly less during the second dietary treatment compared to the first. Lower weight loss with repeated dieting has been shown previously in out- and inpatient samples (2) and in a short-term prospective study (8). A decrease in compliance during the second diet period compared to the first cannot be excluded in a semi-controlled design such as used in the present study. Nevertheless, our data may help to explain why several studies demonstrated that a history of previous dieting and current dieting behavior predict body weight changes over time and are associated with increased body weight and fatness $(5,29)$. Diminished stimulation of endogenous sympathetic nervous system activity and reduced $\beta$-adrenergic sensitivity to catecholamines result in decreased thermogenesis, fat mobilization and oxidation. Consequently, a positive fat balance will be favored, that has been shown to be an important etiological factor in the development and maintenance of obesity (4).

Despite the fact that the subjects had previous weight changes before the start of the study, weight cycling over two years had strong blunting metabolic effects. Baseline values or metabolic changes over the two-year period of the present study did not correlate significantly with previous history of weight cycling, indicating that retrospective analysis may be not suitable for determining weight cycling effects. The data of the present study indicates ongoing metabolic effects of weight cycling. At present it is not known whether metabolic changes with weight cycling are permanent or temporary. It remains also to be established whether detrimental thermogenic effects of weight cycling occur when weight changes are of smaller magnitudes than the changes of $7-15 \mathrm{~kg}$ in the present study.

In summary, the present study demonstrates that weight cycling may have adverse effects on non-resting energy expenditure and substrate utilization in obese women. Under resting conditions no persistent effects of weight cycling on energy metabolism could be detected. Two weight cycles over two years resulted in lower exercise-induced and isoprenaline-induced responses of energy expenditure. Because the decline in thermogenesis appeared to be in the order of 15-20\%, effects of weight cycling on weight, body composition and/or fat distribution may be expected on the long-term although not indicated during the present 2-year study period. It remains therefore to be established whether adverse metabolic effects of weight cycling have consequences for the regulation of body weight on the longer term. Further research should also elucidate whether adverse metabolic effects of weight cycling override potential benefits of moderate weight loss in the obese. Treatment of obesity might remain preferable, since being obese is evidently associated with increased risks on morbidity and mortality.

The results of the present study stress the importance of maintenance of a reduced body weight after successful weight loss. Inclusion of interventions that beneficially manipulate the responsiveness of the sympathetic nervous system may be recommended for treatment of obesity, in order to prevent weight cycling. So far, regular moderate exercise appears to be the only physiological stimulator of importance in manipulating 
this system. Exercise has been shown to increase sensitivity to adrenergic stimulation and fat oxidation (27). Therefore, regular moderate exercise may play a role of importance to prevent adverse metabolic effects of weight cycling and to make maintenance of weight loss easier.

\section{References}

1. Blaak EE, van Baak MA, Kester ADM, Saris WHM. $\beta$-Adrenergically mediated thermogenic and heart rate responses: effect of obesity and weight loss. Metabolism 44: 520-524, 1995.

2. Blackburn GL, Wilson GT, Kanders BS. Stein LJ, Lavin PT, Adler J, Brownell KD. Weight cycling: the experience of human dieters. Am J Clin Nutr 49: 1105-1109, 1989.

3. Brownell KD, Greenwood MRC, Stellar E, Shrager EE. The effects of repeated cycles of weight loss and regain in rats. Physiol Behav 38: 459-464, 1986.

4. Flatt JP. Dietary, fat, carbohydrate balance, and weight maintenance: effects of exercise. Am $J$ Clin Nutr 45: 296-306, 1987.

5. French SA, Jeffery RW, Forster JL, McGovern PG, Kelder SH, Baxter JE. Predictors of weight change over two years among a population of working adults: the Healthy Worker Project. Int $J$ Obes 18: 145-154, 1994.

6. Hjemdahl P. Plasma catecholamines; analytical challenges and physiological limitations. Baillière's Clin Endocrinol Metab 7: 307-353, 1993.

7. Houwelingen van AC, Kester ADM, Kromhout D, Hornstra G. Comparison between the habitual intake of polyunsaturated fatty acids and their concentrations in serum lipid fractions. Eur J Clin Nutr 43: 11-20, 1989.

8. Jebb SA, Goldberg GR, Coward WA, Murgatroyd PR, Prentice AM. Effects of weight cycling caused by intermittent dieting on metabolic rate and body composition in obese women. Int $J$ Obes 15: 367-374, 1991.

9. Kempen KPG, Saris WHM, Senden JMG, Menheere PPCA, Blaak EE, van Baak MA. Effects of energy restriction on acute adrenoceptor and metabolic responses to exercise in obese subjects. Am J Physiol 267: E694-E701, 1994.

10. Kooy van der K, Leenen R, Seidell JC, Deurenberg P. Hautvast JGAJ. Effect of a weight cycle on visceral fat accumulation. Am J Clin Nutr 58: 853-857, 1993.

11. Kuczmarski RJ, Flegal KM, Campbell SM, Johnson CL. Increasing prevalence of overweight among US adults. The National Health and Nutrition Examination Surveys, 1960 to 1991. JAMA 272: 205-211, 1994.

12. Landsberg L. Saville ME, Young JB. Sympathoadrenal system and regulation of thermogenesis. Am J Physiol 247: E181-189, 1984.

13. Leibel RL, Rosenbaum M. Hirsch J. Changes in energy expenditure resulting from altered body weight. $N$ Engl J Med 332: 621-628, 1995.

14. Lissner L. Andres R, Muller DC, Shimokata H. Body weight variability in men: metabolic rate, health and longevity. Int J Obes 14: 373-383, 1990.

15. Manore MM, Berry TE, Skinner JS, Caroll SS. Energy expenditure at rest and during exercise in nonobese female cyclical dieters and in nondieting control subjects. $4 \mathrm{~m} J$ Clin Nurr 54: 41-46. 1991.

16. Melby CL. Schmidt WD, Corrigan D. Resting metabolic rate in weight-cycling collegiate wrestlers compared with physically active, noncycling control subjects. Am J Clin Nurr 52: 409-414, 1990.

17. National Task Force on the Prevention and Treatment of Obesity. Weight cycling. JAMA 272: 1196-1202, 1994.

18. Péronnet F. Massicotte D. Table of non-protein respiratory quotient: an update. Can J Spt Sci 16: 23-29. 1991.

19. Peterson HR, Rothschild M, Weinberg CR, Fell RD, McLeish KR, Pfeifer MA. Body fat and the activity of the autonomic nervous system. $N$ Engl $J$ Med 318: 1077-1083, 1988. 
20. Ravussin E, Bogardus C. Relationship of genetics, and physical fitness to daily energy expenditure and fuel utilization. Am J Clin Nutr 49: 968-975, 1989.

21. Reed DR, Contreras RJ, Maggio C. Greenwood MRC, Rodin J. Weight cycling in female rats increases dietary fat selection and adiposity. Physiol Behav 42: 389-395, 1988.

22. Reed GW, Hill JO. Weight cycling: a review of the animal literature. Obes Res 1: 392-402, 1993.

23. Rodin J, Radke-Sharpe N, Rebuffé-Scrive M, Greenwood MRC. Weight cycling and fat distribution. Int J Obes 14: 303-310, 1990.

24. Schoeller DA, Jones PJH. Measurement of total body water by isotopic dilution: a unified approach to calibrations. In Ellis KJ, Yasumura S, Morgan WD (eds). In vivo body composition studies. London, Institute of Physical Sciences in Medicine pp 131-136, 1987.

25. Siri WE. Body composition from fluid spaces and density: analysis of methods. $\boldsymbol{I n}$ Brozek $\boldsymbol{J}$, Henschel A (eds). Techniques for measuring body composition. Washington DC, National Academy of Sciences pp 223-244, 1961.

26. Steen SN, Oppliger RA, Brownell KD. Metabolic effects of repeated weight loss and regain in adolescent wrestlers. JAMA 260: 47-50, 1988.

27. Tremblay A, Coveney S, Després J-P, Nadeau A, Prud'homme D. Increased resting metabolic rate and lipid oxidation in exercise-trained individuals: evidence for a role of $\beta$-adrenergic stimulation. Can J Physiol Pharmacol 70: 1342-1347, 1992.

28. Verboeket-van de Venne WPHG, Westerterp KR, ten Hoor F. Substrate utilization in man: effects of dietary fat and carbohydrate. Merabolism 43: 152-156, 1994.

29. Wadden TA, Bartlett S, Letizia KA, Foster GD, Stunkard AJ, Conill A. Relationship of dieting history to resting metabolic rate, body composition, eating behavior, and subsequent weight loss. Am J Clin Nutr 56: 203S-208S, 1992.

30. Weir JB de V. New methods for calculating metabolic rate with special reference to protein metabolism. J Physiol 109: 1-9, 1949.

31. Williamson DF, Serdula MK, Anda RF, Levy A, Byers T. Weight loss attempts in adults: goals, duration and rate of weight loss. Am J Public Health 82: 1251-1257, 1992.

32. Wing RR. Weight cycling in humans: a review of the literature. Ann Behav Med 14: 113-119, 1992. 


\section{Introduction}

Serious health concerns of weight cycling effects arose from several large epidemiological studies $(2,12,21,23)$. Although there are inconsistencies across studies, the majority of these observational studies indicate that weight fluctuations may be associated with adverse effects on cardiovascular-and all-cause mortality $(27,38)$.

The mechanisms by which weight cycling might affect mortality in humans remain unexplained, but may implicate modification of cardiovascular risk factors such as serum lipids and lipoproteins. Several studies in humans could however not demonstrate effects of weight cycling on serum lipid profile. No evidence was found that a retrospectively determined history of weight cycling affected serum triglycerides. total-, low-density lipoprotein (LDL)- and/or high-density lipoprotein (HDL)-cholesterol (14, 24, 30). Furthermore, results of the Baltimore Longitudinal Study of Aging demonstrated that body weight variability was not significantly associated with adverse changes of serum triglycerides, total-, LDL- and HDL-cholesterol (21-23).

Data on associations of weight cycling and cardiovascular risk factors and mortality have come from epidemiological studies that unfortunately were not originally designed to address this issue $(1,27,38)$. The purpose of the present study was to prospectively investigate effects of weight cycling on serum lipid and lipoprotein profiles in obese women. In addition, it was examined whether regular moderate exercise modifies serum lipid and lipoprotein profile in weight cycling obese women.

\section{Methods}

\section{Subjects}

The present study was part of a larger project on effects of weight cycling on energy metabolism in obesity $(17,18)$. The study population was a subsample $(n=26)$ of 57 obese females who where recruited by advertisements in local newspapers. Those 57 subjects participated in an 8-week dietary intervention trial to achieve weight loss. The present subsample was selected on the basis of their regain one year after the weight loss period (regain $>70 \%$ of their previous weight loss) and willingness to participate in a second 8-week energy restriction period. The subsample of 26 subjects was matched on the basis of body mass index (BMI) and body fat percentage (\%FM) and randomly assigned to second diet treatment and 1-year follow-up alone (D-WC) or second diet and 1-year follow-up combined with moderate exercise (DEx-WC). Three subjects of DEx-WC group did not complete the study (2 due to pregnancy, and 1 because of poor compliance). There were no differences in baseline characteristics between subjects of D-WC and DEx-WC (Table 7.1).

At recruitement for the weight loss program, the obese females were premenopausal and hald a BMI between 28 and $40 \mathrm{~kg} / \mathrm{m}^{2}$. They were in apparently good health according to a medical cxamination. Our aim was to select women without a self-reported history of repeated diet periods and who never lost $>3 \mathrm{~kg}$. However, the latter selection criterium of almost no weight cycling history appeared to be unrealistic, and therefore 
women reporting the least previous weight cycles were selected. The subjects $(n=23)$ reported dieting an average of $2.7 \pm 0.3$ times (range 1 to 5 times) and had previously lost, in total, an average of $24.3 \pm 3.4 \mathrm{~kg}$ (range 4 to $53 \mathrm{~kg}$ ) before joining our study. There were no differences in dieting history between the two groups. None of the subjects received any medication known to affect the variables measured. They had a stable body weight and had not been on an energy-restricted diet in the 6 months prior to the study. Before treatment all subjects gave written informed consent to participate in the study, that was approved by the Ethics Committee of the University of Limburg.

Table 7.1 Baseline characteristics of weight cycling (D-WC, $n=13$ ) and exercising weight cycling (D-ExWC, $n=10$ ) obese women.

\begin{tabular}{lll}
\hline & D-WC & DEx-WC \\
\hline Age, yr & $38.5 \pm 2.5$ & $38.7 \pm 1.6$ \\
Body weight, $\mathrm{kg}$ & $88.2 \pm 2.2$ & $89.2 \pm 3.5$ \\
Body mass index, $\mathrm{kg} / \mathrm{m}^{2}$ & $32.2 \pm 0.8$ & $32.3 \pm 1.1$ \\
Body fat, \% & $42.3 \pm 1.1$ & $41.2 \pm 1.8$ \\
Fat mass, $\mathrm{kg}$ & $37.4 \pm 1.7$ & $37.3 \pm 2.8$ \\
Fat free mass, $\mathrm{kg}$ & $50.7 \pm 1.0$ & $52.5 \pm 1.5$ \\
Waist-hip ratio & $0.83 \pm 0.01$ & $0.82 \pm 0.02$ \\
Sagittal diameter, $\mathrm{cm}$ & $22.8 \pm 0.7$ & $21.0 \pm 0.6$ \\
\hline
\end{tabular}

Values are means $\pm \mathrm{SE}$.

\section{Procedures}

The total study duration was 120 weeks, consisting of an 8-week very-low calorie diet (VLCD) treatment to achieve weight loss and a 52-week non-controlled follow-up (weight cycle 1), a second 8-week VLCD and 52-week non-controlled follow-up (weight cycle 2). Subjects of DEx-WC participated in a controlled regular moderate exercise program during weight cycle 2 . Measurements of body composition. fitt distribution, lipid and lipoprotein profile were performed before the start of the study (week 0 ), at the end of diet 1 (week 8), at the end of follow-up 1 (week 60: before diet 2 ), at the end of diet 2 (week 68), and at the end of follow-up 2 (week 120). Determinations of maximal aerobic capacity occurred at week $0,60,68$ and 120 . Effects of dietary weight loss on serum lipids and apolipoproteins during the first VLCD treatment period have been described elsewhere (26).

Diet

During both 8-week dietary treatment interventions, subjects were prescribed the same VLCD. The first 4 weeks of the diet consisted of a low-energy formula diet (Modifast, Sandoz, Bern, Switzerland) containing $2.0 \mathrm{MJ} /$ day. It daily provided $50 \mathrm{~g}$ carbohydrates, $52 \mathrm{~g}$ protein, $7 \mathrm{~g}$ fat, and a micronutrient content which meets the Dutch recommended 
daily allowance. In the second part of the energy restriction period, a mixed diet of 3.5 $\mathrm{MJ} /$ day was prescribed. This diet contained $1.4 \mathrm{MJ} /$ day of the formula diet and was, based on provided reference guides with information on energy content of food, supplemented to $3.5 \mathrm{MJ} /$ day by a free choice of foodstuffs. During the two diet periods, subjects were instructed to keep a record of food intake. They weekly came to the laboratory during diet periods to have their body weight measured and food records checked. For D-WC subjects, no directives regarding diet or physical activity were given for both follow-up periods.

\section{Exercise training}

During weight cycle 2, the subjects of the DEx-WC group participated in a training program at a sports centre. Exercise training included 2 training sessions per week, supervised by a professional trainer. These sessions lasted $90 \mathrm{~min}$ and consisted of alternatively aerobic dancing and fitness. The aerobic dance sessions were performed to music and consisted of routines that combined various dance steps with other whole body movements including knee lifts, trunk twists, jumping jacks, kicks, hops, and stationary jogging. The fitness sessions included cardiac and strength training using free weights and machine gym equipment, regularly presented as circuit weight training. The sessions started with a 15-min warming-up of cycling, stepping and/or rowing, followed by 60 min aerobic dancing or fitness, and finished with a 15-min cooling-down period of stretching. During the 8-week energy-restricted diet, the exercise training was intensified with additional individual training sessions, at least 1 or 2 times per week. During these individual sessions, the subjects trained according to a personal fitness schedule for $60 \mathrm{~min}$. The attendance of the subjects during the exercise sessions was $85 \%$ (range $77-98 \%$ ). The exercise intensities were regularly measured by means of heart-rate recordings (Sporttester, Polar Electro, Kempele, Finland). The prescribed intensity of the exercise program was $50-60 \%$ of the maximal oxygen uptake.

\section{Measurements}

Maximal aerobic capacity: For determination of each subject's maximal oxygen uptake $\left(\mathrm{Vo}_{2 \max }\right)$ and mechanical power output $\left(\mathrm{W}_{\max }\right)$, a progressive continuous cycling test on an ergometer (Lode, Groningen, the Netherlands) was performed, as previously described (16), at least 3 and at most 7 days prior to the other measurements. During the test, ventilatory and gas exchange responses were measured continuously, using a computerized open system (Oxycon Beta, Mijnhardt, Bunnik, the Netherlands). Criteria for maximal exercise were forced ventilation, leveling off of oxygen uptake or a respiratory exchange ratio (RER) exceeding 1.1. The highest oxygen uptake achieved for at least $30 \mathrm{~s}$ was taken as $\mathrm{VO}_{2 \max }$.

Body composition and fat distribution: Body weight was measured in the morning (without clothing) in the fasted state on a digital balance accurate to $0.1 \mathrm{~kg}$ (Sauter D7470 , Ebingen, Germany). Height was measured to the nearest $0.1 \mathrm{~cm}$ using a wallmounted stadiometer (model 220 Seca, Hamburg, Germany). BMI was calculated from weight and height $\left(\mathrm{kg} / \mathrm{m}^{2}\right)$. Fat distribution was evaluated by measuring the waist-hip 
ratio (WHR) and sagittal diameter. Waist circumference was measured as the smallest circumference between the rib cage and the iliac crest, with the subject in standing position and breathing quietly. The hip circumference was measured at the level of the widest circumference between the waist and the thighs. WHR was calculated as waist circumference divided by hip circumference. For measurement of the sagittal diameter, the distance between abdomen and back was measured by means of a stadiometer with the subject in supine position.

Body composition was measured by means of two different techniques: isotope dilution and densitometry. The percentage of body fat (\%FM) was calculated from body density and total body water (TBW) according to the 3 compartment model of Siri (35). Deuterium dilution technique was used to measure total body water. Before going to bed at night a ${ }^{2} \mathrm{H}_{2} \mathrm{O}$ dilution was drunk after emptying the bladder (baseline urine sample). The dosage calculation was based on body mass in order to create a ${ }^{2} \mathrm{H}$ excess of $100 \mathrm{ppm}$. A second urine sample was collected in the morning of the next day from the second voiding (0800-1000). Deuterium was measured in urine samples with an isotope ratio mass spectrometer (VG-Isogas Aqua Sira, Middlewhich, Cheshire, UK). TBW was calculated as the measured deuterium dilution space divided by 1.04 (32). On the same morning, whole body density was determined by densitometry with the subject still in the fasted state. Underwater weight was measured to the nearest $0.1 \mathrm{~kg}$ (Sauter D-7470, Ebingen, Germany). Residual lung volume was measured by Helium-dilution with a spirometer (Volugraph 2000, Mijnhardt, Bunnik, the Netherlands) at the moment of underwater weighing. Measurements were done in triplicate and the average was used to calculate body density.

Serum lipids and apolipoproteins: Blood samples were taken after an overnight 12-h fast for determination of serum total cholesterol, triglycerides, HDL- and LDLcholesterol, apolipoproteins A-I and B, and lipoprotein(a) as described previously (26). In order to collect information on the habitual intake of fatty acids, blood samples of representative subsets of $5 \mathrm{D}-\mathrm{WC}$ and $4 \mathrm{DEx}$-WC subjects were additionally used for measurement of the fatty acid composition of serum total lipids, as described before (13).

\section{Statistical analysis}

Data in the text, tables and figures are given as means \pm SE. The skewed distribution of lipoprotein(a) values was normalized by logarithmic conversion. Within both groups, statistical analysis was performed with repeated measurement analysis of variance (ANOVA), post hoc tested with Student paired t-tests. When appropriate, the $\mathrm{P}$ values were corrected according to Bonferroni's inequalities. To determine the effects of weight cycling only, values of week 0,60 , and 120 were included in the statistical analysis since data of week 8 and 68 reflect the combined effects of weight reduction and hypocaloric state. Differences between the groups were tested with a one-way analysis of variance. $\mathrm{P}<0.05$ was regarded as statistically significant. 


\section{Results}

Mean values of body weight during the study of D-WC and DEx-WC subjects are shown in Figure 7.1. Both groups underwent two complete cycles of weight loss and regain during the study, with no significant differences in weight at week $0,8,60$, 68 , and 120 between the two groups. Mean amounts of weight loss and regain during weight cycle 1 and 2 were $-10.3 \pm 0.5,+9.6 \pm 0.4,-7.1 \pm 0.6$ and $+6.8 \pm 1.2 \mathrm{~kg}$ respectively for $\mathrm{D}-\mathrm{WC}$, whereas these values were $-10.6 \pm 1.4,+11.1 \pm 1.7,-9.5 \pm 1.5$ and $+5.1 \pm 1.7 \mathrm{~kg}$ for the DEx-WC group. Table 7.2 shows data on body composition and fat distribution at week 0,60 , and 120. At the end of both follow-up periods, data on body composition and fat distribution were not statistically different from that of week 0 , although \%FM tended to be persistently decreased at the end of the study for DExWC subjects. At week 120, \%FM tended to be declined for DEx-WC subjects compared to subjects of the $\mathrm{D}-\mathrm{WC}$ group $(\mathrm{P}=0.08)$.

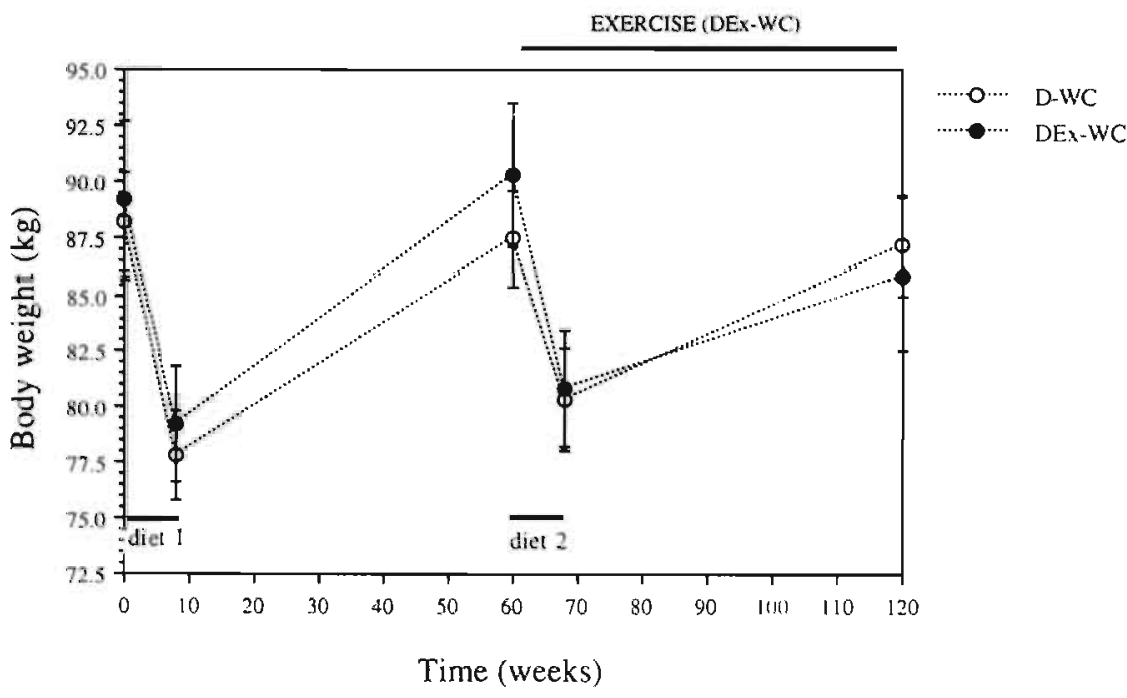

Figure 7.1 Mean values ( \pm SE) of body weight of weight cycling (D-WC, $n=13$ ) and exercising weight cycling (DEx-WC, $n=10$ ) obese women during the study with repeatedly an 8week energy-restricted diet period and subsequent 1-year follow-up.

Participation in the exercise program positively influenced maximal oxygen uptake, since a further decrease of $\mathrm{VO}_{2 \max }$ was prevented in DEx-WC but not in D-WC subjects (Figure 7.2). When $\mathrm{VO}_{2 \max }$ was expressed per $\mathrm{kg}$ body weight, the $\mathrm{D}$-WC group showed a significant decline during the study whereas for DEx-WC subjects a decline in $\mathrm{VO}_{2 \mathrm{max}} / \mathrm{kg}$ body weight during weight cycle 1 was reversed during weight cycle 2 (week 0,60 , and 120 for D-WC: $25.1 \pm 1.1,24.3 \pm 1.3$ and $21.8 \pm 1.1 \mathrm{ml} / \mathrm{min}^{\cdot} \mathrm{kg}^{-1}$, ANOVA week 120 vs 0 and $60, \mathrm{P}<0.001$ and for DEx-WC: $27.0 \pm 1.3,24.7 \pm 1.5$ and $26.9 \pm 1.3 \mathrm{ml} / \mathrm{min}^{\circ} \mathrm{kg}^{-1}$, ANOVA, week 60 vs $0, \mathrm{P}<0.01$ ). 
Tab/c 7.2 Body composition and fat distribution of weight cycling (D-WC. $n=13$ ) and exereising weight cycling (DEx-WC, $n=10$ ) obese women during the study.

\begin{tabular}{llllll}
\hline Variable & & week 0 & week 60 & week 120 & ANOVA \\
\hline Body fat, $\%$ & & & & & \\
& D-WC & $42.3 \pm 1.2$ & $41.7 \pm 1.4$ & $42.0 \pm 1.2$ & $\mathrm{P}=0.67$ \\
Fat mass, kg & DEx-WC & $41.2 \pm 1.8$ & $41.7 \pm 1.4$ & $38.1 \pm 2.2$ & $\mathrm{P}=0.07$ \\
& D-WC & $37.4 \pm 1.7$ & $36.7 \pm 2.0$ & $36.8 \pm 1.7$ & $\mathrm{P}=0.70$ \\
Fat-free mass, kg & DEx-WC & $37.3 \pm 2.8$ & $37.0 \pm 2.3$ & $33.3 \pm 3.0$ & $\mathrm{P}=0.09$ \\
& D-WC & $50.7 \pm 1.0$ & $50.8 \pm 1.0$ & $50.4 \pm 1.0$ & $\mathrm{P}=0.72$ \\
Waist-hip ratio & DEx-WC & $52.5 \pm 1.5$ & $53.3 \pm 1.6$ & $52.6 \pm 1.2$ & $\mathrm{P}=0.31$ \\
& D-WC & $0.83 \pm 0.01$ & $0.84 \pm 0.02$ & $0.83 \pm 0.01$ & $\mathrm{P}=0.43$ \\
Sagittal diameter, cm & DEx-WC & $0.82 \pm 0.02$ & $0.81 \pm 0.02$ & $0.81 \pm 0.01$ & $\mathrm{P}=0.96$ \\
& D-WC & $22.8 \pm 0.7$ & $22.3 \pm 0.9$ & $22.3 \pm 0.8$ & $\mathrm{P}=0.62$ \\
& DEx-WC & $21.0 \pm 0.6$ & $21.1 \pm 0.7$ & $19.9 \pm 0.6$ & $\mathrm{P}=0.17$
\end{tabular}

Values are means \pm SE. Statistical significance was determined by an ANOVA for repeated measurements, post-hoc tested by Student paired t-tests (corrected for Bonferonni's inequalities). To demonstrate weight cycling effects only, values at week 0,6 , and 120 are included in the analysis.

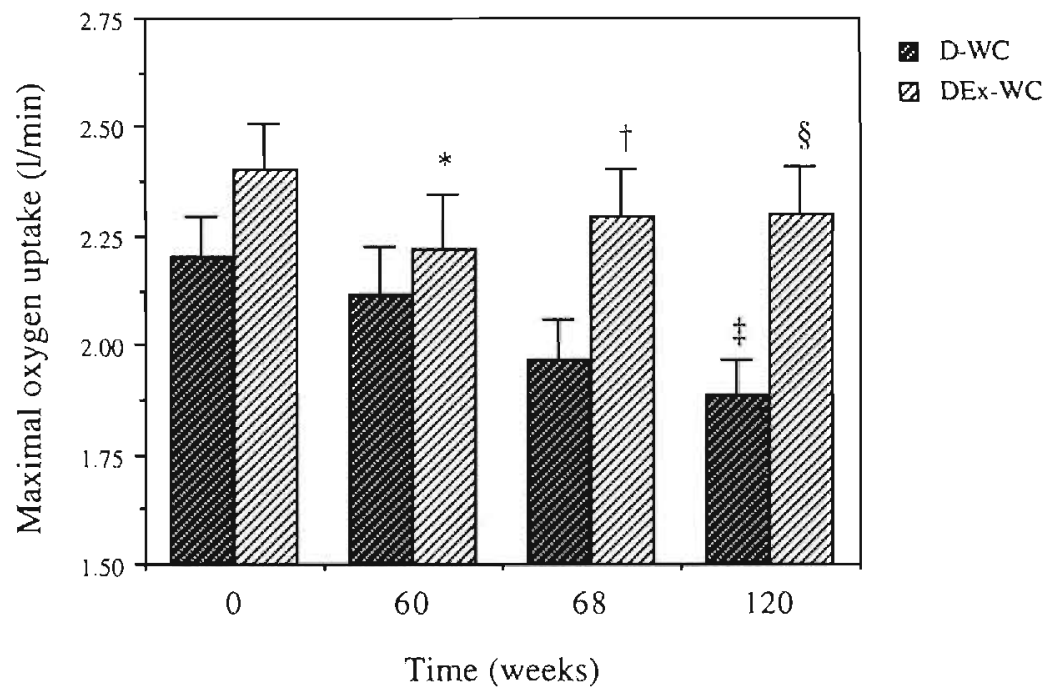

Figure 7.2 Maximal aerobic capacity $\left(\mathrm{VO}_{2 \max }\right.$ ) of weight cycling (D-WC, $n=13$ ) and exercising weight cycling (DEx-WC, $n=10$ ) obese women during the study. Values are means \pm SE. Statistical significance was determined by ANOVA for repeated measurements, post-hoc tested with Student paired t-tests (Bonferroni's inequalities). Differences between groups were tested with an one-way ANOVA. ${ }^{*} \mathrm{P}<0.05$ for the comparison with week $0, \dagger P<0.05$ for the comparison with $\mathrm{D}$-WC, $\ddagger \mathrm{P}<0.01$ for the comparison with week $0, \S \mathrm{P}<0.01$ for the comparison with $\mathrm{D}-\mathrm{WC}$. 


\section{Chapter 7}

Values of serum lipids at week 0,60 , and 120 are shown in Figure 7.3. For both groups, values of serum total and LDL-cholesterol persistently decreased during the study, whereas no changes in serum triglycerides were observed. Values of HDLcholesterol significantly increased in subjects of the D-WC group, but not in the DExWC subjects $(P=0.083)$. Results of serum apolipoproteins and lipoprotein(a) are shown in Figure 7.4. For both groups, it appeared that apolipoprotein A-I and In lipoprotein(a) values did not significantly change during the study, while apolipoprotein $B$ values decreased significantly during the study. The fatty acid composition of serum total lipids did not statistically differ between D-WC and DEx-WC and therefore, the mean results of the two groups are listed in Table 7.3. The data demonstrate no significant differences in fatty acid composition of serum total lipids at week 0,60 , and $I 20$.
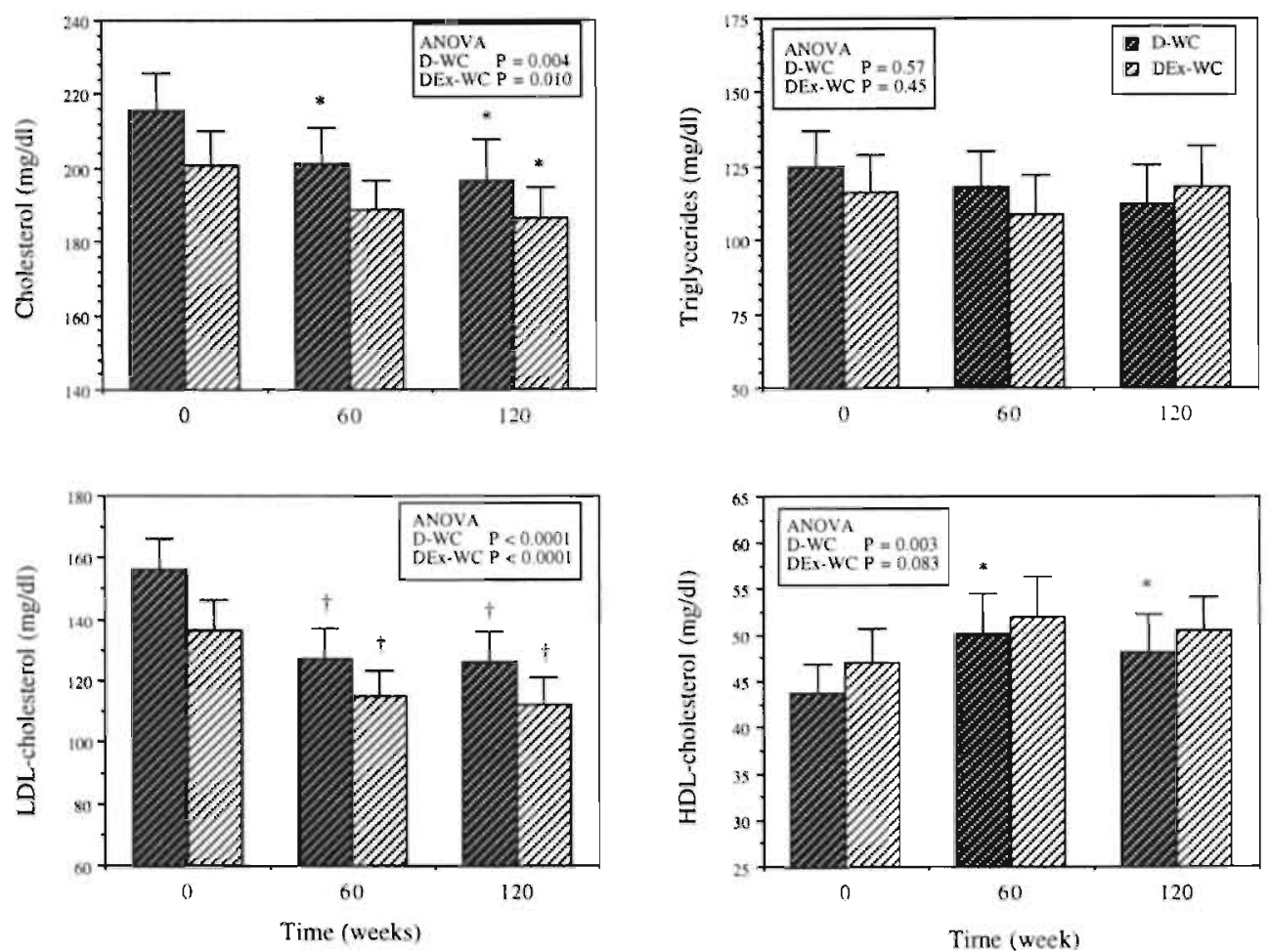

Figure 7.3 Values of triglycerides, total-. LDL- an HDL-cholesterol of weight cycling (D-WC, $n=$ 13 ) and exercising weight cycling (DEx-WC, $n=10$ ) obese women during the study. Values are means \pm SE. Statistical significance was determined by ANOVA for repeated measurements, post-hoc tested with Student paired t-tests (Bonferroni's inequalities). Differences between groups were tested with an one-way ANOVA. $* P<0.05$ for the comparison with week $0, \uparrow \mathrm{P}<0.005$ for the comparison with week 0 . 

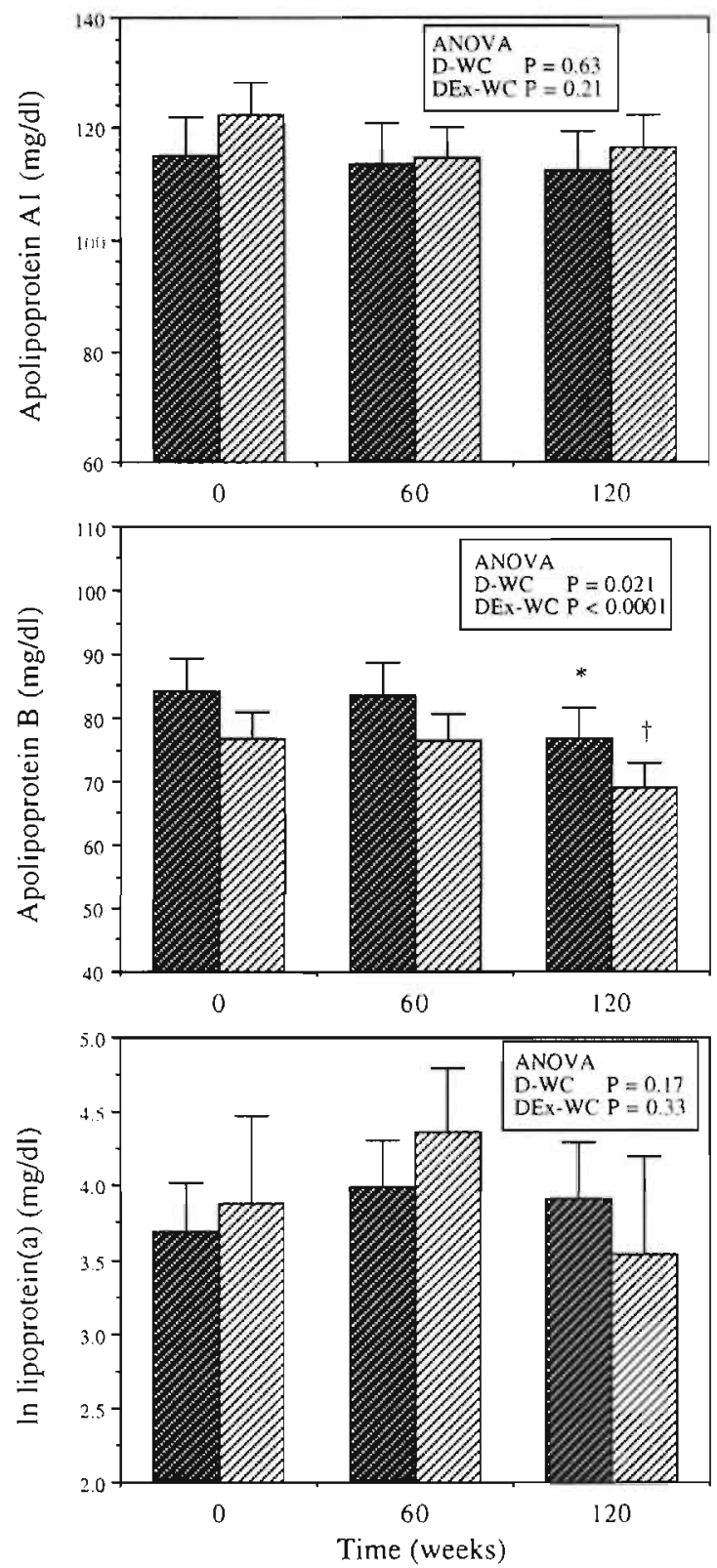

Figure 7.4 Values of apolipoproteins A-I, B, and In lipoprotein(a) of weight cycling (D-WC, $n=$ 13) and exercising weight cycling (DEx-WC, $n=10$ ) obese women during the study. Values are means \pm SE. Statistical significance was determined by ANOVA for repeated measurements, post-hoc tested with Student paired t-tests (Bonferroni's inequalities). Differences between groups were tested with an one-way ANOVA. ${ }^{*} \mathrm{P}<0.05$ for the comparison with week $0,+\mathrm{P}<0.005$ for the comparison with week $O$ and $\mathrm{P}<0.0001$ for the comparison with week 60 . 
Table 7.3 Fatty acid composition of serum lipids (\% of total fatty acids) of weight cycling women.

\begin{tabular}{lrrrl}
\hline Fatty acid & week 0 & week 60 & week 120 & ANOVA \\
\hline Total, $\mu \mathrm{g} / \mathrm{ml}$ & $653 \pm 75$ & $689 \pm 144$ & $711 \pm 97$ & $\mathrm{P}=0.34$ \\
$\sum$ SAFA & $30.3 \pm 2.5$ & $30.6 \pm 4.0$ & $31.1 \pm 3.4$ & $\mathrm{P}=0.36$ \\
$\sum(\mathrm{n}-7)+\sum(\mathrm{n}-9)$ & $23.3 \pm 8.8$ & $23.5 \pm 3.2$ & $23.6 \pm 5.9$ & $\mathrm{P}=0.59$ \\
$\sum(\mathrm{n}-6)$ & $42.2 \pm 5.2$ & $42.1 \pm 5.4$ & $41.5 \pm 5.6$ & $\mathrm{P}=0.29$ \\
$\sum(\mathrm{n}-3)$ & $3.8 \pm 1.0$ & $3.7 \pm 1.0$ & $3.6 \pm 0.9$ & $\mathrm{P}=0.24$ \\
$18: 2(\mathrm{n}-6)$ & $33.3 \pm 3.5$ & $33.0 \pm 3.7$ & $32.8 \pm 4.0$ & $\mathrm{P}=0.32$ \\
$18: 3(\mathrm{n}-3)$ & $0.6 \pm 0.1$ & $0.6 \pm 0.2$ & $0.6 \pm 0.1$ & $\mathrm{P}=0.34$ \\
$20: 4(\mathrm{n}-6)$ & $6.5 \pm 0.9$ & $6.3 \pm 1.0$ & $6.1 \pm 1.0$ & $\mathrm{P}=0.015$ \\
$20: 5(\mathrm{n}-3)$ & $0.7 \pm 0.3$ & $0.6 \pm 0.2$ & $0.6 \pm 0.2$ & $\mathrm{P}=0.091$ \\
$22: 6(\mathrm{n}-3)$ & $1.9 \pm 0.5$ & $1.7 \pm 0.4$ & $1.7 \pm 0.5$ & $\mathrm{P}=0.31$
\end{tabular}

Values are means \pm SE. Values are means of D-WC $(n=5)$ and DEx-WC $(n=4)$ since there were no significant differences between these groups. Statistical significance was determined by an ANOVA for repeated measurements, post-hoc tested by Student paired t-tests (Bonferonni's inequalities). To show weight cycling effects only, values of week 0,60 , and 120 are included in the analysis. $\Sigma$ SAFA, sum of all saturated fatty acids; $\sum(n-7)+\sum(n-9)$, sum of all fatty acids of the ( $n$ 7) and (n-9) family; $\sum(n-6)$, sum of all fatty acids of the (n-6) family; $\Sigma(n-3)$, sum of all fatty acids of the (n-3) family.

\section{Discussion}

Several epidemiological studies have demonstrated an association between fluctuation in body weight over time and cardiovascular morbidity and mortality $(2,12,21,23,27$, 38). This finding implicates a possible modulating influence of weight cycling on cardiovascular risk factors. However, the results of this study provide no support for the hypothesis that weight cycling adversely affects serum lipid and lipoprotein profile, known as strong cardiovascular risk factors (37). Instead, serum lipid and lipoprotein profile of obese women in the present study even appeared to be slightly improved after weight cycling, as indicated by decreased serum apolipoprotein $\mathrm{B}$, total- and LDLcholesterol levels.

Absence of an adverse weight cycling effect on serum lipid profile appears to be in accordance with other previously reported studies $(14,24,30)$. Two studies could not demonstrate correlations between retrospectively determined dieting history and cardiovascular risk factors such as triglycerides, total-, and HDL-cholesterol in obese subjects $(14,24)$. Furthermore. no differences in triglycerides, total-, HDL-, and LDLcholesterol were found between non-obese women with and without a weight cycling history by Rebuffé-Scrive et al (30). In addition, no associations between body weight variability and serum total-, HDL-, and LDL- cholesterol or triglyceride levels were found using data on 846 men of the Baltimore Longitudinal Study of Aging (22).

The apparent contradiction between the association of weight fluctuations with cardiovascular mortality in epidemiological studies and our failure to demonstrate deleterious effects of prospectively evaluated weight cycling on serum lipids and lipoproteins, may be partially related to some methodological limitations of observational 
studies $(1,27,38)$. Most of the reported studies did not attempt to distinguish intentional from unintentional weight loss and not all studies did adequately control for confounding factors such as other risk factors and pre-existing disease, that might influence weight. Furthermore, adverse health consequences of weight cycling have heen suggested to be more pronounced in non-obese subjects $(2,27,29)$.

It remains possible that mechanisms underlying the association between weight cycling and cardiovascular mortality involve other risk factors than lipid profile (22). However, no relationship between retrospectively determined weight cycling history and blood pressure. glucose tolerance, and fat intake could be found in other studies involving obese $(14,24)$, non-obese, mildly overweight $(30)$, and Type II diabetic patients (33). Another important factor that may contribute to the association of weight cycling and mortality is body fat distribution $(22,31)$. Increased intra-abdominal fat has been shown to be strongly associated with increased risk for cardiovascular disease and diabetes (3). Weight cycling has been suggested to be associated with fat accumulation in the abdominal region (31), although this could not be confirmed by others $(17,19,30)$. Also in the present study no persistent changes in WHR and sagittal diameter could be demonstrated after two weight cycles, indicating no major remaining changes in fat distribution. Recent research in animals suggests that weight cycling may alter the fatty acid composition of whole body stores associated with weight cycling. A selective depletion of linoleate and $\alpha$-linolenate in carcass-, liver- and adipose tissue lipids, but not of serum lipids was demonstrated with weight cycling despite adequate fatty acid provision in the diet (5). These changes result in an increased ratio of saturates and monounsaturates to $(n-3)+(n-6)$ polyunsaturates. The physiological significance of these findings on remodeling of fatty acid composition with weight cycling with regard to cardiovascular risk in humans remains to be elucidated. Previous research suggests that adipose tissue fatty acid composition might modulate markers for cardiovascular risk such as serum FFA levels and insulin resistance $(6,7,10)$.

It is well documented that dietary weight loss positively affects lipid profile $(8,11,20$, 24 ) as also has been found in the present study as described previously (26). Decreased serum triglycerides. total cholesterol, LDL-cholesterol and apolipoproteins A-I and B were found in the present study with dietary-induced weight loss (26). However, it remains rather unexpected that weight cycling was associated with a persistent improvement of the serum lipid and apolipoprotein B profile in the present study, in spite of similar body weights at baseline and after two weight cycles. Persistently decreased serum total cholesterol levels have been shown previously in obese subjects one year after VLCD-induced weight loss follow'ed by complete body weight regain (11). On the other hand, return to pre-intervention levels of serum cholesterol and LDL, but increased HDL levels, have been demonstrated 6 months after an 12-week diet or combined diet and exercise intervention in overweight women with only a slight regain of body weight during follow-up (36).

The amount and proportion of several fatty acids in various serum lipid fractions reflects the habitual fatty acid intake (13). Therefore, the fatty acid composition of serum total lipids was analyzed during the present study to evaluate whether adaptations in habitual fat intake may have contributed to the improved lipid profile. The unchanged total amount and percental contribution of the different fatty acids to serum total lipids, 
however, indicate no major differences in fat intake at week 0,60 , and 120 , excluding an influence of major adaptations in habitual dietary fat intake on the obscrved changes in lipid profile. Furthermore, changes in the level of physical activity may have been involved in the observed improvement of lipid profile with weight cycling. since increased physical activity has been demonstrated to positively influence lipid profile ( 4 , 28,34 ). It appeared, however, that both groups slightly increased their level of physical activity, with no differences between the two groups, as assessed with doubly labeled water at week 60 and 120 in representative samples of D-WC $(n=9)$ and DEx-WC $(n=7)(18)$. Physical activity, as expressed as average daily metabolic rate minus sleeping metabolic rate tended to increase for both groups during the second weight cycle (week 60 and 120 for D-WC: $5.18 \pm 0.39$ and $5.68 \pm 0.29 \mathrm{MJ} /$ day, $\mathrm{P}=0.123$ and for DEx-WC: $5.53 \pm 0.59$ and $6.04 \pm 0.37 \mathrm{MJ} /$ day, $\mathrm{P}=0.095$ ). These data indicate that probably also subjects of the D-WC increased their physical activity level during the study. This might contribute to an explanation why we were unable to find additional effects of exercise treatment on serum lipids and why both groups improved their lipid profile during the study.

The reported long-term effects of exercise on serum lipids and lipoproteins are conflicting. No differences in the changes of lipids and lipoproteins have been found during a 6-months follow-up after diet and combined diet and exercise treatment in overweight women (36), whereas beneficial effects of exercise alone have been demonstrated $(9,25,34)$. The studies showing positive effects of exercise on lipoprotein metabolism generally used exercise with higher frequency, duration and/or intensity compared to our study. Moreover, it has been suggested that excrcise- or dietaryinduced effects on serum lipids are more pronounced in men than in women $(20,39,40)$ whereas upper-body obese show greater improvements than lower-body obese (15).

In conclusion, the present study provides no evidence that repeated weight cycling negatively influences serum lipids, apolipoproteins and lipoprotein(a) in obese women and could not demonstrate additional benefits on serum lipid and lipoprotein profile of moderate exercise. Further research is needed to explore possible relationships between weight cycling, cardiovascular risk factors and morbidity or mortality from cardiovascular diseases.

\section{References}

I. Blackburn GL, Borrazzo ECL. Weight cycling (editorial). JAMA 273: 998, 1995.

2. Blait SN. Shaten J, Brownell K, Collins G, Lissner L. Body weight change, all-cause mortality, and cause-specific mortality in the Multiple Risk Factor Intervention Trial. Ann Intern Med 119: 749-757. 1993.

3. Bouchard C. Després J-P. Mauriège P. Genetic and nongenetic determinants of regional fat distribution. Endocr Rev 14: 72-93, 1993.

4. Caspersen CI, Bloemberg BPM, Saris WHM, Merritt RK, Kromhout D. The prevalence of selected physical activities and their relation with coronary heart disease risk factors in elderly men: The Zutphen Study, 1985. Am J Epidemiol 133: 1078-1092. 1991.

5. Chen Z-Y, Menard CR, Cunnane S. Moderate, selective depletion of linoleate and $\alpha$-linolenate in weight-cycled rats. Am J Physiol 268: R498-R505, 1995. 
6. Cunnane SC, Wolever TMS. Jenkins DJA. Response of individual serum free fatty acids to oral glucose: relation with adipose tissue composition. Nutrition 9: 423-429, 1993.

7. Das UN. Insulin resistance and hyperinsulinaemia: are they secondary to an alteration in the metabolism of essential fatty acids? Med Sci Res 122: 243-245, 1994.

8. Dattilo AM, Kris-Etherton PM. Effects of weight reduction on blood lipids and lipoproteins: a meta-analysis. Am J Clin Nutr 56: 320-328, 1992.

9. Després J-P, Tremblay A. Moorjani, Lupien PJ, Thériault G, Nadeau A, Bouchard C. Long-term exercise training with constant energy intake. 3: effects on plasma lipoprotein levels. Int $J$ Obes 14: 85-94, 1990.

10. Field CJ, Ryan EA, Thompson ABR, Clandinin MT. Diet fat composition alters membrane phospholipid composition, insulin binding and glucose metabolism in adipocytes from control and diabetic animals. J Biol Chem 265: 11143-11150, 1990.

11. Hainer V, Kunesová M, Stich V, Parízková P, Zák A, Stukavec V, Hrabák P. Body-fat distribution and serum lipids during the long-term follow-up of obese patients treated initially with a verylow-calorie diet. Ain J Clin Nutr 56: 283S-285S, 1992.

12. Hamm P, Shekelle RB, Stamler J. Large fluctuations in body weight during young adulthood and twenty-five-year risk of coronary death in men. Am J Epidemiol 1129: 312-318, 1989.

13. Houwelingen van AC, Kester ADM, Kromhout D, Hornstra G. Comparison between the habitual intake of polyunsaturated fatty acids and their concentrations in serum lipid fractions. Eur $J \mathrm{Clin}$ Nutr 43: 11-20, 1989.

14. Jeffery RW, Wing RR, French SA. Weight cycling and cardiovascular risk factors in obese men and women. Am J Clin Nutr 55: 641-644, 1992.

15. Kanaley JA, Andresen-Reid ML, Oenning LV, Kottke BA, Jensen MD. Differential health benefits of weight loss in upper-body and lower-body obese women. Am J Clin Nutr 57:20-26, 1993.

16. Kempen KPG, Saris WHM, Senden JMG, Menheere PPCA, Blaak EE, van Baak MA. Effects of energy restriction on acute adrenoceptor and metabolic responses to exercise in obese subjects. Am J Physiol 267: E694-E701, 1994.

17. Kempen K.PG, Blaak EE, van Baak MA, Saris WHM. Weight cycling is associated with blunting of the sympathetically mediated thermogenesis in obesity. Submitted.

18. Kempen KPG, Saris WHM. Can regular moderate exercise prevent adverse metabolic effects of weight cycling in obesity. Submitted.

19. Kooy van der K, Leenen R, Seidell JC, Deurenberg P, Hautvast JGAJ. Effect of a weight cycle on visceral fat accumulation. Am J Clin Nurr 58: 853-857, 1993.

20. Leenen R, van der Kooy K. Droop A. Seidell JC, Deurenberg P. Weststrate JA, Hautvast JGAJ. Visceral fat loss measured by magnetic resonance imaging in relation to changes in serum lipid levels of obese men and women. Arterioscler Thromb 13: 487-494, 1993.

21. Lissner L, Bengtsson C, Lapidus L, Larsson B, Bengtsson B, Brownell K. Body weight variability and mortality in the Gothenburg Prospective Studies of men and women. In Björntorp P. Rossner S (eds). Obesity in Europe 88: Proceedings of the First European Congress on Obesity. Libbey, London pp 55-60, 1989.

22. Lissner L, Andres R, Muller DC, Shimokata H. Body weight variability in men: metabolic rate, health and longevity. Int J Obes 14: 373-383, 1990.

23. Lissner L, Odell PM, D'Agostino RB, et al. Variability of body weight and health outcomes in the Framingham population. $N$ Engl J Med 324: 1839-1844, 1991.

24. Melby CL, Sylliaasen S, Rhodes T. Diet-induced weight loss and metabolic changes in obese women with high versus low prior weight loss/regain. Nutr Res 11: 971-978, 1991.

25. Motoyama M, Sunami Y, Kinoshita F, Irie T. Sasaki J, Arakawa K, Kiyonaga A, Tanaka H, Shindo $M$. The effects of long-term low intensity aerobic training and detraining on serum lipid and lipoprotein concentrations in elderly men and women. Eur J Appl Physiol 70: 126-131, 1995.

26 Muls E, Kempen K, Vansant G, Cobbaert C, Saris W. The effects of weight loss and apolipoprotein E polymorphism on serum lipids, apolipoproteins A-I and B, and lipoprotein(a). Int J Obes 17: 711-716, 1993. 
27. National Task Force on the Prevention and Treatment of Obesity. Weight cycling. JMMA 272: 1196-1202, 1994.

28. Nieman DC, Haig JL, Fairchild KS, De Guia ED, Dizon GP, Register UD. Reducing-diet and exercise-training effects on serum lipids and lipoproteins in mildly obese women. Am J Clin Nur 52: 640-645, 1990.

29. Pamuk ER, Williamson DF, Serdula MK, Madans J, Byers TE. Weight loss and subsequent death in a Cohort of U.S. adults. Ann Intern Med 119: 744-748. 1993.

30. Rebuffé-Scrive M, Hendler R, Bracero N, Cummings N, McCarthy S, Rodin J. Biobehaviural effects of weight cycling. Int J Obes 18: 651-658, 1994.

31. Rodin J, Radke-Sharpe N, Rebuffe-Scrive M. Greenwood MRC. Weight cycling and fat distribution. Int J Obes 14: 303-310, 1990.

32. Schoeller DA, Jones PJH. Measurement of total body water by isotopic dilution: a unified approach to calibrations. In Ellis KJ, Yasumura S, Morgan WD (eds). In vivo body composition studies. Institute of Physical Sciences in Medicine, London pp 131-136, 1987.

33. Schotte DE, Cohen E, Singh SP. Effects of weight cycling on metabolic control in male outpatients with Non-Insulin-Dependent Diabetes Mellitus. Health Psychol 9: 599-605, 1990.

34. Seip RL, Angelopoulos TJ, Semenkovich CF. Exercise induces human lipase gene expression in skeletal muscle but not adipose tissue. Am J Physiol 268: E229-E236, 1995.

35. Siri WE. Body composition from fluid spaces and density: analysis of methods. In Brozek J, Henschel A (eds). Techniques for measuring body composition. National Academy of Sciences, Washington DC pp 223-244, 1961.

36. Svendsen OL, Hassager C, Christiansen C. Six months' follow-up on exercise added to a shortterm diet in overweight postmenopausal women-effects on body composition, resting metabolic rate, cardiovascular risk factors, and bone. Int J Obes 18: 692-698, 1994.

37. Wild RA. Obesity, lipids, cardiovascular risk, and androgen excess. Am J Med 98(suppl lA): 27S-32S, 1995.

38. Wing RR. Weight cycling in humans: a review of the literature. Ann Behav Med 14: 113-119, 1992.

39. Wing RR, Jeffery RW. Effect of modest weight loss on changes in cardiovascular risk factors: are there differences between men and women or between weight loss and maintenance? Int J Obes 19: 67-73, 1995.

40. Wood PD, Stefanick ML, Williams PT, Haskell WL. The effects on plasma lipoproteins of a prudent weight-reducing diet, with or without exercise, in overweight men and women. $N$ Engl $J$ Med 1991;325: 461-466, 1991 . 


\title{
Energy balance during an 8-wk energy-restricted diet with and without exercise in obese women
}

\author{
Kempen KPG, Saris WHM, Westerterp KR
}

Department of Human Biology, University of Limburg, Maastricht, the Netherlands

Am J Clin Nutr 62: 722-729, 1995

\begin{abstract}
The effects of severe energy restriction alone $(2.0 \mathrm{MJ} /$ day for 4 weeks and subsequently $3.5 \mathrm{MJ} /$ day for 4 weeks) or energy restriction plus moderate exercise on energy balance were studied in 20 healthy obese women. Subjects, aged 25-50 yr, were matched on the basis of body mass index and percentage body fat and randomly assigned to diet alone (D) or diet and exercise (DE) for 8 weeks.

DE resulted in a significantly increased loss of fat mass compared with $D(7.8 \pm 0.8$ compared with $5.5 \pm 0.8 \mathrm{~kg}, \mathrm{P}<0.05$ ). The average daily metabolic rate measured with doubly labeled water decreased with both treatments, with no differences between the treatments. Energy balance data show that the DE treatment resulted in a significantly greater energy deficit than the $\mathrm{D}$ treatment. The relative contribution of fat to energy expenditure during exercise was significantly enhanced by DE treatment, whereas it did not change after $D$. The energy expended on physical activity was not changed at the end of both treatments, with no differences between the two groups. The unchanged energy expended on physical activity indicates that DE might be accompanied by partial compensation of daily physical activities outside the training for the energy expended during the training. The energy deficit due to energy restriction alone was not compensated by a decrease in free-living daily physical activities. Addition of moderate exercise to an energy restriction program in obese women has advantages with respect to changes in body composition, energy expenditure and substrate utilization.
\end{abstract}




\section{Introduction}

Decreased energy expenditure concomitant with weight loss has been suggested as one of the causes slowing subsequent weight loss and facilitating weight regain. Loss of fatfree mass and changes in thermogenic hormones contribute to these decreased energy expenditure rates (26). In a recent study by Rising et al (20) it was suggested that obesity is associated with low physical activity. Because physical activity is one of the most variable components of energy expenditure, addition of exercise to a weight loss program in obese subjects might have favorable effects. By increasing exercise, higher rates of energy expenditure can be achieved, and increased energy expenditure might result in a greater weight loss, when energy intake does not change. Furthermore, exercise might have stimulating effects on fat oxidation, which has been shown to be decreased with increasing obesity (9).

It has been suggested that the potential benefit of adding exercise to an energy restriction regimen for achieving weight loss in obesity is mainly attenuation of fat-free mass losses. A recent meta-analysis by Ballor and PoehIman (2) suggests that the majority of the studies on the effects of adding modest regular exercise to a dietaryrestriction regimen resulted in preservation of fat-free mass, rather than in larger weight loss. Because the extent of adaptation to diet alone or combined with exercise treatment is related to the magnitude of the energy deficit, the lack of conclusive results may be explained partially by concomitant changes in other components determining energy balance. Altered food intake or changes in normal daily activities (8) have been suggested as compensatory adaptations for the extra energy deficit from the addition of exercise. However, no compensation in habitual daily activities was shown in obese boys on an exercise treatment (4) or in obese women following a diet treatment alone (2.9-3.5 MJ/day) or combined with exercise (31). However, in the latter study, the observations were limited to measures obtained by using heart-rate monitoring and actometer recordings.

To evaluate the effects of adding exercise to an energy restriction regimen in the treatment of obesity, information about the net changes in total energy expenditure and its various components is necessary. The doubly labeled water (DLW) technique provides an excellent way to measure total energy expenditure over 1-3 weeks under free-living conditions (22). Energy expenditure, measured with DLW, has an accuracy of $1-3 \%$ and a precision of $2-8 \%$ when validated against respirometry (33). Therefore, the present study focuses on the effects of a very-low-energy diet alone or in combination with an exercise program on total free-living energy expenditure and its components in obese women.

\section{Subjects and methods}

\section{Subjects}

Twenty female subjects, aged $25-50$ yr, volunteered for the present study. They were a subsample from a larger group of obese premenopausal women who were recruited for a 
weight loss program. All subjects were apparently healthy according to the results of a medical examination. Before treatment all subjects gave their written informed consent to participate in the study, which was approved by the University's ethical committee. The subjects were matched on the basis of their body mass index (BMI, in $\mathrm{kg} / \mathrm{m}^{2}$ ) and percentage body fat and randomly assigned to either a diet alone (D) or a diet and exercise group (DE). Baseline characteristics of the subjects participating in the present study are listed in Table 8.1.

Table 8.1 Baseline characteristics of subjects treated with 8 weeks diet alone $(\mathrm{D}, n=10)$ or diet and exercise (DE, $n=10$ ).

D DE

\begin{tabular}{lll}
\hline Age, $\mathrm{yr}$ & $36.6 \pm 2.3$ & $39.3 \pm 5.4$ \\
Weight, $\mathrm{kg}$ & $88.3 \pm 1.8$ & $90.4 \pm 2.9$ \\
Body mass index, $\mathrm{kg} / \mathrm{m}^{2}$ & $31.7 \pm 0.9$ & $32.4 \pm 1.3$ \\
Body fat. \% & $41.8 \pm 1.5$ & $41.6 \pm 1.5$ \\
Fat mass, $\mathrm{kg}$ & $37.0 \pm 1.8$ & $38.0 \pm 2.9$ \\
Fat free mass, $\mathrm{kg}$ & $51.4 \pm 1.3$ & $52.4 \pm 1.8$ \\
Waist-hip ratio & $0.84 \pm 0.02$ & $0.83 \pm 0.02$
\end{tabular}

Values are means $\pm S E$. Diet is $2.8 \mathrm{MJ} /$ day. D, diet treatment alone; DE, diet and exercise treatment.

\section{Experimental design}

The study lasted 10 weeks. The first 2 weeks were considered baseline, during which average daily metabolic rate (ADMR), sleeping metabolic rate (SMR), exercise-induced energy expenditure, body composition, and maximal oxygen uptake $\left(\mathrm{VO}_{2 \max }\right)$ were determined. After this period, the subjects followed the D or DE program for 8 weeks. All measurements were repeated at the end of this 8-week period.

Diet

The energy restriction program took place over an 8-week period that was divided into two parts. The first part consisted of a low-energy formula diet (Modifast, Sandoz. Bern, Switzerland) providing $2.0 \mathrm{MJ} /$ day for 4 weeks. It provided $50 \mathrm{~g}$ carbohydrate, $52 \mathrm{~g}$ protein, $7 \mathrm{~g}$ fat, and a micronutrient content that meets the Dutch recommended daily intake. The second part consisted of a mixed diet providing $3.5 \mathrm{MJ} / \mathrm{day}$ from week 5 until week 9 . This diet contained $1.4 \mathrm{MJ} /$ day of the formula diet and was supplemented to $3.5 \mathrm{MJ} /$ day by a free choice of foodstuffs. During the entire period subjects were instructed to record their food intake. During the energy restriction period the subjects came to the laboratory once a week to have their weight measured and food records checked. 


\section{Exercise training}

The DE group participated in a training program that took place at a professional sports center, three times per week during the entire period. The training session was supervised by a professional trainer twice per week. These sessions lasted $90 \mathrm{~min}$ and consisted of alternating sessions of aerobic dancing and fitness. The aerobic dance sessions were performed to music and consisted of routines that combined various dance steps with other whole-body movements including knee lifts, trunk twists, jumping jacks. kicks, hops, and jogging in the place. The fitness sessions included cardiac and strength training using free weights and mechanical gym equipment, regularly presented as circuit weight training. The session started with a 15 -min warm-up of cycling, stepping and/or rowing, followed by $60 \mathrm{~min}$ aerobic or fitness activities as described, and ended in a 15min cool-down with stretching. Additionally, at least one time per week, subjects trained individually according to a personal fitness schedule for $60 \mathrm{~min}$. The attendance of the subjects was monitored. The exercise intensities were regularly determined by heart-rate recordings (Sporttester, Polar Electro, Kempele, Finland). The prescribed intensity of the exercise program was $50-60 \%$ of $\mathrm{VO}_{2 \max }$.

\section{Measurements}

Maximal aerobic capacity: Before and at the end of the D or DE treatment, each subject's $\mathrm{VO}_{2 \max }$ and peak mechanical power $\left(\mathrm{W}_{\max }\right)$ were determined by using a progressive-continuous cycling test on an ergometer (Lode, Groningen, the Netherlands). After an initial 5-min period of cycling at $40 \mathrm{~W}$, followed by $4 \mathrm{~min}$ at $80 \mathrm{~W}$, the workload was increased by $20 \mathrm{~W} / \mathrm{min}$ until the subjects were exhausted. $\mathrm{W}_{\max }$ was defined as the highest load a subject could maintain for 1 min. During the test, ventilatory and gas-exchange responses were measured continuously by using a computerized open-circuit indirect calorimetry (Oxycon Beta, Mijnhardt, Bunnik, the Netherlands). Heart rate was recorded continuously by an electrocardiogram. Criteria for maximal exercise were forced ventilation, leveling off of oxygen uptake, or respiratory exchange ratio (RER) $>1.1$ at maximal exercise. The highest oxygen uptake achieved for $\geq 30 \mathrm{~s}$ was taken as $V_{O_{2} \max }$. Values of $\mathrm{W}_{\max }$ at week 0 and 8 were used to assess each individual intensity of a standardized activity test at week 0 and 8 , respectively.

Energy expenditure: SMR was measured during an overnight stay (1900-0700) in a computerized open-circuit indirect calorimeter $\left(14 \mathrm{~m}^{3}\right)$ equipped with a bed, toilet, television set, and chair. The volume of air drawn through the chamber was measured by a dry gasmeter (Schlumberger, Dordrecht, the Netherlands) and continuously analyzed by a paramagnetic oxygen analyzer (Servomex, Crowborough, UK) and an infrared carbon dioxide analyzer (Hartmann \& Braun, Frankfurt, Germany). Air-flow rate and the oxygen and carbon dioxide concentrations of the ingoing and outgoing air were used to compute oxygen consumption and carbon dioxide production on-line through an automatic acquisition system interfaced with a Macintosh computer (Cupertino, CA). Basal RER and energy expenditure (SMR) were calculated from oxygen consumption and carbon dioxide production (32) during the sleeping period between 0.300 and 0600 and controlled for extra physical activity by a Doppler radar system. 
On the morning after the overnight stay in the respiration chamber, exercise-induced energy expenditure was measured, still in the fasting state, to examine the energy costs of a specific standardized activity. The exercise protocol consisted of $45 \mathrm{~min}$ of exercise on a cycle ergometer at a workload of $45 \%$ of the measured $\mathrm{W}_{\max }$. The exercise was preceded by a 30 -min supine resting period (basal measurement) and followed by a 60 min recovery period with the person in supine rest. Respiratory gas exchange measurements were done continuously during the basal and recovery periods by means of a computerized open-circuit ventilated hood system. During exercise, respiratory gas exchange responses were measured for in total $20 \mathrm{~min}$, integrated over 5 -min intervals, by using computerized indirect calorimetry (Oxycon Beta). Both systems were calibrated with standard gases before each measurement and during the measurement periods. Measured RER was used to calculate carbohydrate and fat oxidation rates, assuming that the RER reflected the nonprotein respiratory quotient (17).

During the first 2 weeks of the study (baseline period) and the last 2 weeks of the energy restriction with or without exercise treatment, ADMR was assessed by the DLW method (33). The dosage calculation was based on body mass and percentage fat to create $300 \mathrm{ppm}$ excess $18 \mathrm{O}$ and $150 \mathrm{ppm}$ excess ${ }^{2} \mathrm{H}$. The isotope drink was administered between 2200 and 2300 after subjects had emptied their bladder and baseline urine samples had been collected. Further urine samples were collected on day 1, 8 and 15 after the first voiding and between 2100 and 2300. Isotopes were measured in urine with an Aqua Sira mass spectrometer (VG-Isogas Ltd, Middlewhich, Cheshire, UK). Carbon dioxide production was calculated from the isotope ratios in baseline, initial and final samples with the equation of Schoeller et al (23) adapted for the measured ratio of the dilution spaces for $18 \mathrm{O}$ and ${ }^{2} \mathrm{H}$ of 1.041 (33). The total body water (TBW) in the equation was calculated from the deuterium dilution space at the start of the observation period. Carbon dioxide production was converted to ADMR by using an energy equivalent based on the individual macronutrient composition of the diet and the use of body fat reserves (35). Energy expenditure of daily physical activity was assessed by expressing ADMR in multiples of SMR [physical activity index (PAI) = ADMR/SMR], or by expressing the energy expended on physical activity plus diet-induced thermogenesis (DIT) as ADMR minus SMR. Because of differences in DIT due to the lower energy intake, before and at the end of treatment, energy expended on physical activity $\left(\mathrm{EE}_{\mathrm{act}}\right)$ was also calculated as ADMR - (SMR + DIT). DIT at the start at the treatments was assumed to be $10 \%$ of ADMR (25). Because of the diet prescribed, energy intake at the end of the treatments was $<10 \%$ of ADMR. Therefore, DIT values at the end of interventions were calculated as $10 \%$ of the actual energy intake. Because it is known that obese subjects underreport their dietary intake $(3,34)$ and energy intake equals ADMR minus released energy from body tissue, the actual energy intake was calculated as average ADMR of week 0 and 8 , minus the energy equivalent of the average daily change in body tissue as a result of the 8 -week treatment.

Body composition: Before and at the end of the study body weight was measured on a digital balance accurate to $0.1 \mathrm{~kg}$ (model D-7470, Sauter, Ebingen, Germany). Height was measured to the nearest $0.1 \mathrm{~cm}$ by using a wall-mounted stadiometer. BMI was calculated from weight and height. Waist circumference was measured as the smallest circumference between the rib cage and the iliac crest, with the subject in standing 
position and breathing quietly. The hip circumference was measured at the level of the widest circumference between the waist and the thighs. Waist-hip ratio (WHR) was calculated as waist circumference divided by hip circumference.

Before and after the D and DE periods body composition was measured with two different techniques: isotope dilution and underwater weighing with simultaneous lungvolume measurement (Helium dilution). The percentage of body fat was calculated from body density and TBW by using the method proposed by Siri (27). Deuterium dilution technique was used to measure TBW. Before going to bed at night during the stay in the respiration chamber the subjects each drank a diluted sample of ${ }^{2} \mathrm{H}_{2} \mathrm{O}$ dilution after emptying their bladders (baseline urine sample). The dosage calculation was based on body mass to create an ${ }^{2} \mathrm{H}$ excess of $100 \mathrm{ppm}$. A second urine sample was collected in the morning of the next day, from the second voiding between 0800 and 1000 . Deuterium was measured in urine samples with an isotope-ratio mass spectrometer (VG Aqua Sira). TBW was calculated as the measured deuterium dilution space divided by 1.04 (33). The same morning, whole-body density was determined by hydrostatic weighing with the subject in the fasted state and before the measurement of exerciseinduced energy expenditure. Underwater weight was measured to the nearest $0.1 \mathrm{~kg}$ (Sauter). Residual lung volume was measured with a spirometer (model 2000, Volugraph, Bunnik, Mijnhardt, the Netherlands) at the moment of underwater weighing. The measurements were done in triplicate and the average value was used in the statistical analysis.

\section{Data analysis}

Datit in the text, tables and figures are given as means \pm SE. Exercise-induced energy expenditure was calculated as the total integrated change over baseline values (areas under curve from $t=0$ to 45 min exercise. $\mathrm{AUC}_{n_{-4}}$ ). Diet and exercise interactions were tested by two-way repeated-measurements analysis of variance (ANOVA) with group (exercise and no exercise) and time (before and after diet) as grouping variables. Posthoc testing was performed by paired (within group) or unpaired (between groups) Student's t tests. Significance levels were adjusted for multiple comparisons according to Bonferroni inequalities. Regression analysis was used to assess associations between measured variables. Analysis of covariance using fat-free mass as the covariate was used to adjust for differences in body weight when comparing metabolic rate values. $\mathrm{P}<0.05$ was accepted as statistically significant. All analyses were performed by using STATVIEW 512+ (Brainpower Inc, Calabas, CA).

\section{Results}

As shown in Table 8.1, no significant differences in variables between the D and DE groups were observed at the start of the study. From the heart-rate recording measurements, it appeared that the mean intensity of the training sessions was $52 \%$ (range 45-60\%) of measured $\mathrm{VO}_{2 \max }$. Changes in body weight and body composition for the $\mathrm{D}$ and $\mathrm{DE}$ group are shown in Table 8.2. Both energy restriction alone and 
combined with exercise treatment resulted in significant decrements of weight, fat mass, and fat-free mass (ANOVA, $\mathrm{P}<0.0001$ ). However, the DE treatment resulted in a significantly increased loss of fat mass compared with the D treatment (ANOVA, P< 0.05 ), whereas total weight loss and loss of fat-free mass were not different between the two groups. The percentage of weight lost as fat mass was $77.1 \pm 4.0 \%$ for the $\mathrm{D}$ group and $88.6 \pm 5.1 \%(\mathrm{P}=0.10)$ for the $\mathrm{DE}$ group.

Table 8.2 Weight loss, fat loss and loss of fat-free mass due to 8-week diet alone or diet/exercise.

\begin{tabular}{lll} 
& \multicolumn{1}{c}{$\begin{array}{c}\mathrm{DE} \\
(n=10)\end{array}$} & $\begin{array}{c}(n=10) \\
\text { Weight loss, } \mathrm{kg}\end{array}$ \\
Fat loss, kg & $7.1 \pm 0.9$ & $9.1 \pm 1.1$ \\
Fat-free mass loss, $\mathrm{kg}$ & $5.5 \pm 0.8$ & $7.8 \pm 0.8^{*}$ \\
& $1.6 \pm 0.3$ & $1.3 \pm 0.5$ \\
\hline
\end{tabular}

Values are means $\pm \mathrm{SE}$. Diet is $2.8 \mathrm{MJ}$ /day. $\mathrm{P}<0.05$ Student unpaired t-test. $\mathrm{D}$, diet treatment alone; $\mathrm{DE}$, diet/exercise treatment.

Changes in $\mathrm{VO}_{2 \max }$, expressed on the basis of fat-free mass, are shown in Figure 8.1. For the $\mathrm{D}$ group the absolute $\mathrm{VO}_{2 \max }$ decreased $6.2 \%$ at the end of energy restriction (ANOVA, $\mathrm{P}<0.05$ ). The DE group showed a tendency toward a small increase of $5.4 \%$ after treatment (ANOVA, $\mathrm{P}=0.051$ ). Expressed per $\mathrm{kg}$ body weight, the $\mathrm{DE}$ group showed a significant increase in $\mathrm{VO}_{2 \max }$ of $13.8 \%$ (26.0 \pm 1.5 compared with $29.6 \pm 1.3$ $\mathrm{ml} / \mathrm{min} \cdot \mathrm{kg}^{-1}$ for week 0 and 8 , respectively, ANOVA, $\mathrm{P}<0.0001$ ), whereas the $\mathrm{D}$ group showed no change ( $25.5 \pm 1.0$ compared with $25.4 \pm 1.2 \mathrm{ml} / \mathrm{min} \cdot \mathrm{kg}^{-1}$ for week 0 and 8 , respectively, NS). For both groups. $\mathrm{W}_{\max }$ did not significantly change in response to treatment (D group: $175 \pm 7$ compared with $167 \pm 10 \mathrm{~W}$ for week 0 and 8 , NS and DE group: $187 \pm 5$ compared with $186 \pm 7 \mathrm{~W}$ for week 0 and 8 ; NS).

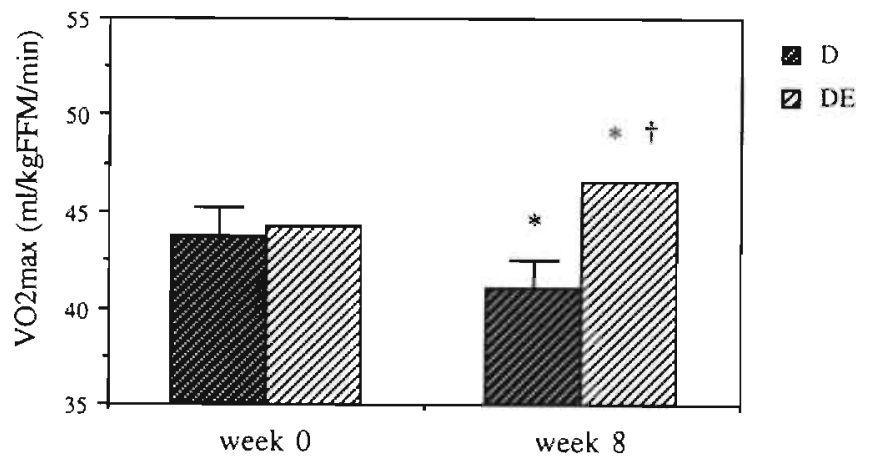

Figure 8.I Maximal oxygen consumption $\left(\mathrm{VO}_{2 \max }\right)$ values of subjects on 8 weeks of diet alone (D. $n=10$ ) or diet and exercise (DE, $n=10$ ). Values are means \pm SE. FFM, fat-free mass. ${ }^{*} \mathrm{P}<0.05$ vs week $0,+\mathrm{P}<0.05$ vs $\mathrm{D}$. 
Results of the SMR and ADMR measurements are shown in Table 8.3. Both the D and DE group showed decreases of $10 \%$ in SMR at the end of the 8-week treatment (ANOVA, $\mathrm{P}<0.001$ ). There were no significant between-group differences in the change of SMR. The RER measured during the night declined significantly in response to the treatments, with no significant differences between the $D$ and $D E$ groups (D group: 0.81 \pm 0.01 compared with $0.77 \pm 0.01$ for week 0 and 8 , ANOVA, $P=0.06$ and $D E$ group: $0.81 \pm 0.01$ compared with $0.77 \pm 0.01$ for week 0 and 8 , ANOVA, $\mathrm{P}<0.01)$. The ADMR, as measured with the DLW method, decreased significantly (ANOVA, P<0.005) after both $\mathrm{D}(12.2 \%)$ and $\mathrm{DE}$ treatments $(9.1 \%)$ as shown in Table 8.3.

Table 8.3 Sleeping metabolic rate and average daily metabolic rate of subjects treated with 8-week diet or diet and exercise.

\begin{tabular}{|c|c|c|c|}
\hline & & $\begin{array}{c}\mathrm{D} \\
(n=10)\end{array}$ & $\begin{array}{c}\mathrm{DE} \\
(n=10)\end{array}$ \\
\hline SMR, MJ/day & $\begin{array}{l}\text { week } 0 \\
\text { week } 8\end{array}$ & $\begin{array}{l}7.0 \pm 0.2 \\
6.3 \pm 0.1 \div\end{array}$ & $\begin{array}{l}7.1 \pm 0.3 \\
6.4 \pm 0.4 \S\end{array}$ \\
\hline ADMR, MJ/day & $\begin{array}{l}\text { week } 0 \\
\text { week } 8\end{array}$ & $\begin{array}{l}12.3 \pm 0.4 \\
10.8 \pm 0.5 \dagger\end{array}$ & $\begin{array}{l}12.1 \pm 0.5 \\
11.0 \pm 0.5 *\end{array}$ \\
\hline
\end{tabular}

Values are means \pm SE. Diet is $2.75 \mathrm{MJ} /$ day. Significantly different from week 0 , two-way ANOVA for repeated measurements, post-hoc Student's paired t-test, $\mathrm{P}<0.05, \leftarrow \mathrm{P}<0.005, \ddagger \mathrm{P}<0.001, \S \mathrm{P}<$ 0.0001 . SMR, sleeping metabolic rate; ADMR, average daily metabolic rate.

Differences in SMR and ADMR before and at the end of the treatments and between the $\mathrm{D}$ and $\mathrm{DE}$ groups were also analyzed in relation to differences in body composition. Analysis of covariance was used to compare the relationships between SMR and fat-free mass, and ADMR and fat-free mass values before and at the end of 8-week treatment, and between $D$ and $D E$ groups. Comparing relations between metabolic rate and fat-free mass by analysis of covariance is a better way of comparing energy expenditure data among subjects with different body composition than expressing energy expenditure per kilogram fat-free mass, because the use of this ratio is only appropriate when the relation between both parameters has no intercept (18). For both groups, there were significant relations between fat-free mass and SMR or ADMR, before as well as at the end of treatment $(P<0.05)$. As tested with analysis of covariance, no statistical differences in slopes and $y$-intercepts of the regression lines between fat-free mass and SMR and ADMR could be demonstrated between the D and DE groups.

Total thermogenic response to the standardized 45-min cycling exercise tended to decrease after both $D$ and $D E$ treatments, although not significantly $(P=0.09)$. No significant differences in exercise-induced thermogenesis between groups could be demonstrated. Figure 8.2 shows that the contributions of carbohydrate and fat oxidation to exercise-induced energy expenditure, expressed as percentage of energy. did not change for D group (carbohydrate: $55.3 \pm 5.7 \%$ compared with $61.7 \pm 4.5 \%$ for 
week 0 and 8 , NS and fat: $44.7 \pm 5.7 \%$ compared with $38.3 \pm 4.5 \%$ for week 0 and 8. NS). For the DE group, the contribution of carbohydrate oxidation to exerciseinduced energy expenditure decreased, whereas the percentage of fat oxidation increased (carbohydrate: $68.7 \pm 3.3 \%$ compared with $53.3 \pm 4.5 \%$ for week 0 and 8 and fat: $31.3 \pm 3.3 \%$ compared with $46.7 \pm 4.5 \%$ for week 0 and 8 , ANOVA, $\mathrm{P}<0.05$, for both comparisons).
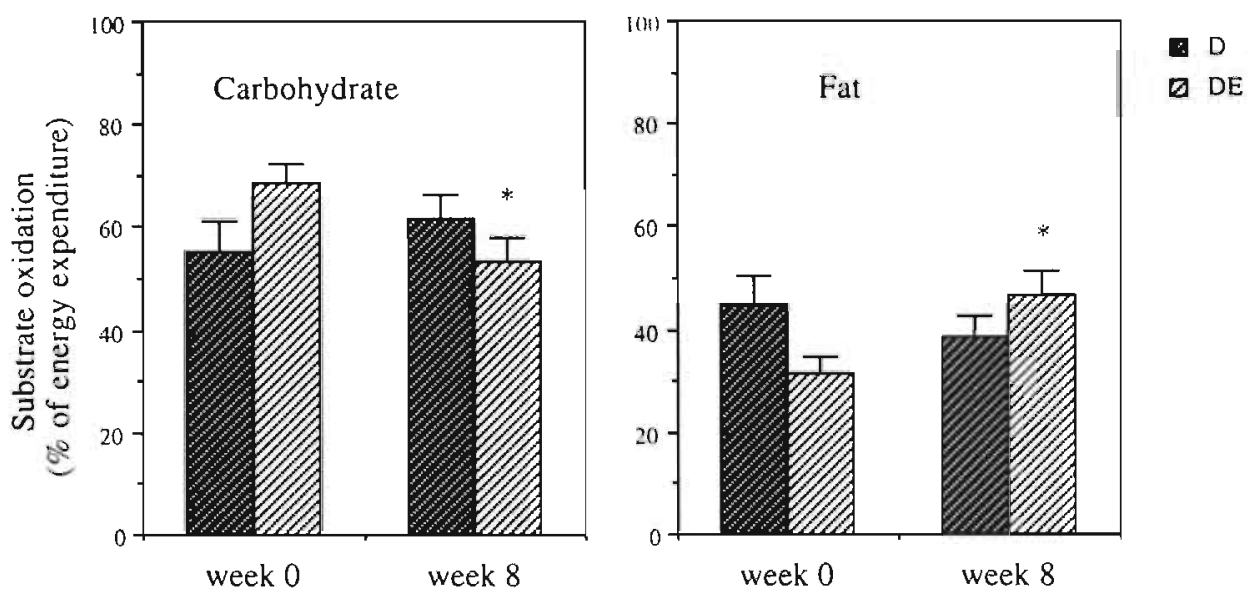

Figure 8.2 Fat and carbohydrate oxidation during $45 \mathrm{~min}$ of exercise [ar $45 \%$ maximal power $\left.\left(W_{\text {max }}\right)\right]$ for the diet $(D, n=10)$ and diet and exercise (DE, $\left.n=10\right)$ groups. Values are means $\pm \mathrm{SE}$. *Significantly different from week $0, \mathrm{P}<0.05$.

Mean daily energy intake during the first 4 weeks with the formula diet, as calculated from the subjects' food records, was 2.3 and $2.1 \mathrm{MJ} /$ day for the $\mathrm{D}$ and $\mathrm{DE}$ groups, respectively (NS). During the second 4 weeks of the diet the reported total daily intake was $3.1 \mathrm{MJ}$ for both groups. consisting of $89 \mathrm{~g}$ carbohydrate, $62 \mathrm{~g}$ protein, $15 \mathrm{~g}$ fat, and a micronutrient intake which meets the Dutch recommended daily intake. However, estimation of the actual food intake is very difficult and obese people in particular tend to underreport their actual food intake $(3,34)$. The actual energy intake equals approximately the mean ADMR of week 0 and 8 minus energy released from the average daily change of body tissue. This method assumes linear decreases in ADMR and body tissue during the 8 -week treatment. For body tissue this assumption appeared to be reasonably justified because $55 \%$ of the weight loss occurred during the first half of the treatment. Assuming that $1 \mathrm{~kg}$ fat provides $38.3 \mathrm{MJ}$ and $1 \mathrm{~kg}$ fat-free mass provides $3.5 \mathrm{MJ}$, the energy equivalent of the weight losses as a result of the treatments can be calculated. It appears that the total energy equivalent of the weight lost during the 8-week treatment for the D group was $216.3 \mathrm{MJ}$, whereas that of the DE group amounted to $303.3 \mathrm{MJ}$. Consequently, the $\mathrm{D}$ group obtained on average $3.9 \mathrm{MJ} /$ day, whereas the DE group obtained $5.4 \mathrm{MJ} /$ day by releasing stored body energy. From this, it can be concluded that in the present study food intake is considerably underreported 


\section{Chapter 8}

by $4.5 \mathrm{MJ} /$ day for the $\mathrm{D}$ group and $\sim 3.1 \mathrm{MJ} /$ day for the $\mathrm{DE}$ group. During the last 2 weeks of the diet the average daily energy intakes for the D and DE groups were $\geq 7.6$ and 6.2 MJ, respectively. Table 8.4 shows the reported and adjusted energy intake. ADMR, and energy balance data during the last 2 weeks of both treatments. From thes $c^{\circ}$ results it appears that the DE group showed a greater negative energy balance compared to the D group.

Table 8.4 Energy intake, energy expenditure, and energy balance during last two weeks of 8 week diet alone (D) or diet and exercise (DE).

\begin{tabular}{lcc}
\hline & $\mathrm{D}$ & $\mathrm{DE}$ \\
& $(n=10)$ & \\
& & $3.1 \pm 0.3$ \\
\hline Reported EI, MJ/day & $7.6 \pm 0.4$ & $6.2 \pm 0.7$ \\
Adjusted EI*, MJ/day & $10.8 \pm 0.5$ & $11.0 \pm 0.5$ \\
ADMR, MJ/day & $-3.2 \pm 0.5$ & $-4.9 \pm 0.6 \div$ \\
Energy Balance $\uparrow$, MJ/day & &
\end{tabular}

Values are means $\pm \mathrm{SE}$. Diet is $2.8 \mathrm{MJ} /$ day. *Adjusted for changes in body weight, calculated as the average of average daily metabolic rate of week 0 and 8 minus the energy equivalent of the average daily change of body tissue as a result of the 8-week treatment, †daily energy intake minus average daily metabolic rate. $\doteqdot$ Significantly different from $\mathrm{D}, \mathrm{P}<0.05$, two way ANOVA for repeated measurements. EI, energy intake; ADMR, average daily metabolic rate.

Physical activity level was calculated as the PAI. Measured PAIs are given in Table 8.5. There were no significant differences in PAI between the D and DE groups, before or after treatment. Table 8.5 also shows the values of ADMR - SMR and energy expended on physical activity (EE $E_{\text {act }}$ ) expressed as ADMR - (SMR + DIT). Assuming DIT values of $10 \%$ of ADMR (25) before treatment, and based on adjusted energy intake of $0.76 \mathrm{MJ}$ and $0.62 \mathrm{MJ} /$ day for $\mathrm{D}$ and $\mathrm{DE}$ groups, respectively, during treatments, it appeared that there were no differences between the $D$ and $D E$ groups before and at the end of the treatments for $\mathrm{EE}_{\mathrm{act}}$. 
Table 8.5 Physical activity levels of obese subjects treated with 8 weeks of diet alone $(\mathrm{D}, n=10)$ or diet and exercise (DE, $n=10$ ).

\begin{tabular}{llll}
\hline & & $\mathrm{D}$ & $\mathrm{DE}$ \\
\hline PAI, x SMR & week 0 & $1.75 \pm 0.06$ & $1.72 \pm 0.07$ \\
& week 8 & $1.74 \pm 0.06$ & $1.75 \pm 0.10$ \\
ADMR-SMR, MJ/day & week 0 & $5.24 \pm 0.37$ & $4.98 \pm 0.45$ \\
& week 8 & $4.60 \pm 0.40$ & $4.60 \pm 0.57$ \\
$\mathrm{EE}_{\text {act, }} \mathrm{MJ} /$ day & week 0 & $4.01 \pm 0.34$ & $3.77 \pm 0.41$ \\
$\mathrm{EE}_{\mathrm{act}}, \mathrm{kJ} /$ day $\mathrm{kg}_{\mathrm{BW}}{ }^{-1}$ & week 8 & $3.94 \pm 0.32$ & $4.02 \pm 0.52$ \\
& week 0 & $45.6 \pm 4.0$ & $42.6 \pm 4.8$ \\
& week 8 & $47.5 \pm 3.7$ & $50.5 \pm 7.1$
\end{tabular}

Values are means \pm SE. Diet is $2.8 \mathrm{MJ} /$ day. PAI, physical activity index calculated as average daily metabolic rate divided by sleeping metabolic rate; SMR, sleeping metabolic rate; ADMR, average daily metabolic rate; $\mathrm{EE}_{\mathrm{act}}$, energy expended on physical activity calculated as average daily metabolic rate minus (sleeping metabolic rate plus diet-induced thermogenesis); BW, body weight.

\section{Discussion}

In the present study, free-living total daily energy expenditure was assessed before and at the end of an 8-week, very-low-energy-diet treatment alone or combined with an exercise program by using the DLW method. Simultaneously, SMR was measured to assess the energy expenditure of daily physical activity by expressing physical activity in multiples of SMR or by expressing the energy expended on physical activity as ADMR - (SMR + DIT). Also, the energy cost of a standardized activity was measured to evaluate the energy expended for a certain activity. By assessing these components of energy balance, it is possible to determine adaptations of the different components of energy balance to $\mathrm{D}$ or $\mathrm{DE}$ treatment. There are many studies in the literature that investigated basal energy expenditure $(7,14,31,36)$. physical activity (31), or DIT, and several studies have determined total free-living energy expenditure in obese subjects (24), but to our knowledge there are no published studies that used the DLW method for measurement of total energy expenditure during weight reduction as a result of D or DE treatment in obese women. The present study showed that addition of moderate exercise to an energy restriction treatment did not accelerate weight loss, which confirms the majority of previous studies $(2,5)$. Addition of exercise to the diet treatment resulted in an extra fat loss in the present study, as was shown also in several other studies that used moderate or severe energy restriction $(14,21,28,36)$. The degree of dietary restriction $(1,29)$ and type, intensity, duration, and frequency of exercise $(7,29,31)$ may be important factors causing the inconsistent results concerning the effects of diet alone compared with diet plus exercise.

In particular, regular moderate aerobic exercise, which was used in the present study, has been shown to result in adaptations favoring fat mobilization and oxidation during exercise. Although there tended to be differences in baseline contributions of carbohydrates and fat to exercise-induced energy expenditure between the groups ( $P=$ 0.059 ), the relative contribution of fat was significantly increased as a result of combined 
diet and exercise treatment in the present study, whereas no significant change occurred as a result of diet alone. Addition of exercise to dietary treatment, therefore, seems of particular importance for treatment of obesity because macronutrient balance, which has been shown to be disturbed in the obese state (9), is positively influenced. Increased fat oxidation from training seems to be of minor importance in the resting state, because during the night no differences in RER could be observed between D and DE treatment. A study by van Dale et al (31) showed that free-living total energy expenditure, measured with heart rate recordings, significantly decreased as a result of both a verylow-energy-diet and diet and exercise treatment. However, this decline was more pronounced from diet treatment alone than from diet combined with exercise. In the present study, the ADMR, as measured with the DLW technique, declined significantly by 12.2 and $9.1 \%$ in the $\mathrm{D}$ and $\mathrm{DE}$ groups, respectively, with no differences between the groups and similar changes in fat-free mass. On the basis of these results there are no indications for different adaptations in total free-living energy expenditure to a verylow-energy-diet alone or diet-exercise treatment.

The ADMR of a subject involves the BMR, which has been shown to be $\sim 5 \%$ higher than the SMR (12), the DIT, and the energy costs of physical activity. The decrease in absolute SMR because of the diet alone or because of combined diet and exercise treatment were of similar magnitude in the present study. Also, when corrected appropriately for changes in fat-free mass, it appears that there were no differences between the groups. Similar decrements for diet and diet and exercise treatment are in line with the findings of several studies that used severe or moderate energy restriction $(6,7,14,36)$, whereas other studies did report differences in the decline of RMR or SMR between a severe or moderate energy-restrictive diet alone or diet and exercise treatment $(10,28,31)$. Regarding these equivocal results, the short-term stimulating effect of exercise on energy expenditure has been suggested to play a role (30), although others reported that exercise must be of a high intensity and long duration before a significant elevation in metabolic rate is observed beyond several hours (19). Discrepancies in the research of post-exercise effects on energy expenditure might also be attributed in part to lack of adequate corrections for changes in body composition and type of the added exercise (15). Furthermore, Ballor (1) suggested that the dietary intake might interact with the effects of addition of exercise on RMR.

The discrepancy between reported energy intake, total energy expenditure, and changes in body energy stores observed in the present study confirms previous studies, suggesting that obese subjects underreport habitual encrgy intake $(3,34)$. However, although subjects of both groups underreported their energy intake, it appears that compliance with the prescribed diet was slightly better in the exercising subjects. It is therefore indicated that addition of exercise to very-low-energy-diet treatment promotes better dietary adherence, which is an additional benefit of exercise that may have even greater importance during treatment of obesity over the long term.

PAI and energy expended on physical activity $\left(E_{\text {act }}\right)$. calculated as ADMR - (SMR + DIT), were not changed by either the $D$ or $D E$ treatment and no differences between the two groups were observed. Furthermore, also if $\mathrm{EE}_{\mathrm{act}}$ data are expressed per kilogram body weight, there were no changes due to the treatment or differences between the treatments. Therefore, it may be concluded that the level of physical activity is not 
increased by combined diet and exercise treatment in obese women compared with diet alone. The DE group trained for $4 \mathrm{~h} /$ week. It can be calculated that the energy expended during the training amounted to $5.9 \mathrm{MJ} /$ week. Assuming a mean activity level for the D group based on the ADMR divided by $24 \mathrm{~h}(0.45 \mathrm{MJ} / \mathrm{h})$ compared with the measured $52 \% \mathrm{VO}_{2 \max }$ for the $\mathrm{DE}$ group, an extra energy deficit of $0.6 \mathrm{MJ} /$ day from the extra physical activity can be calculated for the DE group. Because a difference $<0.6$ $\mathrm{MJ} /$ day was detected by the DLW method in the present study, it might be indicated that the energy expended during the training is partly compensated by a decrease in daily physical activities outside the training sessions. Based on a one-sided significance level of 0.05 , a power of $90 \%$ and assuming an SD of $0.4 \mathrm{MJ} /$ day on the basis of a $4 \%$ precision of the DLW method (33), a sample size of 8 subjects would enable to identify a difference of $0.6 \mathrm{MJ} / \mathrm{day}$. Therefore, with the sample size used in the present study it should have been possible to detect a difference between the groups of $0.6 \mathrm{MJ} /$ day.

A finding of compensation for added exercise seems to be not in agreement with previous studies using DLW, showing no compensatory decrease in daily physical activities after a training program alone in obese boys (4) and after endurance training in lean men and women (16). However, because of different groups of subjects, these studies appear to be not adequately comparable with obese women in the present study. No compensation in daily physical activities for addition of exercise to very-low-energydiet treatment was also shown in obese women (31). However, measurements of total energy expenditure and physical activity were performed by heart-rate monitoring and actometer recordings in the study of van Dale et al (31). With these methods, estimates of energy expenditure from physical activity are not as precise as those with the DLW method, particularly because of uncertainties about the relation between heart rate and energy expenditure during sedentary activities. The present study used the DLW method during weight loss by D or DE treatment for estimating energy expended on physical activity, and the results might indicate partial compensation in physical activity for addition of training to dietary treatment during the non-exercise part of the day.

The results also suggest that there is no decline in daily habitual physical activities due to very-low-energy-diet treatment alone, in agreement with another study in obese women that observed no significant change in dynamic activities ( $\mathrm{EE}>30 \%$ of $\mathrm{VO}_{2 \max }$ ) as measured by actometer recordings (31). A tendency toward increased thermogenic efficiency during a standardized activity, as demonstrated in the present study, combined with lower energy costs for weight-bearing activities due to the decreased body mass might even indicate a slightly increased physical activity level after energy restriction treatment. On the other hand, it was suggested that compensation for a foodenergy-intake deficit occurs at the level of leisure activities in healthy men (13). Whether leisure activities decrease in obese women on a very-low-energy diet is uncertain. In contrast, it is also possible that these activities increase because of improved mobility as a result of decreased body weight.

In summary, addition of exercise to a very-low-energy diet in obese women has advantages with respect to changes in body composition, substrate utilization and energy expenditure. In particular, loss of fat mass was favored, the contribution of fat to oxidation during exercise was increased, and a larger energy deficit was created, compared to diet treatment alone. 


\section{References}

1. Ballor DL. Exercise training elevates RMR during moderate but not severe dietary restriction in obese male rats. I Appl Physiol 70: 2303-2310, 1991.

2. Ballor DL, Poehlman ET. Exercise-training enhances fat-free mass preservation during dietinduced weight loss: a meta-analytical finding. Int J Obes 18: 35-40, 1994.

3. Bandini LG, Schoeller DA, Cyr HN, Dietz WH. Validity of reported intake in obese and nonobese adolescents. Am J Clin Nutr 52: 421-425, 1990.

4. Blaak EE, Westerterp KR, Bar-Or O, Wouters LJM, Saris WHM. Total energy expenditure and spontaneous activity in relation to training in obese boys. Am J Clin Nutr 55: 777-782, 1990.

5. Dengel RD, Hagberg JM, Coon PJ, Drinkwater DT, Goldberg AP. Effect of weight losis by diet alone or combined with aerobic exercise on body composition in older obese men. Metabolism 43: 867-871, 1994.

6. Donnelly JE, Pronk NP, Jacobsen DJ, Pronk SJ, Jakicic JM. Effects of a very-low-calorie diet and physical-training regimens on body composition and resting metabolic rate in obese females. Am J Clin Nur 54: 56-61, 1991.

7. Donnelly JE, Jacobsen DJ, Jakicic JM, Whatley JE. Very-low calorie diet with concurtent versus delayed and sequential exercise. Int J Obes 18: 469-475, 1994.

8. Epstein LH, Wing RR. Aerobic exercise and weight. Addict Behav 5: 371-388, 1980.

9. Flatt JP. Dietary, fat, carbohydrate balance, and weight maintenance: effects of exercise. Am J Clin Nutr 45: 296-306, 1987.

10. Frey-Hewitt B. Vranizan KM. Dreon DM, Wood PD. The effect of weight loss by dieting or exercise on resting metabolic rate in overweight men. Int $J$ Obes 14:327.334, 1990.

11. Garrow J. Meta-analysis on the effect of exercise on the composition of weight loss (letter). Int $J$ Obes 18: 516-517, 1994.

12. Goldberg GR. Prentice AM. Davies HL. Murgatroyd PR. Overnight and basal metabolic rates in men and women. Eur J Clin Nutr 42: 137-144, 1988.

13. Gorsky RD, Calloway DH. Activity pattern changes with decreases in food energy intake. Hum Biol 55: 577-586, 1983.

14. Hill JO, Schlundt DG. Sbrocco T, Sharp T, Pope-Cordle J, Stet son B, Kaler M, Heim C. Evaluation of an alternating-calorie diet with and without exerciss in the treatment of obesity. Am $J$ Clin.Nutr 50: 248-254, 1989.

15. Lemons AD, Kreitzman SN, Coxon A. Howard A. Selection of appropriate exercise regimes for weight reduction during VLCD and maintenance. In J Obes 13: S119-SI23, 1989.

16. Meijer GAL. Janssen GME, Westerterp KR. Verhoeven F. Saris WHM, ten Hoor F. The effect of a 5-month endurance training programme on physical activity: evidence for a sex difference in the metabolic response to exercise. Eur J Appl Physiol 62: 11-17, 1991.

17. Péronnet F, Massicotte D. Table of non-protein respiratory quotient: an update. Can J Sports Sci 16: 23-29, 1991.

18. Ravussin E. Bogardus C. Relationship of genetics, age, and physical fitness to daily energy expenditure and fuel oxidation. Am J Clin Nutr 49: 968-975, 1989.

19. Richard D. Rivest S. The role of exercise in thermogenesis and energy balance. Can J Physiol Pharmacol 67: 402-409, 1989.

20. Rising R, Harper IT, Fontvielle AM, Ferraro RT, Spraul M, Ravussin E. Determinants of total daily energy expenditure: variability in physical activity. Am J Clin Nutr 59: 800-804, 1994.

21. Saris WHM. The role of exercise in the dietary treatment of obesity. Int $J$ Obes 17: S17-S21, 1993:

22. Schoeller DA. Energy expenditure from doubly labeled water: some fundamental considerations in humans. Am J Clin Nutr 38: 999-1005, 1983. 
23. Schoeller DA, Ravussin E, Schutz Y, Acheson KJ, Baertschi P. Jequier E. Energy expenditure by doubly labeled water: validation in humans and proposed calculation. Am J Physiol 250: R823R830, 1986.

24. Schulz LO, Schoeller DA. A compilation of total daily energy expenditures and body weights in healthy adults. Am J Clin Nutr 60: 676-681, 1994.

25. Schutz Y, Bessard T, Jéquier E. Diet-induced thermogenesis measured over a whole day in obese and non-obese women. Am J Clin Nutr 40: 542-552, 1984.

26. Shetty PS. Physiological mechanisms in the adaptive response of metabolic rates to energy restriction. Nutr Res Rev 3: 49-74, 1990.

27. Siri WE. Body composition from fluid spaces and density: analysis of methods. In Brozek J, Henschel A (eds). Techniques for measuring body composition. Washington DC: National Academy of Sciences pp 223-244, 1961.

28. Svendsen OL, Hassager C, Christiansen C. Effect of an energy-restrictive diet, with or without exercise, on lean tissue mass, resting metabolic rate, cardiovascular risk factors, and bone in overweight postmenopausal women. Am J Med 95:131-140, 1993.

29. Sweeney ME. Hill JO, Heller PA, Baney R, DiGirolamo M. Severe vs moderate energy restriction with and without exercise in the treatment of obesity: efficiency of weight loss. Am J Clin Nutr 57: 127-134, 1993.

30. Tremblay A, Alméras N.Boer J, Klein Kranenbarg E, Deprés J-P. Diet composition and postexercise energy balance. Am J Clin Nutr 59: 975-979, 1994.

31. Van Dale D, Schoffelen PGM, ten Hoor F, Saris WHM. Effects of addition of exercise to energy restriction on 24-hour energy expenditure, sleeping metabolic rate and daily physical activity. Eur J Clin Nutr 43: 44I-45I, 1989.

32. Weir JB. New methods for calculating metabolic rate with special reference to protein metabolism J Physiol 109: 1-9, 1949.

33. Westerterp KR, Saris WHR. Limits of energy turnover in relation to physical performance, achievement of energy balance on a daily basis. J Sports Sci 9: 1-15, 1991.

34. Westerterp KR, Verboeket-van de Venne WPHG, Meyer GAL, ten Hoor F. Self-reported intake as a measure for energy intake; a validation against doubly labelled water. In Ailhaud G (ed). Obesity in Europe 91. John Libbey \& Company Lid pp17-22, 1992.

35. Westerterp KR, Kayser B, Wouters LJM, Le Trong J-L. Richalet J-P. Energy balance at high altitude: 6542m. J Appl Physiol 77: 862-866. 1994.

36. Whatley JE, Gillespie WJ. Honig J. Walsh MJ, Blackbum AL. Blackburn GL. Does the amount of endurance exercise in combination with weight training and a very-low energy diet affect resting metabolic rate and body composition? Am J Clin Nutr 59: 1088-1092, 1994. 



\title{
Can regular moderate exercise prevent adverse metabolic effects of weight cycling in obesity?
}

\author{
Kempen KPG, Saris WHM
}

Department of Human Biology, University of Limburg, Maastricht, the Netherlands.

Submitted for publication

\begin{abstract}
Blunting of the sympathetically mediated thermogenesis has been recently found with weight cycling in obese females. The present study examines whether regular, moderate exercise prevents or reverses these adverse metabolic consequences of weight cycling. Metabolic variables and body composition were repeatedly measured in weight cycling obese women (D-WC, $n=13$ ) and exercising weight cycling obese females (DEx-WC, $n=10$ ) before, during and after 2 complete cycles of dietary-induced weight loss and regain over two years. Exercise for DEx-WC subjects started after the first 1-year weight cycle and continued during the second weight cycle of 1 year.

The results demonstrate that exercise prevented a reduction of weight loss that was observed with weight cycling alone, whereas regain of body weight was not prevented. However, exercise tended to result in a persistently decreased body fat percentage. whereas no remaining decline was observed for $D$-WC subjects $(P=0.08)$. Exercise prevented a decrease in maximal oxygen uptake that was seen with weight cycling alone. Furthermore, it appeared that exercise partially prevented declining exerciseinduced responses of catecholamines that were observed with in D-WC subjects. No differences between the groups were observed for exercise-induced responses of energy expenditure, heart rate, free fatty acids, glycerol and glucose. Declining responses of isoprenaline-induced energy expenditure, heart rate and calecholamines observed with weight cycling alone were prevented by exercise.

In conclusion, the results of the present study suggest a stimulating influence and partially prevention of weight cycling-induced blunting sympathetically mediated thermogenic effects as result of exercise in obese women. Therefore, regular moderate exercise may be effective for improving long-term weight maintenance in the treatment of obesity.
\end{abstract}




\section{Introduction}

The major problem in the treatment of obesity is relapse after a successful weight reduction program.Virtually all treated obese patients regain achieved weight loss or even more within a few years. Despite high dieting rates, median weight and prevalence of overweight and obesity are still increasing (19) implicating major public health consequences. Possible adverse metabolic effects of repeated weight loss and regain has been suggested to contribute to the disappointing results of treatment of obesity on the long-term $(5,16)$. The role of weight cycling in altering body composition and metabolic rate $(4,5,34)$, making maintenance of weight loss more difficult, have been supported by some $(4,5,21,34)$ but not all (27). Recently, weight cycling has been demonstrated to be associated with blunting of the sympathetically mediated thermogenesis in a prospective study over two years in obese women (16).

The importance of exercise for body weight control has became evident from numerous previous studies $(6,8,9,30,35,39)$. Since moderate regular exercise has been shown to have several positive physiological effects on energy metabolism and body composition, it may be hypothesized that participation in a prolonged regular exercise program prevents adverse metabolic effects of weight cycling in obesity. Exercise may elevate energy expenditure due to its energy costs during the exercise sessions, although partly compensation by a decrease in normal daily activities might occur (16). Furthermore, exercise may also raise post-exercise metabolic rate $(36,37)$ and promote oxidation of fatty acids consequently leading to a lipid imbalance and loss of body fat $(29,39)$. A stimulating influence on the sympathetic nervous system may play a role in the exerciseinduced physiological adaptations (37). Especially therefore, exercise may be of importance for preventing weight cycling effects since repeated weight loss and regain has been shown to be associated with blunting of the sympathetically mediated thermogenesis (16). In the present study, a possible preventing influence of addition of a moderate regular exercise program on adverse sympathetically mediated metabolic effects of weight cycling in obese females was examined.

\section{Subjects and methods}

\section{Subjects}

Subjects participating in the present study $(n=26)$ were a subsample of 57 obese women who were recruited by advertisement in local newspapers for a dietary weight loss trial. The subsample was selected on the basis of their regain one year after the dietary-induced weight loss (regain $\geq 70 \%$ of their previous weight loss, defined as weight cycling. WC) and were willing to participate a second energy restriction period. Those 26 subjects were matched on the basis of their body mass index (BMI) and body fat percentage (\%FM) and randomly assigned to a second diet treatment and 1-year follow-up alone (D-WC) or second diet and l-year follow-up combined with participation in an exercise program (DEx-WC). Effects of weight cycling without exercise intervention have been described elsewhere (16). 
The obese females recruited for the dietary weight loss program were selected when their BMI was between 28 and $40 \mathrm{~kg} / \mathrm{m}^{2}$. They were premenopausal, had a stable weight over the previous six months and were medically screened to exclude metabolic abnormalities. None of them received any medication known to affect the variables measured. All subjects gave written informed consents to participate in the study, that was approved by the Ethics Committee of the University of Limburg. Three participants of the DEx-WC group did not complete the study (2 due to pregnancy, and 1 because of poor compliance in the exercise program). The present subsample of 23 subjects who completed the study did not differ significantly from the remaining group of subjects in baseline characteristics and there were no differences between D-WC and DEx-WC groups (Table 9.1).

Table 9.1 Baseline characteristics of weight cycling (D-WC, $n=13$ ) and exercising weight cycling (DEx-WC, $n=10$ ) obese women.

\begin{tabular}{lll}
\hline & D-WC & DEx-WC \\
\hline Age, $\mathrm{yr}$ & $38.5 \pm 2.5$ & $38.7 \pm 1.6$ \\
Weight, $\mathrm{kg}$ & $88.2 \pm 2.2$ & $89.2 \pm 3.5$ \\
Body mass index, $\mathrm{kg} / \mathrm{m}^{2}$ & $32.2 \pm 0.8$ & $32.3 \pm 1.1$ \\
Body fat percentage, $\%$ & $42.3 \pm 1.1$ & $41.2 \pm 1.8$ \\
Fat mass, kg & $37.4 \pm 1.7$ & $37.3 \pm 2.8$ \\
Fat free mass, $\mathrm{kg}$ & $50.7 \pm 1.0$ & $52.5 \pm 1.5$ \\
Waist-hip ratio & $0.83 \pm 0.01$ & $0.82 \pm 0.02$ \\
\hline
\end{tabular}

Values are means $\pm \mathrm{SE}$.

\section{Procedure}

The total study lasted 120 weeks, consisting of a controlled 8-week very-low calorie dict (VLCD) treatment to achieve weight loss and a non-controlled 52-week follow-up for both groups (weight cycle 1). Subsequently, the same protocol of 8-week VLCD and 52 -week non-controlled follow-up was repeated for both groups (weight cycle 2). Subjects of the DEx-WC group participated in a moderate exercise program during weight cycle 2. Measurements of body composition, fat distribution, sleeping metabolic rate (SMR), exercise-induced, and isoprenaline(ISO)-induced thermogenesis were performed before the start of the study (week 0 ), at the end of the first diet (week 8 ) and follow-up (week 60), and the end of the second diet (week 68) and follow-up with or without additional exercise (week 120). Maximal aerobic capacity was measured at week $0,60,68$, and 120. During week 58-60 and week 118-120, the average daily metabolic rate (ADMR) was determined under free-living conditions using doubly labeled water. Acute effects of 8-week energy restrictive diet alone or combined with exercise on ADMR as assessed by doubly labeled water has been described previously (15). 
Diet

During both 8 -week diet periods, the subjects were prescribed to the same very-low calorie diet. The first 4 weeks consisted of a low-energy formula diet (Modifast, Bern, Sandoz, Switzerland) containing $2.0 \mathrm{MJ} /$ day. It daily provided $50 \mathrm{~g}$ carbohydrates, $52 \mathrm{~g}$ protein, $7 \mathrm{~g}$ fat, and a micronutrient content which meets the Dutch recommended daily allowance. During the second part of the energy restriction period, the diet contained 1.4 MJ/day of the formula diet, supplemented to $3.5 \mathrm{MJ} /$ day by a free choice of foodstuffs. During the energy restriction periods, subjects were instructed to keep a record of food intake and they came weekly to the laboratory to have their weight measured and food records checked.

\section{Exercise training}

During the second diet and follow-up (weight cycle 2), the subjects of the DEx-WC group participated in a training program that took place at a professional sports centre. The exercise training consisted of 2 training sessions per week, supervised by a professional trainer. These sessions lasted $90 \mathrm{~min}$ and consisted of alternatively aerobic dancing and fitness including aerobic exercise and strength training. The aerobic dance sessions were performed to music and consisted of routines that combined various dance steps with other whole body movements including knee lifts, trunk twists, jumping jacks kicks, hops. and jogging in the place. The fitness sessions included cardiac and strength training using free weights and machine gym equipment, regularly presented as circuit weight training. All sessions started with a 15-min warming-up of cycling, stepping and/or rowing. followed by $60 \mathrm{~min}$ aerobic or fitness as described and ended in 15-min cooling down by stretching. During the energy-restrictive diet, the exercise training was intensified by additional individual training sessions. at least 1 or 2 times per week. During these individual sessions, the subjects trained according to a fitness schedule for $60 \mathrm{~min}$. The attendance of the subjects during the exercise sessions was registered over the year and appeared to be $85 \%$ (range $77-98 \%$ ). The exercise intensities were regularly determined by means of heart-rate recordings (Sporttester, Polar Electro, Kempele, Finland). The prescribed intensity of the exercise sessions was 50-60\% of the maximal oxygen uptake.

\section{Measurements}

Maximum aerobic capacity: Maximal aerobic capacity was determined at least 3. and at most 7 days prior to the other measurements, as previously described (14). Each subject's maximal oxygen uptake $\left(\mathrm{VO}_{2 \max }\right)$ and peak mechanical power $\left(\mathrm{W}_{\max }\right)$ were measured by using an incremental exercise test on an electromagnetically braked cycle ergometer (Lode, Groningen, the Netherlands). During the test, ventilatory and gas exchange responses were measured continuously, using a computerized open system (Oxycon Beta, Mijnhardt, Bunnik, the Netherlands). Heart rate (HR) was recorded continuously by a conventional electrocardiogram system. $W_{\max }$ was defined as the maximum power a subject could maintain for 1 min.Criteria for maximal exercise were 
forced ventilation, leveling off of oxygen uptake, or a respiratory exchange ratio (RER) exceeding 1.1. Highest oxygen uptake achieved for at least $30 \mathrm{~s}$ was taken as $\mathrm{VO}_{2}$ max. Energy expenditure: The ADMR was assessed by the doubly labeled water method as described previously (42). The dosage calculation was based on body mass and fat percentage to create a $300 \mathrm{ppm}$ excess $18 \mathrm{O}$ and $150 \mathrm{ppm}$ excess ${ }^{2} \mathrm{H}$. Shortly, between 2200 and 2300 the isotope drink was administered after subjects had emptied their bladder for collection of baseline urine samples. Further urine samples were collected on day 1,8 and 15 after the first voiding and between 2100 and 2300. Isotopes were measured in urine with an Aqua Sira mass spectrometer (VG-Isogas Ltd, Middlewhich, Cheshire, UK).

SMR was measured during an overnight stay (1900-0700) in a respiration chamber as described before (14). Briefly, SMR and RER were calculated from $\mathrm{O}_{2}$ consumption and $\mathrm{CO}_{2}$ production (41) during the sleeping period between 0300 and 0600 , whereas meanwhile physical activity during the sleeping period was checked by a Doppler radar system. After the overnight fast in the respiration chamber, exercise-induced thermogenesis was measured using a submaximal exercise test. Before the start of the experiment, between 0800 and 0830 , a canula was inserted in an antecubital vein for blood sampling. Measurements were started at least half an hour after insertion of the catheter. The exercise protocol consisted of $45 \mathrm{~min}$ of exercise on a bicycle ergometer at a workload of $45 \%$ of the pre-determined $W_{\max }$. The exercise was preceded by a $30-\mathrm{min}$ supine rest period (baseline measurement) and followed by a 60 -min recovery period with the subject in supine position. Respiratory exchange measurements were done continuously during basal and recovery periods by means of computerized open-circuit indirect calorimetry using a ventilated hood system [Human Biology, University of Limburg, Maastricht, the Netherlands; paramagnetic $\mathrm{O}_{2}$-analyzer (Servomex, Crowborough, UK), infrared $\mathrm{CO}_{2}$-analyzer (Hartmann \& Braun, Frankfurt, Germany) and dry-gas meter (Schlumberger, Dordrecht, the Netherlands)]. During exercise respiratory exchange responses were measured periodically for in total $20 \mathrm{~min}(0-5,15-20,30-35$, and 40-45 min) using a computerized open system (Oxycon Beta, Mijnhardt, Bunnik, the Netherlands). An electrocardiagram was monitored continuously during the experiment. Venous blood samples were collected during baseline $(t=-30$ and $0 \mathrm{~min}$ ), exercise $(t=5,15,30$, and 45 min after starting exercise), and recovery periods $(t=60$, 75 , and $105 \mathrm{~min}$ after starting exercise) for determinations of hematocrit, glucose, free fatty acids (FFA), glycerol, norepinephrine (NE) and epinephrine (EPI).

Two days after the exercise test, ISO-induced thermogenesis was determined after a $12-\mathrm{h}$ fast (overnight). During the experiment, the room temperature was kept between 23-25 ${ }^{\circ} \mathrm{C}$. At least $30 \mathrm{~min}$ after insertion of a catheter (0800-0815), the experiment was started. After 30-min baseline measurement, a continuous infusion of ISO was started in doses of $6,12,23$ and $46 \mathrm{ng} / \mathrm{kg}_{\text {fat-free mass }} \cdot \mathrm{min}$, each dose for $30 \mathrm{~min}$. The dose in the text is related to ISO sulphate, $69 \%$ of which corresponds to ISO free base. During whole the experiment, heart rate (HR) was recorded continuously and when HR had risen 30 beats/min or more, the infusion was stopped. During the whole experiment, energy expenditure (EE) and RER were continuously measured by an open-circuit ventilated hood system (Human Biology, University of Limburg, the Netherlands). EE was calculated according to Weir (41). At the end of the baseline period and each infusion 
period, venous blood samples were taken for determinations of NE, EPI, glucuse. FFA and glycerol.

The computerized open-circuit systems used for measurements of EE and RER were carefully calibrated before and at timed intervals during each test. Measured RER values during exercise-induced and ISO-induced energy expenditure were used to calculate carbohydrate and fat oxidation rates, assuming that the RER reflected the non-protein respiratory quotient (26). During the study period when measurements took place, the precision of the gas analyzers and the calibration procedures was checked by methanol (Merck 64271, Darmstadt, Germany) combustion tests of on average 2-h duration (range 1-4 h). The RER of in total 40 methanol combustion tests was found to be $0.676 \pm 0.001$ (range 0.650 to 0.690 ) with a coefficient of variation of $1.2 \%$. Oxygen was overestimated with $1.1 \pm 0.3 \%$ (range -4.6 to $4.1 \%$ ) and carbondioxide with $1.3 \%$.

Body composition and fat distribution: Body weight was measured on a digital balance accurate to $0.1 \mathrm{~kg}$ (Sauter, D-7470, Ebingen, Germany). Height was measured to the nearest $0.1 \mathrm{~cm}$ using a wall-mounted stadiometer (Seca, Germany). Body weight and height were used to calculate BMI $\left(\mathrm{kg} / \mathrm{m}^{2}\right)$. Fat distribution was evaluated by waist-hip ratio (WHR) and sagittal diameter. Waist circumference was measured as the smallest circumference between the rib cage and the iliac crest, with the subject in standing position breathing quietly. The hip circumference was measured at the level of the widest circumference between the waist and the thighs. WHR was calculated as waist divided by hip circumference. The sagittal diameter was measured using a stadiometer as the distance between abdomen and back with a subject in supine position.

Body composition was measured using 2 different techniques: isotope dilution and densitometry with simultaneous lung volume measurement (Helium-dilution). The $\% \mathrm{FM}$ was calculated from body density and total body water (TBW) according to the 3compartment model of Siri (33), which is independent on the assumptions inherent to either density of fat-free mass (FFM) and fat mass (FM) or the hydration factor of FFM (7). TBW was measured by the deuterium dilution technique. Before going to bed at night during the stay in the respiration chamber a ${ }^{2} \mathrm{H}_{2} \mathrm{O}$ dilution was drunk after emptying the bladder (baseline urine sample). The dosage calculation was based on body mass in order to create a ${ }^{2} \mathrm{H}$ excess of $100 \mathrm{ppm}$. A second urine sample was collected on the next day in the morning from the second voiding between 0800 and 1000. Deuterium was measured in urine samples with an isotope ratio mass spectrometer (VG-Isogas Aqua Sira). TBW was calculated as the measured deuterium dilution space divided by 1.04 (31). At the same morning, before the moderate exercise test, whole body density was determined by hydrostatic weighing. Underwater weight was measured to the nearest $0.1 \mathrm{~kg}$ (Sauter D-7470, Ebingen Germany) and simultaneously residual lung volume was measured with a spirometer (Volugraph, 2000, Mijnhardt. Bunnik, The Netherlands). The measurements were done in triplicate and the average was used to calculate body density.

\section{Biochemical analysis}

Glucose was determined in plasma of heparinized blood by means of a hexokinase method (Cobas Bio, Roche Diagnostics, Hoffmann-La Roche. Basle. Switzerland). 
whereas hematocrit was determined using a microcapillary system. Serum was prepared for FFA analyses (Cobas Fara, Wako NEFA C; Wako Chemicals, Neuss, Germany) and glycerol (Cobas Bio, Boehringer, Mannheim, Germany). Concentrations of plasma NE and EPI, sampled with heparin and put into glutathione containing tubes on ice, were determined by means of high-performance liquid chromatography (12).

\section{Statistical analysis}

Data in the text, tables and figures are given as means \pm SE. It appeared that for each dose of ISO infused, the EE and $\mathrm{HR}$ responses reached a steady state after $10 \mathrm{~min}$, as previously demonstrated (3). Therefore, mean values of the last 20 min were taken as representatives for that dose. The RER reached a steady state after 20 min infusion after a rapid initial increase at the start of the infusion, as previously described (3). The steady-state value for RER was therefore taken as the mean of the last 10 min of infusion. $\beta$-Adrenergic sensitivity was defined as the dose of ISO necessary to increase resting $\mathrm{EE}$ by $15 \%$ (dose $\triangle \mathrm{EE}=15 \%$ ) whereas, the sensitivity for $\mathrm{HR}$ response was defined as the dose of ISO necessary to increase resting HR by 25 beats/min $\left(\mathrm{CD}_{25}\right)$. Total exercise-induced $\left(A U C_{E X}\right.$ ) and ISO-induced $\left(A U C_{I S O}\right.$ ) response curves were calculated as the total integrated changes over baseline values. EE of daily physical activity was assessed by expressing ADMR in multiples of SMR (physical activity index $(\mathrm{PAI})=\mathrm{ADMR} / \mathrm{SMR})$, or by expressing energy expended on physical activity plus dietinduced thermogenesis as ADMR minus SMR.

To evaluate weight cycling effects, data of week 8 and 68 were excluded in the statistical analysis, since these results reflect the combined effects of weight reduction and hypocaloric state. Weight cycling effects were analyzed as differences between values before and after a weight cycle ( $\Delta$ week $60-0$ for weight cycle $I$ and $\Delta$ week 120-60 for weight cycle 2). Within both groups, the results were analyzed with repeated measurements analysis of variance (ANOVA). To analyze changes within groups, post-hoc testing was performed by Student's paired t-tests. When appropriate, P values of post hoc comparisons were adjusted according to Bonferroni's inequalities. Differences between groups were tested with one-way analysis of variance. Significance levels were set at $\mathrm{P}<0.05$.

\section{Results}

\section{Body composition and fat distribution}

There were no significant differences in body weight during the study between the DWC and DEx-WC groups as indicated in Figure 9.1. For D-WC, weight loss 2 was significantly lower than weight $\operatorname{loss} 1$, whereas there were no significant differences between weight loss 1 and 2 for the DEx-WC group (Figure 9.1). For both groups, it appeared that regain 2 was significantly less than regain 1, also when expressed as percentage of body weight. The amount of regain was not statistically different from the amount of previous weight loss, however, except for the DEx-WC group during weight 


\section{Chapter 9}

cycle 2 when subjects participated the exercise program and regain of weight was significantly lower than the previous weight loss (Figure 9.1).

There were no significant persistent effects of weight cycling on \% FM in subjects of DWC, whereas \%FM of the DEx-WC group tended to be declined at week 68 and 120 compared to D-WC (Figure 9.1). The decline in \%FM as result of the second diet during the study was significantly higher for DEx-WC compared to D-WC $(-5.3 \pm 0.5$ and -2.9 $\pm 0.4 \%$ respectively, $\mathrm{P}<0.001$ ). Furthermore, values of $\triangle \% \mathrm{FM}$ (week 120-60) were significantly different between the groups (for D-WC $0.3 \pm 0.7 \%$ and for DEx-WC -2.6 $\pm 1.4 \%, \mathrm{P}=0.05$ ), while there were no differences in values of $\Delta \% \mathrm{FM}$ (week $60-0$ ). No significant differences were observed in values of fat-free mass, WHR and sagittal diameter during the study between the groups (Table 9.2).

\section{Maximal aerobic capacity, sleeping and average metabolic rate}

Table 9.2 includes values of maximal aerobic capacity, sleeping and average metabolic rate measured during the study. In Figure 9.2 it is demonstrated that $\Delta \mathrm{W}_{\max }$ (week 120 60 ) of the DEx-WC group was significantly increased compared to that of D-WC, whereas there were no significant differences in $\Delta \mathrm{W}_{\max }$ (week 60-0). It appeared that participation in an exercise program during weight cycle 2 significantly prevented a further decrease in $\mathrm{VO}_{2 \max }$ for the $\mathrm{DEx}$-WC group, whereas $\mathrm{VO}_{2 \max }$ was significantly decreased after both weight cycles in D-WC (Figure 9.2).

Sleeping metabolic rate tended to be declined at the end of the study for D-WC, while it did not persistently change for DEx-WC (Table 9.2). No statistically significant differences between the groups could be demonstrated in values of SMR expressed per $\mathrm{kg}$ FFM or sleeping RER. The ADMR values of week 60 and 120 were not significantly different within both groups, with also no differences between the groups (Table 9.2). For both groups ADMR-SMR tended to be increased at the end of the study (week 60 and 120 for D-WC: $5.18 \pm 0.39$ and $5.68 \pm 0.29 \mathrm{MJ} / \mathrm{day}, \mathrm{P}=0.12$ and for DEx-WC: $5.53 \pm 0.59$ and $6.04 \pm 0.37 \mathrm{MJ} /$ day, $\mathrm{P}=0.09$ respectively), while the PAI was significantly increased for the D-WC group only (week 60 and 120 for D-WC: $1.74 \pm 0.07$ and $1.87 \pm 0.06, P=0.05$ and for DEx-WC: $1.78 \pm 0.08$ and $1.89 \pm 0.07, P=$ 0.23 respectively). 

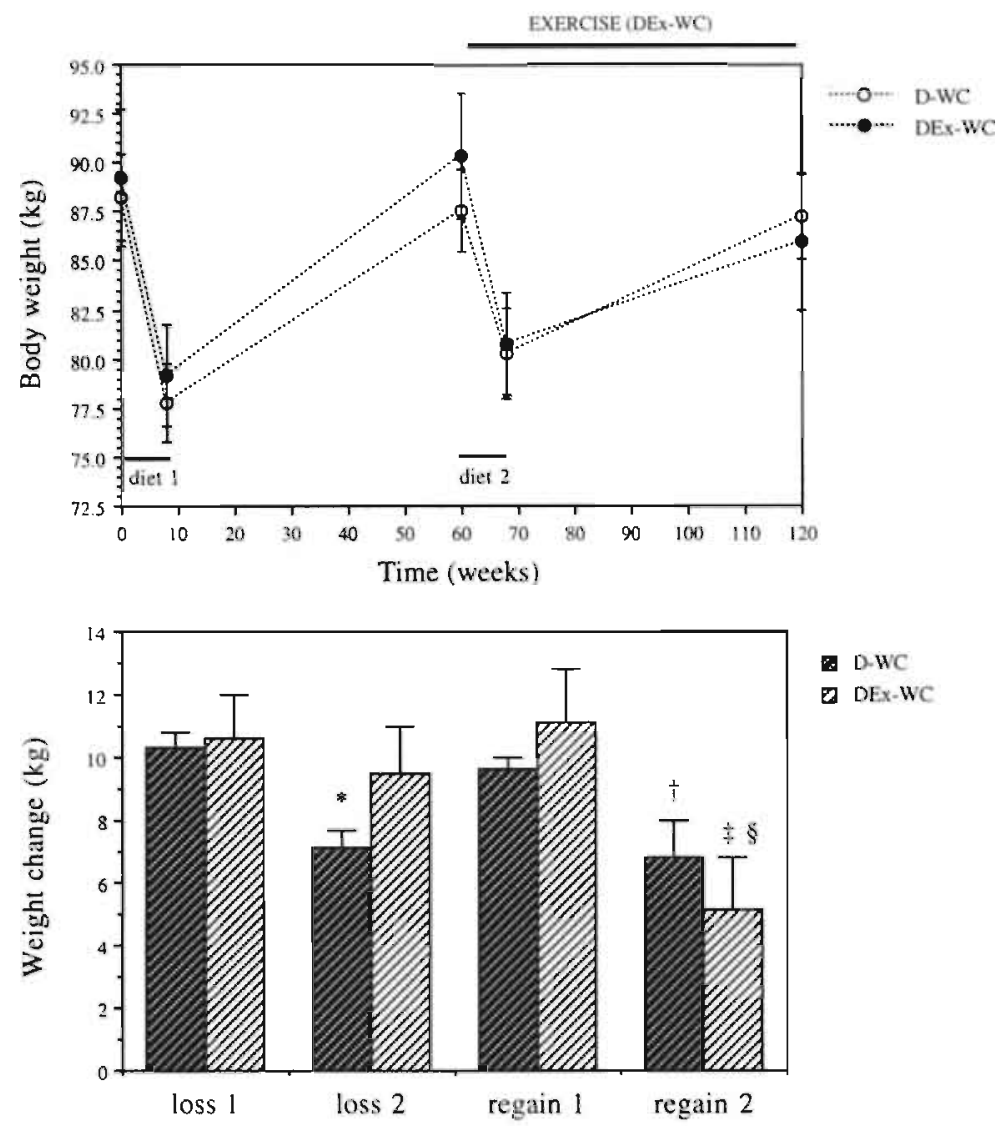

D.WC

D. DEx-WC

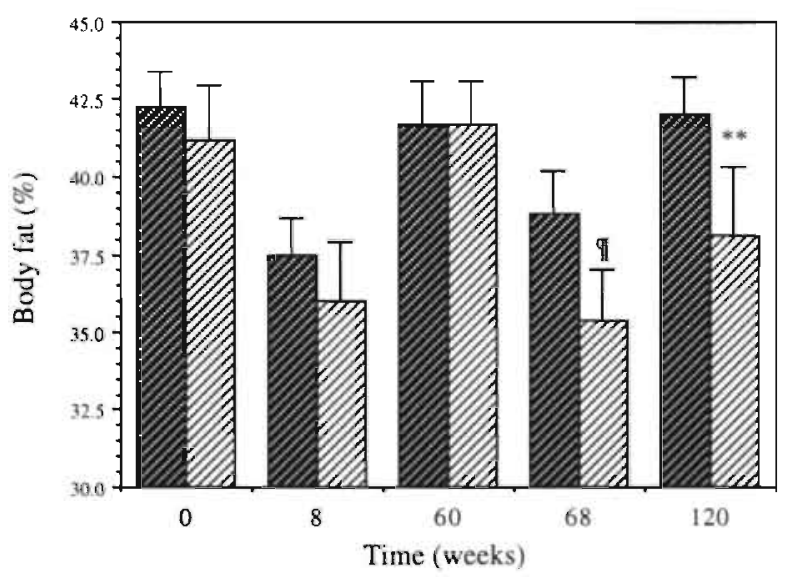

Figure 9.1 Values of body weight, weight changes, and body fat percentage of weight cycling (DWC. $n=13$ ) and exercising weight cycling (DEx-WC, $n=13$ ) obese women. Values are means $\pm \mathrm{SE} . * \mathrm{P}<0.001$ vs loss $1, \uparrow \mathrm{P}<0.05$ vs regain $1, \ddagger \mathrm{P}=0.001$ vs regain $1, \S \mathrm{P}$ $<0.05$ vs loss $2, \mathrm{IP}=0.10$ vs D-WC, ${ }^{* *} \mathrm{P}<0.05$ vs D-WC. 
Table 9.2 Values of body composition, fat distribution, maximal aerobic capacity, sleeping and average daily metbolic rate for weight cycling (D-WC) and exercising weight cycling (DEx-WC) obese women.

\begin{tabular}{|c|c|c|c|c|c|c|}
\hline \multirow[b]{2}{*}{ wick } & \multicolumn{3}{|c|}{ D-WC $(n=13)$} & \multicolumn{3}{|c|}{$\mathrm{DEx}-\mathrm{WC}(n=10)$} \\
\hline & 0 & 60 & 120 & 0 & 60 & 120 \\
\hline Weight, kg & $88.2 \pm 2.2$ & $87.5 \pm 2.1$ & $87.2 \pm 2.2$ & $89.2 \pm 3.5$ & $90.3 \pm 3.2$ & $85.9 \pm 3.4$ \\
\hline Body fat, \% & $42.3 \pm 1.1$ & $41.7 \pm 1.4$ & $42.0 \pm 1.2$ & $41.2 \pm 1.8$ & $41.7 \pm 1.4$ & $38.1 \pm 2.2 *$ \\
\hline Waist-hip ratio & $0.83 \pm 0.01$ & $0.84 \pm 0.02$ & $0.83 \pm 0.01$ & $0.82 \pm 0.02$ & $0.81 \pm 0.02$ & $0.81 \pm 0.01$ \\
\hline Sagittal diameter, $\mathrm{cm}$ & $22.8+0.7$ & $22.3 \pm 0.9$ & $22.3 \pm 0.8$ & $21.0 \pm 0.6$ & $21.1 \pm 0.7$ & $19.9 \pm 0.6$ \\
\hline$W_{\text {max }}$, Watt & $160 \pm 10$ & $163 \pm 9$ & $159 \pm 7$ & $178 \pm 9$ & $173 \pm 12$ & $182 \pm 10^{\dagger}$ \\
\hline $\mathrm{VO}_{2 \max } / \mathrm{kg} \mathrm{BW}, \mathrm{ml} / \mathrm{min} \cdot \mathrm{kg}^{-1}$ & $25.1 \pm 1.1$ & $24.3 \pm 1.3$ & $21.8 \pm 1.1 \ddagger$ & $27.0 \pm 1.3$ & $24.7 \pm 1.5 \$$ & $26.9 \pm 1.31$ \\
\hline RER during night & $0.81 \pm 0.01$ & $0.81 \pm 0.01$ & $0.82 \pm 0.01$ & $0.81 \pm 0.01$ & $0.80 \pm 0.01$ & $0.82 \pm 0.01$ \\
\hline $\mathrm{SMR}, \mathrm{kJ} / \mathrm{nt}$ m & $4.76 \pm 0.14$ & $4.81 \pm 0.12$ & $4.55 \pm 0.13^{* *}$ & $4.77 \pm 0.14$ & $4.84 \pm 0.13$ & $4.76 \pm 0.15$ \\
\hline $\mathrm{ADMR}, \mathrm{MJ} /$ day & & $12.2 \pm 0.04$ & $12.3 \pm 0.3$ & & $12.7 \pm 0.7$ & $12.9 \pm 0.5$ \\
\hline
\end{tabular}

Values are means $\pm \mathrm{SE}$. The intervention of an exercise treatment is started in DEx-WC at week 60 (after 1 weight cycle). W mechanical power; $\mathrm{VO}_{2 \max }$, maximal oxygen uptake; BW, body weight; RER, respiratory exchange ratio; SMR, sleeping metabolic rate; ADMR, average daily metabolic rate. ${ }^{*} \mathrm{P}=0.08$ one-way ANOVA for the comparison with $\mathrm{D}-\mathrm{WC}, \mathrm{P}=0.07$ repeated measurement ANOVA for the comparison with week $60 ; \$ P=0.07$ one-way ANOVA for the comparison with $D$-WC: $¥ P<0.001$ repeated measurement ANOVA, $\mathrm{P}<0.001$ for the comparison with week 0 and 60 (corrected for Bonferroni's inequalities); $\$ P<0.01$ repeated measurement ANOVA, $\mathrm{P}<0.05$ for the comparison with week 0 (corrected for Bonferroni's inequalities); $\mathbb{P P}<0.005$ one-way ANOVA for the comparison with $\mathrm{D}-\mathrm{WC} ;{ }^{* *} \mathrm{P}=0.10$ repeated measurement $\mathrm{ANOVA}, \mathrm{P}=0.09$ for the comparison with week 60 (corrected for Bonferroni's inequalities). 

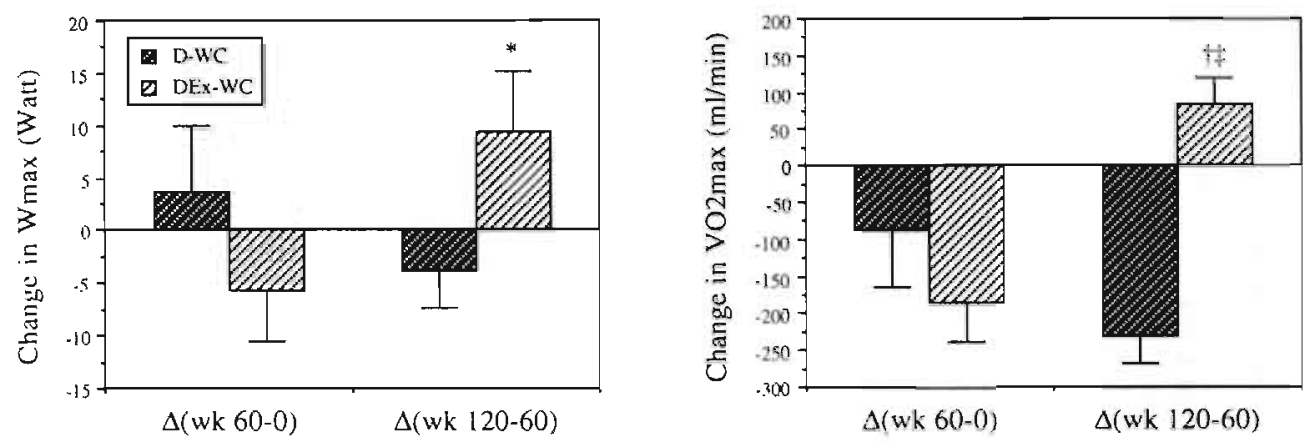

Figure 9.2 Changes in maximal mechanical power $\left(\mathrm{W}_{\max }\right)$ and oxygen uptake $\left(\mathrm{VO}_{2 \max }\right)$ of weight cycling (D-WC, $n=13$ ) and exercising weight cycling (DEx-WC, $n=10$ ) obese women. Values are means $\pm \mathrm{SE}$. Exercise for DEx-WC was performed during weight cycle 2 (week 60-120). ${ }^{* P}<0.05$ vs $\mathrm{D}$-WC, $+\mathrm{P}<0.00$ I vs $\mathrm{D}$-WC, $\ddagger \mathrm{P}=0.005$ vs $\Delta($ week $60-0)$.

\section{Exercise-induced energy expenditure}

Baseline values of EE, RER, HR, hematocrit, NE, EPI, FFA, glycerol, and glucose are shown in Table 9.3. These baseline values did not significantly differ at week 0,60 , and 120 . Since values of hematocrit did not change over time and between groups, no corrections were necessary for plasma values. Table 9.4 lists the total exercise-induced responses of EE, HR, catecholamines, FFA, glycerol and glucose. Responses of exerciseinduced EE, NE, and glycerol significantly declined during the study for both groups. There were no significant differences in the decreasing responses of exercise-induced EE, HR, FFA, glycerol and glucose during the study between the groups, although there tended to be a difference between the groups in exercise-induced EE at week 120 .

Figure 9.3 demonstrates that the declines in exercise-induced NE responses as a result of weight cycle 1 and 2 did significantly differ for $\mathrm{D}$-WC subjects, whereas there were no significant differences in $\Delta$ (week 60-0) and $\Delta$ (week 120-60) for the DEx-WC group. Furthermore, it appeared for the DEx-group, that the $\Delta$ (week 120-60) of the exerciseinduced EPI response was significantly larger than the $\Delta$ (week 60-0), while no change occurred in the D-WC group (Figure 9.3).

\section{Isoprenaline-induced energy expenditure}

In Table 9.5, the isoprenaline-induced responses of EE, HR, catecholamines, FFA, glycerol and glucose are listed. Isoprenaline-induced EE significantly decreased and $\triangle \mathrm{EE}=15 \%$ increased during the study for the D-WC group, whereas no statistically significant changes could be observed for DEx-WC. The declines in isoprenalineinduced $\mathrm{HR}$ response and increase in $\mathrm{CD}_{25}$ for D-WC were not seen for DEx-WC. Moreover, $\mathrm{CD}_{25}$ tended to be even decreased after addition of exercise treatment for DEx-WC (Figure 9.4). Furthermore, the decreases in isoprenaline-induced responses of catecholamines found for D-WC, could not be observed for the DEx-WC group. 
Table 9.3 Basal variables at week 0,60 and 120 of weight cycling (D-WC) and exercising weight cycling (DEx-WC) obese women.

\begin{tabular}{lcccccc}
\hline & \multirow{2}{*}{ week } & 0 & D-WC $(n=13)$ & 60 & 120 & \multicolumn{2}{c}{ DEx-WC $(n=10)$} \\
& & & & & 60 & 120 \\
\hline Energy expenditure, $\mathrm{kJ} / \mathrm{min}$ & $5.05 \pm 0.11$ & $5.05 \pm 0.10$ & $4.87 \pm 0.11$ & $5.16 \pm 0.18$ & $5.20 \pm 0.18$ & $5.05 \pm 0.14$ \\
Respiratory exchange ratio & $0.84 \pm 0.02$ & $0.84 \pm 0.02$ & $0.83 \pm 0.01$ & $0.86 \pm 0.02$ & $0.85 \pm 0.03$ & $0.82 \pm 0.02$ \\
Heart rate, beats/min & $70 \pm 3$ & $71 \pm 3$ & $68 \pm 3$ & $70 \pm 3$ & $68 \pm 2$ & $66 \pm 2$ \\
Hematocrit, \% & $39 \pm 1$ & $40 \pm 1$ & $40 \pm 1$ & $40 \pm 1$ & $40 \pm 1$ & $39 \pm 1$ \\
Norepinephrine, $\mathrm{pg} / \mathrm{ml}$ & $235 \pm 18$ & $205 \pm 22$ & $199 \pm 21$ & $234 \pm 20$ & $214 \pm 19$ & $239 \pm 21$ \\
Epinephrine, $\mathrm{pg} / \mathrm{ml}$ & $50 \pm 8$ & $79 \pm 18$ & $60 \pm 14$ & $34 \pm 4$ & $73 \pm 18$ & $64 \pm 15$ \\
Free fatty acids, $\mu \mathrm{mol} / \mathrm{l}$ & $475 \pm 43$ & $419 \pm 19$ & $474 \pm 28$ & $501 \pm 75$ & $503 \pm 48$ & $491 \pm 74$ \\
Glycerol, $\mu \mathrm{mol} / \mathrm{l}$ & $50.1 \pm 6.9$ & $44.1 \pm 6.9$ & $32.4 \pm 4.3$ & $55.2 \pm 6.3$ & $58.2 \pm 6.4$ & $35.3 \pm 8.1 *$ \\
Glucose, $\mathrm{mmol} / \mathrm{I}$ & $5.42 \pm 0.19$ & $5.65 \pm 0.17$ & $5.42 \pm 0.18$ & $5.39 \pm 0.17$ & $5.75 \pm 0.15$ & $5.45 \pm 0.18$
\end{tabular}

Values are means \pm SE. Exercise for DEx-WC started at week 60 (after 1 weight cycle). ${ }^{*} \mathrm{P}=0.083$ repeated measurement ANOVA.

Table 9.4 Exercise-induced responses of energy expenditure, heart rate, catecholamines. free fatty acids, glycerol and glucose at week 0 , 60 and 120 for weight cycling (D-WC) and exercising weight cycling (DEx-WC) obese women.

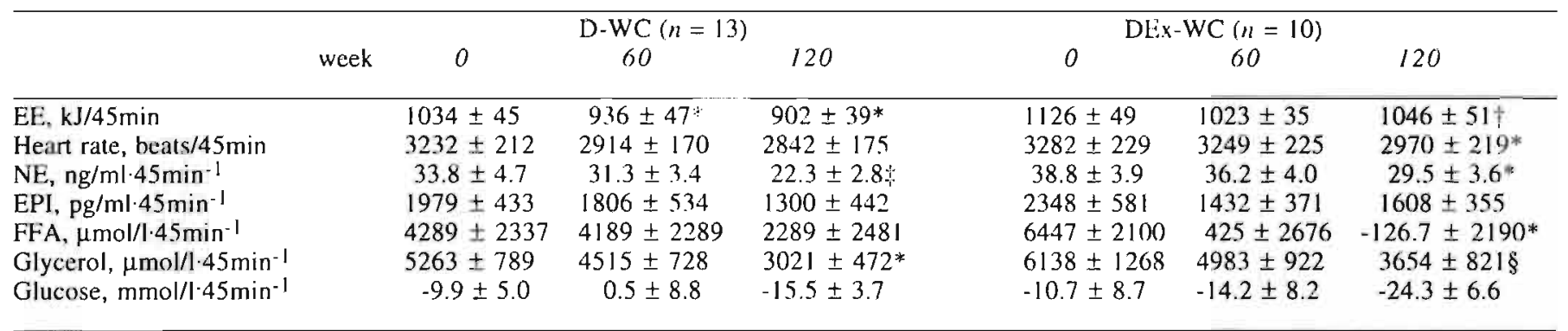

Values are means \pm SE. Exercise for DEx-WC started at week 60 (after I weight cycle). EE, energy expenditure; NE, norepinephrine; EPI, epinephrine; FFA, free fatty acids. ${ }^{*} \mathrm{P}<0.05$ repeated measurement ANOVA, $\mathrm{P}<0.05$ for the comparison with week 0 (corrected for Bonferroni's inequalities); $+\mathrm{P}<0.05$ one-way ANOVA for the comparison with $\mathrm{D}-\mathrm{WC}, \mathrm{P}=0.08$ repeated measurement $\mathrm{ANOVA}$; $\ddagger \mathrm{P}<$ 0.05 repeated measurement ANOVA, $\mathrm{P}<0.05$ for the comparison with week 0 and 60 (corrected for Bonferroni's inequalities); $\$ \mathrm{P}<$ 0.05 repeated measurement ANOVA, $\mathrm{P}<0.05$ for the comparison with week 60 (corrected for Bonferroni's inequalities). 
Table 9.5 lsoprenaline-induced responses of energy expenditure, heart rate, cutecholamines and several metabolic substrates at week 0,60 and 120 for weight cycling (D-WC) and exercising weight cycling (DEx-WC) obese women.

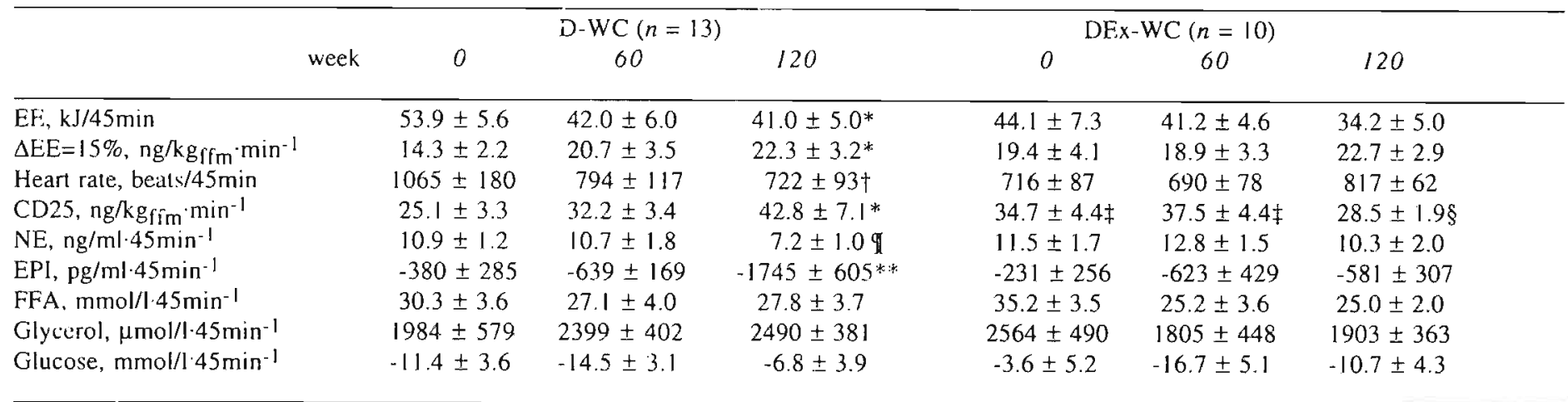

Values are means $\pm \mathrm{SE}$. Exercise intervention for DEx-WC started at week 60 (after 1 weight cycle). EE, energy expenditure; $\Delta \mathrm{EE}=\mathrm{I5 \%}$, the dose of isoprenaline necessary to increase resting energy expenditure by $15 \%$; $\mathrm{CD} 25$, the dose of isoprenaline necessary to increase resting heart rate by 25 beats/min; NE, norepinephrine; EPI, epinephrine; FFA, free fatty acids. ${ }^{*} \mathrm{P}<0.05$ repeated measurement $\mathrm{ANOVA}, \mathrm{P}<0.05$ for the comparison with week $O$ (corrected for Bonferroni's inequalities); $\dagger P<0.05$ one-way ANOVA for the comparison with $D$-WC, $P=0.07$ repeated measurement ANOVA: $\ddagger \mathrm{P}=0.09$ one-way repeated measurement ANOVA for the comparison with $\mathrm{D}$-WC; $\$ \mathrm{P}<0.05$ repeated measurement ANOVA, $\mathrm{P}=0.08$ for the comparison with week 60 (corrected for Bonferroni's inequalities). $\mathrm{P}<0.01$ one-way repeated measurement ANOVA for the comparison with D-WC; $\mathrm{IP}<0.05$ repeated measurement ANOVA, $\mathrm{P}<0.05$ for the comparison with week 0 (corrected for Bonferroni's inequalities), $\mathrm{P}<0.05$ one-way repeated measurement ANOVA for the comparison with $\mathrm{D}$-WC; $*$ * $\mathrm{P}=0.08$ repeated measurement ANOVA, $\mathrm{P}=0.06$ one-way repeated measurement ANOVA for the comparison with D-WC. 

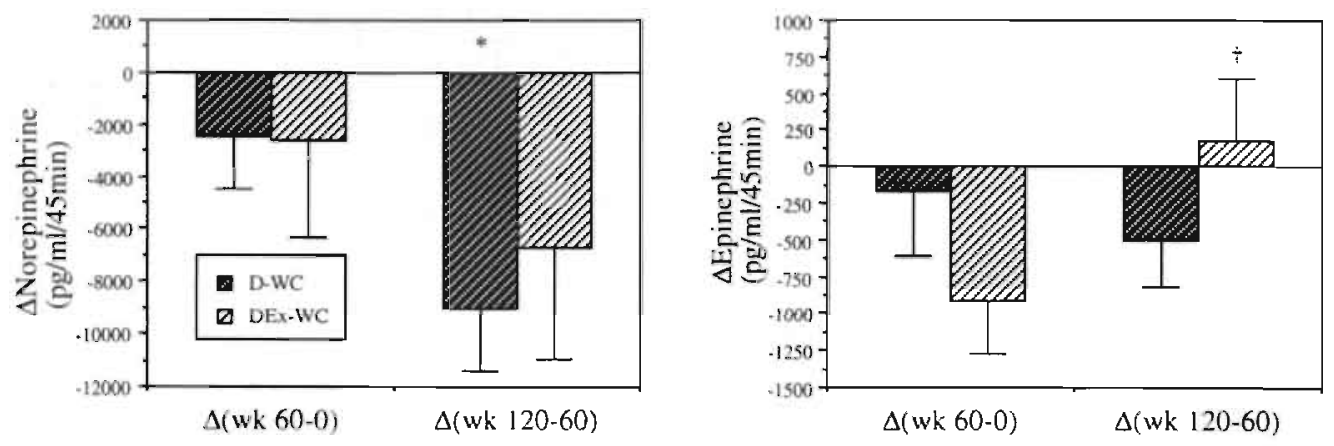

Figure 9.3 Changes in exercise-induced responses of catecholamines during two weight cycles of obese women (D-WC, $n=13$ ) and exercising obese women (DEx-WC, $n=10$ ). Values are means $\pm S E$. Exercise for DEx-WC was performed during weight cycle 2 (week 60 120). ${ }^{*} \mathrm{P}<0.01$ vs $\Delta$ (week $\left.60-0\right),+\mathrm{P}<0.05$ vs $\Delta$ (week $\left.60-0\right)$.

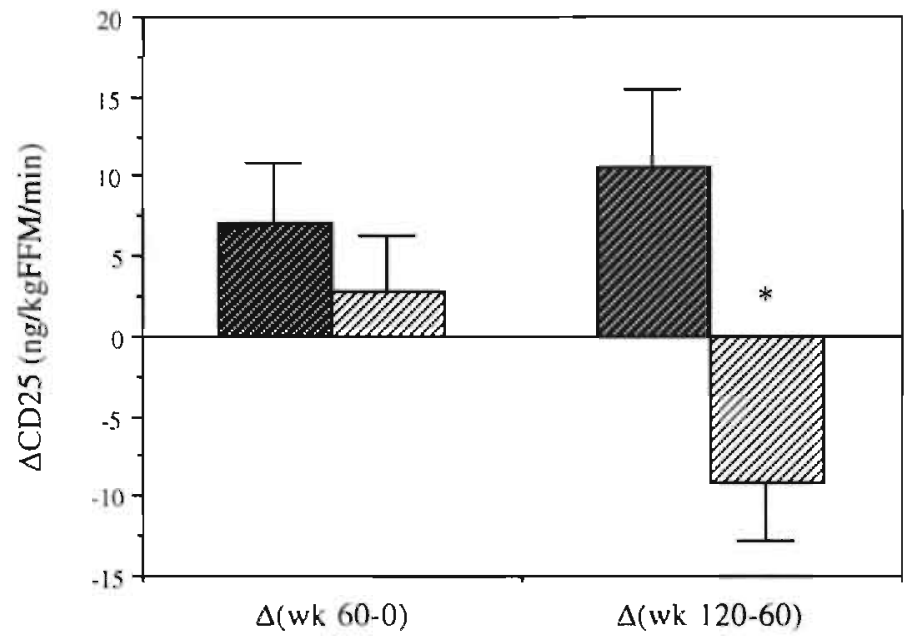

- D-WC

๑ DEx-WC

Figure 9.4 Changes in chronotropic sensitivity $\left(\mathrm{CD}_{25}\right)$ during two weight cycles of obese women (D-WC, $n=13$ ) and exercising obese women (DEx-WC, $n=10$ ). Values are: means \pm $\mathrm{SE}$. Exercise for DEx-WC was performed during weight cycle 2 (week 60-120). ${ }^{*} \mathrm{P}<$ 0.01 vs $\Delta$ (week 60-0), $\uparrow \mathrm{P}<0.05$ vs $\Delta$ (week 60-0). 


\section{Discussion}

Recently, we have demonstrated that weight cycling is associated with a blunting of the sympathetically mediated thermogenesis in a prospective study over two years in obese women (16). For the present study, it was hypothesized that participation in a regular moderate exercise program on a longer-term prevents adverse metabolic effects in weight cycling obese women and positively influences weight and body composition.

The present study demonstrates promoting effects of exercise on dietary-induced fat loss and partial prevention of regain after successful weight loss in obese weight cycling women compared to weight cycling controls alone. Moreover, the results provide evidence for a stimulating influence and partial prevention of weight cycling-induced blunting sympathetically mediated effects due to moderate regular exercise, as indicated by lower declining catecholamine responses and increased chronotropic sensitivity compared to weight cycling obese controls. This indicates involvement of adaptations of sympathetically mediated metabolic mechanisms in the observed positive effects of exercise on maintenance of weight loss and body composition. The importance of exercise to improve long-term weight maintenance in the treatment of obesity has been previously demonstrated in several studies $(6,8,9,30,35,39)$. In addition, our study for the first time demonstrates that regular moderate exercise is effective in preventing adverse effects of weight cycling on energy metabolism and control of body weight.

Participation in a regular moderate exercise program of weight cycling obese women resulted in partial prevention of declining responses of catecholamines under stimulated conditions in the present study. That training may enhance the adrenal medullary secretory capacity has also been shown before in male volunteers $(17,18)$. Further research should elucidate involved underlying physiological mechanisms, but it may be indicated that moderate regular exercise results in increased density and/or improved functioning of presynaptic $\beta$-adrenoceptors modulating sympathetic neurotransmission. These $\beta$-adrenoceptors have been demonstrated to facilitate stimulation-evoked norepinephrine release rate and release of adrenal catecholamines into the systemic circulation (10).

Our data demonstrated increased chronotropic sensitivity and enhanced maximal aerobic capacity in weight cycling exercising obese females compared to controls. Hence it is likely that sensitivity of cardiac $\beta$-adrenoceptors and cardiac output are enhanced as a result of exercise. This might be the consequence of increased density, affinity and/or functioning of cardiac $\beta$-adrenoceptors consequently leading to incruases in cardiac rate and force of contraction after a challenge (10). The obscrved effects might be $\beta_{1}$ - and/or $\beta_{2}$-mediated, since these receptors have been demonstrated to equally contribute to the ISO-induced heart rate response (2).

However, no detectable effects of exercise on exercise-induced and isoprenalineinduced whole-body thermogenic and lipolytic responses and metabolic substrates involved could be demonstrated in the present study. These results appear to be in contrast with a study of Nielsen et al (25) demonstrating increased thermogenic responses to ephedrine in obese and lean subjects after training. However, the training in the study of Nielsen et al (25) consisted of cycling for $1 \mathrm{~h}$ at $60-80 \%$ of $\mathrm{VO}_{2 \max }$, five days per week for in total 5 weeks. Explanations for absence of exercise-induced effects on 
thermogenesis and lipolysis in the present study remain speculative. It might indicate tissue-specific adaptations of training in weight cycling obese women, perceptible in cardiac but not in thermogenic and lipolytic responses. The tissue primarily involved in exercise-induced and ISO-induced thermogenesis is skeletal muscle whereas adipose tissue is mainly responsible for lipolysis $(2,3)$. The results therefore do not indicate major training-induced adaptations of skeletal muscle and adipose tissue as far as they are detectable with the methods used in the present study.

Many training-induced physiological adaptations of skeletal muscle and adipose tissue has been described, depending on intensity, duration and frequency of the exercise. These adaptations include enhanced skeletal muscle glycogen storage capacity and synthesis rate (1), increased skeletal muscle $\beta_{2}$-adrenoceptor density, although the latter may be species-specific to rats but not to humans (22). Furthermore. catecholaminesstimulated lipolysis of adipocytes has been shown to be enhanced by exercise training $(28,39)$ whereas capacity to oxidize lipids is increased, probably mainly as a result of increased intramuscular transport capacity and greater utilization of intramuscular lipid $(22,24,29,39,40)$. It have to be realized that possible adaptations of skeletal muscle and adipose tissue are likely to be small as a result of moderate training such as used in the present study and may be hard to detect on a whole body level $(2,3)$. On the other hand, an exercise program for obese subjects has to be within the physical ability of most individuals. It therefore requires an adequate intensity and frequency to improve motivation and compliance and to be feasibly incorporated in normal daily life on the longer-term.

Although no effects of exercise could be demonstrated in weight cycling obese women on thermogenic and lipolytic responses in the present study, the observed physiological adaptations of increased catecholamine responses, increased chronotropic sensitivity and enhanced maximal aerobic capacity are likely to beneficially influence energy metabolism because of several reasons. Firstly, maximal aerobic capacity has been demonstrated to be a factor capable of modifying the relationship between meal size and diet-induced thermogenesis, since individuals with a higher $\mathrm{VO}_{2 \max }$ responded to a meal with a greater caloric expenditure than individuals with a lower $\mathrm{VO}_{2 \max }(11)$. In addition, higher postprandial energy expenditure levels after 12 weeks of training has been observed in lean, obese, and diabetic subjects (32). Secondly, an increased resting metabolic rate has been reported by some, but not all, after training $(37,39)$ and it has been suggested that this is mediated by enhanced sympathetic tone (37). The observed tendency to increased sleeping and resting energy expenditure values in exercising females compared to weight cycling controls in the present study indicates similar adaptations to exercise. The unchanged daily molabolic rate values, however. may indicate partial compensation of energy expended during training hours by a decrease in normal daily activities.

Finally, the observed positive effects of exercise on body weight and body composition suggest an important role of sympathetically mediated adaptations in energy metabolism, although it cannot be excluded that other factors might also be involved. It has been suggested that the regulation of food intake is linked to the level of physical activity (29). Food intake may be better regulated at higher levels of physical activity through a higher carbohydrate intake at the expense of fat $(29,39)$, possibly preventing weight 
gain (20). On the other hand, no change in energy intake and macronutrient composition of the diet during training has been described in overweight females (13). Since the number of subjects per group were too small in relation to the statistical power, we did not analyze macronutrient intake.

In conclusion, the present study demonstrates partial prevention of weight cyclinginduced adverse metabolic effects as result of moderate exercise in obese women. Exercise counteracted weight cycling-induced declining maximal aerobic capacity and decreased responses of catecholamines. Furthermore, $\beta$-adrenergically mediated chronotropic sensitivity was enhanced by exercise. These exercise-induced metabolic adaptations may be involved in the observed stimulating effects of exercise on dietaryinduced fat loss and prevention of weight regain. Therefore, moderate regular exercise appears to be effective for improving long-term weight maintenance in the treatment of obesity.

\section{References}

1. Allenberg $\mathrm{K}$, Nilsson $\mathrm{M}$, Landin $\mathrm{K}$, Lindgarde $\mathrm{F}$. Glycogen and lactate synthetic pathways in human skeletal muscle in relation to obesity, weight reduction abd physical training. Eur $J$ Clin Invest 18: 250-255, 1988.

2. Blaak EE, van Baak MA, Kemerink GJ, Pakbiers MTW, Heidendal GAK, Saris WHM. $\beta$ Adrenergic stimulation of energy expenditure and forearm skeletal muscle metabolism in lean and obese men. Am J Physiol 267: E306-315, 1994.

3. Blaak EE, van Baak MA, Kester ADM. Saris WHM. B-Adrenergically mediated thermogenic and heart rate responses: effect of obesity and weight loss. Metabolism 44: 520-524, 1995.

4. Blackbum GL, Wilson GT, Kanders BS, Stein LJ, Lavin PT, Adler J, Brownell KD. Weight cycling: the experience of human dieters. Am J Clin Nutr 49: 1105-1109. 1989.

5. Brownell, KD, Greenwood MRC, Stellar E, Shrager EE. The effect of repeated cycles of weight loss and regain in rats. Physiol Behav 38: 459-464, 1986.

6. Dale van D, Saris WHM, ten Hoor F. Weight maintenance and resting metabolic rate 18-40 months after diet/exercise treatment. Int J Obes 14: 347-359, 1990

7. Goran MI, Poehlman ET, Danforth E, Nair KS. Comparison of body fat estimates derived from underwater weight and total body water. Int J Obes 18: 622-626, 1994.

8. Grilo CM. Physical activity and obesity. Biomed Pharmacother 48: 127-136, 1994.

9. Hensrud DD, Weinsier RL, Darnell BE, Hunter GR. A prospective study of weight maintenance in obese subjects reduced to normal body weight without weight-loss training. Am J Clin Nutr 60 : 688-694, 1994.

10. Hieble JP, Ruffolo RR. Functions mediated by $\beta$-adrenoceptor activation. In Ruffolo RR (ed). $\beta$ Adrenoceptors: molecular biology, biochemistry and pharmacology. Prog Basic Clin Pharmacol Karger, Basel 7: 173-209, 1991.

11. Hill JO, Heymsfield SB, McMannus III C, DiGirolamo M. Meal size and thermic response to food in male subjects as a function of maximum aerobic capacity. Metabolism 33: 743-749, 1984.

12. Hjemdahl P. Plasma catecholamines; analytical challenges and physiological limitations. Baillière's Clin Endocrinol Metab 7:307-353, 1993.

13. Keim NL, Barbieri TF, Belko AZ. The effect of exercise on energy intake and body composition in overweight women. Int J Obes 14: 335-346, 1990.

14. Kempen KPG, Saris WHM, Senden JMG, Menheere PPCA, Blaak EE, van Baak MA. Effects of energy restriction on acute adrenoceptor and metabolic responses to exercise in obese subjects. Am J Physiol 267: E694-E701, 1994. 
15. Kempen KPG, Saris WHM, Westerterp KR. Energy balance during 8 weeks energy-restrictive diet with and without exercise in obese females. Am J Clin Nutr 62: 722-729, 1995.

16. Kempen KPG, Blaak EE, van Baak MA, Saris WHM. Weight cycling is associated with blunting of the sympathetically mediated thermogenesis in obesity. Submitted.

17. Kjar M, Christensen NJ, Sonne B, Richter EA, Galbo H. Effect of exercise on epinephrine turnover in trained and untrained male subject. $J$ Appl Physiol 59:1061-1067, 1985.

18. Kjær M. Exercise effects on adrenergic regulation of energy metabolism. In Lamb DR, Gisolfi $\mathrm{CV}$ (eds). Perspectives in exercise science and sports medicine, vol 5: Energy metabolism in exercise and sport. Wm C Brown Communications Inc, Dubuque, IA pp 345-376, 1992.

19. Kuczmarski RJ. Flegal KM, Campbell SM, Johnson CL. Increasing prevalence of overweight among US adults. The National Health and Nutrition Examination Surveys, 1960 to 1991. JAMA 272: 205-211, 1994.

20. Lissner L, Strupp DA, Kalkwarf HJ, Roe DA. Dietary fat and the regulation of energy intake in human subjects. Am J Clin Nutr 46: 886-892, 1987.

21. Manore MM, Berry TE, Skinner JS, Carroll SS. Energy expenditure at rest and during exercise in nonobese female cyclical dieters and in nondieting control subjects. Am J Clin Nutr 54: 4l-46, 1991.

22. Martin WH, Coggan AR, Spina RJ, Saffitz JE. Effects of fiber type and training on $\beta$ adrenoceptor density in human skeletal muscle. Am J Physiol 257: E736-E742, 1989.

23. Marin WH, Dalsky GP. Hurley BF, Matthews DE, Bier DM, Hagsberg JM, Rogers MA. King DS, Hoolszy JO. Effect of endurance training on plasma free fatty acid tumover and oxidation during exercise. Am J Physiol 265: E736-E742, 1989.

24. Miller JP, Pratley RE, Goldberg AP, Gordon P, Rubin M, Treuth MS, Ryan AS, Hurley BF. Strenght training increases insulin action in healthy 50- 10 65-yr-old men. J Appl Physiol 77: 1122-1127, 1994.

25. Nielsen B, Astrup A, Samuelsen P, Wengholt H, Christensen NJ. Effect of physical training on thermogenic responses to cold and ephedrine in obesity. Int J Obes 17: 383-390, 1993.

26. Péronnet F, Massicotte D. Table of non-protein respiratory quotient: an update. Can J Sports Sci 16: 23-29, 1991 .

27. Prentice AM, Jebb SA, Goldberg GR, Coward WA, Murgatroyd PR, Poppitt SP, Cole TJ. Effects of weight cycling on body composition. Am J Clin Nutr 56: 209S-216S, 1990.

28. Riviere D, Crampes F, Beauville M, Garrigues M. Lipolytic response of fat cells to catecholamines in sedentary and exercise-trained women. $J$ Appl Physiol 66: 330-335, 1989.

29. Saris WHM. Physiological aspects of exercise in weight cycling. Am J Clin Nurr.49: 1099-1104, 1989.

30. Saris WHM, Koenders MC, Pannemans DLE, van Baak MA. Outcome of a multicenter outpatient weight-management program including very-low-calorie diet and exercise. Am J Clin Nutr 56: 294S-296S, 1992.

31. Schoeller DA, Jones PJH. Measurement of total body water by isotopic dilution: a unified approach to calibrations. In Ellis KJ, Yasumura S, Morgan WD (eds). In vivo body composition studies. London, Institute of Physical Sciences in Medicine pp 131-136, 1987.

32. Segal KR, Blando L, Ginsberg-Fellner F, Edaño A. Postprandial thermogenesis at rest and postexercise before and after physical training in lean, obese, and mildly diabetic men. Metabolism 41: 868-878, 1992.

33. Siri WE. Body composition from fluid spaces and density: analysis of methods. In Brozek J, Henschel A (eds). Techniques for measuring body composition. Washington DC, National Academy of Sciences pp 223-244, 1961.

34. Steen SN, Oppliger RA, Brownell KD. Metabolic effects of repeated weight loss and regain in inadolescent wrestlers. JAMA 260: 47-50, 1990.

35. Svendsen OL, Hasager C, Christiansen C. Six months' follow-up on exercise added to short-term diet in overweight postmenopausal women-effects on body composition, resting metabolic rate, cardiovascular risk factors and bone. Int J Obes 18:692-698, 1994. 
36. Tremblay A, A. Nadeau A, Fournier G, Bouchard C. Effect of a three-day interruption of exercise-training on resting metabolic rate and glucose-induced thermogenesis in trained individuals. Int J Obes 12: 163-168, 1988.

37. Tremblay A, Coveney S, Després J-P, Nadeau A, Prud'homme D. Increased resting metabolic rate and lipid oxidation in exercise-trained individuals: evidence for a role of $\beta$-adrenergic stimulation. Can J Physiol Pharmacol 70: 1342-1347, 1992.

38. Tremblay A, Alméras N, Boer J, Klein Kranenbarg E, Després J-P. Diet composition and postexercise energy balance. Am J Clin Nutr 59: 975-979, 1994.

39. Tremblay A, Beumann B. Exercise-training, macronutrient balance and body weight control. Int J Obes 19: 79-86, 1995.

40. Vusse van der GJ, Reneman RS. Lipid metabolism in muscle. In Rowell LB. Shephard JT (eds). Handbook of physiology. Integration of motor, circulatory, respiratory and metabolic control during exercise. In press.

4l. Weir JB de V. New methods for calculating metabolic rate with special reference to protein metabolism. J Physiol 109: 1-9, 1949.

42. Westerterp KR, Wouters L, van Marken Lichtenbelt WD. The Maastricht protocol for the measurement of body composition and energy expenditure with labeled water. Obes Res 3[suppl. 1]: 49-57, 1995. 



\section{General discussion}

Concerns for adverse weight cycling effects have received tremendous publicity in the past years, despite lack of convincing evidence as based on currently available literature. The prospective research described in the present thesis involves metabolic consequences of weight cycling in obesity. The design of the study included repeated controlled weight loss interventions, with subsequent non-controlled long-term followup periods with weight regain, resulting in weight cycling.

The first part in the project concentrated on energy restriction-induced weight loss. Physiological adaptations of energy metabolism to weight loss were elucidated, with emphasis on the sympathetic nervous system, skeletal muscle metabolic characteristics, and serum lipids and lipoproteins. The next step in the project was to investigate effects of weight cycling on energy metabolism, body composition, and serum lipid and lipoprotein profiles. Finally, a possible beneficial influence of regular, moderate physical exercise on energy metabolism, body composition, and serum lipid and lipoprotein profiles was evaluated in weight cycling obese women.

\section{Metabolic effects of dietary-induced weight loss}

Brownell et al (12) demonstrated for the first time that weight cycled obese rats showed a significantly increased food efficiency compared to controls, indicating development of energetic efficiency with weight cycling. It remains to be elucidated whether this finding may be extrapolated to effects of weight cycling in humans.

It is well established that acute energy restriction is associated with increased energetic efficiency (70). Levels of energy expenditure decline with energy restriction, as result of several adaptive physiological changes in order to reattain energy balance. Decreased activity of metabolically active tissue, related to hormonal changes, contributes to this acute energy restriction-induced increased metabolic efficiency. The involved hormonal changes include alterations of sympathetic nervous system activity, changes in thyroid metabolism, and changes in pancreatic peptide hormones such as insulin and glucagon. The consequences are promotion of endogenous substrate mobilization, leading to an increase in circulating free fatty acids and muscular oxidation of fatty acids in order to spare carbohydrate. With proceeding energy restriction (after 5-10 days), a further decrease in energy expenditure is mainly attributed to loss of metabolically active tissue. In states of chronic energy deficiency, acute hormonal alterations in catecholamines. insulin and thyroid status appear to persist over longer periods of time (70). These chronic changes in energy balance have been studied extensively in malnourished or 
lean individuals. So far, it is unknown whether these persistent changes in energy efficiency also occur during energy restriction in obese subjects and if so whether these changes are reversible during the weight maintenance phase.

\section{Modulation of adrenoceptors}

The importance of sympathetic nervous system activity in the etiology of obesity $(7,55)$ and adaptations to changes in energy intake $(50,54.80)$ has been previously established. For evaluating metabolic adaptations to weight cycling it may therefore be obvious to concentrate on possible changes in sympathetic nervous system activity during weight reduction. One of the factors mediating sympathetic nervous system activity is the status of adrenoceptors. Adrenoceptor status partially determines the sensitivity and responsiveness of tissues to catecholamines. Energy restriction has been shown to modulate catecholamine levels $(50,54,70)$, but nutritional influences on adrenoceptor status are not well established. From the study described in Chapter 2, it was concluded that adrenoceptor density can be modulated by energy restriction. An exercise-induced up-regulation of lymphocyte $\beta_{2}$-adrenoceptors was observed after energy restriction that did not occur before the diet, whereas an increase in basal platelet $\alpha_{2}$-adrenoceptor number was observed.

Easy accessible circulating blood cells, rather than less accessible catecholamine target tissues such as skeletal muscle, are often used to determine adrenoceptor status $(10,47)$. Using the model of circulating blood cells to assess adrenoceptor status may, however, be associated with several limitations for interpretation of derived study results. Firstly, it is based on the assumption that the status of adrenoceptors on blood cells can be extrapolated to adrenoceptor status of other tissues and this has been suggested to be valid only in a subtype-specific fashion $(10,11,47)$. Therefore, lymphocytes containing a homogeneous population of $\beta_{2}$-adrenoceptors may suitably reflect adrenoceptor status of skeletal muscle, that mainly contains $\beta_{2}$-adrenoceptors (46). This is confirmed by the significant relationship between the density of $\beta_{2}$-adrenoceptors of skeletal muscle and lymphocytes as described in Chapter 2. However, extrapolation of adrenoceptor status on blood cells to tissues containing mixed adrenoceptor subtypes such as adipose tissue may be of limited value $(17,47)$.

Secondly, alterations in adrenoceptor density and affinity may not be necessarily related to changes of hemodynamic and metabolic responses to catecholamines in vivo (47). Adrenoceptor status represents only a single index of sympathetic nervous system activity. This may be misleading when considering functional events since additional regulatory factors are involved such as balance between $\alpha$ - and $\beta$-adrenoceptors, postreceptor events, levels of circulating catecholamines, and other regulatory systems with opposite effects. The alterations in blood cell adrenoceptor status as result of energy restriction as described in Chapter 2 were associated with increased exercise-induced lipolytic, thermogenic, and chronotropic responses, whereas responses of catecholamines were unchanged. These findings indicate that the observed exercise-induced upregulation of $\beta_{2}$-adrenoceptors was associated with functional metabolic consequences. as in agreement with others demonstrating a $\beta$-adrenergic supersensitive state after weight loss $(4,7)$. However, the importance of increased platelet $\alpha_{2}$-adrenoceptor density with energy restriction remains unknown, since no obvious physiological 
adaptations were observed that may be in agreement with functional basal $\alpha_{2}-$ adrenoceptor up-regulation. Moreover, a decrease in $\alpha_{2}$-adrenoceptor number and an increase in $\beta$-adrenergic activity of adipocytes were observed with fasting in hamsters (13), indicating less or no metabolic importance of basal platelet $\alpha_{2}$-adrenoceptor upregulation.Thus, altogether the results of the study described in Chapter 2 indicate functional up-regulation of $\beta_{2}$-adrenoceptors of adipose tissue, skeletal muscle and cardiac tissue. However, since the determined physiological variables such as serum concentrations of glycerol and free fatty acids, energy expenditure and respiratory exchange ratio only reflect whole body responses, no conclusions on contributions of different tissues to overall metabolic changes to energy restriction can be drawn.

In summary, it appears that adrenoceptors can dynamically be modulated by energy restriction. Especially alterations of $\beta$-adrenoceptors are likely to be of importance for functional adaptations in energy metabolism. In addition, exercise may play a role in the up-regulation of $\beta_{2}$-adrenoceptors and this is probably of special importance in the obese. Further research should establish tissue-specific alterations of different adrenoceptors with nutritional modulation and their functional role in physiological adaptations. In addition, it is not known whether weight cycling modulates adrenergic receptor status, but at present there are no indications in the literature to assume persistent changes in adrenoceptor status with weight cycling. Since the observed declined exercise-induced catecholamine responses with weight cycling as described in Chapter 6 were associated with blunted thermogenic, lipolytic, and cardiac responses it may be speculated that no persistent exercise-induced up-regulation of $\beta$-adrenoceptors occurred.

\section{Skeletal muscle adaptations}

The role of impaired fat utilization in development and maintenance of large fat stores has previously been suggested $(24,84)$. Recent data indicate that at least part of this defect is located in skeletal muscle $(6,15)$. Skeletal muscle represents a large tissue of the body accounting for $20-30 \%$ of oxygen consumption during rest, and up to $90 \%$ during exercise (84). Consequently, even small muscular adaptations may have metabolically significant effects. Therefore, energetic adaptations to energy restriction and weight cycling may involve changes in fat oxidation that take place in skeletal muscle. Until now, the available literature does not report on muscular adaptations to weight cycling. In Chapter 3 it is concluded that muscular adaptations to energy restriction involve increased intracellular fatty acid transport capacity, whereas activity of oxidative enzymes was not changed. These muscular adaptations were associated with an increased basal relative contribution of lipid oxidation to energy expenditure. An implication of these findings is that an increased cytosolic H-FABP content enables the skeletal muscle to meet the demands of increased fatty acid utilization during energy restriction.

Although the physiological significance for human energy metabolism remains to be established, the data suggest a role for skeletal muscle cytosolic H-FABP in metabolic adaptations to energy restriction. Previous studies, mainly performed in animals, have demonstrated that FABPs are involved in the transcytoplasmic transport of poorly 
soluble fatty acids and intracellular lipid homeostasis $(3,26,27)$. Recently. a polymorphism of the intestinal FABP locus was identified in Pima indians that may account for reduction in insulin action in this group (2). Nevertheless, for most assumed functions of FABPs no definite evidence has yet been given and intracellular fatty acid transport capacity is probably not rate-limiting in overall intramuscular fatty acid utilization (77). Despite these findings, there are indications for involvement of FABPs in cellular fat utilization. Firstly, a quantitative relationship between skeletal muscle mitochondrial fatty acid oxidation capacity and H-FABP content has been described $(26,27)$. Skeletal muscle H-FABP appeared to be related to the proportion of oxidative fibers and activity of oxidative enzymes, as described in Chapter 3. Secondly, the cytoplasmic FABP content of heart muscle and reliance on fatty acids for energy supply have recently been demonstrated to increase upon induction of experimental diabetes in rat and normalization of FABP levels and substrate metabolism occurred after transplantation of islets of Langerhans (28). Therefore, the observed increase in skeletal muscle H-FABP content as result of energy restriction as described in Chapter $\mathbf{3}$ is likely to be involved in accompanying cellular metabolic alterations.

Increased $\mathrm{H}-\mathrm{FABP}$ content is likely to enhance the cytoplasmic solubility of long-chain fatty acids and their transcytoplasmic flux. However, increased skeletal muscle H-FABP combined with unchanged activity of the oxidative enzymes citrate synthase and HAD may suggest a discrepancy between fatty acid transport and utilization after energy restriction. The importance of this finding is not known, but it may be speculated that the discrepancy between transport and utilization reflects a temporary state in which $\mathrm{H}$ FABP is an early marker for adaptation to changes in nutritional status. Furthermore, it is possible that more fatty acids enter other intracellular pathways such as are storage as triglycerides, which needs more H-FABP but unchanged oxidative enzyme activity.

Thus, although the increased skeletal muscle intracellular fatty acid transport capacity is likely to be involved in the metabolic adaptations to energy restriction, the exact physiological significance remains uncertain. It has to be realized, however, that small adaptations of skeletal muscle may have relevant consequences on a whole body level since skeletal muscle considerably contributes to total oxygen consumption and respiratory exchange ratio of the body (84). Whether adaptations of muscular intracellular fatty acid transport capacity persist beyond the acute periods of hypocaloric state and weight loss, or during weight cycling, is currently unknown. It may be speculated that the muscular adaptations of H-FABP are likely the rcsult of the acute energy-restrictive state, since weight cycling was associated with decreased sympathetically mediated thermogenic and lipolytic responses, whereas fat oxidation tended to be impaired (Chapter 6).

\section{Serum lipids and lipoproteins}

Weight variability has been demonstrated to be associated with increased cardiovascular morbidity and mortality $(8,33)$. Therefore, possible adverse weight cycling effects may involve modulation of cardiovascular risk factors such as serum lipids and lipoproteins $(53,83)$. When firstly concentrating on effects of weight loss, it has been shown that energy restriction-induced weight loss is advantageous in normalizing serum lipids and 
lipoproteins in obese subjects, although HDL-C values appear to be decreased during active weight loss (20) as in agreement with our results (Chapter 4). In our study, decreased levels of serum triglycerides, total cholesterol, LDL- and HDL-cholesterol, apo $\mathrm{B}$, and apo A-I were found with weight loss, whereas mean serum levels of $\mathrm{Lp}$ (a) were not significantly influenced by energy restriction. However, there appeared to be responders and non-responders in changing serum $L p(a)$ levels after treatment, dependent on initial $L p(a)$ levels as in agreement with others (71). Subjects with high initial levels ( $>25-30 \mathrm{mg} / \mathrm{dl}$ ) demonstrated a decrease, while no change was found with energy restriction in those with low levels at baseline. The study described in Chapter 4 provides no support for the hypothesis that basal levels and energy restriction-induced alterations of $\mathrm{Lp}(\mathrm{a})$ and other lipoprotein variables are dependent on apo $\mathrm{E}$ polymorphism.

Serum levels of $L p(a)$ appeared to be rather resistant to pharmacological and dietary modifications and have been suggested to mainly genetically determined (9). Apo E polymorphism is considered to be an important genetic factor, that has been demonstrated to influence serum lipid and lipoprotein levels $(22,32,82)$ including $L p(a)$ (43). We only observed a significant contribution of apo E polymorphism to baseline TC values whereas no influence was observed on baseline or energy restriction-induced changes of LDL-C, apo B, TG, HDL-C, apo A-I, and Lp(a). Probably the small sample size and relative homogeneity in lipid values of the normolipidemic obese study population contribute to the observed results, that appear to conflict with others demonstrating a significant influence of apo $\mathrm{E}$ polymorphism on lipid and lipoprotein metabolism $(22,32$. 82) including $L p(a)$ (43). On the other hand, it has been suggested that the genomic region encoding the apo(a) glycoprotein accounts for greater than $90 \%$ of the variation in plasma $L p(a)$ concentrations (9). implicating that apo (a) genotype rather than apo $E$ polymorphism determines the regulation of Lp(a). Recently, however, it has been shown that beside apo(a) size, Lp(a) particle density is associated with variation in HDL-C and apoB-containing lipoproteins. This indicates similar underlying pathways (60), that do not exclude a role of apo E polymorphism.

\section{Predicting metabolic variables}

There is considerable variation in weight loss achieved by obese individuals who are enrolled in a weight loss program. The precise role of metabolic variables that regulate energy expenditure and substrate utilization in relation to weight loss outcome is not well established. More knowledge on metabolic variables related to successful weight loss may be useful to identify individuals who will benefit most from treatment. The study described in Chapter $\mathbf{5}$ shows that basal sympathetic nervous system activity and insulin resistance were of significant predictive value for dietary-induced fat loss.

The prognostic value of pre-treatment plasma catecholamine levels appeared to be in accordance with our original hypothesis on involvement of sympathetic nervous system activity in regulation of energy restriction-induced body fat loss and others (1). The importance of sympathetic nervous system activity for prediction of dietary-induced fat loss may be related to the finding, that sympathetic nervous system activity has been demonstrated to contribute to energy expenditure (81). In addition, a role of sympathetic 
nervous system activity in the development and maintenance of obesity has been suggested $(7,55)$.

Recently, fat utilization has been demonstrated to be impaired in obesity and this defect may be at least partially localized in skeletal muscle $(6,15)$. In addition, 24 -h fat oxidation has been indicated to be involved in weight loss outcome in obese women (1). Therefore, the finding of a tendency toward an inverse relation between energy restriction-induced decline of body fat and pre-treatment relative fat utilization during exercise was rather unexpected. This finding was to be attributed to differences in absolute amounts of carbohydrate oxidized during exercise between successful and less successful subjects, that consequently had an impact on relative contributions of substrates since absolute fat oxidation rates were similar. Those subjects oxidizing more carbohydrates during exercise were more successful in losing body fat on a very-lowcalorie diet than those oxidizing lower amounts of carbohydrates. Furthermore, exerciseinduced responses of glucose and insulin were inversely related to decrease in body fat percentage strongly indicating involvement of hyperinsulemia and insulin sensitivity in the regulation of body fat stores.

The observed findings of involvement of pre-treatment hyperinsulemia and insulin resistance in weight loss outcome may be related to several accompanying metabolic disturbances. Firstly, insulin resistance has been demonstrated to be associated with diminished thermogenic responses to nutrient administration $(29,61,69)$. Furthermore, lower oxidation of carbohydrate may reduce the activity of the glycogen cycle resulting in lower energy costs (23) and modulation of energy intake by increasing dietary fat (76). The observed involvement of insulin sensitivity in weight loss outcome also fits in the general idea that insulin resistance is an adaptation to resist further weight gain. An important role of skeletal muscle for insulin resistance has been previously demonstrated (44), but when combining our data of Chapter $\mathbf{3}$ and $\mathbf{5}$, no significant relationships between skeletal muscle characteristics and measured metabolic variables reflecting insulin sensitivity could be found.

In conclusion, low basal sympathetic nervous system activity, hyperinsulinemia and insulin resistance decrease the probability of successful weight loss to dietary treatment in obese women. However, if we include the weight regain period and predict weight cycling, there appeared to be no indications for a role of basal sympathetic nervous system activity and insulin resistance on the basis of the present data since no significant correlations of these variables were observed with a calculated weight cycling index which quantifies the amount of weight cycling during the study. This may implicate that in stead of individual metabolic parameters, behavioral factors may be involved in body weight regulation on a longer term.

\section{Metabolic and health consequences of weight cycling}

\section{Energy metabolism}

Weight cycling has been suggested to be associated with unfavorable alterations of energy metabolism. The study described in Chapter 6 confirms this suggestion by 
demonstrating that weight cycling in obese women is associated with blunting of sympathetically mediated thermogenic, chronotropic, and lipolytic responses. These effects appeared to be independent of changes in body composition. Although several reviews on weight cycling $(53,57,63,83)$ conclude on the basis of available data that there is no convincing evidence for adverse weight cycling effects on energy expenditure and body composition, this is the first prospective study that studied energy metabolism under stimulated conditions after repeated weight loss and regain.

So far, studies on weight cycling effects have been mainly focussed on steady state measurements. In addition, they often were cross-sectional in design and mainly evaluated short-term effects. It is possible that weight cycling is associated with small metabolic adaptations that are not detectable with the methods used so far. Therefore additional information on weight cycling effects should preferably come from long-term prospective studies that also include dynamically functional tests, to be able to detect even small adaptations. Animal research is more in favor of a metabolic effect of weight cycling since a reduced norepinephrine-stimulated oxygen consumption in cycling mice has previously been demonstrated compared to controls (21).

Some concerns may be addressed regarding several intervening factors that might influence interpretation of the results of the study described in Chapter 6. These factors include the ageing process going on, and changes in dietary and physical activity pattern that might occur during the study. Ideally, an appropriate control group would enable to determine the influence of these confounding factors. For the present study, an adequate control group is exceedingly difficult to find since it should include stableweight obese women without a weight cycling history. However, there are several strong indications that the blunted sympathetically mediated metabolic effects demonstrated in the present study are likely to be mainly a consequence of weight cycling. Firstly, although the ongoing ageing process has been demonstrated to influence sympathetic nervous system activity, energy metabolism, and body composition (72), its influence over 2 years is likely to be rather small. In a study of Toth et al (74), the predicted relative rate of decline in peak $\mathrm{VO}_{2 \max }$ due to age appeared to be $10 \%$ per decade, as assessed in 224 females between 18 and 81 yr. Over two years the predicted decline in peak $\mathrm{VO}_{2 \max }$ would be $2 \%$, whereas the observed decline in $\mathrm{VO}_{2 \max }$ in the present study amounted $12.2 \%$. Furthermore, as discussed in Chapter 6, there are no indications that major changes in dietary intake pattern as evaluated by resting RER values and fatty acid composition of plasma lipids, and physical activity level as determined by doubly labeled water, occurred during the study. Finally, energy metabolism may also be altered as a consequence of differences in energy balance. Decreased energy expenditure and altered metabolism during weight loss, as measured in week 8 and 68 of the study, are the combined result of weight loss and the hypocaloric state. Similar sleeping RER values, fasting venous norepinephrine, free fatty acids and glycerol values at week 0,60 , and 120 indicate, however, no significant differences in energy balance, but weight stable conditions at these time points, excluding interference of weight cycling effects due to hypo- or hypercaloric state.

Therefore, the results of the study described in Chapter $\mathbf{6}$ indicate adverse metabolic consequences of weight cycling in obese women. Findings of adverse metabolic effects of weight cycling were strengthened by partial regression analysis demonstrating that the quantity of weight cycling, reflecting repeated weight loss and regain. was related to 
the magnitude of changes in metabolic variables. The data indicate that weight cycling is associated with diminished endogenous sympathetic nervous system activity and decreased $\beta$-adrenergic sensitivity to catecholamines under conditions of stimulation, as assessed by a physiological exercise stress test and an artificial isoprenaline stress test. This implicates possible consequences for regulation of weight, body composition and fat distribution on the longer term (55), although so far not indicated by our study and other prospective human data $(42,53,57)$. Long-term data on effects of weight cycling is lacking and therefore, the physiological significance of weight cycling for body weight regulation on the longer term remains unknown. Some implications for a role of weight cycling in weight gain come from previous studies demonstrating that a history of previous dieting predict increases in body weight over time (25) and is associated with increased body weight, fat percentage and waist-hip ratio (79). Possible underlying mechanisms of the observed adverse metabolic effects of weight cycling remain highly speculative but may involve modulation of lipoprotein lipase (12), increased hyperinsulinemia (16), or changes in fatty acid profile of various tissues (14).

The original plan was to recruit subjects without a weight cycling history for the present study, but this selection criterium appeared to be unrealistic. Therefore, women reporting the fewest previous weight cycles were selected for the study. Although this way of recruitment may influence interpretation of results, ongoing metabolic effects of weight cycling are indicated by the present study. Despite previous weight cycles before the start of the study, weight cycling over two ycars appeared to have blunting metitholic effects under stress conditions. It is not known whether these effects persist over longer periods of time or whether detrimental metabolic effects of weight cycling also occur with smaller magnitudes of weight changes. Currently also unknown is whether weight cycling effects appear when weight loss or cycling occur over a longer period of time and whether it matters if weight loss is intentional or unintentional. Studies providing such basic information are therefore needed to clarify clinically important components of weight cycling.

It will be clear that the results may have been influenced by subjects who dropped out during the study. However, no serious bias that would have influenced the main conclusions of the study is likely because of several reasons. Firstly, although a third of the subjects did not continue the study after the first weight cycle, since further participation was offered optional, the reasons for drop out were diverse. The reasons given for drop-out were change to a busy job $(29 \%)$. pregnancy $(24 \%)$, medical reasons unrelated to the study (19\%), moving (14\%), and non-compliance to diet (14\%). Secondly, we measured body weight of all subjects (except four) at 8-9 months after the first energy-restrictive diet. and it appeared that dropped out subjects did not differ in body weight or weight gain from the remaining subjects at that time.

It has to be realized that the results of the present study in obese women can not be extended to all subjects who lose and regain weight. It remains possible that weight cycling effects differ in men and women, or in obese and non-obese. Furthermore, possible weight cycling effects might be dependent on fat distribution because visceral abdominal fat may respond different in metabolism from other fat depots $(38,39)$. Although, in our study population fat distribution, as assessed by waist-hip ratio or sagittal diameter, was not significantly correlated with weight loss outcome (Chapter 5) 
or weight cycling effects, this may be related to the methods used which are not accurate to assess the visceral fat depots (41). The study described in Chapter 6 does not enable to determine subgoups at high risk because of the relatively homogeneity in body fat percentage and waist-hip ratio of the study population. Further research should establish whether certain subgroups are at high risk for adverse metabolic effects of weight cycling.

\section{Serum lipid and lipoprotein profile}

Variability in body weight has been indicated to increase the risk of overall and cardiovascular mortality $(8,33,49)$, implicating modulation of cardiovascular risk factors. A possible link between serum lipid and lipoprotein profile changes and weight cycling is therefore one of the first options to analyze. In Chapter 7 it is concluded that weight cycling in obese women did not adversely affect serum lipids and lipoproteins. This appears to be in accordance with other human studies that fail to demonstrate adverse effects of weight cycling on serum lipids $(37,62)$. In addition, no evidence for modulating effects of weight variability on several other cardiovascular risk factors such as blood pressure, fasting blood levels of glucose and insulin, impaired glucose tolerance, dietary fat intake, fat distribution, and metabolism have been found $(37,48,62,68)$.

Potential mechanisms mediating the association between body weight variability and cardiovascular mortality remain therefore to be determined. Recent data speculatively indicate alterations of the composition of highly unsaturated fatty acids in circulating lipid pools with weight changes. These alterations may consequently lead to changes in platelet-endothelial interactions and in inflammatory components of atherosclerosis (56). The physiological significance of possible remodeling of fatty acid composition with weight cycling for cardiovascular risk deserves further study. Our results do not indicate such an effect since plasma total lipid fatty acid profile remained rather stable over time. Epidemiological studies may have certain limitations when evaluating the influence of weight cycling on morbidity and mortality. Firstly, in those studies intentional weight loss is not or difficult to distinguish from unintentional weight loss which rather may reflect underlying illness. Secondly, the often used coefficient of variation of body weight to measure weight variability may not adequately reflect weight cycling $(53,83)$. Furthermore, detrimental effects of weight cycling on health may be more pronounced in those who are not obese and caution should be taken in applying findings of population-based studies to the obese. There is increasing support for the idea that adverse effects of weight fluctuations have no direct relation with intentional weight loss in obese individuals. Finally, a number of important disturbing factors that are not adequately controlled for may produce artificial associations which are unrighty designed to weight cycling, such as for instance smoking, pre-existing illness, psychological well-being, body composition and fat distribution. Therefore, more experimental research is needed to further clarify the observed findings of health risk of weight variability in observational epidemiology and whether weight cycling in obese individuals is linked to this health related problem. 


\section{Physical exercise and weight cycling}

Since moderate, regular exercise has been shown to be beneficial for maintenance of weight loss in obesity on the long term (31), it may be speculated that physical exercise may prevent adverse metabolic effects of weight cycling. The study described in Chapter $\mathbf{8}$ focussed on effects of addition of exercise to energy restriction as weight loss treatment. The effects of exercise when combined with energy restriction for weight loss treatment of obesity have been contradictory. Some studies reported greater weight loss, greater loss of fat mass and preservation of fat-free mass, and a smaller decline in resting energy expenditure with addition of exercise to dietary weight loss treatment $(19,58,65,66,67)$ whereas others failed to find such effects $(18,45)$. Occurrence of a compensatory decrease in daily physical activity for extra exercise might contribute to these conflicting results. Evaluation of adaptations in total free-living energy expenditure by doubly labeled water provides information that enables to assess whether compensation in daily activity occurs with combined diet and exercise treatment. Previous studies have demonstrated no compensatory decrease in daily physical activities after a training program alone in obese boys (5) and after endurance training in lean men and women (52). Furthermore, no compensation in daily physical activity for addition of exercise to diet treatment was shown in obese women, as assessed with heart rate monitoring and actometer recordings (19). On the other hand, a compensatory decline in physical activity outside the training has been shown in elderly persons during endurance training (30).

Also in a recently published study of Racette et al (58) maintenance of total daily freeliving energy expenditure was demonstrated with combined diet and exercise treatment in obese women as assessed with doubly labeled water. The data of Racette et al (58) therefore indicate no compensation of physical activity level outside the training sessions for the energy expended during the training. In contrast, from Chapter $\mathbf{8}$ it can be concluded that addition of moderate exercise to an energy-restrictive diet in obese women did not result in a smaller decrement of the average daily metabolic rate than energy restriction alone. This implicates that energy expended during the exercise sessions was partially compensated by a decrease in daily physical activities outside the training sessions. These contrasting results may possibly be attributed to differences in the energy content and composition of the prescribed diets and intensity level of the performed exercise. In the study of Racette et al (58), the prescribed diets consisted of normal food with a energy content of approximately $5 \mathrm{MJ}$ per day with either a low-fat or low-carbohydrate content. In addition the exercise intensity amounted $60-65 \%$ of maximal aerobic capacity, which is slightly higher than the intensity used in our study. Furthermore, there appeared to be differences in baseline total daily energy expenditure level between the exercise and non-exercise groups in the study of Racette et al (58) which may interfere with interpretation of their study results. Thus, our results on compensatory decrease in daily physical activity for energy expended during training appear to be a once-only finding so far. Altogether the available data on this topic rather point more to no compensation in daily physical activity for extra exercise.

Although our data indicated partial compensation for extra exercise, a greater energy deficit was observed with combined diet and exercise treatment compared to diet alone. 
This finding might be related to benelicial effect of exercise on dietary compliance, as recently suggested (59) and confirmed by our data. Additional beneficial effects of the extra exercise were seen on body composition, energy balance and substrate utilization as in agreement with others $(58,66,67,76)$. Addition of exercise to energy restriction resulted in significantly increased fat loss and greater energy deficit than diet alone. Furthermore, the relative contribution of lipid oxidation to energy expenditure during exercise was stimulated by combined diet and exercise treatment. These data implicate that beside total energy expenditure other factors are of importance for a possible beneficial influence of addition of exercise to an energy-restrictive regimen such as substrate oxidation ratio and dietary compliance. An increase in oxidation of fat relative to the use of carbohydrate has been demonstrated previously with aerobic exercise (24, $51,64,75,76,78)$. Duration and intensity of the exercise program and possibly its schedule in relation to meals may be variables contributing to the magnitude of beneficial effects of addition of exercise to dietary treatment for achieving weight loss (24). The results of the study described in Chapter 8, however, demonstrate that beneficial effects of adding exercise to energy restriction in obese women can be achieved with a rather moderate exercise program existing of 4-5 hours exercise per week at an intensity of 50-60\% of the maximal aerobic capacity.

Finally, in Chapter 9 possible beneficial effects of long-term moderate physical exercise on adverse metabolic effects of weight cycling as described in Chapter 6 were evaluated. The results demonstrated partial prevention of regain and favorable influence on body fat percentage in exercising weight cycling women compared to weight cycling controls alone. These effects of exercise appeared to mediated by partial prevention of the blunting sympathetically mediated metabolic effects of weight cycling alone, as indicated by lower declining exercise-induced catecholamine responses, isoprenaline-induced thermogenic responses and increased chronotropic sensitivity. These results are in agreement with previous reported effects of exercise including enhanced adrenal medullary secretory capacity (40), improved cardiac $\beta$-adrenoceptor status (35). The functional importance of the observed training-induced adaptations of sympathetic nervous system activity in weight cycling women remains uncertain since no changes were observed in substrate metabolism. However, it has to be realized that collected data were based on venous plasma levels and whole-body respiratory measurements. In addition responses to isoprenaline were related to the administered dose whereas plasma isoprenaline concentration-response curve are preferable for accuracy (7). Therefore, it is possible that the methods used do not have the accuracy to detect small changes in substrate metabolism.

The results of the study described in Chapter 9 stress the importance of moderate regular physical exercise for maintenance of weight loss and body weight regulation in the treatment of obesity. Beneficial effects of exercise on the long term has become evident from numerous previous studies $(31,34,66,73,76)$. The influence of physical activity on body weight involves multiple pathways although not all could be confirmed by the present study, such as preservation of fat-free mass, maintenance of energy expenditure, and modulation of energy intake. In the context of new ideas of importance of macronutrient balance in relation to body weight control, exercise appears to be an important stimulus to increase lipid oxidation. For beneficial effects of exercise 
on macronutrient balance, the composition of the diet consumed may be additionally of importance since a high fat diet has been suggested to counteract effects of exercise (76). Data on modulation of food intake by increasing physical activity demonstrate a better regulation of food intake consisting of a shift toward higher carbohydrate intake at the expense of fat $(36,64,76)$.

One of the problems with exercise for body weight control, is that compliance is difficult to achieve, especially in obese individuals. To induce and maintain beneficial effects of exercise on a long-term basis, exercise and food habits have to be incorporated in the individual lifestyle. Therefore, improvement of adherence and motivation to succeed exercise treatments requires further research. The study described in Chapter 9, however, demonstrate that even modest levels of activity are sufficient to achieve partial prevention of regain after a dietary weight loss treatment. An important role for modest regular exercise for body weight control is therefore indicated.

In summary, the studies described in the present thesis demonstrate that weight cycling in obese women is associated with blunted $\beta$-adrenergically thermogenic effects. This finding further implicates involvement of sympathetic nervous system activity in the etiology and maintenance of obesity. In addition, this prospective study showed that repeated weight loss and regain may be a factor that contributes to further development or maintenance of the obese state, although detrimental effects on the sympathetic nervous system were not reflected in variables such as body weight, fat percentage and resting metabolic rate.

The adverse metabolic effects of weight cycling demonstrated in the present thesis raise the question whether efforts to lose weight may be more detrimental than obesity per se. Health related risks of obesity increases exponentially with increasing body mass index above $30 \mathrm{~kg} / \mathrm{m}^{2}$. Observing the impact of weight cycling on body weight or weight regulating variables, there is no strong argument to stop obesity treatment. However, at lower levels of body mass index, especially individuals who have no risk factors for obesity-related illness should be recommended to avoid weight loss efforts and to maintain a stable body weight. Only those who are seriously overweight or those with increased obesity-related risk factors may be advised to undertake weight loss efforts provided that the individual is well motivated. To prevent weight cycling, individual efforts to reduce weight may be preferably medically supervised. Increasing physical activity, especially in the weight maintenance phase, and consuming a well-balanced diet are important factors to maintain body weight and prevent weight cycling. It should be realized that successful weight loss on the long term requires permanent lifestyle changes in exercise and food habits. 


\section{References}

1. Astrup A, Beumann B, Gluud C, Bennett P, Tjur T, Christensen N. Prognostic markers for dietinduced weight loss in obese women. Int J Obes 19: 275-278, 1995.

2. Baier LJ, Sacchettini JC, Knowler WC, Eads J, Paolisso G, Tataranni PA, Mochizuki H, Bennett PH, Bogardus C, Pruchazka M. An amino acid substitution in the human intestinal fatty acid binding protein is associated with increased fatty acid binding, increased fat oxidation, and insulin resistance. J Clin Invest 95: 1281-1287, 1995.

3. Bas NM. The cellular fatty acid binding proteins: aspects of structure, regulation, and function. Int Rev Cytol 111: 143-184, 1988.

4. Berlin I, Berlan M, Crespo-Laumonnier B, Landault C, Payan C, Puech AJ, Turpin G. Alterations in $\beta$-adrenergic sensitivity and platelet $\alpha_{2}$-adrenoceptors in obese women: effect of exercise and caloric restriction. Clin Sci 78: 81-87, 1990.

5. Blaak EE, Westerterp KR, Bar-Or O, Wouters LJM, Saris WHM. Total energy expenditure and spontaneous activity in relation to training in obese boys. Am J Clin Nutr 55: 777-782. 1992.

6. Blaak EE, van Baak MA, Kemerink GJ, Pakbiers MTW, Heidendal GAK. Saris WHM. $\beta$ Adrenergic stimulation of energy expenditure and forcarm skeletal muscle metabolism in lein and obese men. Am J Physiol 267: E306-E315, 1994.

7. Blaak EE, van Baak MA, Kester ADM, Saris WHM. $\beta$-Adrenergically mediated thermogenesis and heart rate responses: effect of obesity and weight loss. Metabolism 44: 520-524, 1995.

8. Blair SN, Shaten J, Brownell K, Collins G, Lissner L. Body weight change, all-cause mortality, and cause-specific mortality in the Multiple Risk Factor Intervention Trial. Ann Intern Med 119: 749-757, 1993.

9. Boerwinkle E, Leffert CC, Lin J, Lackner C, Chiesa G, Hobbs HH. Apolipoprotein(a) gene accounts for greater than $90 \%$ of the variation in plasma lipoprotein(a) concentration. $J \mathrm{Clin}$ Invest 90: 52-60, 1992.

10. Brodde O-E, Michel MC, Gordon EP. Sandoval A, Gilbert EM, Bristow MR. B-Adrenoceptor regulation in the human heart: can it be monitored in circulating lymphocytes? Eur Heart $J$ 10(suppl B): 2-10, 1989.

11. Brodde O-E, Daul A, Michel-Reher M, Boomsma F, Man in 't Veld AJ, Schlieper P, Michel MC. Agonist-induced desensitization of $\beta$-adrenoceptor function in humans. Circulation 81: 914$921,1990$.

12. Brownell KD, Greenwood MRC, Stellar E, Shrager EE. The effects of repeated cycles of weight loss and regain in rats. Physiol Behav 38: 459-464, 1986.

13. Carpéné C, Galitzky J, Saulnier-Blache J-S, Lafontan M. Selective reduction of $\alpha_{2}$-adrenergic responsiveness in hamster adipose tissue during prolonged starvation. Am J Physiol 250: E80E88, 1990.

14. Chen A-Y, Menard CR, Cunnane SC. Moderate, selective depletion of linoleate and $\alpha$-linolenate in weight-cycled rats. Am J Physiol 268: R498-R505, 1995.

15. Colberg SR. Simoneau J-A, Thaete FL, Kelly DE. Skeletal muscle utilization of free fatty acids in women with visceral obesity. J Clin Invest 95: 1846-1853, 1995.

16. Contreras RJ, Williams VL. Dietary obesity and weight cycling: effects on blood pressure and hear rate in rats. Am J Physiol 256: R1209-R 1219, 1989.

17. Crampes F, Marceron M, Beauville M, Riviere D. Garrigues M, Berlan M, Lafontan M. Platelet alpha $_{2}$-adrenoceptors and adrenergic adipose tissue responsiveness after moderate hypocaloric diet in obese subjects. Int J Obes 13: 99-110, 1989.

18. Dale van D, Saris WHM, Schoffelen PFM, ten Hoor F. Does exercise give an additional effect in weight reduction regimens? Int J Obes 11: 367-375, 1987.

19. Dale van D, Schoffelen PFM, ten Hoor F, Saris WHM. Effects of addition of exercise to energy restriction on 24-hour energy expenditure, sleeping metabolic rate and daily physical activity. Eur J Clin Nutr 43: 44J-451, 1989 
20. Dattilo AM, Kris-Etherton PM. Effects of weight reduction on blood lipids and lipoproteins: a meta-analysis. Am J Clin Nutr 56: 320-328, 1992.

21. Desautels M, Dulos RA. Effects of repeated cycles of fasting-refeeding on brown adipose tissuc composition in mice. Am J Physiol 255: E120-E128, 1988.

22. Dreon DM, Fernstrom HA, Miller B, Krauss. Apolipoprotein E isoform phenotype and LDL subclass response to a reduced-fat diet. Arterioscler Thromb Vasc Biol 15: 105-111, 1995.

23. Felber J-P, Golay A. Regulation of nutrient metabolism and energy expenditure. Metabolism 44(suppl 2): 4-9, 1995.

24. Flatt JP. Dietary fat, carbohydrate balance, and weight maintenance: effects of exercise. Am $J$ Clin Nutr 45: 296-306, 1987.

25. French SA, Jeffery RW, Forster JL, McGovern PG, Kelder SH, Baxter JE. Predictors of weight change over two years among a population of working adults: the Healthy Worker Project. Int $J$ Obes 18: 145-154, 1994.

26. Glatz JFC, van der Vusse GJ, Veerkamp JH. Fatty acid-binding proteins and their physiological significance. News Phys Sci 3: 41-43, 1988.

27. Glatz JFC, van der Vusse GJ. Cellular fatty acid-binding proteins: current concepts and future directions. Mol Cell Biochem 98: 237-251, 1990.

28. Glatz JFC, van Breda E, Keizer HA, de Jong YF, Lakey JRT, Rajotte RV, Thompson A, van der Vusse GJ, Lopaschuk GD. Rat heart fatty acid-binding protein content is increased in experimental diabetes. Biochem Biophys Res Comm 199: 639-646, 1994.

29. Golay A, Schutz Y, Meyer HU, Thiébaud D, Curchod B, Maeder E, Felber J-P, Jequier E. Glucose-induced thermogenesis in nondiabetic and diabetic obese subjects. Diabetes 31: 1023$1028,1982$.

30. Goran MI, Poehlman ET. Endurance training does not enhance total energy expenditure in healthy elderly persons. Am J Physiol 263: E950-E957, 1992.

31. Grilo CM. Physical activity and obesity. Biomed Pharmacother 48: 127-136, 1994.

32. Gylling H, Kontula K, Miettinen TA. Cholesterol absorption and metabolism and LDL kinetics in healthy men with different apoprotein E phenotypes and apoprotein B Xba I and LDL receptor Pvu II genotypes. Anterioscler Thromb Vasc Biol 15: 208-213, 1995.

33. Hamm P. Shekelle RB, Stamler J. Large fluctuations in body weight during young adulthood and twenty-five year risk of coronary death in men. Am J Epidemiol 129:312-318, 1989.

34. Hensrud DD, Weinsier RL, Damell BE. Hunter GR. A prospective study of weight maintenance in obese subjects reduced to normal body weight without weight-loss training. Am J Clin Nutr 60: 688-694, 1994.

35. Hieble JP, Ruffolo RR. Functions mediated by $\beta$-adrenoceptor activation. InRuffolo RR (ed). $\beta$ Adrenoceptors: moelcular biology, biochemistry and pharmacology. Prog Basic Clin Pharmacol, Basel, Karger 7: 173-209, 1991.

36. Janssen GME, de Graef CJJ, Saris WHM. Food intake and body composition in novice athletes during a training period to run a marathon. Int J Sports Med1O(suppl 1): S17-S21, 1989.

37. Jeffery RW, Wing RR, French SA. Weight cycling and cardiovascular risk factors in obese men and women. Am J Clin Nutr 55: 641-644, 1992.

38. Kanaley JA, Andresen-Reid ML, Oenning L, Kottke BA, Jensen MD. Difterential health benefits of weight loss in upper-body and lower-body obese women. Am J Clin Nutr 57: 20-26, 1993.

39. Kanaley JA, Cryer PE, Jensen MD. Fatty acid kinetic responses to exercise. J Clin Invest 92 : 255-261, 1993.

40. Kjar M. Exercise effects on adrenergic regulation of energy metabolism. In Lamb DR, Gisolfi VD (eds). Perspectives in exercise science and sports medicine, vol 5: Energy metabolism in exercise and sport. Wm C Brown Communications, Inc, Dubuque IA, pp 345-376, 1992.

41. Kooy van der K, Leenen R, Seidell JC, Deurenberg P, Droop A, Bakker CJG. Waist-hip ratio is a poor predictor of changes in visceral fat. Am J Clin Nutr 57: 327-333, 1993.

42. Kooy van der K, Leenen R, Seidell JC, Deurenberg P. Hautvast JGAJ. Effect of a weight cycle on visceral fat accumulation. Am J Clin Nutr 58: 853-857, 1993. 
43. Knijff de P, Kaptein A, Boorsma D, Princen HM, Frants RR, Havekes LM. Apolipoprotein E polymorphism affects plasma levels of lipoprotein(a). Atherosclerosis 90: 169-174, 1991.

44. Kotkiewski M. Role of muscle morphology in the development of insulin resistance and metabolic syndrome. Presse Med23: 1393-1399, 1994.

45. Lemmons AD, Kreitzmann SN, Coxon A, Howard A. Selection of appropriate exercise regimens for weight reduction during VLCD and maintenance. Int J Obes 13: 119-123, 1989.

46. Liggett SB, Shah SD, Cryer PE. Characterization of $\beta$-adrenergic receptors of human skeletal muscle obtained by needle biopsy. Am J Physiol 254: E795-E798, 1988.

47. Liggett SB, Shah SD, Cryer PE. Human tissue adrenergic receptors are not predictive of responses to epinephrine in vivo. Am J Physiol 256: E600-E609, 1989.

48. Lissner L. Andres R, Muller DC, Shimokata $\mathrm{H}$. Body weight variability in men: metabolic rate, health and longevity. Int J Obes 14: 373-383, 1990.

49. Lissner L, Odell PM, D'Agostino RB, Stokes J, Kreger BE, Belanger AJ, Brownell KD. Variability of body weight and health outcomes in the Framingham population. $N$ Engl J Med 324: 1839$1844,1991$.

50. Macdonald IA. Sympathetic nervous system and malnutrition. In Kinney JM. Tucker HN (eds). Energy metabolism: tissue determinanis and cellular corollaries. Raven Press, LDT., New York, pp 247-265, 1992.

51. Martin WH, Dalsky GP, Hurley BF, Matthews DE, Bier DM, Hagsberg JM, Rogers MA, King DS, Holloszy JO. Effect of endurance training on plasma free fatty acid turnover and oxidation during exercise. Am J Physiol 265: E736-E742, 1989.

52. Meijer GAL, Janssen GME, Westerterp KR, Verhoeven F, Saris WHM, ten Hoor F. The effect of a 5-month endurance training programme on physical activity: evidence for a sex difference in the metabolic response to exercise. Eur J Appl Physiol 62: 11-17, 1991.

53. National Task Force on the Prevention and Treatment of Obesity. Weight cycling. JAMA 272: 1196-1202, 1994.

54. O'Dea K, Esler M, Leonard P. Stockigt JR, Nestel P. Noradrenaline turnover during under- and over-eating in normal weight subjects. Metabolism 31: 896-899, 1983.

55. Peterson HR, Rothschild M, Weinberg CR, Fell RD, McLaish KR, Pfeifer MA. Body fat and the activity of the autonomic nervous system. N Engl J Med 318:1077-1083, 1988

56. Phinney SD. Weight cycling and cardiovascular risk in obese men and women (letter). Am J Clin Nutr 56: 781, 1992.

57. Prentice AM, Jebb S, Goldberg GR, Coward WA, Murgatroyd PR, Poppitt SD, Cole TJ. Effects of weight cycling on body composition. Am J Clin Nutr 56: 209S-216S, 1991.

58. Racette SB, Schoeller DA. Kushner RF, Neil KM. Herling-Iaffaldano K. Effects of aerobic excrcise and dietary carbohydrate on energy expenditure and body composition during weight reduction in obese women. Am J Clin Nutr 61: 486-494, 1995.

59. Racette SB, Schoeller DA, Kushner RF, Neil KM. Exercise enhances dietary compliance during moderate energy restriction in obese women. Am J Clin Nutr 62: 345-349. 1995.

60. Rainwater DL, Ludwig MJ, Haffner SM, VandeBerg JL. Lipid and lipoprotein favtors associated with variation in $\mathrm{Lp}$ (a) density. Arterioscler Thromb Vasc Biol 15: 313-319, 1995.

61. Ravussin E, Acheson KJ, Vernet O. Danforth E, Jéquier E. Evidence that insulin resistance is responsible for the decreased thermic effect of glucose in human obesity. $J$ Clin Invest 76 : 1268-1273, 1985.

62. Rebuffé-Scrive M, Hendler R, Bracero N, Cummings N, McCarthy S, Rodin J. Biobehavioral effects of weight cycling. I $n t$ J Obes 18: 651-658, 1994.

63. Reed GW. Hill JO. Weight cycling: a review of the animal literature. Obes Res 1: 392-402, 1993.

64. Saris WHM. Physiological aspects of exercise in weight cycling. Am J Clin Nutr 49: 1099-1104. 1989.

65. Saris WHM, van Dale D. Effects of exercise during VLCD diet on metabolic rate, body composition and aerohic power: pooled data of four studies. Int J Obes 13(suppl 2): 169-170. 1989. 
66. Saris WHM, Koenders MC, Pannemans DLE, van Baak MA. Outcome of a multicenter outpatient weight-management program including very-low-calorie diet and exercise. Am J Clin Nutr 56: 294S-296S, 1992.

67. Saris WHM. The role of exercise in the dietary treatment of obesity. Int J Obes 17(suppl 1): S17-S21, 1993.

68. Schotte DE, Cohen E, Singh SP. Effects of weight cycling on metabolic control in male outpatients with Non-Insulin-Dependent Diabetes Mellitus. Health Psychol 9: 599-605, 1990.

69. Segal KR, Blando L, Ginsberg-Fellner F, Edaño A. Postprandial thermogenesis at rest and postexercise before and after physical training in lean, obese, and mildly diabetic men. Metabolism 41: 868-878, 1992.

70. Shetty PS. Physiological mechanisms in the adaptive response of metabolic rates to energy restriction. Nutr Res Rev 3: 49-74, 1990.

71. Sönnichsen AC, Richter WO, Schwandt P. Reduction of lipoprotein(a) by weight loss. Int J Obes 14: 487-494, 1990.

72. Supiano MA, Linares OA, Smith MJ, Halter JB. Age-related differences in norepinephrine kinetics: effect of posture and sodium-restricted diet. Am J Physiol 259: E422-E431, 1990.

73. Svendsen OL, Hassager C, Christiansen C. Six months' follow-up on exercise added to short-term diet in overweight postmenopausal women-effects on body composition, resting metabolic rate, cardiovascular risk factors and bone. Int J Obes 18: 692-698, 1994.

74. Toth MJ, Gardner AW, Ades PA, Poehlman ET. Contribution of body composition and physical activity to age-related decline in peak $\mathrm{VO}_{2 m a x}$ in men and women. $J$ Appl Physiol 77(2): 647652, 1994.

75. Tremblay A, Coveney S, Després J-P, Nadeau A, Prud'homme D. Increased resting metabolic rate and lipid oxidation in exercise-trained individuals: evidence for a role of $\beta$-adrenergic stimulation. Can J Physiol Pharmacol 70: 1342-1347, 1992.

76. Tremblay A, Buemann B. Exercise-training, macronutrient balance and body weight control. Int J Obes 19: 79-86, 1995.

77. Vork MM, Glatz JFC, van der Vusse GJ. On the mechanism of long chain fatty acid transport in cardiomyocytes as facilitated by cytoplasmic fatty acid binding protein. $J$ theor Biol 160: 207222. 1993.

78. Vusse van der GJ, Reneman RS. Lipid metabolism in muscle. In Rowell LB, Shephard JT (eds). Handbook of physiology. Integration of motor, circulatory, respiratory and metabolic control during exercise. In press.

79. Wadden TA, Bartlett S, Letizia KA, Foster GD, Stunkard AJ. Relationship of dieting history to resting metabolic rate, body composition, eating behavior, and subsequent weight loss. Am J Clin Nutr 56: 203S-208S, 1992.

80. Webber J, Macdonald IA. Metabolic actions of catecholamines in man. Baillière's Clin Endocrinol Metabolism 7: 393-413, 1993.

81. Welle S, Schwartz RG, Statt M. Reduced metabolic rate during $\beta$-adrenergic blockade in humans. Metabolism 40: 619-622, 1991.

82. Williams PT. Dreon DM, Krauss RM. Effects of dietary fat on high-density-lipoprotein subclasses are influenced by both apolipoprotein $\mathrm{E}$ isoforms and low-density-lipoprotein subclass patterns. Am J Clin Nutr 61: 1234-1240, 1995.

83. Wing RR. Weight cycling in humans: a review of the literature. Ann Behav Med 14: 113-119, 1992.

84. Zurlo F, Larson K, Bogardus C, Ravussin E. Skeletal muscle metabolism is a major determinant of resting energy expenditure. J Clin Invest 86: 1423-1427, 1990.

85. Zurlo F, Nemeth PM, Choksi RM, Sesodia S, Ravussin E. Whole-body energy metabolism and skeletal muscle biochemical characteristics. Metabolism 43: 481-486, 1994. 


\section{Summary}

Many obese people have a long history of dieting with often successful weight reductions, but also disappointing relapses. Concerns for adverse effects of a pattern of repeated weight loss and regain have received tremendous publicity in the past years, despite lack of convincing evidence based on the currently available literature. Reduced energy expenditure levels and increased body fatness have been suggested to be consequences of weight cycling. Furthermore, weight variability has been reported to be associated with increased cardiovascular and all-cause mortality, indicating modulation of cardiovascular risk factors due to weight cycling. The studies described in this thesis were intended to prospectively investigate metabolic effects of weight cycling in obesity. Metabolic variables, body composition, serum lipid and lipoprotein profiles were assessed in obese women during a two-year period of repeated voluntary dietaryinduced weight loss and non-controlled follow-up. A possible role for exercise in the regulation of body weight control and energy metabolism in the course of a weight cycle was additionally evaluated.

Acute effects of energy restriction are partially related to adaptations of sympathetic nervous system activity and adrenoceptor status may be involved. To what extent energy restriction modulates this regulation is still debated. In Chapter 2, it was demonstrated that eight weeks of energy restriction in obese women did not affect the status of blood cell $\beta$-adrenoceptors in rest. However, an up-regulation of $\beta$ adrenoceptors was observed under exercise stress, associated with increased thermogenic and lipolytic responses. Density of blood cell $\alpha$-adrenoceptors under resting conditions was increased with energy restriction. although this was indicated to be of less or no metabolic importance. From this, it can be concluded that dynamic modulation of the status of adrenoceptors is probably of importance for metabolic consequences of thermogenesis and lipolysis as result of energy restriction. Metabolic adaptations to energy restriction involve an increase in fat oxidation that may partially take place in skeletal muscle. Chapter 3 shows that muscular metabolic adaptations to energy restriction may involve increased intracellular fatty acid transport capacity, whereas activity of oxidative enzymes was not changed. The observed increased cytosolic fatty acid-binding protein content is likely to enable the skeletal muscle to meet the demands of increased fatty acid utilization during energy restriction.

Energy restriction beneficially affected serum lipids and lipoproteins, although HDLcholesterol appeared to be decreased during active weight loss (Chapter 4), as also previously reported by others. The cardiovascular risk factor lipoprotein(a) has been suggested to be mainly genetically determined and rather resistant to pharmacological and dietary interventions. Our data demonstrate that dietary-induced weight loss did not change mean serum lipoprotein(a) concentrations. However, responses of lipoprotein(a) to dietary intervention were related to initial values. Subjects with pre-treatment values above $30 \mathrm{mg} / \mathrm{dl}$ showed a significant decline of serum lipoprotein(a), while no change was found in subjects with low values at baseline. The responses of serum lipid and lipoprotein variables to weight loss treatment as observed in our study appeared to be not dependent on apolipoprotein E polymorphism. 
There is considerable inter-individual variation in amounts of weight and fat mass lost as result of energy-restricted diet treatment. This variation has been suggested to be related to dietary adherence, body composition, energy expenditure, and substrate utilization. Possible metabolic factors involved in the modulation of quantity and composition of weight loss in obese women were evaluated in Chapter 5. Low basal plasma levels of norepinephrine and hyperinsulinemia decreased the probability of successful weight loss to dietary treatment. These results indicate that basal sympathetic nervous system activity and insulin resistance are involved in the mobilization of body fat stores during energy deficiency.

The study described in Chapter $\mathbf{6}$ demonstrates that weight cycling in obese women is associated with decreased exercise-induced and isoprenaline-induced responses of energy expenditure. Under basal conditions, no effects of weight cycling on metabolic rate could be detected. The results indicate that a pattern of repeated weight loss and regain over two years in obese women is associated with blunting of sympathetically mediated thermogenic, chronotropic, and lipolytic responses. So far, this is the first prospective human study demonstrating adverse metabolic effects of weight cycling in obesity. Our data confirm previous findings of animal studies. and may contribute to partially explain the poor long-term results of treatment for obesity. These adverse effects of weight cycling on energy metabolism may stress the importance of maintenance of a reduced body weight after successful weight loss on the long-term. Although not indicated during our two-years study period, the observed metabolic effects of weight cycling may implicate consequences for regulation of weight, body composition, and fat distribution over a longer period of time. Future research should answer these important questions.

Since weight variability may increase health risks, weight cycling may modulate cardiovascular risk factors. A possible link between weight cycling and alterations in serum lipid and lipoprotein profiles was evaluated in Chapter 7. The results show that repeated weight loss and regain in obese women did not adversely affect serum lipids and lipoproteins. These results are in accordance with other human studies that fail to demonstrate negative effects of weight cycling on serum lipids. Also. no evidence for modulating effects of weight cycling on other risk factors for cardiovascular diseases have been reported. Therefore, potential mechanisms mediating an association between weight variability and cardiovascular mortality remain to be established. It appeared furthermore that moderate regular exercise had no beneficial effects on serum lipid and lipoprotein profiles in weight cycling obese women.

Physical activity plays an important role in the control of body weight. When exercise is added to energy restriction for weight loss treatment of obesity, conflicting results have been found. This inconsistency in results may be related to possible compensatory reductions in normal daily life activities in order to compensate for the greater energy deficit due to the added exercise. To assess whether compensation in daily activities occurs with combined diet and exercise treatment in obese women. adaptations of total free-living energy expenditure were measured with doubly labeled water (Chapter 8). Addition of moderate exercise to an 8-week energy-restricted diet did not result in a smaller decrement of the average daily metabolic rate than diet alone. This implicates that energy expended during the exercise sessions was partially compensated by a decrease in daily physical activity outside the training sessions. The finding of partial 
compensation of physical activity is not in accordance with other studies. Energy content and composition of the prescribed diet, frequency and intensity of the performed exercise may contribute to these inconsistent results. Although our data indicated partial compensation in activity for extra exercise, beneficial effects of adding exercise to dietary treatment for obesity were found. Combined diet and exercise treatment resulted in significantly increased fat loss and greater energy deficit compared to diet alone. Furthermore, the relative contribution of lipid oxidation to energy expenditure during exercise was stimulated by combined diet and exercise treatment. These data implicate that beside total energy expenditure other factors are of importance for beneficial effects of exercise added to energy restriction, such as substrate utilization and dietary adherence. It can be concluded that beneficial effects of adding exercise to energy restriction for treatment of obesity can be achieved with exercise of moderate intensity and frequency.

Long-term effects of physical exercise to prevent adverse metabolic effects of weight cycling are described in Chapter 9. The data demonstrated partial prevention of regain and favorable influence on body fatness due to extra physical activity in weight cycling obese women. However, this preventive effect was modest. Exercise partially prevented the blunted sympathetically mediated metabolic effects observed with weight cycling. (Chapter 6). These physiological adaptations to long-term exercise may contribute to the observed beneficial effects of exercise on weight and body composition. Moderate, regular exercise is therefore effective for improving weight maintenance for long-term treatment of obesity. Improvement of adherence and motivation to succeed exercise treatments in obese requires further research.

In conclusion, the studies described in the present thesis demonstrate that weight cycling in obese women is associated with blunted $\beta$-adrenergically mediated thermogenic effects. This finding further implicates involvement of sympathetic nervous system activity in the etiology and maintenance of the obese state. Furthermore. moderate, regular exercise is of great importance for maintenance of weight loss and body weight regulation for long-term treatment of obesity. 



\section{Samenvatting}

Veel mensen met obesitas (vetzucht) hebben een lange historie van diëten met vaak succesvol gewichtsverlies, maar tevens teleurstellende toename van gewicht. Gedurende de laatste jaren zijn mogelijke negatieve effecten van herhaalde gewichtsschommelingen uitgebreid in de publiciteit geweest, ondanks het feit dat wetenschappelijk gezien weinig overtuigende bewijzen voorhanden waren. Een verlaagd energiegebruik en een toename van de hoeveelheid lichaamsvet zijn gesuggereerd als mogelijke gevolgen van herhaalde afname en toename van gewicht. Verder zijn er aanwijzingen dat het schommelen in gewicht mogelijk gepaard gaat met een verhoogde mortaliteit, in het bijzonder ten gevolge van cardiovasculaire aandoeningen. Deze laatste bevinding kan impliceren dat herhaalde gewichtsschommelingen mogelijk bepaalde cardiovasculaire risicofactoren beïnvloeden.

Het onderzoek beschreven in dit proefschrift is uitgevoerd om effecten van herhaalde gewichtsschommelingen op de energiestofwisseling te bestuderen bij personen met obesitas. Dit werd gedaan door metabole variabelen, lichaamssamenstelling, en serum lipiden en lipoproteïnen te bepalen tijdens een periode van twee jaar met herhaalde periodes van gewichtsreductie door een energiebeperkt dieet, gevolgd door ongecontroleerde follow-up periodes. Tevens is onderzocht of door extra lichamelijke inspanning mogelijke nadelige effecten van herhaalde gewichtsschommelingen op de energiestofwisseling voorkomen zouden kunnen worden.

Acute effecten door beperking van de voedselinname (energiebeperking) zijn deels gerelateerd aan veranderingen in de activiteit van het sympathische zenuwstelsel. Modulatie van de status van adrenerge receptoren zou daarbij van belang kunnen zijn. In welke mate energiebeperking de regulatic van adrenerge receptoren beinvloedt is echter nog steeds onduidelijk. In Hoofdstuk 2 werd gevonden dat energiebeperking gedurende acht weken in obese vrouwen geen invloed had op de $\beta$-adrenerge receptor status van bloedcellen in de rust situatie. Daarentegen werd na energiebeperking een toename van het aantal $\beta$-adrenerge receptoren gevonden tijdens inspanningsstress. Deze toename ging gepaard met verhoogde thermogene en lipolytische responsen. Het bleek tevens dat de dichtheid van bloedcel $\alpha$-adrenerge receptoren tijdens rust was toegenomen ten gevolge van energiebeperking. Dit leek echter van weinig of geen metabool belang te zijn. Deze gegevens duiden erop dat modulatie van de status van adrenerge receptoren waarschijnlijk van belang is bij de metabole gevolgen van energiebeperking.

Metabole aanpassingen aan energiebeperking betreffen onder andere een toename in vetoxidatie, die waarschijnlijk deels plaatsvindt in de skeletspier. Hoofdstuk 3 beschrijft een toename van de intracellulaire transportcapaciteit van vetzuren als een mogelijke aanpassing van de skeletspier aan energiebeperking, terwijl de activiteit van oxidatieve enzymen niet veranderde. De gevonden toename van de hoeveelheid vetzuurbindend eiwit in het cytosol van de skeletspier zal deze waarschijnlijk in staat stellen om aan het verhoogde vetzuurgebruik tijdens energie beperking tegemoet te komen. 
Serum lipiden en lipoproteïnen werden op een gunstige manier beïnvloed door energiebeperking, alhoewel het serum HDL-cholesterol gedaald bleek te zijn tijdens de acute fase van gewichtsverlies (Hoofdstuk 4). Het wordt verondersteld dat de cardiovasculaire risicofactor lipoproteïne(a) voornamelijk genetisch bepaald wordt. Serum lipoproteïne(a) concentraties lijken dan ook nogal moeilijk te beïnvloeden door farmacologische of dieet interventies. Onze resultaten toonden aan dat de gemiddelde serum lipoproteïne(a) concentraties niet veranderden door gewichtsverlies ten gevolge van energiebeperking. Het bleek echter dat de verandering van lipoproteïne(a) gerelateerd bleek te zijn aan de initiële waarde. Personen met waarden $>30 \mathrm{mg} / \mathrm{dl}$ voor behandeling, bleken een significant daling te vertonen met gewichtsverlies, terwijl geen verandering werd gevonden bij personen met lage aanvangswaarden. De veranderingen in serum lipiden en lipoproteïnen ten gevolge van gewichtsverlies bleken verder niet afhankelijk van het apolipoproteïne E polymorfisme.

De hoeveelheid gewichts- en vetverlies ten gevolge van een energiebeperkt dieet blijkt aanzienlijk te variëren tussen personen. Deze variatie lijkt gerelateerd aan dieettrouw, lichaamssamenstelling, energiegebruik en substraat metabolisme. In Hoofdstuk 5 wordt ingegaan op de metabole variabelen die mogelijk betrokken zijn bij de regulatie van de hoeveelheid en samenstelling van gewichtsverlies in obese vrouwen. Het bleek dat lage basale plasma noradrenaline waarden en hyperinsulinemie de kans op succesvol gewichtsverlies deden verminderen. Deze resultaten duiden op een belangrijke rol van sympathische activiteit en insuline resistentie bij de mobilisatie van vetvoorraden in het lichaam tijdens energie deficiëntie.

Het onderzoek beschreven in Hoofdstuk 6 toont aan dat herhaalde schommelingen van gewicht in obese vrouwen gepaard gaan met verminderde thermogene responsen tijdens matige inspanning en isoprenaline infusie. Geen veranderingen van het basale energiegebruik werden waargenomen. De resultaten geven aan dat in obese vrouwen een patroon van herhaalde afname en toename van gewicht gedurende twee jaar gepaard gaat met afgevlakte sympathisch gemedieerde thermogene, chronotrope en lipolytische responsen. Dit is de eerste prospectieve humane studie die aantoont dat herhaalde gewichtsschommelingen gepaard gaan met nadelige effecten op het energie metabolisme in een obese onderzoekspopulatie. Onze gegevens bevestigen eerdere bevindingen van dierexperimentcel onderzock, en kunnen bijdragen aan een verklaring voor de slechte lange termijn resultaten van de behandeling van obesitas. De ongunstige effecten van herhaalde schommelingen van gewicht op de energiestofwisseling benadrukken het belang van handhaven van succesvol gewichtsverlies op de langere termijn. Alhoewel er geen duidelijke aanwijzingen waren tijdens onze twee jarige studie, kunnen de gevonden nadelige metabole effecten gevolgen hebben voor de regulatie van gewicht, lichaamssamenstelling en vetverdeling op langere termijn. Toekomstig onderzoek zal aandacht moeten besteden aan deze belangrijke vragen.

Gezondheidsrisico's voor cardiovasculaire aandoeningen zijn mogelijk verhoogd door variabiliteit in lichaamsgewicht. Dit zou kunnen betekenen dat bepaalde cardiovasculaire risicofactoren beïnvloed worden door herhaalde schommelingen van gewicht. Een mogelijk verband tussen gewichtsschommelingen en veranderingen in serum lipid en lipoproteïne profiel is daarom bestudeerd in Hoofdstuk 7. De gegevens toonden dat herhaalde schommelingen in gewicht niet gepaard gingen met nadelige veranderingen in serum lipiden en lipoproteïnen. Deze resultaten komen overeen met 
andere humane studies die geen nadelige effecten op serum lipiden konden aantonen door herhaalde afname en toename van gewicht. Tevens zijn er vooralsnog geen aanwijzingen voor modulerende effecten van herhaalde gewichtsschommelingen op andere cardiovasculaire risicofactoren gerapporteerd. Mogelijke onderliggende mechanismen van een verband tussen gewichtsvariabiliteit en cardiovasculaire mortaliteit blijven dan ook nog onbekend. De resultaten toonden tevens dat regelmatige inspanning van matige intensiteit geen extra gunstige effecten had op het serum lipid en lipoproteïn profiel.

Fysieke activiteit speelt een belangrijke rol in de regulatie van het lichaamsgewicht. Tegenstrijdige resultaten zijn gevonden wanneer inspanning werd toegevoegd aan energiebeperking bij de behandeling van obesitas. Dit is mogelijk toe te schrijven aan een daling van de normale dagelijkse lichamelijke activiteit als compensatie voor het groter energietekort door de extra inspanning. Ter bepaling of een compensatoire afname van de dagelijkse activiteit plaatsvindt met gecombineerde dieet en sport behandeling in obese vrouwen, zijn veranderingen in het totale energiegebruik onder dagelijkse leefomstandigheden gemeten met dubbel gelabeld water (Hoofdstuk 8). Het toevoegen van matige inspanning aan energiebeperking gedurende 8 weken had geen effect op de daling van het totale energiegebruik die werd gevonden bij energiebeperking alleen. Dit wijst erop dat de energie, gebruikt tijdens de inspanningssessies, mogelijk deels gecompenseerd werd door een afname in lichamelijke activiteit buiten de training. Deze bevinding van gedeeltelijke compensatie in activiteit lijkt niet in overcenstemming met andere gerapporteerde studies. De hoeveelheid energie en de samenstelling van het voorgeschreven dieet, en de frequentie en intensiteit van de uitgevoerde lichamelijke activiteit, zijn factoren die kunnen bijdragen aan deze tegenstrijdige resultaten. Hoewel onze gegevens duiden op gedeeltelijke compensatie van lichamelijke activiteit, werden toch gunstige effecten gevonden van inspanning. toegevoegd aan een dieet behandeling. Dieet gecombineerd met inspanning resulteerde in een significant verhoogd verlies aan vetmassa en een groter energietekort in vergelijking met dieet alleen. Verder was de bijdrage van het vetgebruik aan de energieverbranding tijdens inspanning gestimuleerd door extra training. Deze gegevens impliceren dat naast het totale energiegebruik ook andere factoren van belang zijn bij gunstige effecten van inspanning toegevoegd aan energiebeperking. zoals substraatgebruik en dieettrouw. Geconcludeerd kan worden dat een gunstige invloed van extra lichaamsbeweging tijdens energiebeperking ter behandeling van obesitas al bereikt kan worden door inspanning van matige intensiteit en frequentie.

Mogelijke lange termijn effecten van lichamelijke activiteit ter voorkoming van nadelige metabole effecten van herhaalde afname en toename van gewicht zijn beschreven in Hoofdstuk 9. De data laten zien dat toename van gewicht deels werd voorkomen en de lichaamssamenstelling gunstig beïnvloed werd door extra lichaamsbeweging. Het preventieve effect was echter matig. Inspanning voorkwam gedeeltelijk de afgevlakte sympathisch gemedieerde metabole effecten door herhaalde gewichtsschommelingen (Hoofdstuk 6). Deze fysiologische aanpassingen aan inspanning op lange termijn kunnen een rol spelen bij de gevonden gunstige effecten op gewicht en lichaamssamenstelling. Regelmatige lichamelijke activiteit van matige intensiteit is daarom effectief in het verbeteren van handhaving van gewichtsverlies op lange termijn. 
Om inspanningsprogramma's te laten slagen ten behoeve van behandeling van obesitus op langere termijn is het echter nodig de aandacht te richten op verbetering van motivatie en participatie van de deelnemers.

Concluderend kan gesteld worden dat herhaalde gewichtsschommelingen in obese vrouwen gepaard gaan met verminderde $\beta$-adrenerg gemedieerde thermogene effecten. Deze bevinding impliceert dat de activiteit van het sympathische zenuwstelsel een rol kan spelen bij de ontwikkeling en het in stand houden van obesitas. Verder blijkt dat regelmatige lichamelijke inspanning van matige intensiteit van belang is voor het behouden van gewichtsverlies en de regulatie van het lichaamsgewicht ter behandeling van obesitas op lange termijn. 


\section{Abbreviations}

\begin{tabular}{|c|c|}
\hline ANOVA & analysis of variance \\
\hline ADMR & average daily metabolic rate \\
\hline ATP & adenosine triphosphatc \\
\hline AUC & area under curve \\
\hline $\mathrm{B}_{\max }$ & number of binding sites \\
\hline BMI & body mass index \\
\hline BMR & basal metabolic rate \\
\hline $\mathrm{CHO}$ & carbohydrate \\
\hline $\mathrm{CO}_{2}$ & carbon dioxide \\
\hline $\mathrm{CV}$ & coefficient of variation \\
\hline BW & body weight \\
\hline $\mathrm{CS}$ & citrate synthase \\
\hline DEx-WC & diet and exercise weight cycling group \\
\hline DIT & diet induced thermogenesis \\
\hline DLW & doubly labeled water \\
\hline D-WC & diet weight cycling group \\
\hline D-WM & diet weight maintenance group \\
\hline $\mathrm{EE}$ & energy expenditure \\
\hline $\mathrm{EE}_{\mathrm{act}}$ & energy expended on physical activity \\
\hline EI & energy intake \\
\hline ELISA & enzyme-linked immuno-sorbent assay \\
\hline FFA & free fatty acids \\
\hline FFM & fat-free mass \\
\hline$\% \mathrm{FM}$ & body fat percentage \\
\hline h & hour \\
\hline $\mathrm{HAD}$ & 3-hydroxyacyl-CoA dehydrogenase \\
\hline HDL & high density lipoprotein \\
\hline H-FABP & heart-type fatty acid-binding protein \\
\hline${ }^{2} \mathrm{H}_{2} \mathrm{O}$ & deuterium \\
\hline${ }^{2} \mathrm{H}_{2}{ }^{18} \mathrm{O}$ & doubly labeled water \\
\hline $\mathrm{HR}$ & heart rate \\
\hline ICYP & {$\left[{ }^{125} \mathrm{I}\right]$ iodocyanopindolol } \\
\hline$K_{\mathrm{d}}$ & dissociation constant \\
\hline $\mathrm{kg}$ & kilogram \\
\hline LDL & low density lipoprotein \\
\hline Lp(a) & ]ipoprotcin(a) \\
\hline $\min$ & minute \\
\hline MJ & megajoule \\
\hline$n$ & number \\
\hline NS & not significant \\
\hline $\mathrm{O}_{2}$ & oxygen \\
\hline
\end{tabular}




\section{Abbreviations}

$P$

PA

PAI

ppm

r

RER

RMR

$S$

SD

SE

SMR

SNS

$t$

TBW

TC

TG

VLCD

vol

$\mathrm{VO}_{2 \max }$

W

WHR

$\mathrm{W}_{\max }$

wt

ww

yr probability

physical activity

physical activity index

parts per million

Pearson product moment correlation

respiratory exchange ratio

resting metabolic rate

second

standard deviation

standard error

sleeping metabolic rate

sympathetic nervous system

time

total body water

total cholesterol

triglycerides

very low calorie diet

volume

maximal oxygen uptake

watt

waist-hip ratio

peak mechanical power

weight

wet weight

year 


\section{Dankwoord}

Tenslotte wil ik graag het grote aantal personen bedanken die mee hebben geholpen aan de totstandkoming van deze dissertatie. Ik realiseer me heel goed dat een dergelijk omvangrijk en langdurig onderzoek. zoals beschreven in dit proefschrift, weinig kans van slagen heeft zonder het enthousiasme en de betrokkenheid van anderen. De deelnemers aan het onderzoek waren daarbij onmisbaar. Dames, ik heb bewondering voor jullie doorzettingsvermogen en ben jullie zeer erkentelijk voor alle medewerking aan het onderzoek.

Een aantal mensen wil ik graag met name noemen.

Allereerst wil ik mijn promotor Wim Saris bedanken voor de kans die ik gekregen heb om aan dit onderzoek te mogen werken. Wim, ik denk dat ik dankzij je goede inhoudelijke suggesties en stimulerende invloed terug kan kijken op een succesvolle periode bij Humane Biologie. Je enthousiasme en inventiviteit zijn altijd een grote inspiratie voor me geweest. Ik heb in deze periode veel geleerd; deze ervaring zal me ongetwijfeld in mijn verdere loopbaan goed van pas komen.

Mijn collega's Ellen Blaak en Marleen van Baak ben ik dank verschuldigd voor de vele inhoudelijke discussies en versies van manuscripten ter beoordeling. Bedankt voor jullie altijd weer kritische blik die heeft bijgedragen aan grondige verbeteringen. Ellen, jouw rol in het geheel is wel heel groot geweest, variërend van ondere andere kamergenootje, medeauteur, vriendin van de dans, jogging maatje tot nu binnenkort paranimf.

De leden van de beoordelingscommissie, Prof. Hill, Dr. Seidell, Prof. Nieuwenhuijzen Kruseman, Prof. van de Vusse en Prof. Zwaal wil ik graag bedanken voor de beoordeling van het proefschrift.

Het schrijven van wetenschappelijke publicaties vereist teamwerk. Ik wil dan ook alle medeauteurs van de verscheidene publicaties die dit project voortbracht hartelijk bedanken voor de prettige samenwerking en kritische wijze waarop de concepten zijn beoordeeld. In dit verband wil ik in het bijzonder de succesvolle samenwerking met het Universitaire Ziekenhuis Gasthuisberg te Leuven noemen. Erik Muls en Greet Vansant wil ik daarvoor van harte bedanken.

Zonder de hulp van Jos Stegen en Joan Senden was er door de berg bloedmonsters geen doorkomen aan. Mijn dank voor al het analytisch werk dat jullie verricht hebben voor dit onderzoek. Jos, ik hoop van harte dat die ene wens van je nog eens in vervulling gaat in de toekomst! Voor alle hulp bij technische problemen wil ik graag Paul Schoffelen en Loek Wouters noemen. Bedankt, voor alle keren dat mijn technisch inzicht te kort schoot, ook al was dat maar een kwestie van de stekker insteken.

$\mathrm{Na}$ het eerste jaar van metingen was het een verademing om in het tweede jaar de hulp van stagiëres te krijgen. Hilde Gereards en Peggy van de Hoogen wil ik dan ook bedanken voor alle gedeelde vroege en late uurtjes en de waardevolle bijdrage aan de werkzaamheden.

Zonder verder namen te noemen wil ik alle collega's van Humane Biologie bedanken voor de fijne tijd die ik daar doorgebracht heb. Ik hoop van harte de afsluiting van dit proefschrift samen met jullie te vieren. Overgaand van oude collega's op nieuwe, wil ik 


\section{Dankwoord}

ook graag de mensen op mijn nieuwe werkplek bedanken voor het begrip voor mijn nog niet geheel afgeronde werkzaamheden op de Universiteit. Het zal niet lang meer duren voordat mijn concentratie voor $100 \%$ bij mijn nieuwe baan zal liggen.

Alle anderen die op enigerlei wijze bij het geheel betrokken zijn geweest ben ik zeer erkentelijk.

Mijn ouders wil ik bedanken voor de wijze waarop zij altijd voor mij klaar staan. Yvette, met jou als paranimf aan mijn zij kan het niet meer stuk. Bob, je bent een prachtbroer. Verder wil ik al mijn vrienden en familieleden bedanken voor de warme belangstelling maar vooral ook alle leuke afleiding.

Tenslotte, Peter. Jij hebt mij kennis laten maken met het bourgondische leven in het Zuid-Limburgse. Met jou hoop ik daar ook nog lang te genieten. Bedankt voor je begrip en alles wat jij extra deed in deze drukke periode; ik weet zeker dat nu weer betere tijden voor ons aanbreken. 


\section{Curriculum vitae}

Kitty P.G. Kempen werd op 21 september 1967 in Venray geboren. In 1985 behaalde zij haar VWO diploma aan de scholengemeenschap Jeruzalem te Venray. In datzelfde jaar begon zij haar studie gezondheidswetenschappen, met als afstudeerrichting Biologische Gezondheidkunde, aan de Rijksuniversiteit Limburg te Maastricht. Tijdens haar afstudeerstage bij de afdeling Interne Geneeskunde van het Academisch Ziekenhuis Maastricht werkte zij aan klinisch onderzoek naar behandelingsmethoden voor Type II diabetes mellitus. In september 1989 behaalde zij haar doctoraal diploma, waarna zij gedurende zes maanden werkzaam was aan toxicologisch en immunologisch onderzoek bij de Vakgroep Arbeidsgeneeskunde (Rijksuniversiteit Limburg). Het in het proefschrift beschreven onderzoek werd uitgevoerd van oktober 1990 tot juli 1995 aan de Vakgroep Humane Biologie van de Rijksuniversiteit Limburg, waar zij als Onderzoeker in Opleiding was aangesteld door de Nederlandse Organisatie voor Wetenschappelijk Onderzoek. Sinds 1 juli 1995 is zij werkzaam als Medical Writer bij N.V. Organon, een farmaceutische business unit van Akzo-Nobel. 



\section{Publications}

\section{Articles}

- Blaak EE, van Baak MA. Kempen KPG, Saris WHM. The effect of hand heating on $\mathrm{O}_{2}$ consumption of the contralateral arm. J Appl Physiol 72: 2364-2368, 1992.

- Muls E, Kempen KPG, Vansant G, Cobbaert C, Saris WHM. The effects of weight loss and apolipoprotein E polymorphism on serum lipids, apolipoproteins A-I and B, and lipoprotein(a). Int $J$ Ohes 17: 711-716, 1993.

Blaak EE, van Baak MA, Kempen KPG, WHM Saris. Role of $\alpha$ - and $\beta$-adrenoceptors in sympathetically mediated thermogenesis. Am J Physiol 264: E11-17, 1993.

- Kempen KPG, Saris WHM, Senden JMG, PPCA Menheere, EE Blaak, MA van Baak. Effects of energy restriction on acute adrenoceptor and metabolic responses to exercise in obese subjects. Am J Physiol 267: E694-E701, 1994.

- Blaak EE, van Baak MA, Kempen KPG, Saris WHM. Weight reduction and the $\beta$ adrenergically mediated thermogenesis in obese men. In Ditschuneit $\mathrm{H}$, Gries FA, Hauner H (eds). Obesity in Europe 1993. John Libbey Company Ldt, London pp 111-118, 1994.

- Muls E, Kempen KPG, Vansant G, Saris WHM. Is weight cycling detrimental to health? A review of the literature in humans. Int J Obes 19 (suppl 3): 46-50, 1995.

- Kempen KPG, Saris WHM, Westerterp KR. Energy balance during an 8-wk energy-restricted diet with and without exercise in obese women. Am J Clin Nutr 62: 722-729, 1995.

Kempen KPG, Saris WHM, Kuipers H, Glatz JFC, van der Vusse GJ. Skeletal muscle characteristics before and after energy restriction in obesity: fiber type, enzymatic $\beta$-oxidative capacity and fatty acid-binding protein content. Submitted for publication.

- Kempen KPG, Saris WHM, Stegen JCHC, Kester ADM. Predictors of fat loss during verylow calorie diet in obese females. Submitted for publication.

- Kempen KPG, Blaak EE, van Baak MA, Saris WHM. Weight cycling is associated with blunting of the sympathetically mediated thermogenesis in obesity. Submitted for publication.

- Kempen KPG, Vansant G, Muls E, Saris WHM. Weight cycling does not adversely affect serum lipids and lipoproteins in obese women. Submitted for publication.

Kempen KPG, Saris WHM. Can regular moderate exercise prevent adverse metabolic effects of weight cycling in obesity? Submitted for publication.

\section{Abstracts}

- Kempen KPG, Stegen JCHC, Blaak EE, van Baak MA, Saris WHM. Relation between weight reduction and beta-adrenergic stimulation in obese women. Int J Obes 16 (suppl 1): 60, 1992. Kempen KPG, Stegen JCHC, Blaak EE, van Baak MA, Saris WHM. Weight cycling has no effect on beta-adrenergic stimulation in obese women. Int J Obes 16 (suppl 1): 60), 1992.

- Kempen KPG, Blaak EE, van Baak MA, Saris WHM. Effect of weight reduction on acute response to exercise of adrenoceptors in obese subjects. Int J Obes 17 (suppl 2): 28, 1993. 
- Kempen KPG. Blaak EE, van Baak MA, Saris WHM. Relation between skeletal muscle $\beta_{2}$ adrenoceptors in obese female subjects. Int J Obes 17 (suppl 2): 28, 1993.

- Muls E, Kempen KPG, Vansant G, Cobbaert C, Saris WHM. Effects of weight loss and apo E isoforms on lp(a). Int J Obes 17 (suppl 2): 93, 1993.

- Kempen KPG, Saris WHM, van Baak MA. A 1-year weight cycle has no effect on body composition and energy expenditure in obese females. Int J Obes 18 (suppl 2): 52, 1994.

- Kempen KPG, Saris WHM, van Baak MA. Muscle fiber type, body fatness and substrate oxidation during exercise in obese females. Int J Obes 18 (suppl 2): 96, 1994.

- Kempen KPG, Westerterp-Plantenga MS, Saris WHM. Cognitive restraint predicts amount of weight cycles and failure in obese women. Int J Obes 19 (suppl 2): 28, 1995.

- Kempen KPG, Saris WHM. Enhanced fat utilization during exercise due to 8 weeks combined VLCD/exercise compared to VLCD alone in obese females. Int J Obes 19 (suppl 2): 33, 1995.

- Kempen KPG, Saris WHM. Energy balance as assessed with doubly labeled water during 8 weeks VLCD with and without exercise in obese females. Int J Obes 19 (suppl 2): 91, 1995. 

